\title{
Performance and Permeability
}

\author{
An Investigation of the Mashrabiya \\ for use within the Gibson Desert
}

\section{William Samuels}

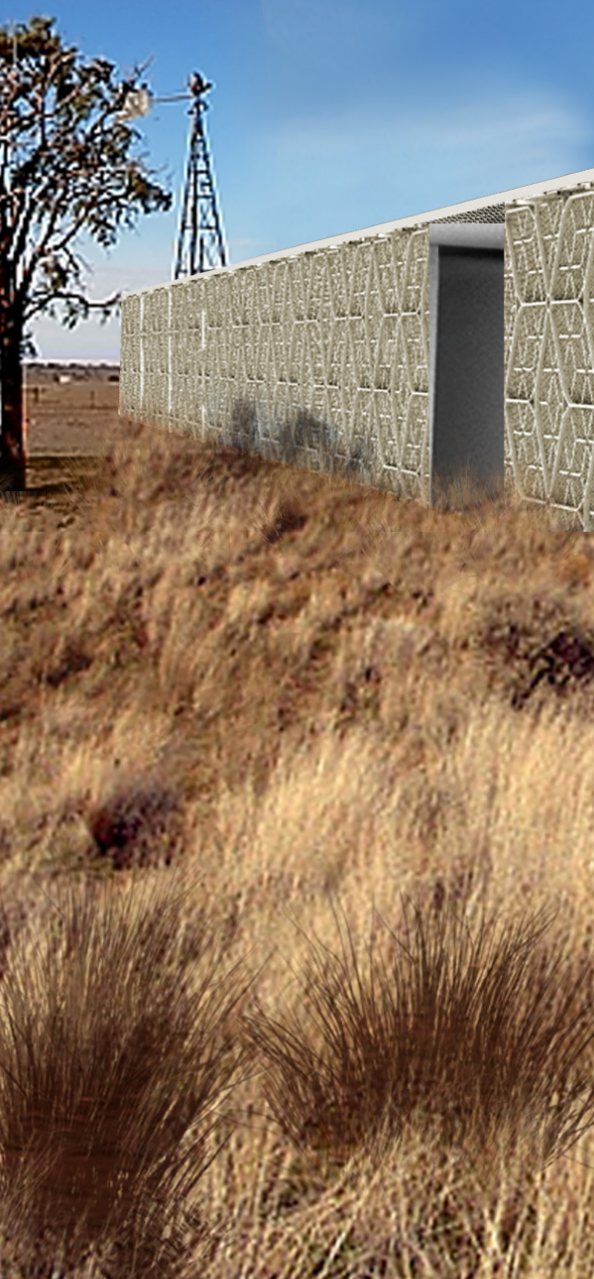




\title{
Performance and Permeability
}

\author{
An investigation of the mashrabiya \\ for use within the Gibson Desert \\ By William Samuels
}

A thesis submitted in partial fulfilment of the requirements for a Master of Architecture (Professional) degree

Victoria University of Wellington

School of Architecture and Design

Supervisor: Tobias Danielmeier

February 2011 
"[The modern architect] must renew architecture from the moment when it was abandoned; and he must try to bridge the existing gap in its development by analyzing the elements of change, applying modern techniques to modify the valid methods established by our ancestors, and then developing new solutions that satisfy modern needs."

Shearer, Walter. Preface to Natural Energy and Vernacular Architecture, p.xxii-xxiii 


\section{Abstract}

This study investigates a traditional Middle Eastern building element, the mashrabiya, and looks at the potential application of this device within the contemporary context of the Giles Weather Station in the Gibson Desert of Australia. The mashrabiya is a carved wooden screen used to control the fierce desert conditions of the Middle East. It created conditions of comfort within an extreme climate but is no longer prescribed due to the restrictive economic constraints involved with its construction.

The research firstly considered the history of the mashrabiya and its various roles within the traditional Middle Eastern dwelling and then applied contemporary fabrication and design processes to its construction. The use of a CNC mill to construct the screen revealed new variables and opportunities for their manipulation, thereby providing for new design possibilities which transform the way in which it controls the desert conditions. The result was substantial improvements in cost, performance and versatility of the screen.

Due to this program of research the mashrabiya was able to be applied to the Giles Weather Station in a much more ambitious manner than would otherwise have been possible. As a result of this the weather station aims to be architecturally unique, both in appearance and in functional performance. 
Introduction: Giles and Traditional Architecture

1. History of the Mashrabiya

1.1 Desert Context 18

1.2 Development 20

$\begin{array}{ll}1.3 & \text { Construction of the Mashrabiya } \\ 1.4 & 22\end{array}$

$\begin{array}{ll}1.4 & \text { Decline of the Mashrabiya } \\ & 24\end{array}$

1.4.1 Cultural 24

$\begin{array}{lll}\text { 1.4.2 Practical } & 25\end{array}$

1.5 Contemporary Interpretation of the Mashrabiya 27

1.6 Conclusion 28

2. Function of the Mashrabiya $\quad 29$

$2.1 \quad$ Temperature Regulation 30

2.1.1 Role of the Mashrabiya 30

$2.2 \quad$ Light Control 32

2.2.1 Direct Light

2.2.2 Diffuse Skylight $\quad 32$

2.2.3 Glare 33

$2.3 \quad$ Airflow Regulation 34

2.3.1 Role of the Mashrabiya $\quad 34$

2.3.2 Airflow Drivers $\quad 34$

$2.4 \quad$ Humidity Control 36

2.5 Visual Privacy 38

$\begin{array}{ll}2.6 & \text { Aesthetic and Social Role } \\ 2.7 & 39\end{array}$

2.7 Conclusion 40

Analysis $\quad 3 . \quad$ Parameters of the mashrabiya 4

$3.1 \quad$ Baluster Diameter/Length Ratio $\quad 44$

$3.2 \quad$ Baluster Angle $\quad 46$

3.3 Baluster Section 48

3.4 Sectional Layers 50

$3.5 \quad$ Baluster Offset $\quad 52$

3.6 Pattern 54

3.7 Materiality 56

$\begin{array}{lll}3.8 & \text { Conclusion } & 58\end{array}$

Application $\quad$ 4. $\quad$ Application of research $\quad 59$

4.1 Development of a Mashrabiya Component 60

$\begin{array}{lll}4.2 & \text { Construction } & 62\end{array}$

4.3 Structural Additions $\quad 63$

4.4 Roof Screen 66

4.5 Evaporative Cooling Sprays $\quad 68$

$\begin{array}{ll}4.6 & \text { Thermal Chimneys } \\ & 70\end{array}$

$\begin{array}{ll}4.7 & \text { Architectural interpretation }\end{array}$

$\begin{array}{ll}4.8 \text { Conclusion } & 74\end{array}$

5. Giles Weather Station $\quad 75$

$\begin{array}{lll}5.1 & \text { Building Plan } & 76\end{array}$

$\begin{array}{llll}\text { Discussions } & 6 . & \text { Discussions } & 99\end{array}$

6.1 Traditional Craft and Contemporary Fabrication $\quad 100$

6.2 Individual Parameters of the Mashrabiya 101

6.3 Giles Weather Station 102

$\begin{array}{ll}\text { 7. Conclusion } & 105\end{array}$

$\begin{array}{ll}\text { Appendix } 1 \text { - Giles weather data } & 117\end{array}$

Appendix 2 - Computer analysis results $\quad 125$ 


\section{Acknowledgements}

I would like to acknowledge the continued support and assistance of the following:

My supervisor, Tobias Danielmeier. Mike Donn and Robin Skinner for their help and advice throughout the year. My Dad for his constant support and my friends for helping maintain sanity. Additionally, I would like to acknowledge the work of architect Hassan Fathy, whose book 'Natural Energy and Vernacular Architecture' inspired much of this research. 


\section{Introduction: Giles and Traditional Architecture}

"What appears to be needed, therefore, is an appraisal of the conditions under which the traditional solutions are technically, environmentally, socially, and economically valid, so that use can be made of this knowledge in appropriate situations. It would be of great benefit also if societies with similar conditions could share their traditional solutions to specific problems. Following appraisal, some solutions may be rejected as inappropriate, but a scientific understanding of the principles upon which they are based could serve as a useful foundation upon which to develop new solutions more in keeping with the local economics, environment, and society than those that have replaced the traditional ones. Many traditional techniques could be improved, using new materials and knowledge, rather than totally abandoned."

Fathy, Hassan. Natural Energy and Vernacular Architecture. Foreword, p.xvii 


\section{Introduction}

In August 1873 a group of four travellers, led by the great adventurer Alexander Giles, set forth in an attempt to cross the wild desert plains of central Australia. Their journey was all the more impressive on account of the long list of failed attempts before them: a list compiling many who had died in the attempt. Eight months into their journey and short on supplies and water, Giles and the youngest member of the exploration, Alfred Gibson, made a desperate attempt to cross a vast and arid stretch of desert. One by one their horses, driven mad by heat and thirst, died beneath them. Eight days later Giles stumbled out, weak from thirst and near delirium, alone. Gibson had perished, yet another victim of the unrelenting desert conditions. ${ }^{1}$ The all encompassing heat, the arid landscape and the harsh, unwavering sun; such extremes of climate are beyond the capacity of human tolerance, both psychologically and physiologically. Giles and his crew were beaten by a land so severe that it renders the human capacity useless. Such is the untenable nature of the desert that concerns of comfort long give way to matters of sheer survival, as the unfortunate Gibson found.

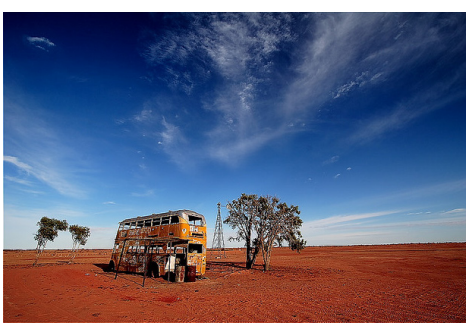

Fig. 1- The Gibson Desert of central Australia
Over a hundred and forty years later the aptly named Gibson Desert remains one of the most inhospitable places on earth. For the few who brave the heat, one outpost is particularly worthy of note. The Giles Weather Station, named for the luckless explorer, is the only manned meteorological outpost for 2.5 million square kilometres. ${ }^{2}$ Sited near the original 1874 base camp, the weather station now monitors the same scorching heat and arid conditions that once conquered Alfred Gibson. The importance of this weather station cannot be understated, for not only does it provide a rare glimpse into the climatic extremes of desert life but it also is a key point in predicting the weather conditions for the southern states of Australia. ${ }^{3}$ In the midst of furnace-like conditions a few lone scientists brave the heat to conduct critically important scientific research.

It is interesting therefore that the architecture of the Giles Weather Station, a facility for advanced climate research, is so climatically inapt. Tin sheds, which would not look out of place in a suburban Sydney back yard, serve as houses. Mechanical ventilation and cooling (HVAC) units adjoin every room, waging constant battle against the intense heat. The buildings are wasteful, inefficient and uncomfortable. The weather station serves as an example of the fact that although our technology may be advanced, intelligent application of it is often found wanting.

1 Giles, Ernest. Australia twice traversed, Vol. 2, p. 46

2 Storm Boys. Report on Giles Weather Station shown on Landline, ABC network, 2006.

3 History of Giles Weather Station, Australian Bureau of Meteorology. www.bom.gov.au/sa/giles/history.shtml 


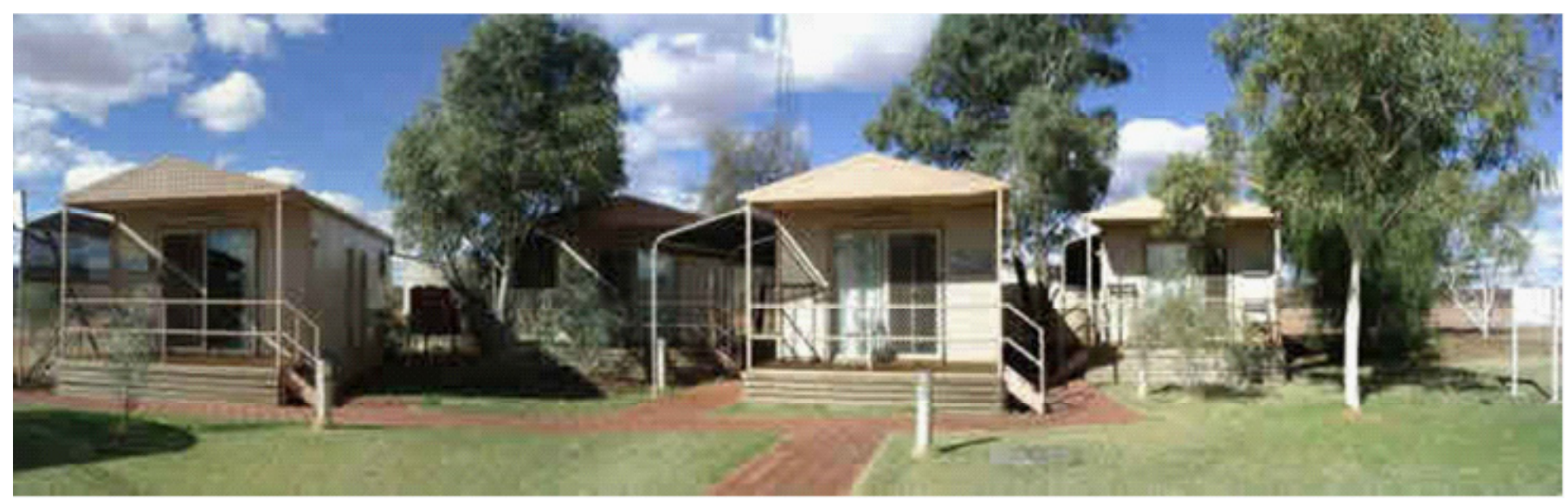

Fig. 2- Residential units at the Giles Weather Station.

It is also an example of how the knowledge once possessed by traditional societies has been forgotten. The extreme conditions faced within the Gibson Desert have been successfully dealt with in the almost identical climate of the Middle East for thousands of years. The solutions that they developed were based on passive, craft-based architecture that worked with the climate, rather than fighting against it. They developed architectural typologies which, even in the middle of a merciless desert, managed to create comfort. Yet whether due to technological development, rapid globalization or changes to the economics of construction these traditional architectural solutions are now being forgotten or ignored.

Although old, parts of those historic solutions could potentially be applied in the Gibson Desert. "The survival of traditional societies over hundreds and thousands of years indicates that they surely possess knowledge that can still be of great value either in its original form or as the basis for new developments." ${ }^{\prime 4}$ The vernacular desert architecture of the Middle East is a broad field however, covering hundreds of different building typologies, thermal strategies and traditional solutions and as such cannot be covered fully within one study. Therefore the question asked within this research is if the investigation and adoption of just one element of the traditional Middle Eastern desert architecture could benefit the architecture of the Giles Weather Station. The element chosen for this research is the mashrabiya, a carved wooden screen which was highly important in combating the extreme desert climate.

The mashrabiya is a lattice screen that was used within Middle Eastern desert architecture to regulate light, heat, airflow, humidity and privacy. It was a highly prized feature in these countries, not only because of its extraordinary versatility and effectiveness at controlling the climate but also because of its delicacy and beauty. Its use enabled desert buildings to become light, breezy and open, creating comfortable and socially engaging conditions. Its decline from use has resulted in the loss of both a huge wealth of knowledge and the sheer aesthetic value that it once brought to the streets of the Middle East.

4 Shearer, Walter. Foreword to Natural Energy and Vernacular Architecture by Hassan Fathy, p.xvi 
This study researches the functional aspects of the mashrabiya and applies this knowledge to the Giles Weather Station with the aim of creating a more effective and climatically appropriate built form within the Gibson Desert. The first two chapters describe the history and functional performance of the traditional mashrabiya, investigating its role within the Middle Eastern desert architecture from its initial development through to its eventual decline from use. Its precise functional attributes are isolated and defined in terms of the relationship between the physical parameters of the mashrabiya and the influence that they have on the internal environment. This leads to the third chapter which applies contemporary digital design and fabrication methods to the construction of the mashrabiya and in so doing develops a series of mathematical rules for the optimization of each of its physical variables. The result is that the cost, performance and architectural versatility of the screen are greatly improved.

Chapter four develops the component based system and associated features required to apply the experimental mashrabiya developed in the previous chapter to the Giles Weather Station. With this research the mashrabiya is transformed from a traditional window screen into something far more appropriate for the context of the Giles Weather Station, the form of which becomes a unique expression of a functional solution to the extreme conditions of the Gibson Desert. The design of the weather station is a demonstration of the viability of traditional architectural knowledge within a contemporary environment.

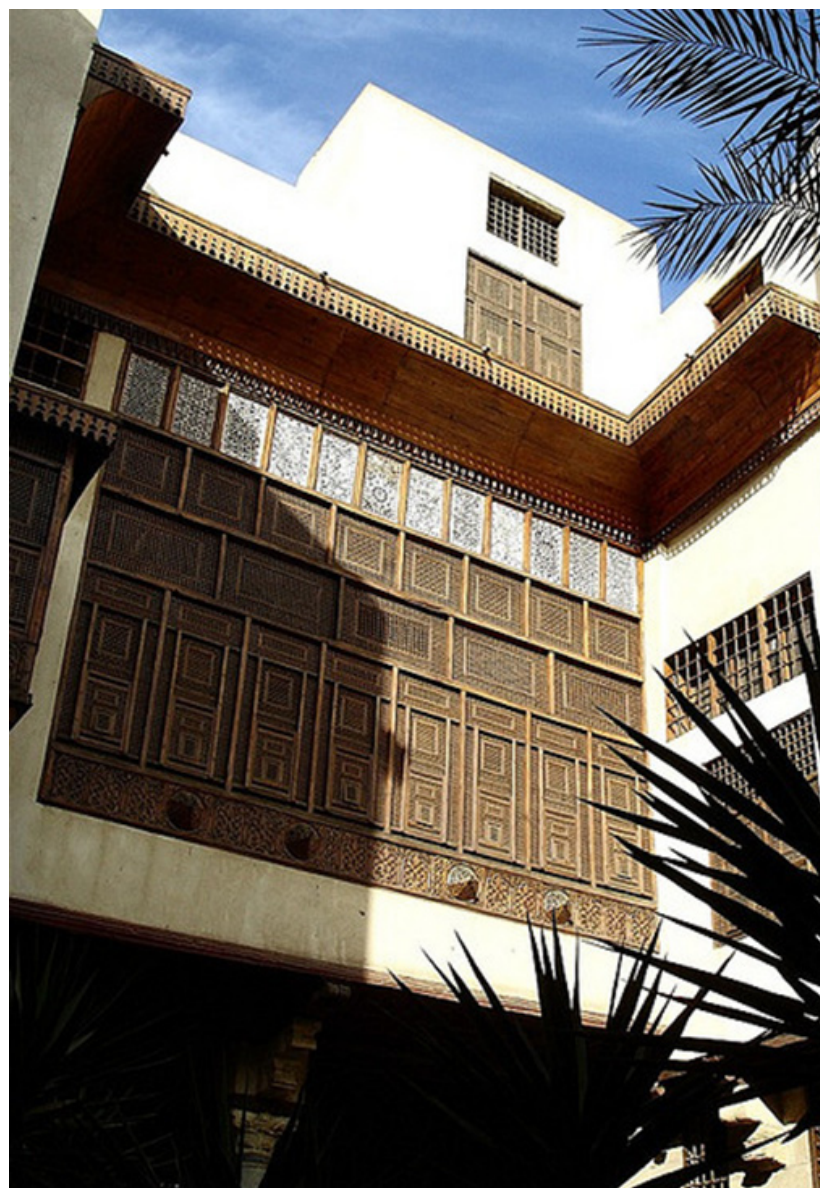

Fig. 3- Mashrabiya used within a building in Cairo, Egypt 


\section{Chapter 1: History of the Mashrabiya}

For the mashrabiya to be considered as a viable architectural solution to the problems faced within the Gibson Desert an understanding of its history is required. As Hassan Fathy points out, any traditional architectural solution must be understood implicitly in terms of its scientific, social and constructional aspects before any attempt can be made to apply it to a contemporary situation. ${ }^{5}$ Precisely how and why the mashrabiya came to be used needs to be investigated. Just as important to understand are the reasons behind its eventual decline from popular use- reasons which are currently prohibiting it from being applied to modernday architecture. Without a full appreciation of the role that it played within the traditional Middle Eastern dwelling any application of the mashrabiya into the context of the Gibson Desert would be inherently flawed.

Therefore the aim of this chapter is to provide the background information required to appreciate the traditional construction and application of the mashrabiya. This is accomplished by exploring the mashrabiya's history from its initial development within Middle Eastern desert architecture to its eventual decline from use. Each part is an important chapter in the story of the mashrabiya, providing important insights into the applicability of the screen within contemporary western architecture and the Giles Weather Station.

5 Fathy, Hassan. Natural Energy and Vernacular Architecture, p.9 


\subsection{Desert Context}

The desert plains of the Middle East, held in the deathly grip of an unforgiving sun, roasted slowly over countless millennia, becoming barren, sandy and inhospitable. From the countries of the Northern Sahara, Egypt, the Arabian Peninsula and all the way through to Iraq the dominant climatic condition is one of extreme heat. ${ }^{6}$ The scorching temperatures are exacerbated by the aridity which evaporates every drop of water, parches the tongue and dries the skin. Such conditions are beyond the capacity of human tolerance and without an effective architectural intervention discomfort quickly leads to incapacity or even death.

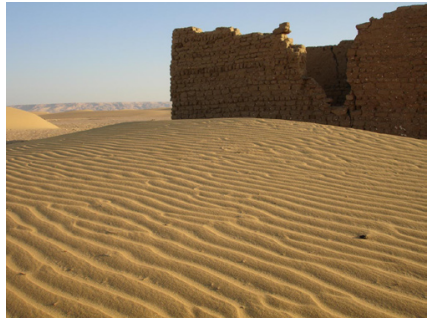

Fig. 4- Ancient mud building within the Egyptian Desert.
Yet within this furnace-like environment lived a great many people whose existence was enabled by strong vernacular traditions; people who built houses designed as cool points of respite amidst the baking sands. Thick earth walls created dark shelters, shielded from the harsh rays of the sun. The heavy earth forms were bastions against the desert heat, cooling in the cold night air and retaining that coolness during the day. Courtyards filled with desert plants would act as sinks for this night air, storing it until day when it would flow out into each room of the building. Strategically located fountains and pools would further cool the air as it passed through the rooms, while high ceilings and wind catchers would draw the hot exhaust air up and out of the building. The result was dramatic and resulted in a method of living which defied the extreme desert conditions. But not everything worked so well in this format. The lack of openings resulted in interiors that were too dark to undertake daily tasks and had no real connection with the street or neighbouring houses. Airflow was restricted and consequently the rooms were often poorly ventilated and stuffy. Although cool, the buildings were not necessarily comfortable and were effectively shut off from the world.

The solution to these problems was provided by the mashrabiya, a carved wooden screen that let in ambient light yet restricted direct light. In this capacity it was able to cover wide openings on the side of the building without causing an increase in internal temperature, resulting in a steady airflow and ensuring the rooms remained cool yet were light, breezy and comfortable. Additionally, they provided privacy to the occupants, an important factor in the predominantly Islamic countries of the Middle East. The mashrabiyas took on an artistic character, driving the architectural expression of these desert houses. They became prized for their beauty, yet regardless of their visual merit they still remained highly functional and practical objects.

6 Badawy, Alexander. Architectural Provision against Heat in the Orient, p.122 
Fig. 5- The Bayt Al-Suhaymi house in Cairo, dating from 1648, has some of the finest examples of domestic mashrabiya still in existence.
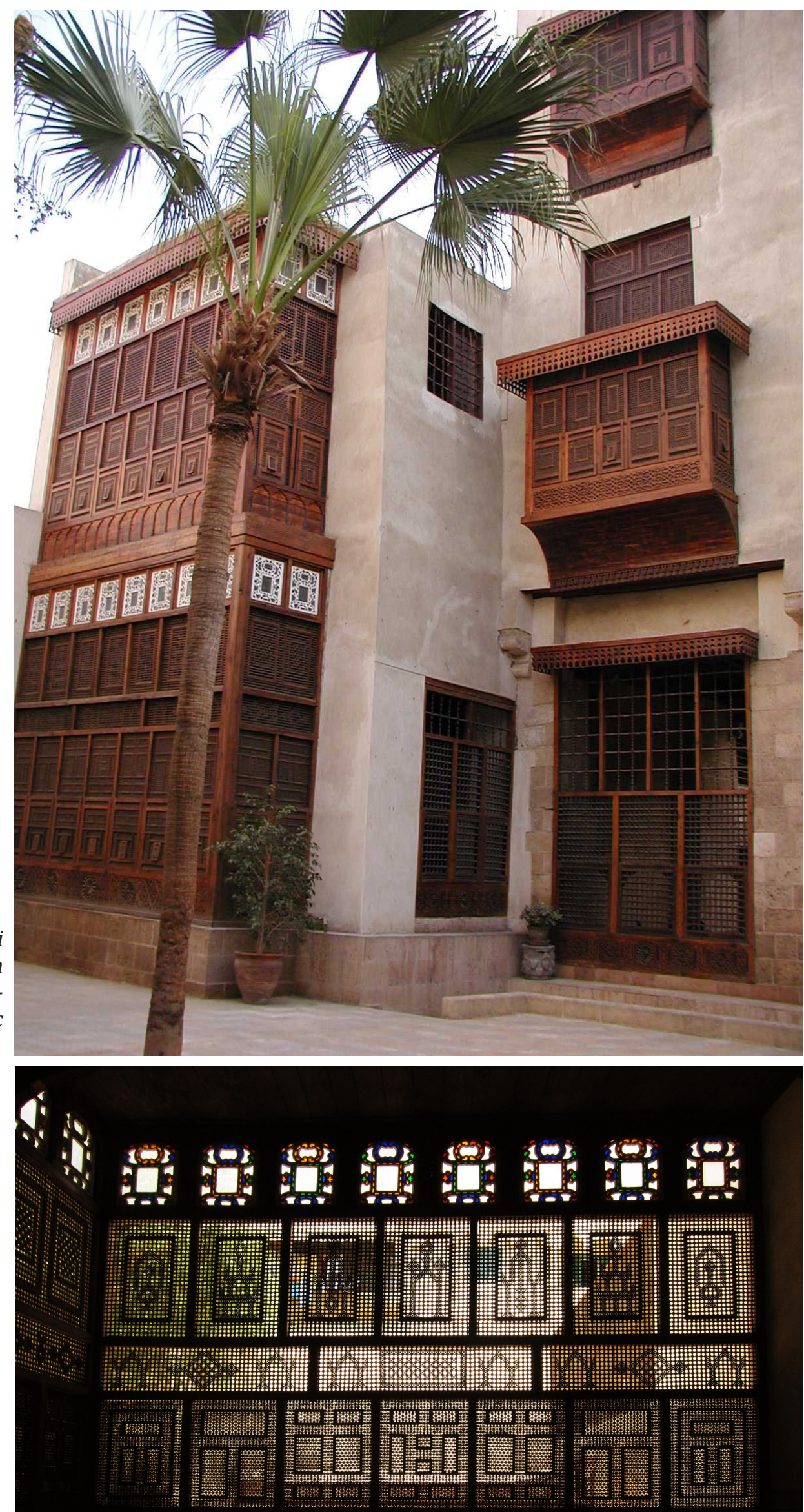

Fig. 6- Inside the building it is light and airy. The mashrabiya softens the light entering and becomes like a veil gently covering the building. 


\subsection{Development}

Due to the ever-evolving nature of architecture, it is difficult to pinpoint when the mashrabiya first became used. What is certain is that its development and optimization was a process that occurred over many hundreds of years. Martin Briggs speculates that while its origins could possibly be found in the Coptic churches in Egypt, "the earliest authenticated examples occur in the Ayyūbid cenotaphs (thirteenth century) in the mosque of Imām ash-Shāfi'i, in the railings surrounding the tomb of Sultan Qalāwūn."7 From this point onwards, and especially during the Ottoman reign in Egypt (1517-c1805), the use of mashrabiya screens in domestic residences became widespread. ${ }^{8}$ Due to the effectiveness of the mashrabiya in creating a comfortable internal environment within the extreme heat of the desert it became a very popular architectural feature, spreading quickly throughout the desert countries of the Middle East. Cities such as Cairo in Egypt, Jeddah in Saudi Arabia and Basra in Iraq have particularly widespread examples of their use. ${ }^{9}$

As each country adopted the mashrabiya it was slowly adapted to suit their particular climatic, social and cultural requirements, so that various regional differences can now be seen between the mashrabiya of individual towns and countries. "Thus, while in Rosetta and Alexandria these are made of turned woodwork, resembling that of Cairo though less elaborate, the window-openings of houses in Damietta, Mansurah, Matariyyah, etc. are filled with a trellis formed of delicately fretted strips of wood, equally appealing in a different way."10 Although the style and detailing of the mashrabiya often changes between countries it is important to note that functionally they each perform the same role. Along with stylistic changes to the screen there were regional variations of the name itself. In Yemen it is called the takhrima, barmaqli in Tunis, Shamashil in Iraq and rowshin in Jeddah, amongst a multitude of others. ${ }^{11}$ For the purpose of this study the name and spelling used will be 'mashrabiya' and the style used as the primary reference point for detailed analysis will be the turned wooden screens that are most popular in Cairo. The screens were distinctive in their delicacy and intricacy, and are the style that is most commonly recognized as true 'mashrabiya. ${ }^{12}$ Additionally, the climate of the Gibson Desert is extremely similar to that of Cairo, meaning that the functional performance of the screen should be able to translate relatively easily between the two locations.

\footnotetext{
7 Briggs, Martin S. Muhammadan Architecture in Egypt and Palestine, p.210

8 Kenzari, Bechir and Yasser Elsheshtawy. The ambiguous veil- On Transparency, the Mashrabiy'ya, and Architecture, p.21

9 Kenzari and Elsheshtawy, p.20

10 Briggs, p.160

11 Kenzari and Elsheshtawy, p.18

12 Gelil, Nermine Abdel. A new mashrabiyya for contemporary Cairo: Integrating traditional latticework from Islamic and Japanese cultures, p.37
} 


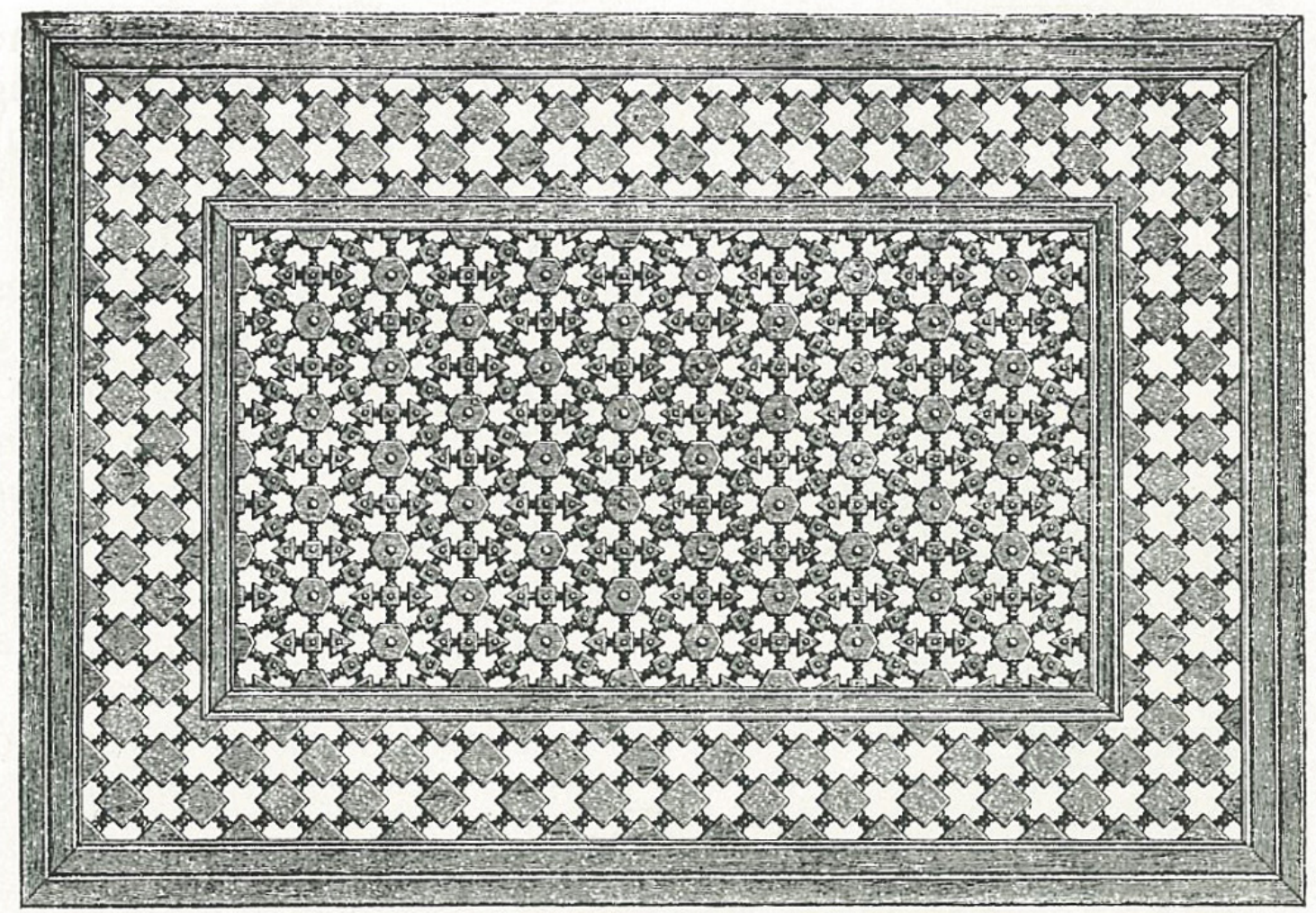

Fig. 7- Examples of different styles and patterns of mashrabiya

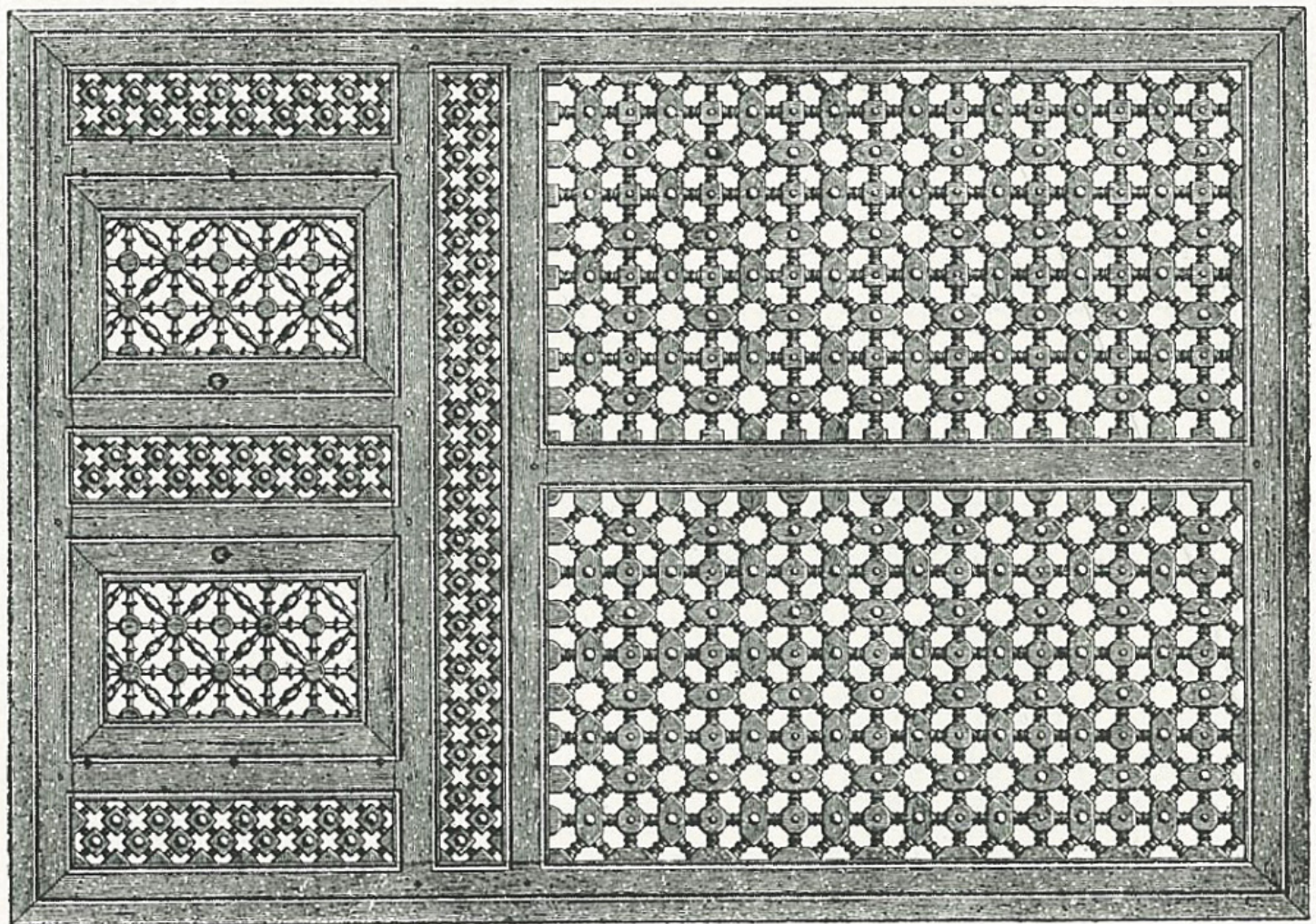
found within Cairo. 
The early $19^{\text {th }}$ century was a golden age for the mashrabiya, with the combination of climatic functionality and ornamental detailing driving its demand. "The vernacular architecture of the Arab World and neighbouring regions not only solved the climatic problems but did so with a combination of beauty and physical and social functionality."13 The desire to have the most elaborate and decorative screen kept craftsmen constantly innovating and developing ever finer details. Rich families imported rare wood from distant lands to distinguish their mashrabiya, often using teak all the way from India or Java. ${ }^{14} \mathrm{~A}$ great trade ensued, a whole industry based upon this valued commodity. As the demand for the mashrabiya grew, so too did the skill and expertise of the craftsmen, each of whom would express his own unique style and artistic qualities in his work. ${ }^{15}$

\subsection{Construction of the Mashrabiya}

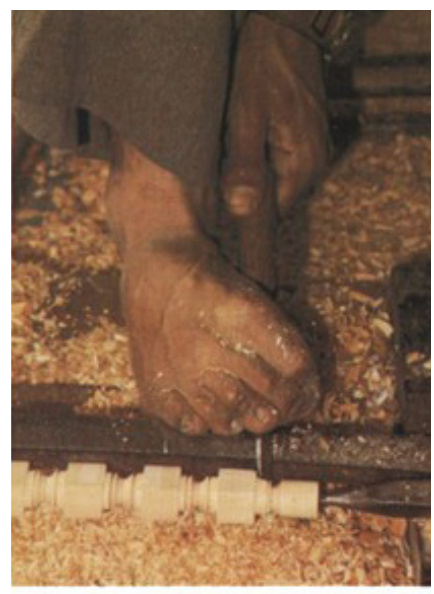

The importance of the craftsmen cannot be understated, for not only did they create the artistry and aesthetics of the mashrabiya but they also controlled the exact functional properties of the screen by varying its attributes during construction. They defined precisely how the screen mediated the boundary between the extreme desert heat and the cooler interior, controlling the amount of light, heat and air allowed in. It is a testament to the ingenuity and skill of these craftsmen that they were able to temper the environment to the extent that they did. That comfort could arise amidst such intolerable conditions speaks volumes of the knowledge and experience that is ingrained within the architectural forms that they created.

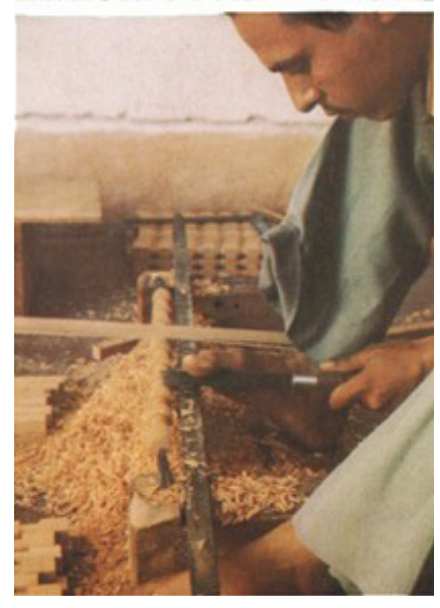

Fig. 8- Craftsmen in Cairo turning the lengthy primary balusters on a lathe.
Egypt, a country consisting primarily of deserts and low-lying river deltas, is a land almost devoid of large trees. "There are few countries so sparsely planted as Egypt and the neighbouring parts of Syria." ${ }^{16}$ Therefore timber was hard to come by in any great quantities and only small branches and sticks were available, meaning that the mashrabiya had to be constructed from a large number of small interconnected elements rather than being carved from a single block of timber. The craftsman would use a lathe to turn each stick to the required thickness and length, beginning with a series of long primary balusters. These could be anywhere between $100 \mathrm{~mm}$ to a metre in length, depending upon the scale and detail of the final mashrabiya, and would provide the basic framework of the screen. ${ }^{17}$ The balusters were turned to create a series of cylindrical lengths that were periodically broken by larger spherical or cubic pieces that would become the connection points for the

13 Shearer, Walter. Foreword to Natural Energy and Vernacular Architecture by Hassan Fathy, p.xv

14 Akbar, Sameer. The Diminishing Role of Windows from Traditional to Modern: The Case of Jeddah, Saudi Arabia p.17

15 Briggs, p.211

16 Briggs, p.203

17 Briggs, p.211 
lateral balusters. At each of these connection points the craftsman would drill a hole into which the shorter secondary baluster fitted. To ensure the wood could expand and contract freely with the changes in desert temperature the connection point was made without glue or nails, a constraint that required a high degree of accuracy during construction. ${ }^{18}$ Once a grid of balusters had been created it was secured within a frame to sprevent loosening. The frames also acted as structural elements, spreading any wind and gravity load throughout the length of the screen to avoid stressing any individual balusters. The net result was a precisely designed and constructed screen stretching over a large opening, with up to and even over a million individual components ${ }^{19}$ acting in unity to control precisely the internal spatial qualities.

By changing the length and diameter of each baluster the craftsman could control the internal conditions of the space..$^{20}$ The ratio between the two defined the porosity of the screen, which directly affected the way in which it regulated light, heat and airflow. Regardless of the various climatic and social requirements, each building had an "optimal absolute and relative size"21 for the length and diameter of its mashrabiya balusters, ensuring that a precise solution could be tailored to suit every unique building. It was up to the craftsman to determine these sizes during production and thus control the internal climate of the building with precision.

Fig. 9- A small section of a mashrabiya, held in place with elastic bands.

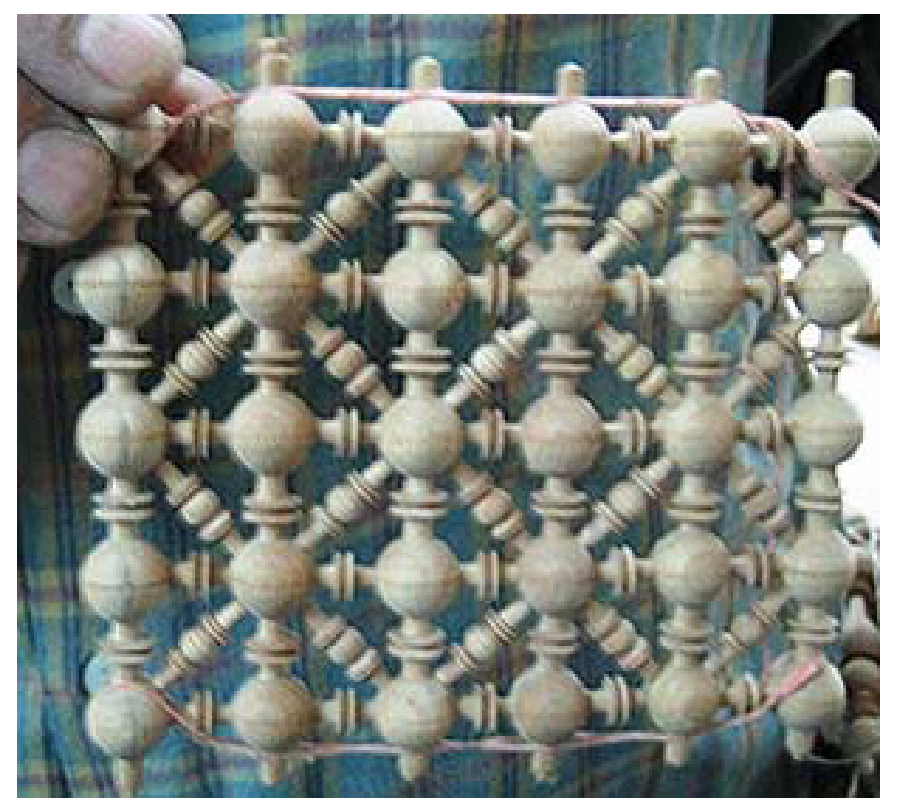

18 Briggs, p. 211

19 The mashrabiya used within the Arab Organizations Headquarters Building has over four million individual pieces of wood used within its construction. http://www.arabfund.org/aohq/mashrabi.htm

20 Fathy, p.49

21 Ibid 


\subsection{Decline of the Mashrabiya}

By the early $20^{\text {th }}$ Century however the mashrabiya was experiencing a significant decline in use. It is now hardly used at all, and those that do remain are usually old and in a state of decay and disrepair. The reasons behind the decline in use of the mashrabiya are twofold, based upon cultural and practical considerations. ${ }^{22}$ A rapid modernization and increase in globalization spread new technologies and styles throughout the world, leaving vernacular traditions behind. Additionally a changing economic structure born from the industrial revolution made small craft-based industries redundant, meaning that the construction process of the mashrabiya could not compete with new forms of mass production.

\subsubsection{Cultural}

Mashrabiya and similar forms of traditional architecture have been utilized in Egypt and the Middle East for centuries, providing an architectural form specifically adapted to the harsh climatic conditions of these desert countries. "It is perhaps the remarkable suitability of the Egyptian house to the exacting demands of the climate that chiefly explains the slight change in its development through hundreds and even thousands of years." ${ }^{23}$ However with the rapid growth of Europe and America in the $19^{\text {th }}$ and $20^{\text {th }}$ Centuries it became important for the slow developing economies of the Middle East to adopt the modern appearance of western values and, as such, architecture. ${ }^{24}$ Therefore building elements such as the mashrabiya, which had provided such an effective architectural solution for hundreds of years, came to be viewed as antiquated and anachronistic. "It was symbolic because the image of villas and apartments was modern and thus, if the [mashrabiya] was fixed on a villa or apartment, the modern image which people were keen to express would be distorted." 25 In their place popular European architectural forms and styles were adopted. "By the end of the nineteenth century Cairo had become a unique architectural exhibition in which all European styles were displayed."26 These new building typologies were not designed for use within the extreme climate of the Middle East however and would quickly overheat beneath the scorching desert sun.

The new styles of architecture generally consisted of static thermal zones rather than rooms designed to facilitate passive ventilation, ${ }^{27}$ meaning the mashrabiya was unable to be applied to window openings and became redundant. The alternative was mechanically driven ventilation and cooling equipment such as air-conditioners. The air-conditioner became

22 Akbar, p.18

23 Briggs, p.146

24 Kenzari and Elsheshtawy, p.22

25 Akbar, p.18

26 Sakr, Tarek Mohamed Refaat. Early Twentieth-Century Islamic Architecture in Cairo, p.76

27 Akbar, p.19 
widespread as it is a relatively effective way of controlling the internal climatic conditions with a high degree of accuracy and ease and quickly replaced the traditional solutions such as the mashrabiya.

Unfortunately, the use of mechanically driven cooling equipment brought with it a number of problems. Air conditioning units require a large amount of power and money to run compared to traditional passive cooling methods. "In many of these [hot climate] countries, air-conditioning accounts for more than $70 \%$ of the national electrical power consumption. However, less than a century ago, the inhabitants of these countries lived in buildings that incorporated only natural-cooling (i.e. far cheaper) techniques for achieving thermal comfort." ${ }^{28}$ Even worse is the fact that the architectural elements once used to cool these desert cities, such as the mashrabiya, malqaf and salsabil created a sense of identity that is conspicuously absent within the buildings now used in their place. "When the modern architect replaced these decorative elements with air-conditioning equipment, he created a large vacuum in his culture. He has become like a football player playing football with a cannon. If the purpose of the game is scoring goals, then assuredly he can score a goal with every shot. But the game itself will disappear, and so will any diversion for the spectators, except perhaps in the killing of the goalkeeper."29 The true value of the mashrabiya is that it not only played an extremely important functional role but it did so in a way that added significantly to the architectural expression of the city, something that is not matched to any degree by its replacements.

\subsubsection{Practical}

The huge economic changes that occurred following the industrial revolution of the $19^{\text {th }}$ century meant that traditional craft-based architecture became financially unviable. ${ }^{30}$ The process of carving and inserting each individual baluster of the mashrabiya was labourintensive and incredibly time consuming, and even historically the mashrabiya was expensive to produce. "The [mashrabiyas] were the most sophisticated objects in the traditional houses of Jeddah... As such, they were the most expensive elements in the building." ${ }^{31}$ This may once have been a method of construction that was economically viable, but now that the building industry is mechanized and production is based on reducing the time and cost involved, detailed craftwork such as mashrabiya struggles to remain relevant.

28 W.J. Batty, H. Al-Hinai and S.D. Probert. Natural-cooling techniques for residential buildings in hot climates, p.301

29 Fathy, p.xxi

30 Akbar, p.18

31 Akbar, p.17 
Ultimately, the underlying reason as to why the mashrabiya is no longer used within Middle Eastern architecture is that the construction process prohibits its use. Skyrocketing costs mean that architects have no option but to forgo the vernacular traditions in favour of modern alternatives such as air conditioners. If a new form of fabrication could be established that was capable of mass-producing the mashrabiya to be financially competitive with the mechanical alternatives then the screen could once again become a viable solution to the problems of desert climate.

Fig. 10- Many of the remaining mashrabiyas are very old and decaying, such as this one in Eritrea.

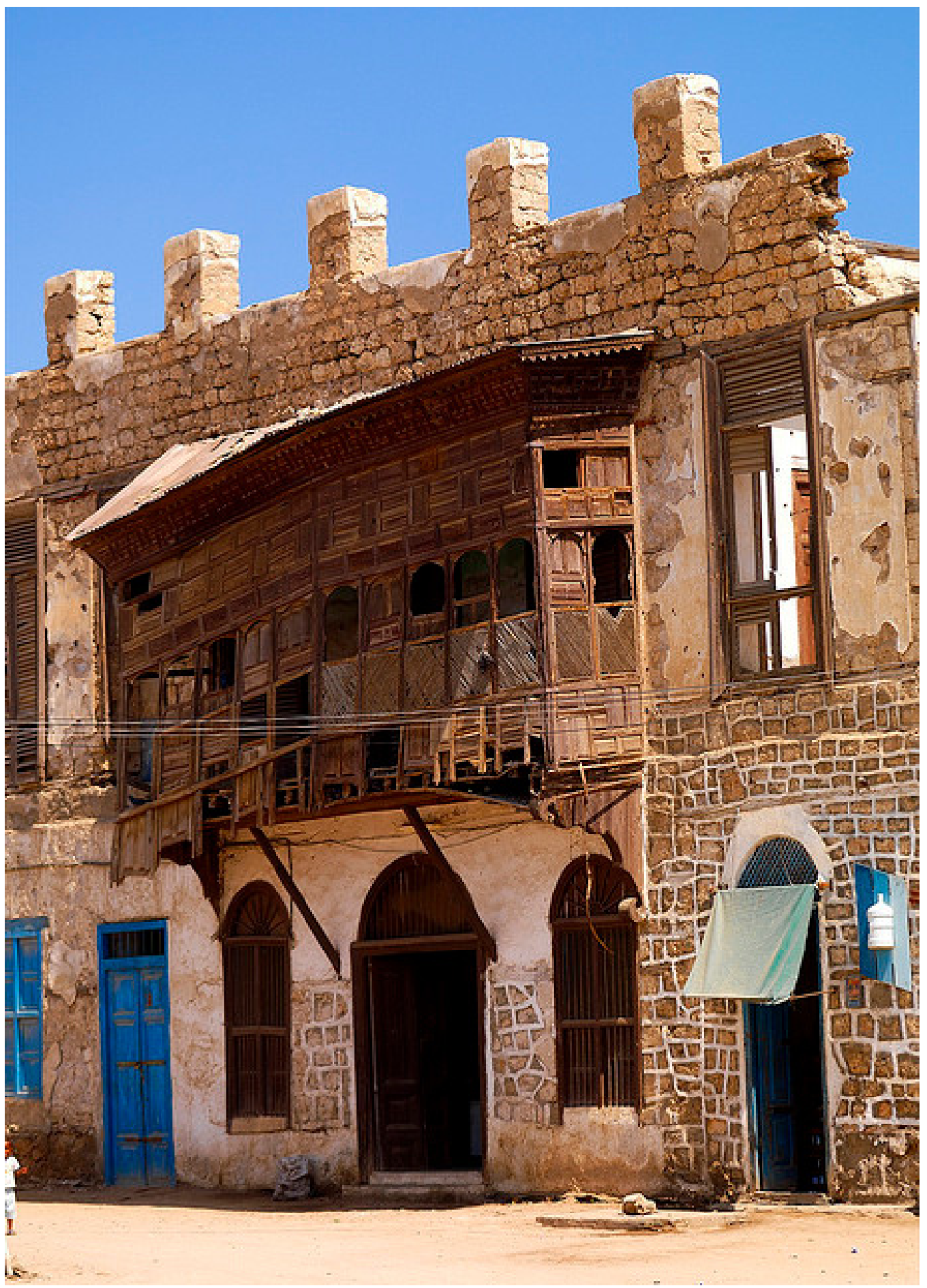




\subsection{Contemporary Interpretation of the Mashrabiya}

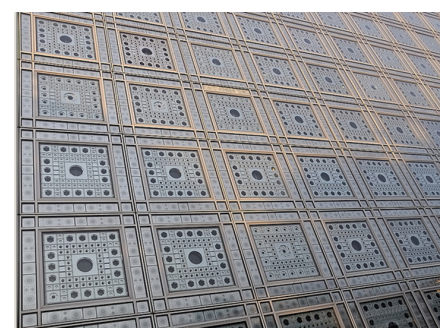

Fig. 11- Mashrabiya inspired screens on Jean Nouvel's Institut du Monde Arabe in Paris.

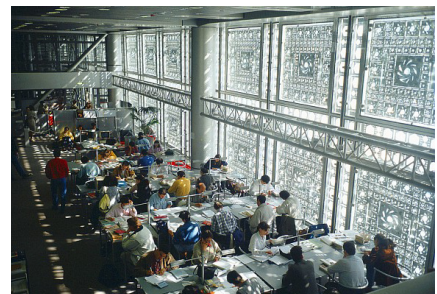

Fig. 12-Interior view

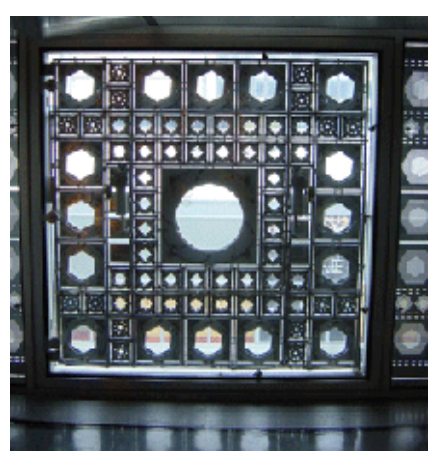

Fig. 13- Detail view

The mashrabiya has a certain mystique surrounding it that holds some appeal to contemporary architects. The precision and delicacy of the detailing speaks of a dedicated craft tradition that is not commonly seen in modern-day designs. As such there has been recent interest in reinterpreting the mashrabiya, or at least the aesthetic aspects of the mashrabiya, in new architectural works.

Jean Nouvel, a Priztker prize-winning architect, has interpreted the mashrabiya in a number of his facade designs. His use of the mashrabiya focuses upon the intricacies and patterns that provide the screen with much of its charm, a charm that he captures in a dramatic and lively fashion. It can be noted however that while the facades are effective at filtering light and providing for a visual spectacle they do not have the same functional role within the building as a traditional mashrabiya once did. Their use is in direct conjunction with glass curtain walls that block any airflow and create static thermal zones, meaning the internal spaces need to be climatically regulated by means of HVAC units.

It is understandable that the visual intricacy of the mashrabiya should be the focus of reinterpretation within contemporary architecture however there is a firmly established body of knowledge within the mashrabiya that is easily overlooked. The mashrabiya is an architectural element that has been developed over hundreds of years to perform the important task of controlling the internal climate of a building and it has been proven to be extremely successful. Whilst it is easy to focus merely upon that which holds a visual appeal, "what is more important is that the historical prototypes combine with recent technological advancements [to] lead to a more natural and environmental-friendly architectural design." ${ }^{32}$ For this reason the focus of this study is to determine precisely the functional capacity of the mashrabiya. It will endeavour to understand how the screen is able to successfully control the climate and how a contemporary interpretation can form from that.

32 Saranti, K. Air moving in and through building: historical prototypes and contemporary applications, p.5 


\subsection{Conclusion}

For hundreds of years the mashrabiya was prized as a highly functional and decorative element of Middle Eastern desert architecture. Indeed, the sheer artistry in the use of tiny wooden balusters to create elaborate patterns belies what an integrally important role it played within desert architecture. Without the mashrabiya the houses within these countries would have been dark, stuffy and uncomfortable. Yet the rapid global changes that occurred during the $19^{\text {th }}$ and $20^{\text {th }}$ centuries have effectively rendered traditional architectural technologies such as the mashrabiya redundant. The incompatibility of the traditional construction methodology with a new post-industrial economy means that it has become far too expensive. That, coupled with a diverse range of new technologies such as air conditioners, has meant that this long-admired craft is no longer used.

Nevertheless there is a wealth of knowledge inherent within the mashrabiya that is clearly being overlooked due the technical difficulties involved in its construction. The way in which it controlled the internal climate of the building while at the same time enhancing the aesthetic and social aspects of the architecture is unmatched by any of its contemporary replacements. For this knowledge to be usable in a contemporary context and within the Giles Weather Station the entire process of construction has to be rethought. The use of a cheap alternative fabrication process to recreate the mashrabiya has the potential to re-establish the screen as a viable architectural element and to tap into its body of knowledge. Before this can be done however the individual functions of the mashrabiya have to be isolated and defined and the factors which influence these functions need to be established. 


\section{Chapter 2: Function of the mashrabiya}

The previous chapter described the rise and fall of the mashrabiya within Middle Eastern desert architecture, but its history does not explain its reasons for being used. Its role within the building was complex, with many different functions. Each of these functions need to be determined to further understand how it can be utilized within the context of the Gibson Desert and what performance aspects need to be optimized for the Giles Weather Station.

The suffocating desert heat of the Middle East required strict building typologies, involving large areas of thermal mass, shaded interiors and small openings. The mashrabiya was developed to increase the amount of ambient light and airflow, allowing the building to be cooled while also creating a much-needed connection with the outside world. Hassan Fathy defines the mashrabiya as having five primary functional roles: light control, airflow regulation, temperature regulation, humidity control and visual privacy. ${ }^{33}$ In addition to this there are also the aesthetic and social attributes of the mashrabiya which cannot be overlooked. This chapter defines each specific function of the mashrabiya in relation to these climatic problems and looks to understand exactly how the screen influences the internal climate of the building.

33 Fathy, p.47 


\subsection{Temperature Regulation}

Deserts are among the hottest places on Earth. Temperatures of up to 50 degrees Celsius ${ }^{34}$ are far beyond what the human body is capable of tolerating, with both comfort and survival depending upon an appropriate form of thermal control. Therefore the first role of every architectural intervention in the desert is to dramatically reduce the temperature of the living space. The vernacular architecture of the Middle East has been developed specifically to regulate internal temperature, primarily through the use of large walls with a high thermal inertia, darkened interiors and small openings.

Alongside the extreme heat is the large diurnal shift in desert temperatures, often up to 20 degrees. ${ }^{35}$ Thermal comfort needs to be attained not just in the heat of the day but also in the cooler parts of the year, whether that be at night or in winter. Deserts can be bitterly cold in winter and any architectural response needs to acknowledge this by allowing heating to occur in the coldest months. The range of temperatures within which comfort can be achieved is reasonably low and depends not just upon the heat storage capacity of the building but also on a variety of other factors, such as the relative humidity, the rate of airflow and the amount of direct sunlight within the space. Each of these factors is regulated in some manner by the mashrabiya.

\subsubsection{Role of the Mashrabiya}

It was not the mashrabiya on its own that cooled the building, but rather an intelligent combination of architectural features, each designed to reduce heat gains and create a cool, steady internal environment. The mashrabiya acted as a mediator within all this, regulating the external boundary layer by blocking any direct sunlight, creating a constant airflow and facilitating evaporative cooling.

Direct sunlight is the cause of the severe temperatures and arid conditions in the desert, heating the earth and air until it borders on unbearable for human occupation. The thin atmosphere common within deserts means that the amount of heat energy transmitted through the sun is extreme, far higher than in milder climates. ${ }^{36}$ The mashrabiya restricted solar gain by shading the interior during the hot summer months, yet was able to provide for heating in the cooler parts of the year by allowing direct sunlight in during winter (see 2.2.1).

34 Koch-Nielsen, Holger. Stay cool: a design guide for the built environment in hot climates, p. 27

35 Karaman, Aykut. Vernacular approaches to passive cooling in arid zones, p.3

36 Aljofi, E. The potentiality of reflected sunlight through Rawshan screens, p.817 
As the mashrabiya allowed for large openings within the building it created a gentle breeze that passed through the internal spaces. A constant airflow helped sweat to evaporate from the skin of the occupant, a process that greatly affects the apparent air temperature. The amount of air that flowed through the mashrabiya (and therefore the rate of cooling) was determined by the size and the porosity of the screen along with the driver at the air exhaust point of the building (see 2.3 and 4.6).

By placing water sources in the mashrabiya the temperature of the air that passed through it was reduced through evaporative cooling. This is important as the external air could be extremely hot to start with, meaning that its cooling capacity as it flowed through the internal space was compromised. By introducing evaporative cooling elements into the mashrabiya it actively cooled the air as it passed through, creating a far more pleasant internal temperature (see 2.4).

Each of these cooling and heating processes depends upon certain attributes of the screen in terms of its porosity and sizing. A more porous screen will let in more light in the winter but also increase the amount of air flowing through the space, changing the efficiency of the evaporative cooling systems. Therefore it is important to understand the interdependencies between the different attributes and functions of the mashrabiya. A change made to affect one process may end up having an adverse impact upon another function.

Fig. 13- The heating and cooling requirements for Giles. The blue line indicates that for most of the year a significant amount of cooling is required, while there is also some need of heating (red) in Winter.

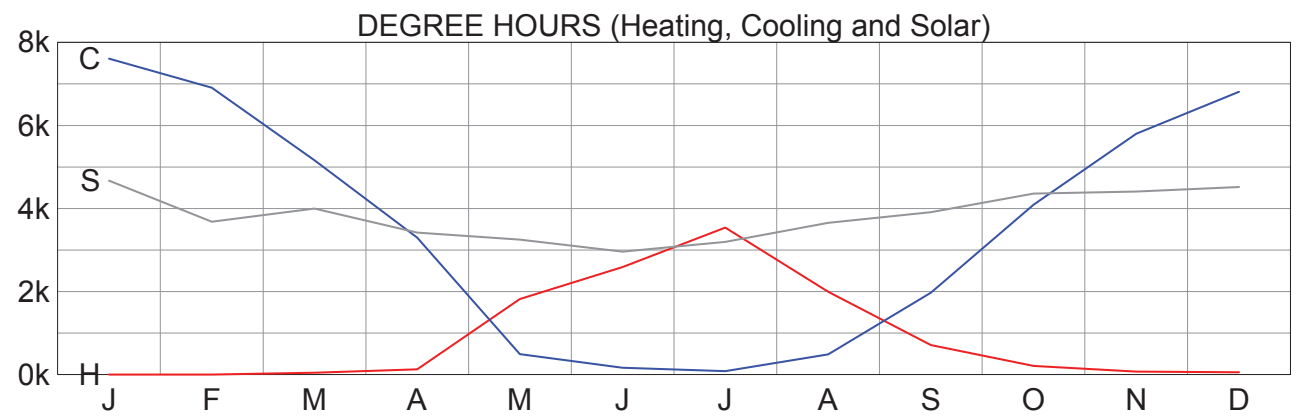




\subsection{Light Control}

As previously established the control of direct sunlight is of critical importance within desert architecture. There are three aspects of light that need to be controlled; the heating caused by direct solar gain, the internal daylighting requirements and lastly the visual qualities of light, such as glare. Each of these aspects is controlled through the mashrabiya, which was an effective solution to these problems in that it was able to control exactly what type of light entered the building. The light changed from something harsh and unwanted to a highly desirable feature of the internal space.

\subsection{1. $\quad$ Direct Light}

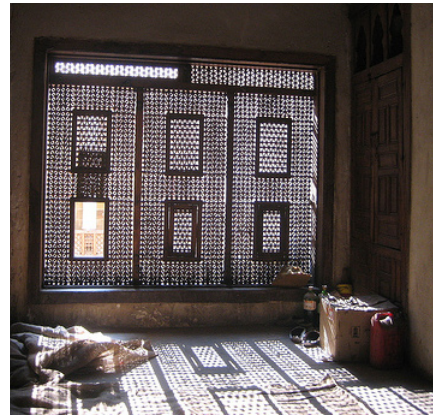

Fig. 15- Here the screen casts delicate shadows throughout the room, allowing light in for heating in winter.
Blocking summer sun and reducing internal solar gain was the most important priority for desert architecture, while at the same time allowing for a small quantity of light to enter during the cold winter months. The mashrabiya was the key to controlling when and how much direct sunlight entered the building. Summer light was blocked by closely spaced balusters yet in winter the sun angle was much lower in the sky and could pass through the interstices, warming the building from within. In this manner it is possible to maintain a stable, comfortable temperature all year round. The mashrabiya on the equatorial facade of the building became the active face as it was able to directly bring light into the building when required.

The precise point in time at which the mashrabiya changed from being a cooling device to a heating device is critically important to understand; if this point is placed too early or late in the year it becomes counterproductive. This point was determined by the ratio between the length and diameter of the individual balusters of the screen which defined the angle at which light could begin to enter the building and consequently the time of year that this would occur (see 3.1).

\subsubsection{Diffuse Skylight}

Although the building needed to block direct light it also required sufficient internal daylighting to allow for regular activities to occur. Diffuse skylight is useful within desert climates as it can create well lit internal conditions without dramatic heat gain, meaning that the "maximum use of indirect and internally reflected light is the most appropriate form of daylighting." ${ }^{37}$ The mashrabiya was an important tool in allowing ambient light into the internal space without letting in direct sunlight.

37 Koch-Nielsen, p. 86 


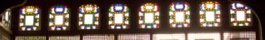

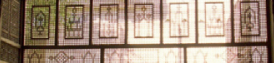

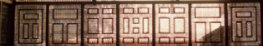

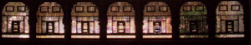

Fig. 16- As shown here, the mashrabiya is able to allow sufficient ambient light into the room without allowing any direct light in.

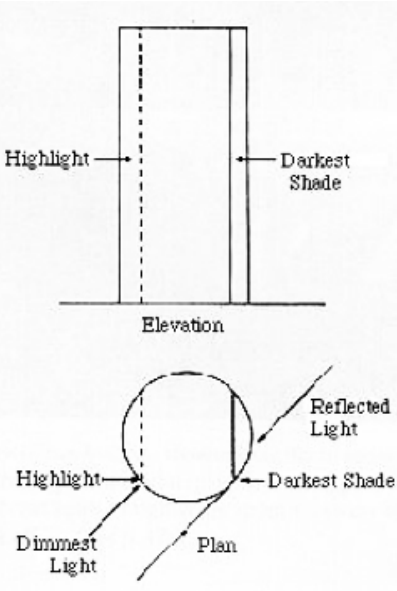

Fig. 17- This plan and elevation of a mashrabiya baluster explains the gradation of light over the rounded surface.
The amount of diffuse light that enters a room depends primarily on the size and porosity of the mashrabiya, along with the reflectivity and materiality of the balusters. ${ }^{38}$ These parameters controlled how much ambient light entered into the rooms and as a result would determine what tasks were able to be performed by the occupants. For example, if one were to read in the room it would require a high level of ambient light and therefore a relatively porous mashrabiya, whereas if the screen were merely covering a bedroom the amount of ambient light required could be much lower. In this manner there is a direct link between the parameters of the screen and the programmatic requirements of the building.

\subsubsection{Glare}

There are also the visual properties of the light which had to be controlled. Desert sunlight is extremely harsh due to a thin atmosphere and often contrasts sharply with the darkened internal spaces. ${ }^{39}$ This, along with a high level of reflected ground light, ${ }^{40}$ creates almost unbearable glare. The extreme variation in light levels causes intense visual discomfort, and an adequate 'visual buffer zone' is required in areas of transition from the exterior to interior.

The control of glare and reflected ground light was very effectively achieved by the mashrabiya which, unlike the brise-soleil or similar shading devices, managed to diffuse the light entering and reduce contrast to the extent that looking out onto the open street was like 'looking through a pane of darkened glass made of lace."41 The use of rounded balusters meant a shadow gradient was created on the internal surface of each baluster, which dramatically reduced any contrast that would otherwise have been created with square sectioned balusters. "The balusters, round in section, graduate the light reaching their surfaces, thus softening the contrast between the darkness of the opaque balusters and the brightness of the glare entering through the interstices... Therefore, with the mashrabiya the eye is not dazzled by the contrast as in the case of the brise-soleil." 42 The combined effect of this delicate and intricate form of construction was that the light passing between the balusters was softened dramatically, becoming vastly more appealing and desirable than that outside.

38 Aljofi, p.818

39 Konya, Allan. Design primer for hot climates, p.50

40 Koch-Nielsen, p.86

41 Fathy p.47

42 Ibid 


\subsection{Airflow Regulation}

One of the primary methods by which humans cool themselves in desert climates is through perspiring. As sweat evaporates from a person's body it cools the skin through a process of heat transfer. For this process to be effective and continuous an adequate airflow rate is required to convey the emitted water vapour away from the skin, as sweat will only evaporate if the adjacent air is capable of increasing in humidity. This means that air movement will increase the rate of heat loss; hence a gentle breeze can provide significant cooling. ${ }^{43}$

For this reason it is important that desert buildings have a constant, steady internal airflow. The layout of rooms traditionally provided for them to be interconnected to ensure crossventilation, with the mashrabiya providing the large openings required while still restricting any direct light access. Whether the air is driven by temperature or pressure differential, the airflow rate is defined by the size and porosity of the mashrabiya, the parameters of which directly affect the comfort levels of the internal space.

\subsubsection{Role of the Mashrabiya}

The construction, location and sizing of the mashrabiya determine the apparent temperature within the building. The airflow rate is proportional to the porosity of the screen, meaning that if the interstices constitute $80 \%$ of the total mashrabiya area (Porosity Factor [PF or $\varphi]=0.8)^{44}$ then the airflow through the opening will be at $80 \%$ of what it would have been with no mashrabiya in place. The result is a similar reduction in the cooling capacity of the airflow.

If airflow is looked at in conjunction with evaporative cooling techniques (see 2.4), then criteria for determining the optimum dimensions of the mashrabiya can be established. Evaporative cooling processes work most successfully at high air velocities (up to a maximum of approximately $1 \mathrm{~ms}^{-1}$ for human comfort), ${ }^{45}$ and the air velocity is dependent upon the sizing and porosity of the mashrabiya. As the porosity of the screen is usually determined by the lighting conditions (see 2.2) the overall size is the factor that is adjusted to allow for adequate airflow. The optimum size for a mashrabiya can therefore be calculated through determining the desired flow rate, the porosity of the screen and the airflow driver.

\subsubsection{Airflow Drivers}

Ventilation in the traditional Middle Eastern desert house was usually driven by one of two methods; airflow due to pressure differential (wind) and airflow due to temperature

43 Fathy, p.27

44 Gandemer, Jacques, and Alain Guyot. La Protection Contre Le Vent, p.55

45 Santamouris, M. and D. Asimakopoulos. Passive cooling of buildings, p.407 
differential. In both of these circumstances the mashrabiya acts as the primary inlet for the air and thus plays a critical role in how it flows through the space. It is important to fully understand both of these conditions as the rate at which they draw air through the space will directly affect the sizing and design of the mashrabiya.

When there is a relatively predictable wind direction on a site then this can be used as the driver for ventilating the internal space. Many cities have a prevailing wind that can be relied upon to blow consistently, and as such have set up wind catchers (malqafs) and similar systems to harness this naturally occurring breeze.$^{46} \mathrm{Or}$, even simpler, openings on opposing walls of a room can be positioned to create a pressure differential between the inlet and outlet, resulting in an airflow between the two ${ }^{47}$ The size of these openings and the porosity of the mashrabiyas which cover them determine the flow rate between the two, as defined by the principle $\left[F=C A_{1} v\right],{ }^{48}$ with $A_{1}$ being substituted with $A_{P F}$ or $\left(A_{1} \cdot \varphi\right)$.

On a calm day however there is still a need for air to flow through a room. For this reason creating airflow through the use of a temperature differential can be a much more convenient and reliable method of cooling a space. "Air is warmed, causing convection, with the warm air rising and being replaced by cooler air. A cool draft is created in the space between the warm area and the cool-air intake opening... It is most important when the outside air is still and yet the interior requires ventilation to achieve comfort." ${ }^{49}$ Additional drivers such as solar chimneys can be used to ensure a steadier flow through the space. Again, the mashrabiya acts as the air entry point for this system and its size and porosity need to be calculated accordingly.

Fig. 18- A town in Pakistan utilising wind catchers or 'malqafs' to harness the local air current.

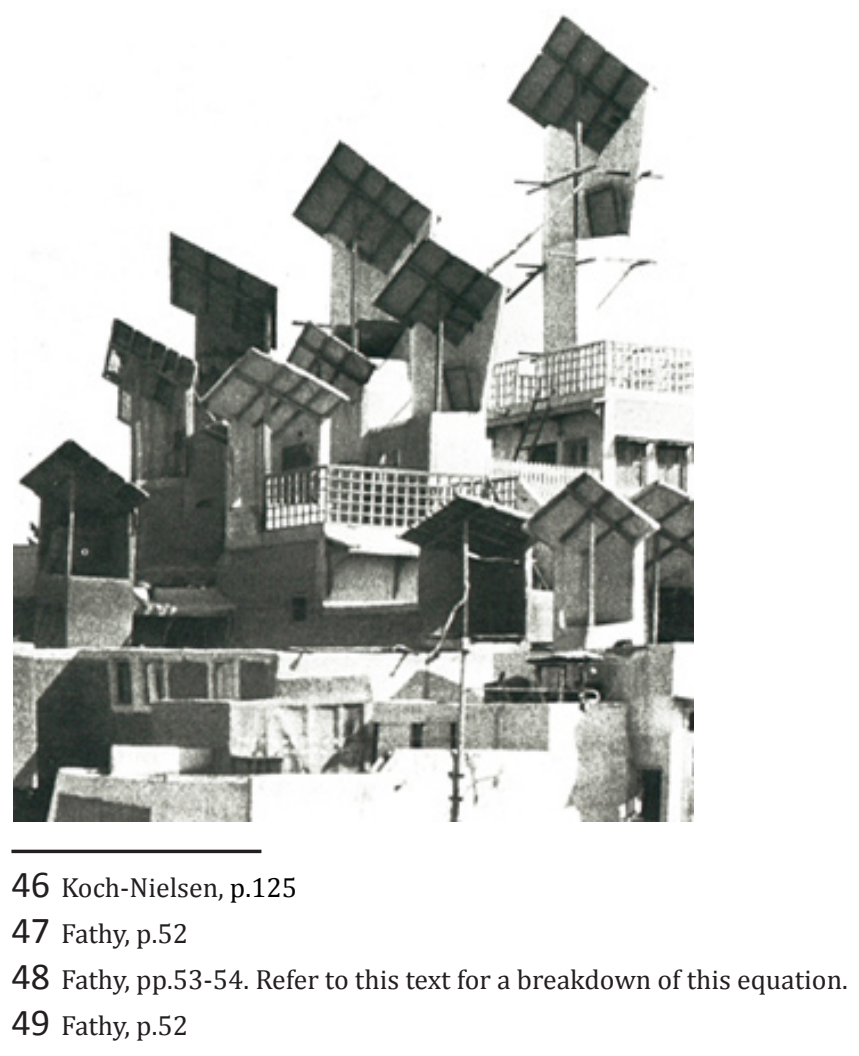




\subsection{Humidity Control}

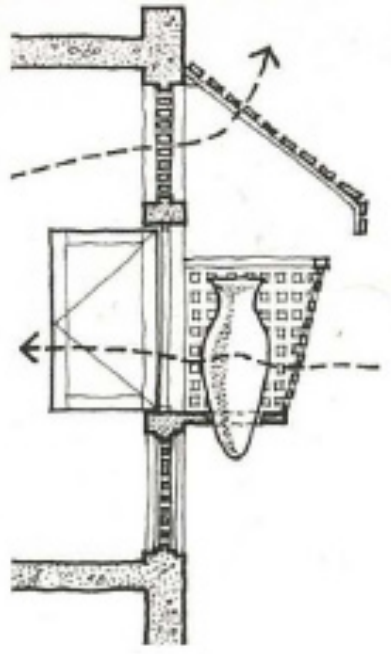

Fig. 19- A porous clay water jar used to cool the air as it passed through the mashrabiya and into the building behind.
In extreme desert climates the humidity can drop below $20 \%{ }^{50}$ When the humidity is this low it is extremely uncomfortable, with skin over-drying and the body losing large amounts of moisture. Alternatively, if the humidity is too high then it restricts the ability of the body to lose heat through perspiration. The recommended humidity levels for comfort are generally put at between $30-80 \% .^{51}$ To be effective at cooling any breeze blowing through the space should have its temperature lowered and relative humidity increased. The mashrabiya, as the primary air intake point of the building, is in a position to facilitate this cooling.

When porous clay water jars known as 'goolas' or 'zias' were placed in front of the mashrabiya the air flowing past would cool as it evaporated small quantities of water from the surface of the jars, a process known as evaporative cooling. ${ }^{52}$ "This latent heat of evaporation must be supplied by the wet surface, which thus loses heat or is cooled. This process is called adiabatic cooling, because it does not involve a transfer of heat to or from the air participating in the process. Therefore, the air is allowed to cool as it expands and to heat as it contracts, and the temperature, pressure, and relative humidity of the air change without varying the total heat content." ${ }^{\prime 3}$ Essentially this means that the decrease in air temperature is matched by an increase in air humidity. If this process is provided for effectively it can dramatically cool the air that enters the room and make it far more comfortable. The mashrabiya facilitated this process by controlling the direction and flow rate of the air. ${ }^{54}$

The village of Bãris, in Al-Khãrga Oasis, Egypt, was designed by Hassan Fathy using nothing but traditional design and construction methodologies. The way in which he cooled the buildings was by employing evaporative cooling devices at the air intake of each room. It has been said of the buildings that although the temperature could be up to 48 degrees Celsius outside, inside it was cold enough to make people shiver. ${ }^{55}$ It is this cooling capacity which makes evaporative cooling techniques so vital to desert architecture.

50 Karaman, p.3

51 Cook, Jeffrey (ed.) Passive cooling systems, p.361

52 Briggs, p. 147

53 Fathy, p.23

54 As a side effect of this process the water in the clay jars would also cool and be nice to drink, hence the name of 'mashrabiya,' which translates as 'drinking place.' Briggs, p.148

55 Gallo, Cettina. Passive cooling as design methodology: some examples from the past to the present, p.311 


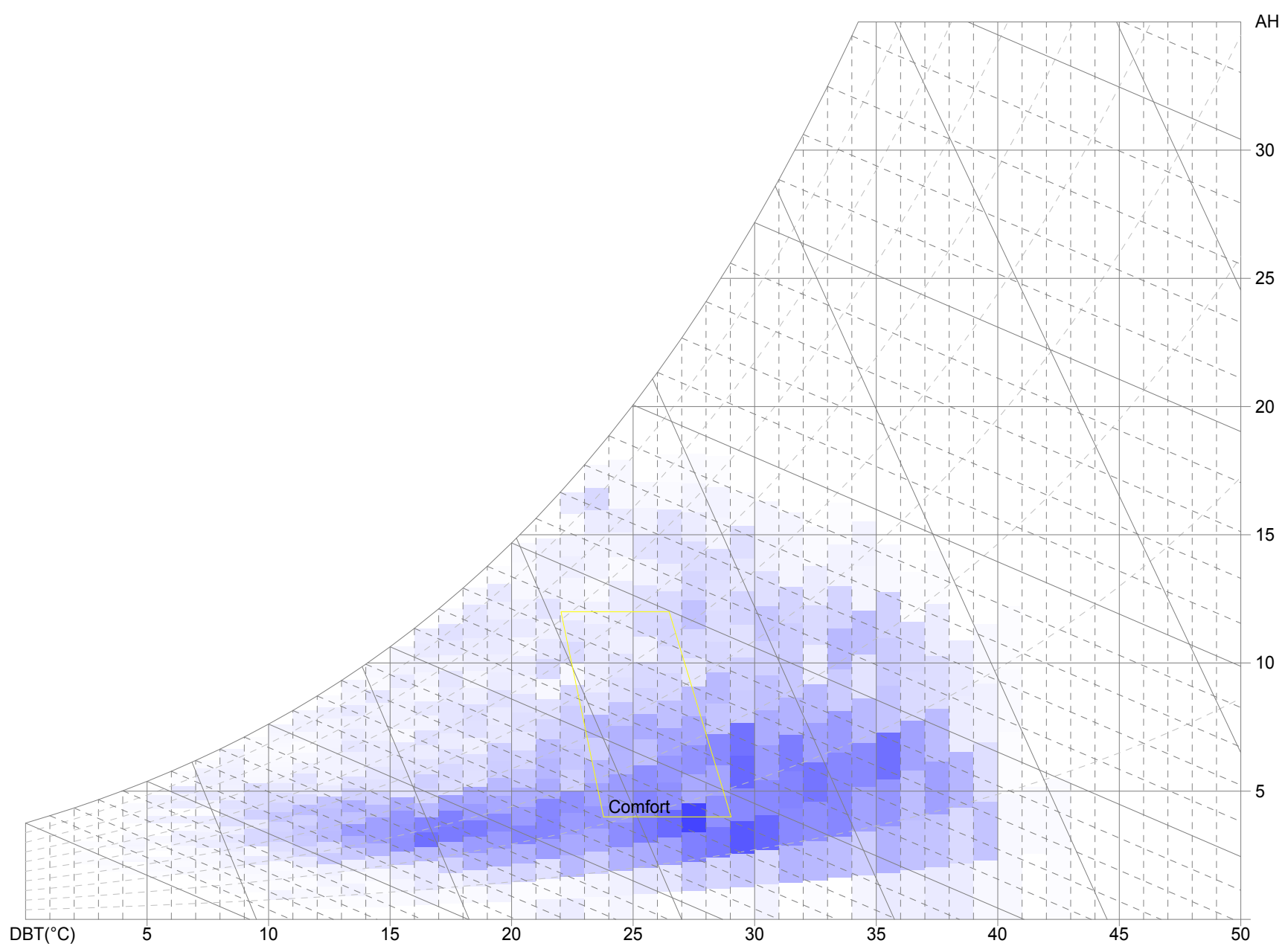

Fig. 20- This psychrometric chart for Giles describes the zone of comfort (yellow) and the actual experienced conditions (blue). As can be seen, any building designed within this location must both reduce the air temperature and increase its humidity to reach this zome of comfort. 


\subsection{Visual Privacy}

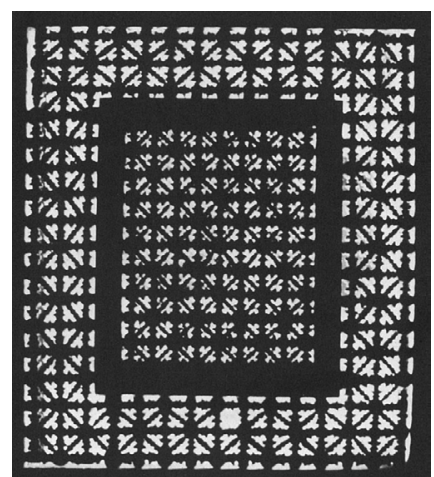

Fig. 21- Here the focus is placed upon the individual balusters of a mashrabiya, creating a visual barrier.

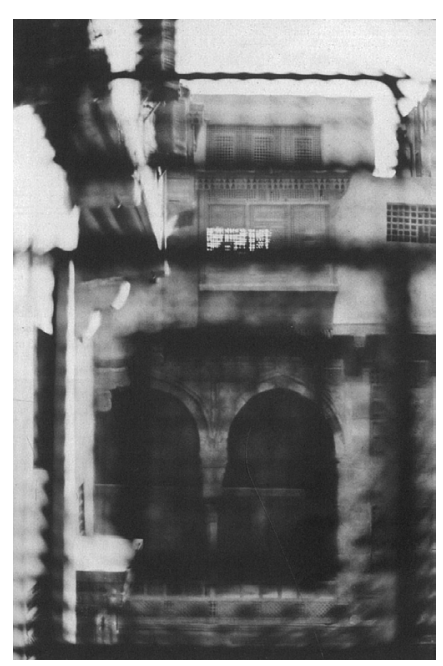

Fig. 22- The same mashrabiya but viewed from the inside and with the focus being placed upon the brightly lit external courtyard, becoming almost transparent as a result.
Privacy was an important issue within the predominantly Islamic architecture of the Middle East. With strict cultural rules about privacy, especially regarding women, the traditional Islamic building sought to restrict views into the building. ${ }^{56}$ The closely spaced bars of the mashrabiya allowed the inhabitants of the building to see out but not for those outside to see in. For people outside a building a mashrabiya would present a visual barrier, the darkened interior being far outshone by the brightness of the wooden balusters. For those inside the building the opposite was true. The brighter external conditions became the focus and the small balusters of the mashrabiya would diminish in visual dominance due to the scale and sheer number of them. What would appear to those outside as a solid object became lacelike in its transparency for those inside.

The factors which controlled this privacy were a combination of screen porosity and lighting conditions. By manipulating these two factors a screen could change from being visually opaque to having the appearance of being completely transparent. This use of these fairly basic principles of optics was extraordinarily effective in creating the desired spatial boundary between inside and outside of the desert home. It allowed the mashrabiya to act as an instrument of social interaction by providing people with a 'meeting chamber' in which they could converse with the street without being seen, yet in which they were also afforded the vibrancy of verbal communication with passersby and views into the neighbourhood..$^{57}$ This is an aspect which is no longer seen with the use of glazed windows. "The relationship between people and the outdoors does not exist anymore."58 Without the two-way mediation between the interior and exterior that the mashrabiya provided contemporary desert buildings are essentially closed affairs. 


\subsection{Aesthetic and Social Role}

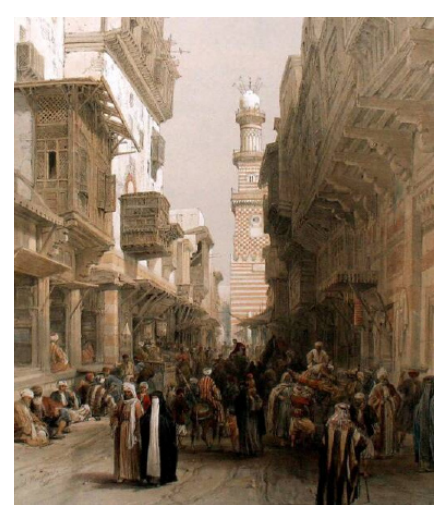

Fig. 23- $A$ view of an ancient street lined with mashrabiyas.
Additionally, although not a functional aspect, the mashrabiya also filled a much needed aesthetic role within these buildings. With heavy walls creating a stark and solid impression a visual counterpoint was required, something to break the heaviness with delicacy. "The exterior of the building is bare to the extreme. One side only, as a rule, faces a street, and that street is narrow." 59 The mashrabiya added vibrancy and life to these streets by creating new points of aesthetic expression. The delicacy and intricacy of the screens was the perfect visual contrast to the functionalist architecture of thermal mass.

The decorative aspects of the mashrabiya became a social statement. The more complex and delicate mashrabiyas were highly prized yet extremely expensive, so became symbols of wealth. "Objects attached to buildings become an important means to convey the identity of the occupiers to neighbours and passersby. Thus rowshans [mashrabiyas] were beautifully engraved." ${ }^{\prime 0}$ In their capacity as a representative of the household's identity the carved screens are unmatched in any form by their contemporary replacements. With their ability to be carved into a multitude of intricate patterns they act as a conduit for artistic and social expression, providing a personal touch and aesthetic focus to a house. 


\subsection{Conclusion}

There are five primary functional roles of the mashrabiya- the regulation of light, heat, humidity, airflow and privacy. As a result of these functions the mashrabiya allowed desert buildings to be comfortable, light and breezy, maintaining a stable temperature throughout the entire year. The screens provided a level of privacy for the occupants while creating much needed interaction with the surrounding street and neighbourhood. They turned a stark, unadorned architecture into something far more expressive; a uniquely decorative and ornamental way of building that tied aesthetic qualities seamlessly with critical functionality.

One of the reasons the mashrabiya became so widespread is because its use could be customized to each individual circumstance. The amount of light, heat, humidity, airflow and privacy afforded to a building could all be adjusted to fit the requirements of its specific location and program. This versatility is important to understand in terms of the physical variables of the mashrabiya that affect the internal climate, especially if the screen is to be optimised for use within the Gibson Desert.

Porosity, scale and overall size are the primary factors that influence the performance of the traditional mashrabiya. The ratio between the baluster length and diameter, which determines the porosity of the screen, was the variable which was most frequently changed to affect the internal spatial conditions. The problem, however, that has become apparent in this research is that there are too few variables in the traditional mashrabiya screen to give absolute control over each functional aspect. For example, if one were to increase the porosity of the screen it would simultaneously directly affect the light, airflow, privacy and heating regulation of the mashrabiya.

A further investigation was therefore undertaken to determine other aspects of the screen capable of being altered via contemporary methods of manufacture in order to optimally control the screen's performance. 


\section{Chapter 3: Parameters of the mashrabiya}

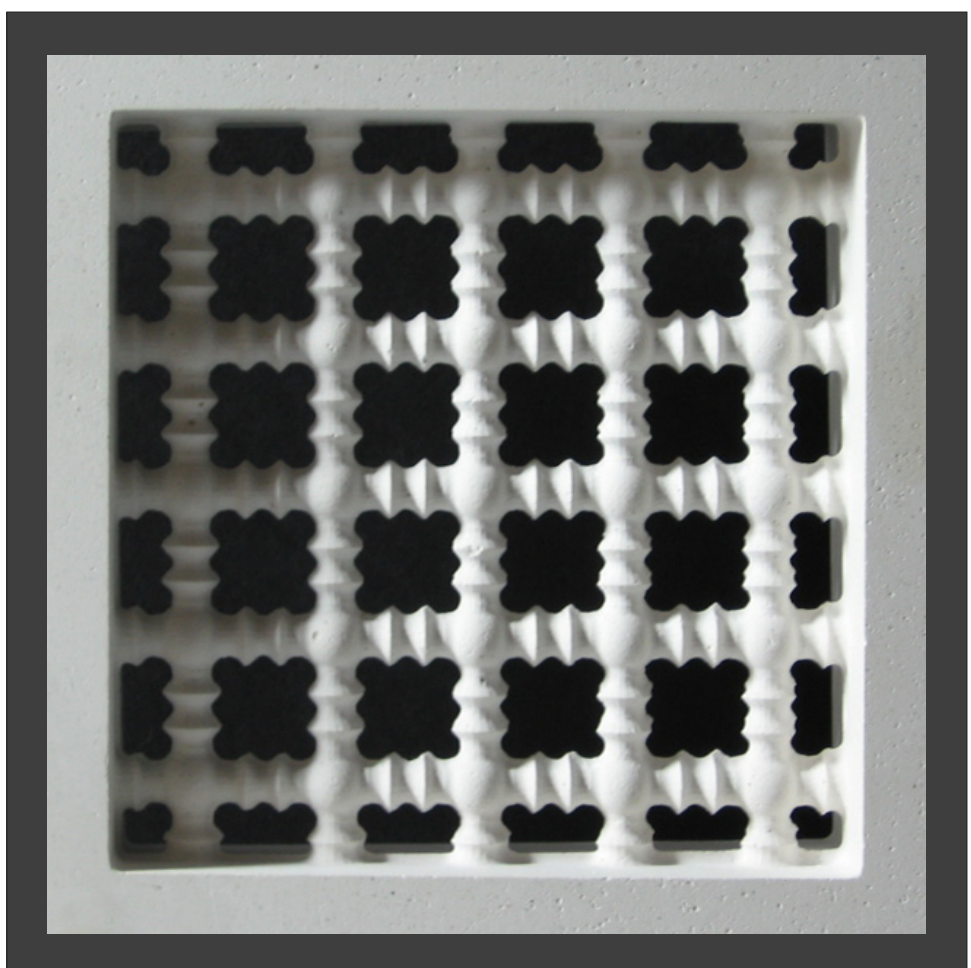

Fig. 24- By experimenting with the use of contemporary fabrication processes to construct the mashrabiya a number of significant advances can be made and a lot more is revealed about the individual parameters of the screen. Here the screen has been carved from plaster by a computer numerically controlled (CNC) router. 


\section{Parameters}

In the previous chapter the precise role that the mashrabiya played within traditional Middle Eastern desert architecture was defined. What still has to be established is exactly how the mashrabiya achieved this, in terms of which physical variables controlled its functional properties. The traditional means of altering the climatic properties of the screen was to alter the diameter and length of the individual balusters, changing the overall porosity. ${ }^{61}$ Beyond this however the mashrabiya was restricted in its versatility by the limitations of its construction process.

Changing the production methodology suddenly gives access to a far greater number of variables and control over the mashrabiya. The use of computer numerically controlled (CNC) milling devices, now a common form of digital fabrication, gives a much higher degree of accuracy, speed and versatility than was previously possible using hand driven lathes. By using a flip-bed CNC system, where a block is cut, flipped and a matching cut is made on the other side, a screen of almost any possible shape can be made. This means that the individual section, shape and dimension of each baluster can be precisely defined to provide the optimal climatic and spatial control.

With so many more variables being available to work with under this new system it is important to understand each and know how they affect the internal space. Therefore this chapter determines the exact causal links between each physical variable in the design of the mashrabiya and the impact that has on the internal environment. The variables analysed are: baluster diameter, length, angle and cross section, sectional layers, baluster offset, pattern and materiality. This information provides the basis for creating an optimized and climatically appropriate mashrabiya screen for the Giles Weather Station.

The following research is based upon defining the variables for the Northern façade of the building, which is the most active face. A similar process can be undertaken to determine the affect each variable will have if the mashrabiya were to be applied to the other facades or the roof, based upon the same basic mathematical principles. The scope of this research will however be focussed solely upon creating an accurate description of the variables for use on the equatorial façade of the building.

61 Fathy, p.47 
Baluster Length
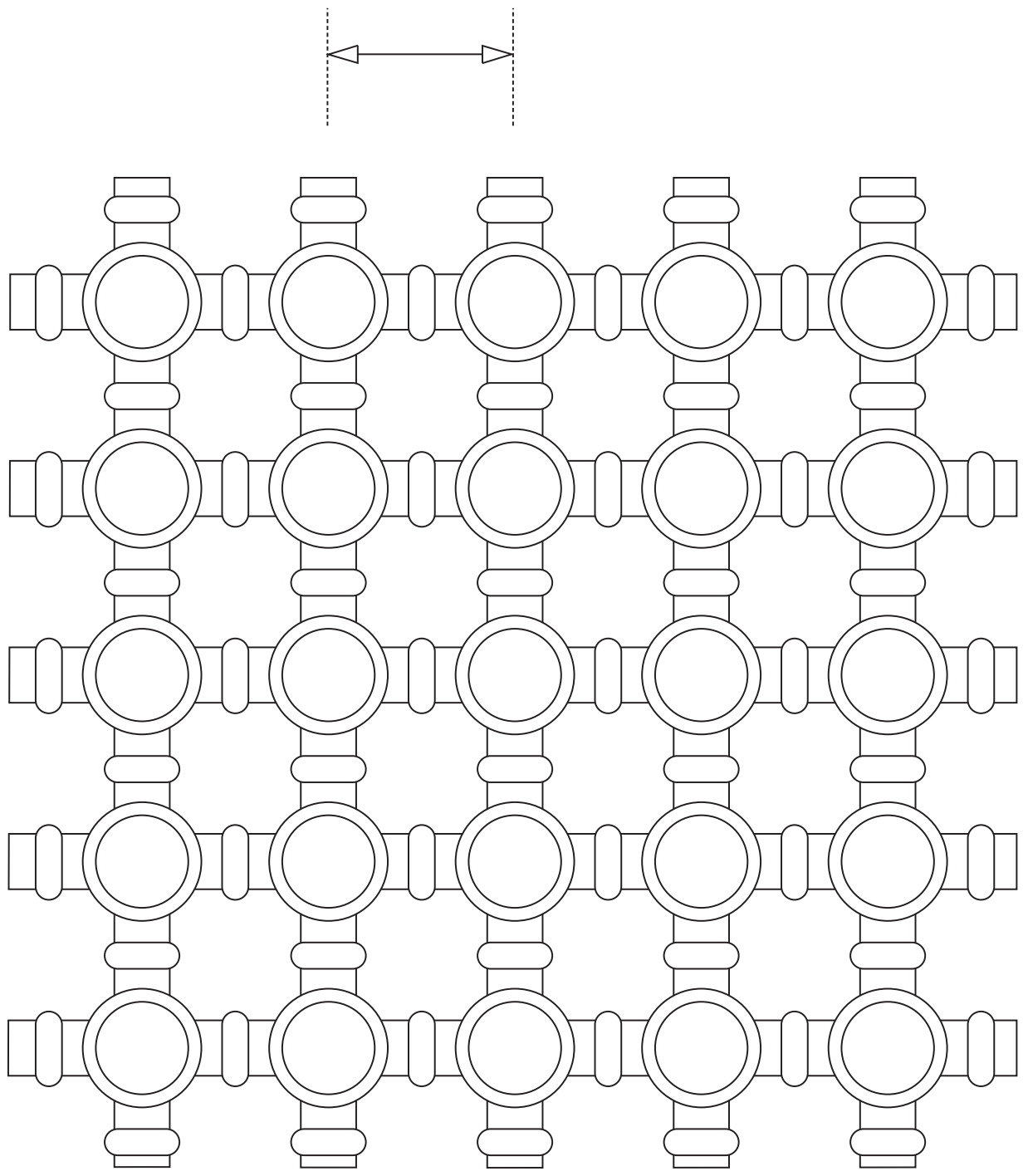

Fig. 25- Traditional Mashrabiya Typology
Baluster Diameter

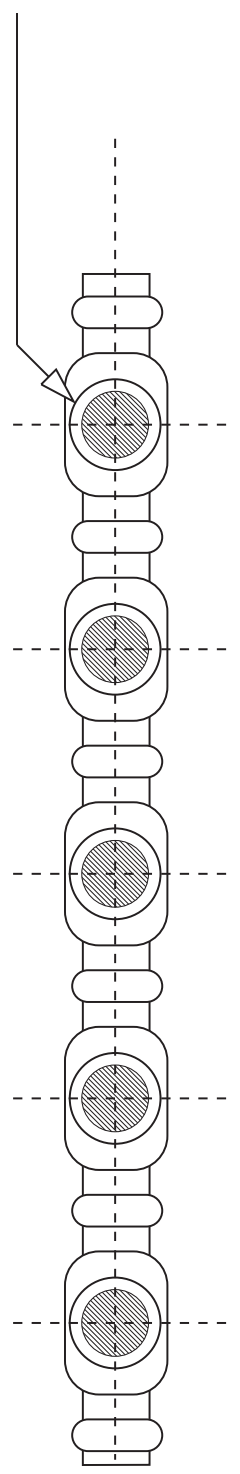




\subsection{Baluster Diameter/Length Ratio}

Stereographic Diagrams

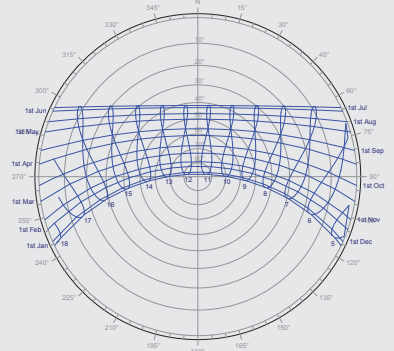

Fig. 26- Stereographic diagrams are a common method of describing heating, shading and solar gain throughout the year for a certain location. The image above is a spherical projection of the annual solar path over Giles. Comprehensive information regarding the interpretation of stereographic diagrams can be found in the publication 'Shading and sun control' by the AIA.

(a)

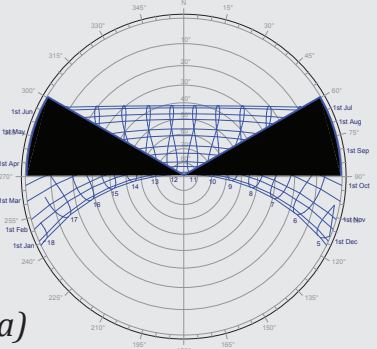

(b)

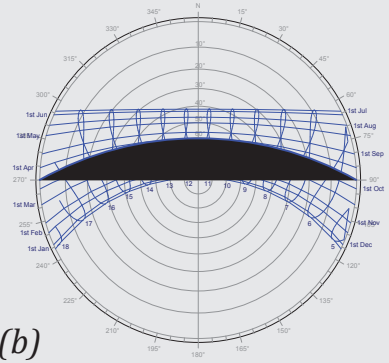

The shading mask overlayed on top of the stereographic diagram represent the times of the year in which the analysis point is placed in complete shadow. Image (a) shows the shading caused by vertical mashrabiya balusters, while (b) shows the impact of horizontal balusters.
The ratio between the baluster diameter and length (D/L Ratio) was traditionally used to define the functional characteristics of the mashrabiya. This directly affected the porosity of the screen, which controlled the ambient light, privacy and airflow. Additionally, the ratio between diameter and length also defined exactly the time of year in which direct light entered the room, determining the critical moment when the space would switch from being cooled to being heated. If this were too soon in the year the room would overheat dramatically and become unliveable. If it were too late then the space would be bitterly cold during the winter months.

As direct sunlight is the primary driver of the thermal environment in the desert it stands that this should be the initial consideration when determining the variables. The most important function of the screen is to restrict direct sunlight during the harsh summer months. The porosity of the screen therefore becomes subservient to the D/L Ratio and will be adjusted accordingly further into this study.

The time of the year at which direct sunlight will enter the building can be calculated through the use of shading masks, which will determine when $100 \%$ of the interior space is in shadow (see fig. $27 \mathrm{~b}$ on facing page). To start with the time of year in which absolutely no direct light can enter the space must be defined through the use of a stereographic temperature diagram. Fig. 26b clearly shows the points during the year when the climate is too hot and too cold. By drawing a line through the diagram at the times where no direct light should enter the space due to overheating, the point at which the building is in complete shade can be determined. This line will correspond with a sun altitude angle $\left(\theta^{1}\right)$ on the stereographic diagram, which can then be used to calculate the $\mathrm{D} / \mathrm{L}$ ratio through the formula $\left[\mathrm{D} / \mathrm{L}=\operatorname{Cos} \theta^{1}\right]$. This formula establishes the exact ratio between the baluster length and diameter to ensure $100 \%$ shading will begin at this time of year. 


\section{a) D/L Ratio}

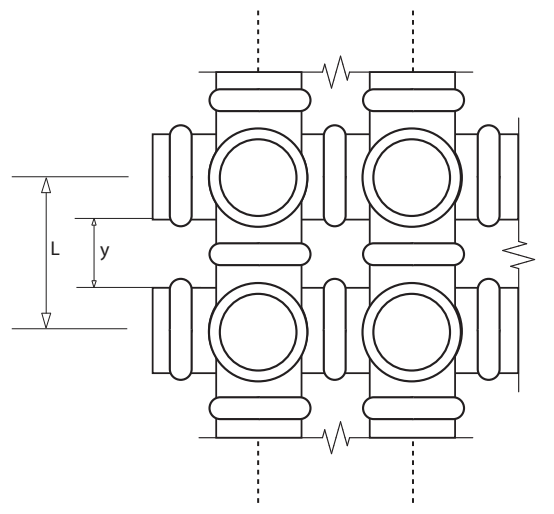

Elevation

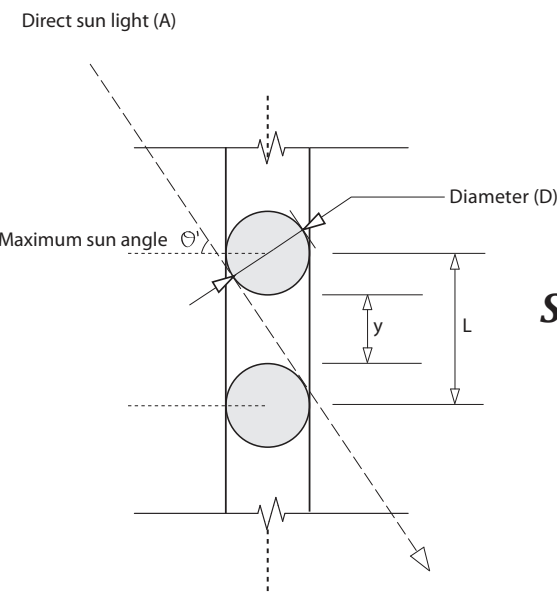

$\mathrm{D} / \mathrm{L}=\operatorname{Cos} \theta^{\prime}$ b) Giles Weather Station
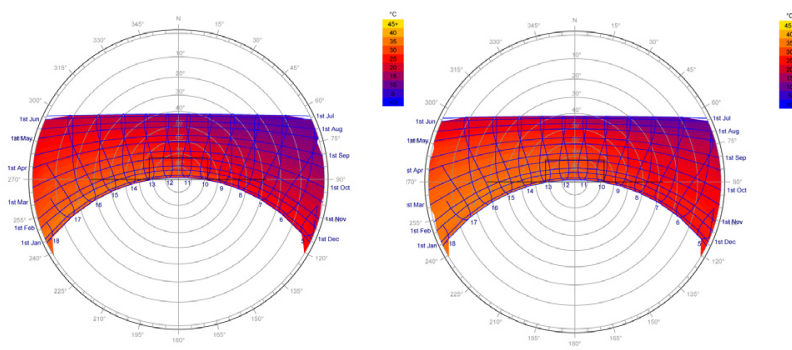

Stereographic temperature projection for Janurary through June (I) and July through to December ( $r$ ) recorded at Giles Weather Station. The purple areas shown primarily during the winter and in the early morning are the points where heating is required. Refer to appendix 1 for more detailed information.
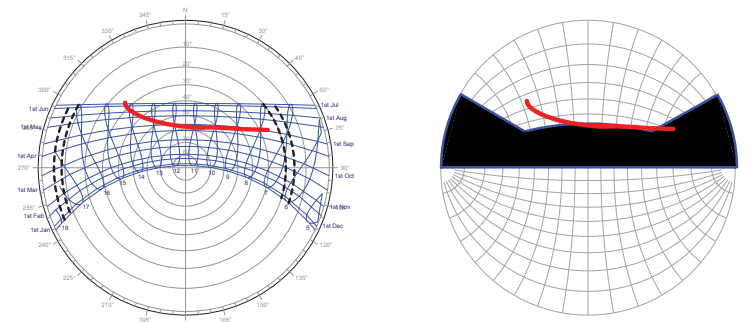

The red line indicates the time of the year in which the change from cooling to heating must occur. The shading mask ( $r$ ) represents a $D / L$ ratio of 0.5 , which corresponds to a maximum sun angle of 60 degrees. c) Test Screen

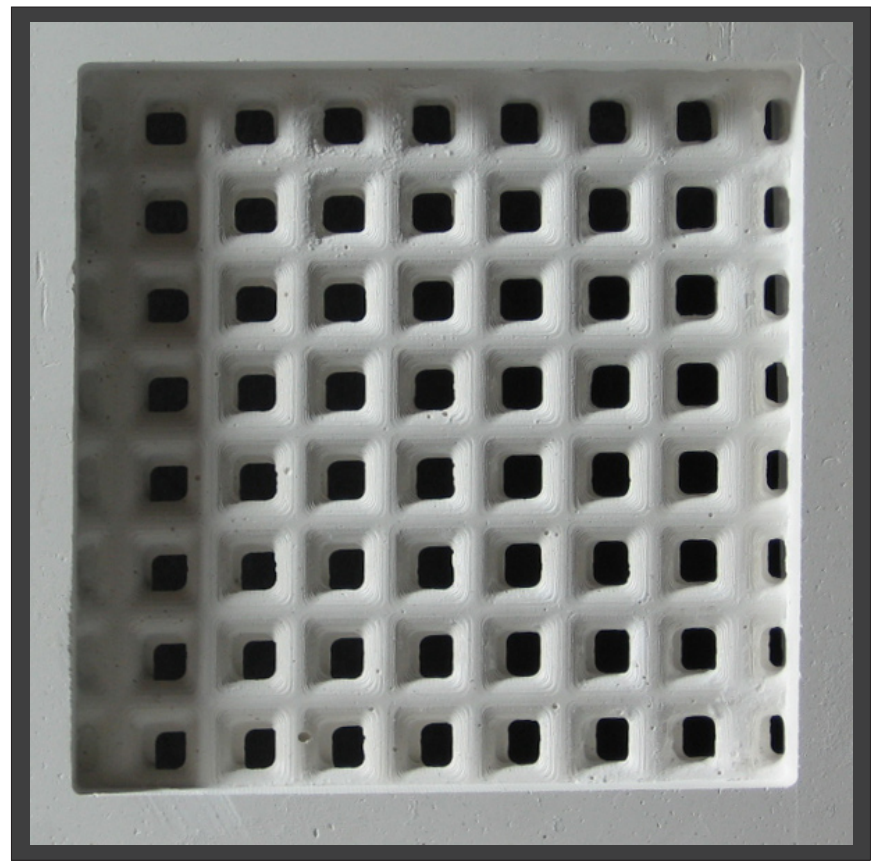

This screen at Giles is designed for a maximum horizontal and vertical sun angle of 60 degrees:

$D / L=\operatorname{Cos} 60$

$D / L=0.5$

d) Results

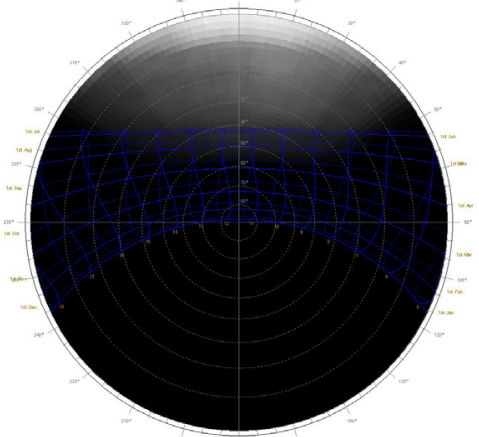

Shading Percentage

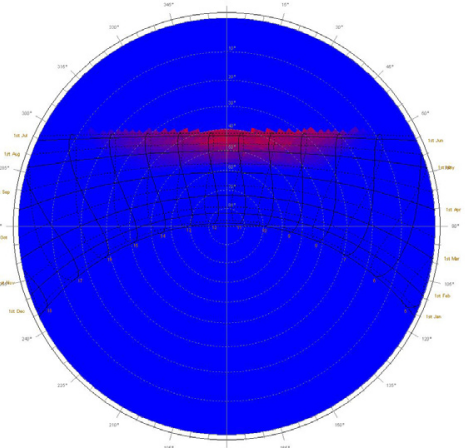

Thermal Gain
This diagram shows the total shading percentage due to the $D / L$ ratio of 0.5 of the test screen. Although some light is allowed in the screen is clearly not porous enough to be effective. Refer to appendix 2 for more information on all anal$y$ sis and results.

The thermal gain as a result of this winter light starts at the right time of year yet is clearly not sufficient to heat the room, nor does it favour morning over evening sun. 


\subsection{Baluster Angle}

With a $\mathrm{D} / \mathrm{L}$ ratio established a further variable, the baluster angle, can be used to define what time of day the sunlight enters the building. This was not something that was possible to achieve in the traditional construction of the mashrabiya, yet is an important consideration as the mornings are consistently a lot cooler than in the evenings. This means that for a stable temperature throughout the day sunlight is required during the morning but needs to be blocked during the evening.

As the balusters rotate from vertical to horizontal their associated shading masks change accordingly, moving from a symmetrical shape to one that favours the morning or evening sun (See Fig. 28a on facing page). By applying this to the stereographic temperature graph it can be determined exactly what angle is required on both the vertical and horizontal balusters to provide the correct daily solar gain. By incorporating the previously established $\mathrm{D} / \mathrm{L}$ ratio an accurate shading diagram can be formed which will precisely map the times of the year in which complete shading is provided by the mashrabiya. 

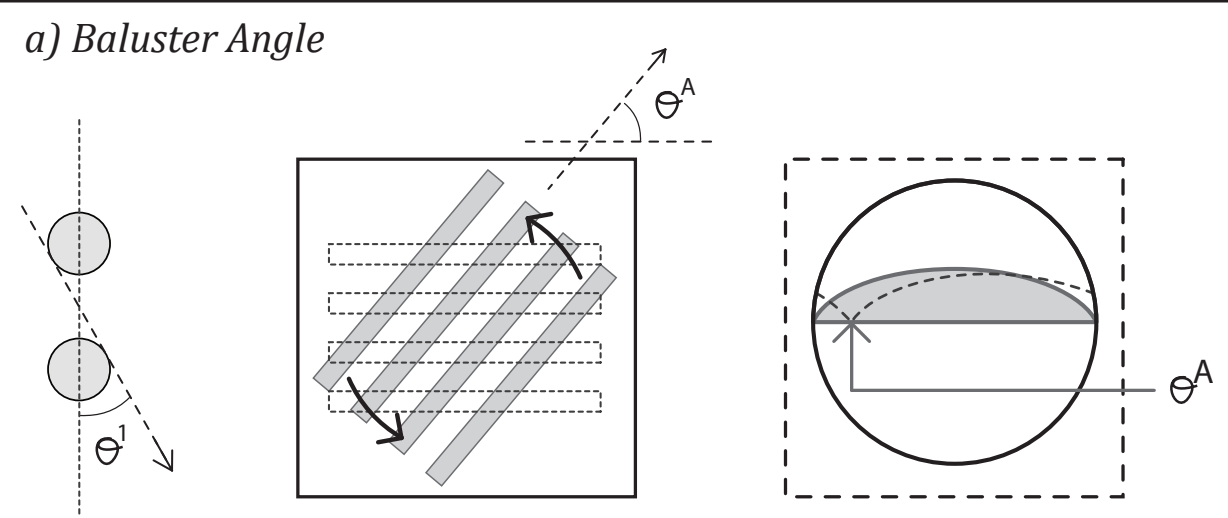

\section{Section}

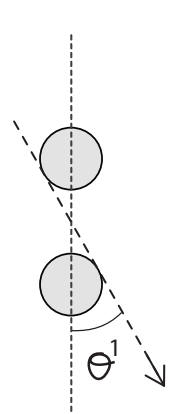

\section{Vertical baluster rotation}
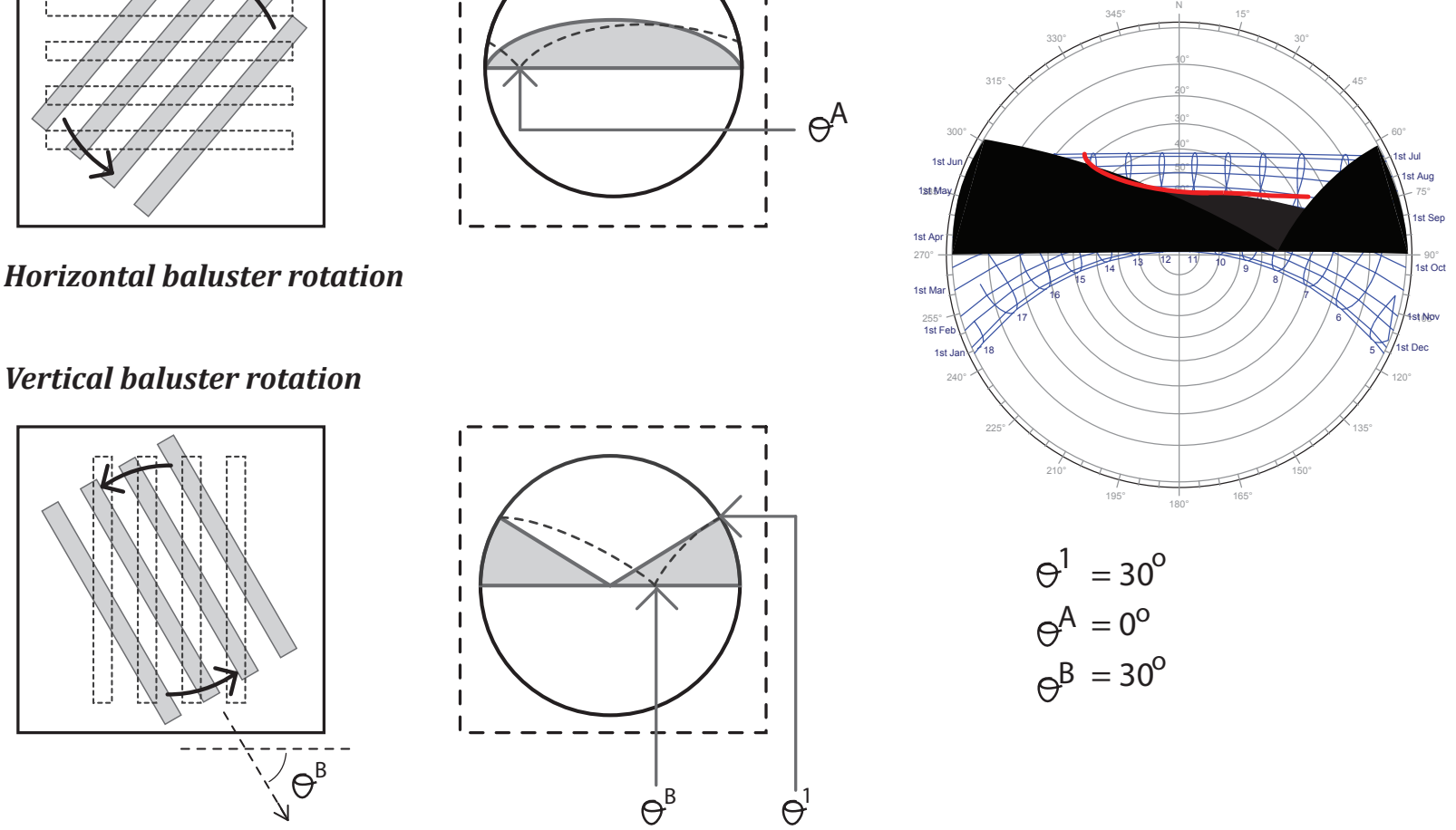

$$
\begin{aligned}
& \theta^{1}=30^{\circ} \\
& \theta^{A}=0^{\circ} \\
& \theta^{B}=30^{\circ}
\end{aligned}
$$

Plan

Elevation

Giles Weather Station

b) Test Screen

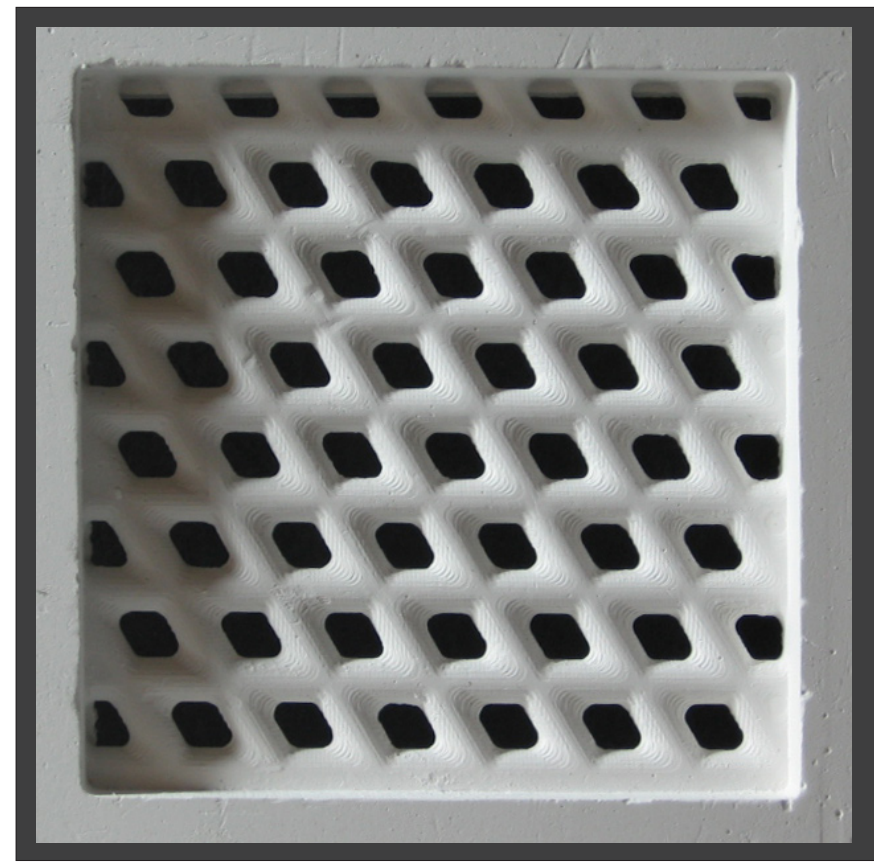

This test screen for Giles has a horizontal baluster angle of 0 degrees and a vertical baluster angle of 60 degrees. The rotation of the vertical balusters makes a dramatic visual shift from the traditional form of the mashrabiya, as well as improving its functional performance.

c) Results

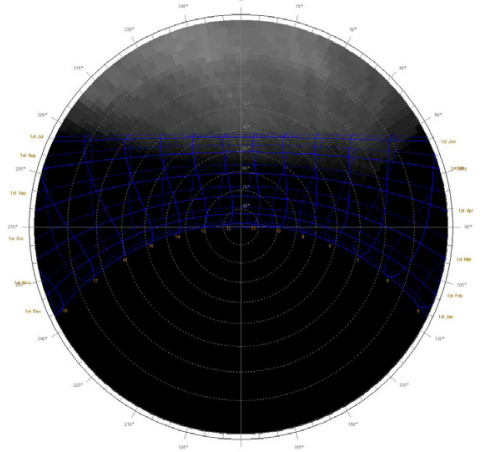

Shading Percentage

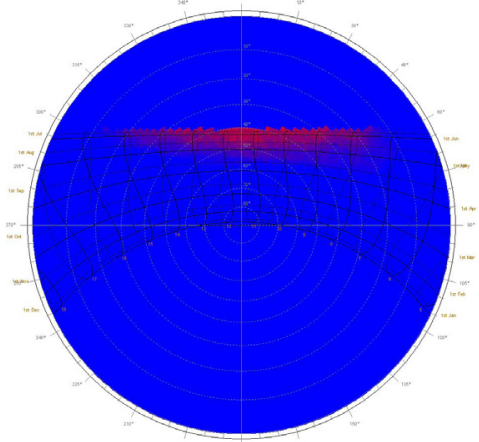

Thermal Gain
The shading mask begins to favour the early morning sun, with less light being allowed into the building during the hotter afternoon period.

Although the thermal gain seems to still be mostly during the middle of the day the morning gain will become more apparent as the screen porousity increases. 


\subsection{Baluster Section}

Now that the placement of the balusters has been defined their cross sectional shape needs to be considered. Traditionally the sectional shape of the balusters was circular, due to the nature of turning balusters on a lathe. It served an important purpose as the circular section created a diffuse gradient of shadow across the inner surface of the mashrabiya, greatly reducing visual contrast and glare. ${ }^{62}$ For this reason any changes to the sectional shape of the balusters should be based upon a derivation of the circular section to ensure that shadow diffusion is retained. Changing the sectional shape of the mashrabiya balusters allows the porosity of the screen to increase or decrease without changing the shading mask. This gives the ability change the airflow rate and the amount of ambient light entering the space without letting any additional direct light into the building during summer. Additionally, reducing the section of each baluster will dramatically increase the amount of solar gain in the winter from a fairly trivial amount to one that can actively heat the space. It should be noted that altering the section of each baluster changes the angle at which sunlight can get into the building, meaning adjustments must be made to the $\mathrm{D} / \mathrm{L}$ ratio calculations to compensate (see Fig. 29a on facing page).

As previously indicated the lighting conditions takes precedence over the other climatic considerations at this point and should drive the decision-making. Both the solar gain in winter and the amount of ambient light entering the building are determined by the porosity of the screen. The porosity factor of the screen (PF or $\varphi$ ) describes the ratio of open screen to that which is covered by balusters and can be calculated by dividing the total area of the opening by the total area of the interstices. A PF of 1 is equivalent to an opening without a mashrabiya, i.e. $100 \%$ porosity. A reduction in the baluster width will increase the PF value, increasing the amount of ambient light and air passing through the screen. The PF value has to be high enough to allow adequate ambient light to enter the space for normal activities to occur.

The airflow rate is also directly affected by these changes to the porosity of the screen. The interdependency between the lighting conditions and the airflow rate is too closely linked to allow a precise evaluation of each on an individual basis. Therefore it is proposed that the airflow rate be defined by a secondary driver such as a thermal chimney, the parameters of which are subservient to those of the mashrabiya (see 4.6). The porosity of the screen will still affect the airflow rate, but changes can be made at the exit point to respond to the conditions present at the mashrabiya, allowing the airflow to be manipulated without affecting the amount of light being introduced to the space.

62 Fathy, p.47 


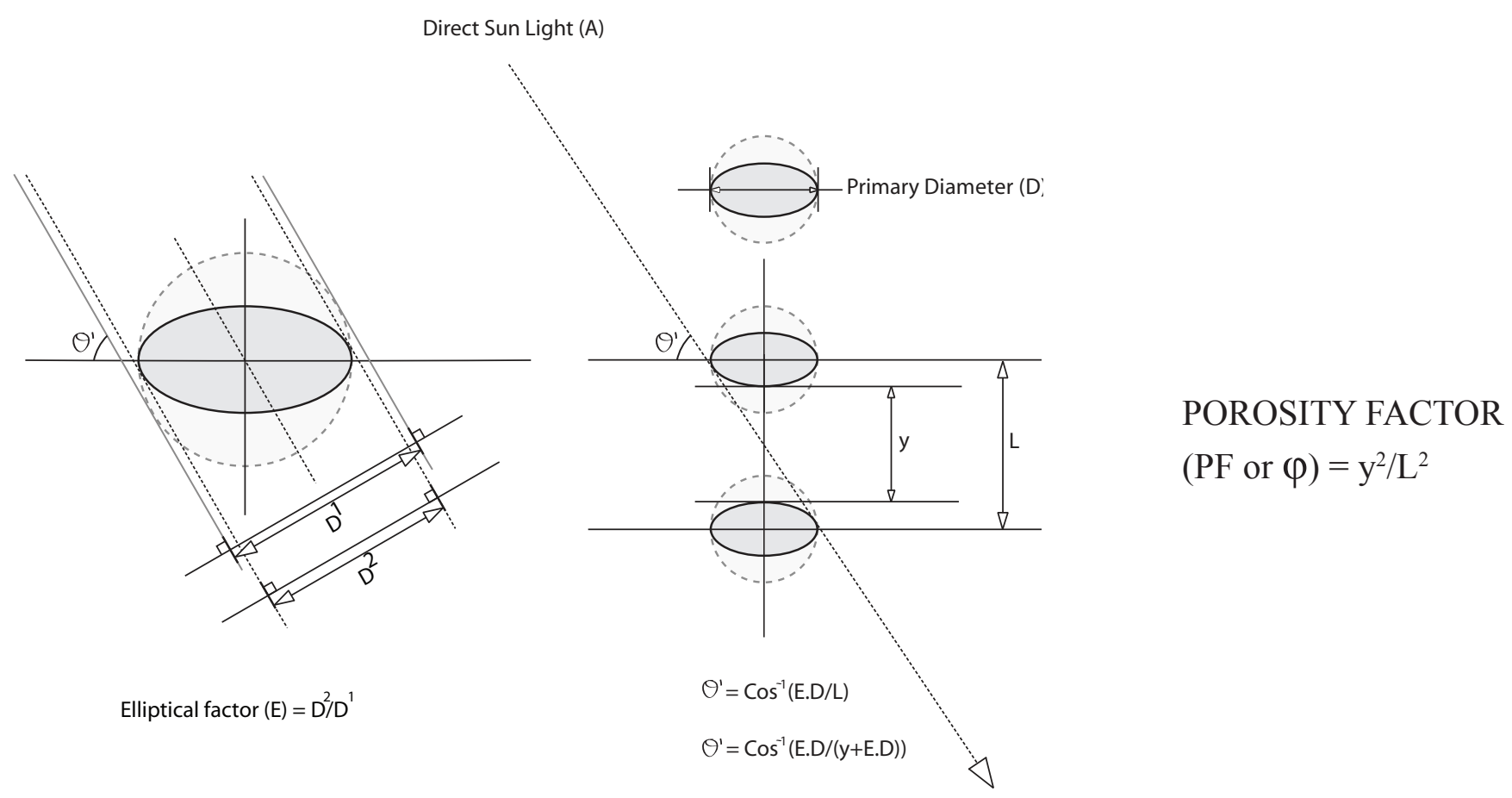

Section

Section

\section{b) Test Screen}

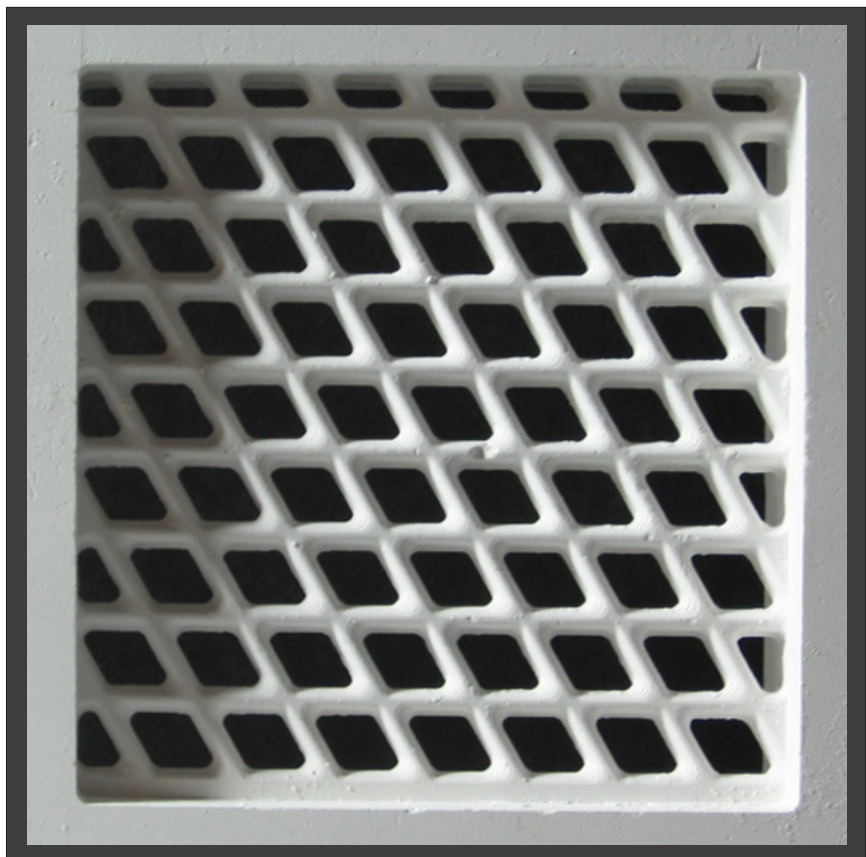

Here the baluster width is halved, resulting in a PF of 0.56. The results are dramatic, creating an immediate increase in solar gain during the winter period while still providing complete shading during the hotter months. Additionally, the screen becomes far more open and transparent as a result, increasing ambient light and airflow. c) Results

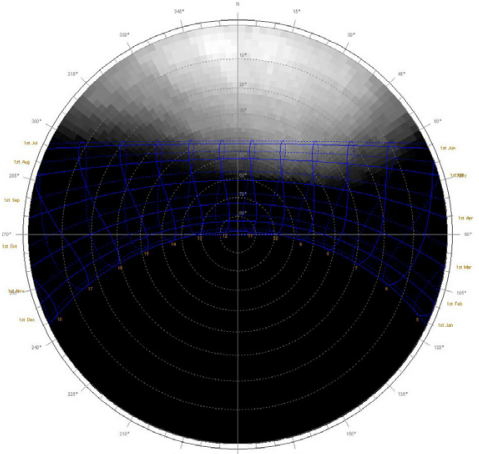

The shading percentage graph shows a dramatic improvement in the amount of morning light that it lets into the building, becoming significant enough to provide for winter heating.

Shading Percentage

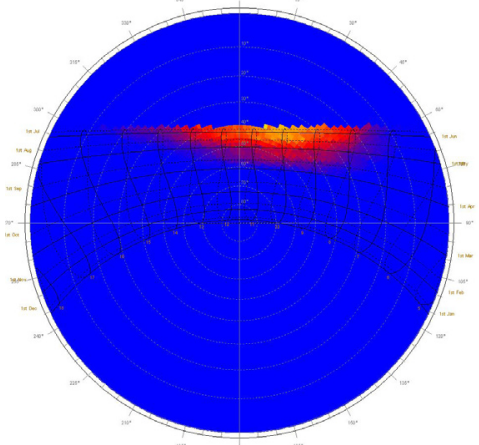

As a result of this increase in direct light the internal solar gain within the building also increases. It can now be seen more clearly how this screen begins to favour morning over evening sunlight. 


\subsection{Sectional Layers}
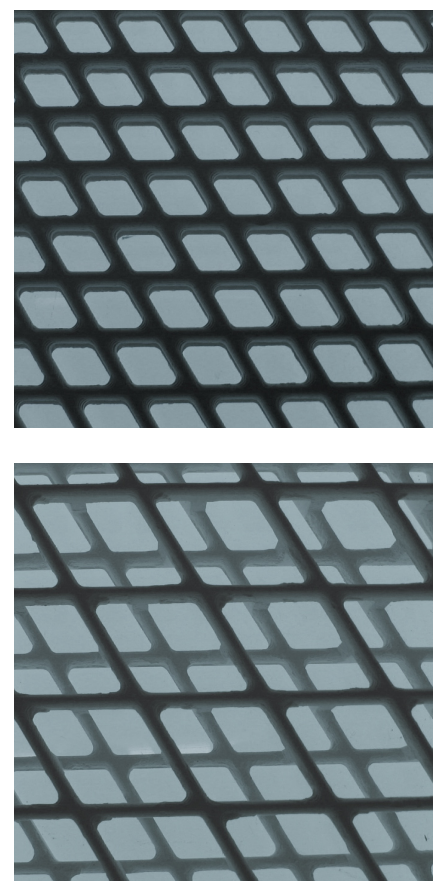

Fig. 30- The reduction in contrast between the screen and the exterior is important to minimise glare. Adding a second plane of blausters (bottom) significantly decreases the contrast.
An advantage of constructing the screen with CNC milling tools is the ability to add new dimensions and depth to the screen in the form of multiple layers. This makes for a visually dramatic shift from the traditional form of the mashrabiya and results in a number of important benefits, from the control of solar gain to the reduction of overall glare.

The use of additional layers changes the way that light passes through the screen. It is still possible to use the previously determined D/L ratio, baluster angle and sectional shape as a basis for the screen but certain ways in which the light passes through during winter are different. The nature of the layered balusters means that in winter there are points at which the interstices of each layer directly line up with the angle of the sun (see Fig. 31a on facing page). The result of this is that the effective porosity of the screen increases dramatically in during these times, increasing the amount of solar gain within the building.

After performing various shadow tests and computer simulation it became apparent that the optimal number of layers is two. This ensures more direct light into the building during winter than both the single and triple layered variations. The single layer lacks the dynamic nature of the double-layered screen, while the triple layered screen has too many crossbalusters and becomes counterproductive.

By introducing an extra layer to the mashrabiya its ability to reduce glare becomes even more effective. Glare is a by-product of having two dramatically different lighting conditions within the field of view. Instead of having one layer of darkened balusters the new layer creates two, each of different brightness. The first layer of balusters, that which is closest to the outside, benefits from light reflected off the second layer of balusters, thus reducing the amount of shadows across its surface. This creates a two-tiered transition between the interior and exterior, greatly reducing both the visual contrast and the glare.

Adding additional layers to the mashrabiya also creates a more visually dynamic surface, one that changes in appearance and opacity depending upon the viewpoint of the observer. Although the mashrabiya was a functional element, it was its visual qualities that truly set it apart from similar devices. The intricacy and delicacy of the screens were a visual wonder, and any contemporary interpretation must express those qualities to do any level of justice to the original form. The use of additional layers within the mashrabiya comfortably achieves that by adding to the visual intrigue and spectacle of the screen. 


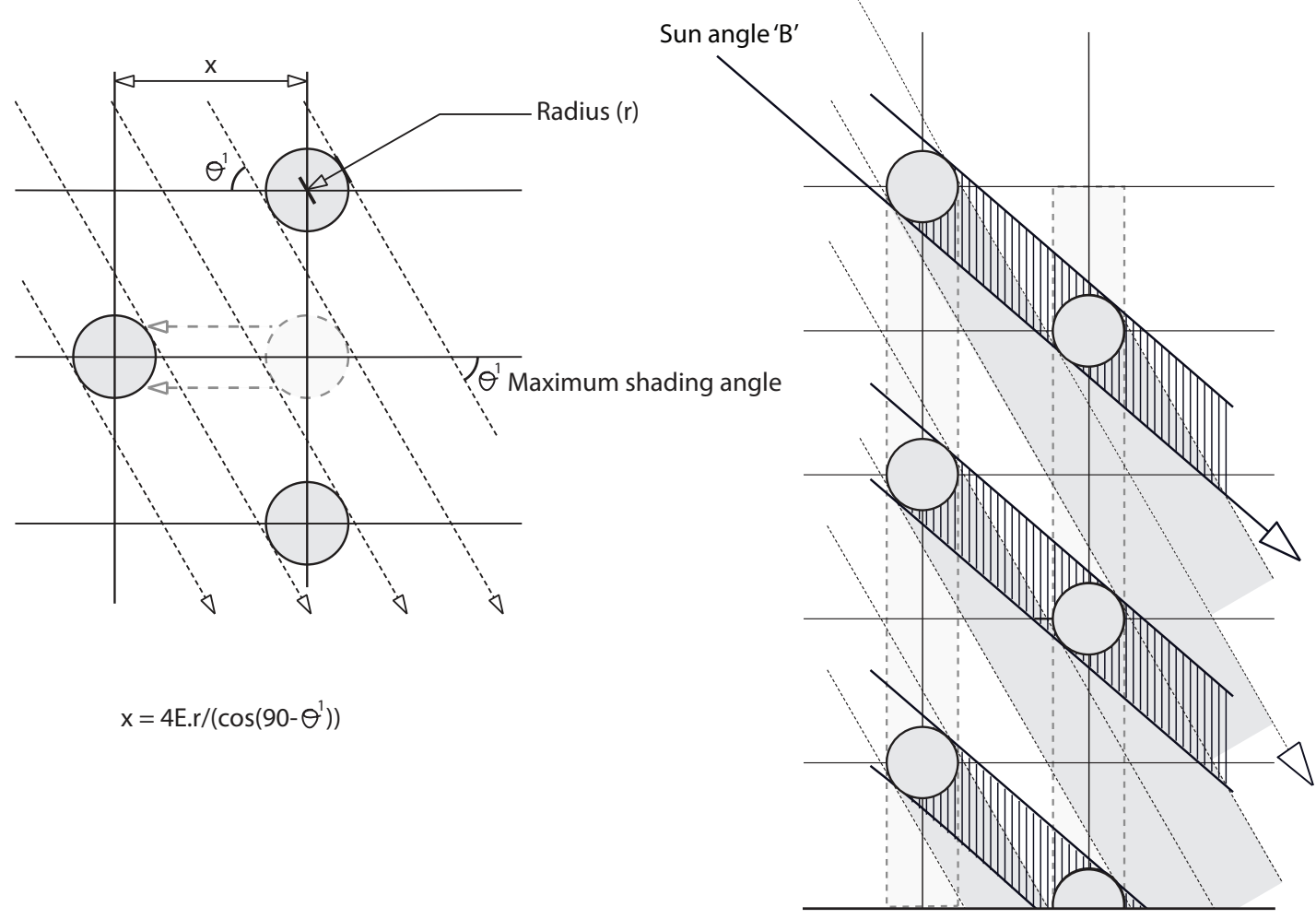

As can be seen here, the seperation of layers can immediately improve the functional performance of the screen. In winter the shadows cast by one layer of balusters can overlap directly onto the next layer, such as with sun angle ' $B$,' increasing the amount of light that enters the room. During summer the screen still blocks all direct light, as with sun angle 'A.'

\section{Section}

\section{Section}

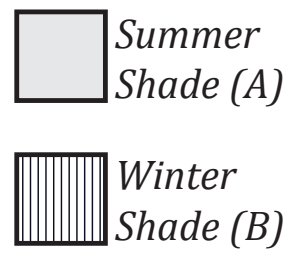

\section{b) Test Screen}

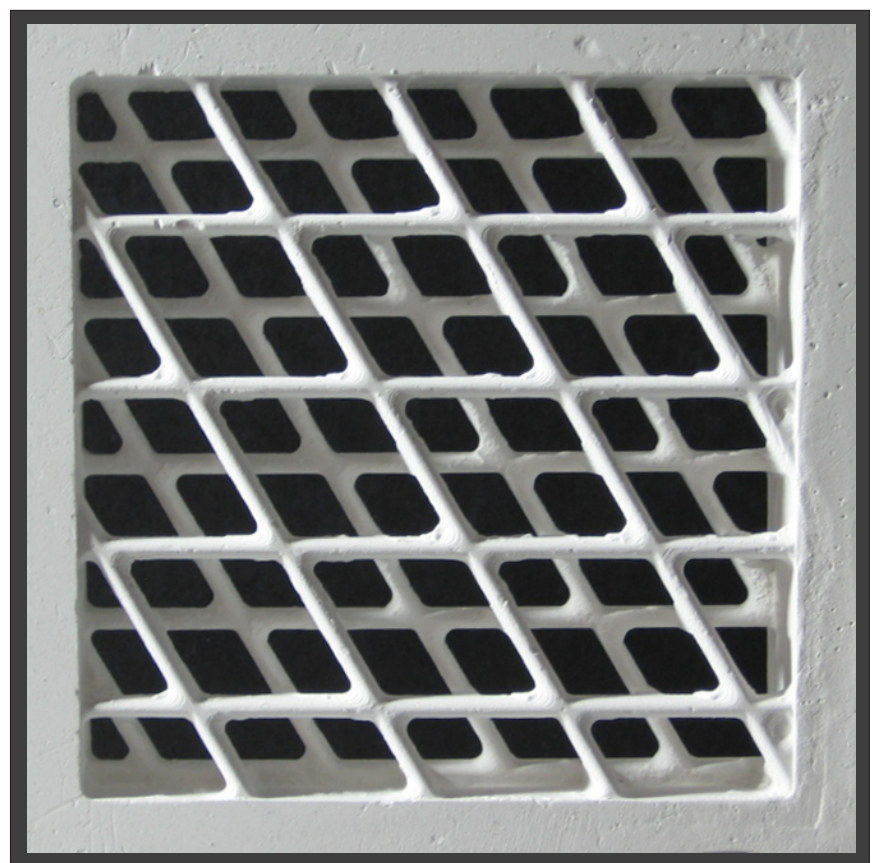

The additional layer of balusters creates an extra level of intrigue and complexity to the screen, driving the aesthetics in a completely new direction.

c) Results

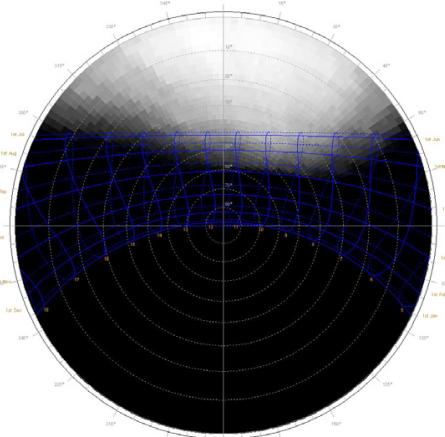

Shading Percentage

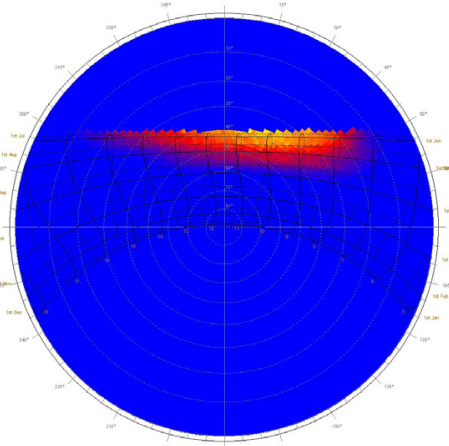

Thermal Gain
Although the improvements in both the shading percentage and thermal gain as a result of this added layer are relatively small they do have an impact on its functionality.

The true value of the extra layer of balusters however is within the visual aesthetics, especially in the changing shadow patterns and porosity that is created by having a dynamic pattern such as this. 


\subsection{Baluster Offset}

The baluster offset describes the degree to which the two layers of the mashrabiya line up. It is possible for the layers to be offset in a manner which does not directly impact upon the lighting or airflow conditions through the space, yet which alters the apparent transparency of the screen. By having a multiple layered screen the 'visual porosity' changes dependent upon the position in which a person stands and the angle at which they look at the screen, effectively meaning their ability to see through it varies across its surface. Offsetting the balusters gives a level of control to the designer over which area of the screen is more or less visually transparent. This becomes a key design consideration in designing for privacy, for example in the Giles Weather Station where a swimming pool is directly adjacent to tourist areas. By offsetting the balusters in a downwards fashion the bathers are protected from view while the tourists are still able to see clearly out from the mashrabiya in an upwards direction. This control is not universally exact as there are areas of the screen where it will not be possible to completely block the viewshaft, but in principle this method works very effectively.

For the offset to ensure that the direct light is not affected precision is required. The vertical offset needs to be matched by a horizontal offset, the ratio of which has been found to be determined by the equation $\left[X_{1} / X_{2}=2 Y_{1} /\left(Y_{1}+Y_{2}\right)\right]$ (see Fig. 32a on facing page), ensuring that the solar gains are kept constant. 


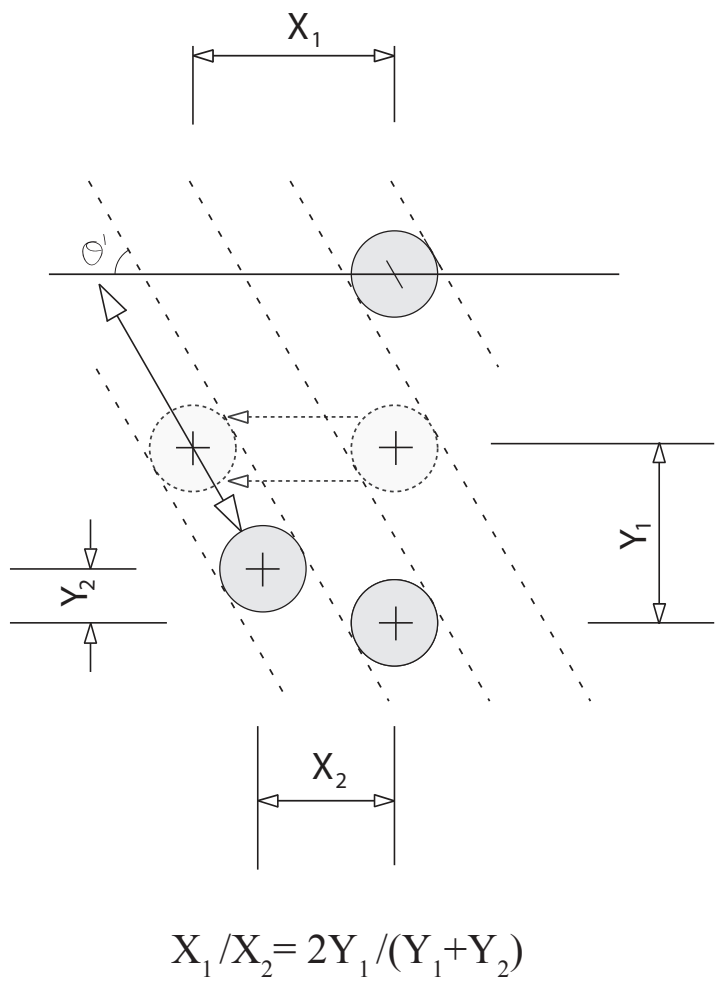

Section

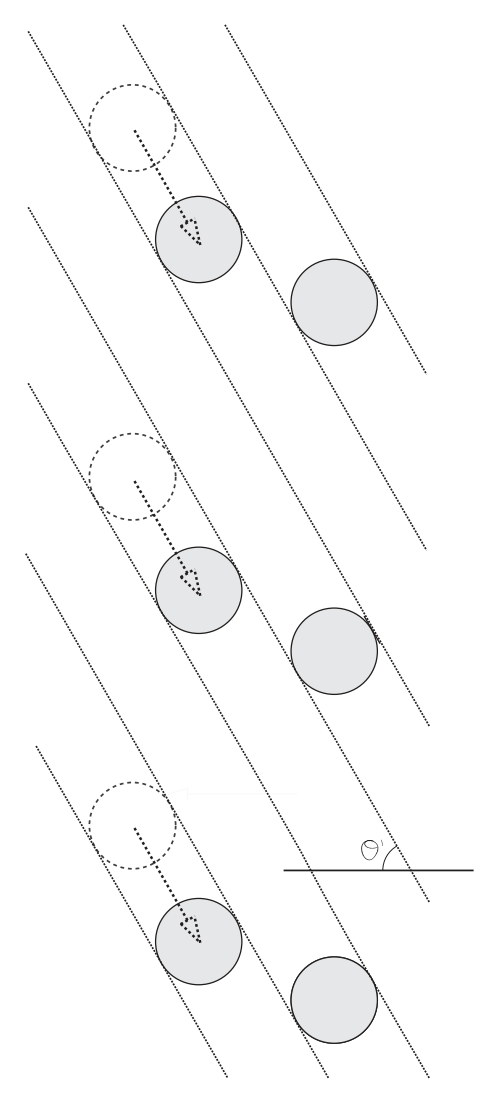

For the offset to have no impact upon the shading mask and thermal gain within the building the balusters have to be offset at the same angle as the maximum sun angle, in this case 60 degrees. This ensures that even though their positions have changed the balusters can still provide complete shading during the summer months.

b) Test Screen

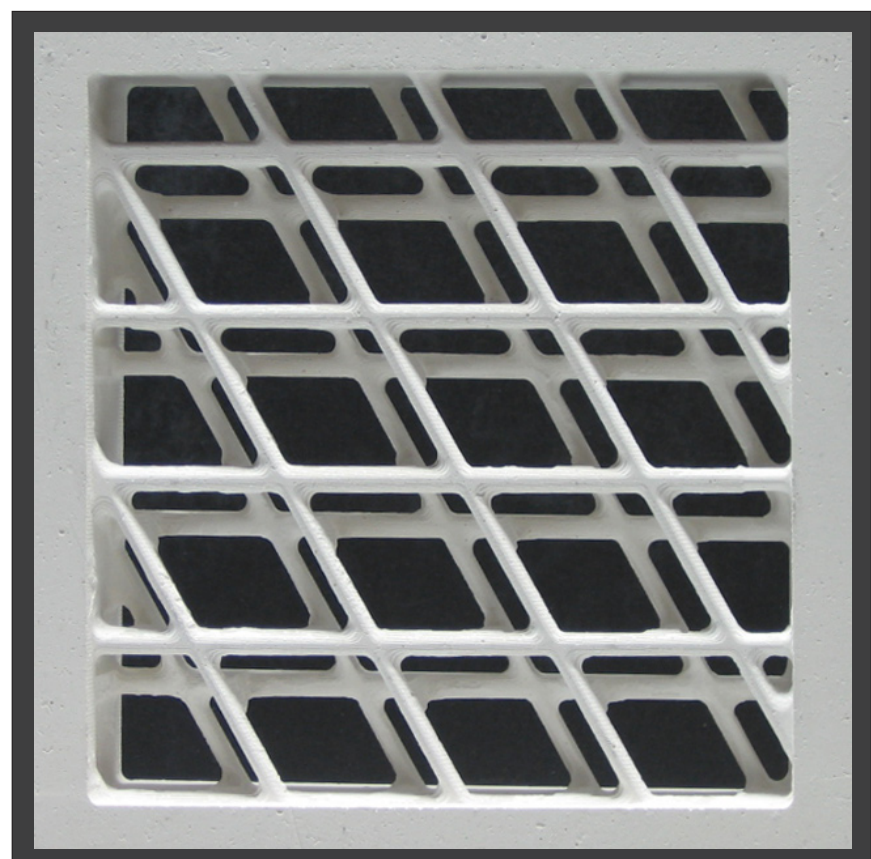

Section

This test shows a baluster offset which favours the lower left of the screen. This will create a more visually transparent area at that point and a less transparent area at the top right of the screen. This becomes apparent in a large scale mashrabiya, where the cone of vision of the viewer can see the balusters from a number of different angles. If applied correctly this can result in a screen that precisely controls both views and privacy. 


\subsection{Pattern}

The pattern of the screen is something that begins to move away from functionality and reach into areas of aesthetic judgment. The use of patterning within the previously established constraints of the screen allows the mashrabiya to adopt certain characteristics that are unique to the individual designer and building. The input of each craftsman's style was a key stylistic attribute in traditional mashrabiya and risks being lost with the introduction of computer aided design and manufacturing techniques. Therefore this point in the production of the new mashrabiya is based primarily upon introducing stylistic qualities into the screen.

The use of a non-linear pattern does have its benefits, mainly in the reduction of a moiré effect that occurs when a number of linear elements are regularly spaced across a surface. This was solved in the traditional mashrabiya with the use of rounded knobs in the centre of each baluster that reduced the 'visual spread' across the surface of the screen. "The characteristic shape of the lattice with its lines interrupted by the protruding sections of the balusters produces a silhouette which carries the eye from one baluster to the next across the interstices, vertically and horizontally. This design corrects the slashing effect caused by the flat slats of the brise-soleil and harmoniously distributes the outside view over the plane of the opening, superimposing it on the decorative pattern of the mashrabiya so that it resembles a darkened glass made of lace." ${ }^{63}$ As such, a similar approach to breaking up the linearity of the screen is required in any contemporary adaptation.

Any pattern adopted must work within the constraints of the previously established parameters of the screen. This means the baluster dimensions, angles and spacing must remain very close to the original form for it to remain effective. This restricts the patterning to relatively minor changes however there is still ample opportunity to creatively interpret the form of the mashrabiya. Fig. 33 on the facing page shows examples of test patterns that fit within the constraints of the established parameters for the Giles Weather Station.

63 Fathy, p.47 

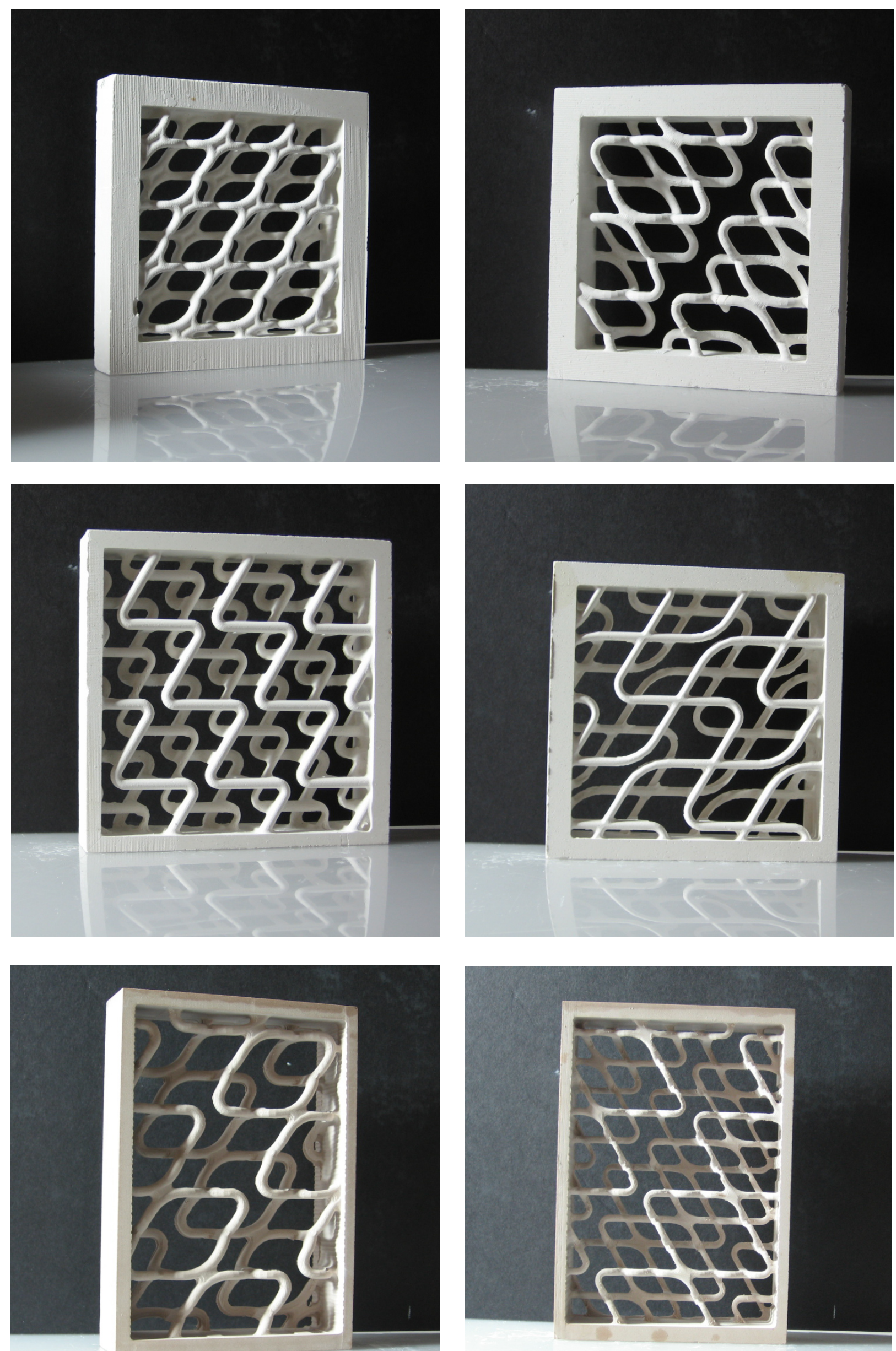

Fig. 33- Test Patterns 


\subsection{Materiality}

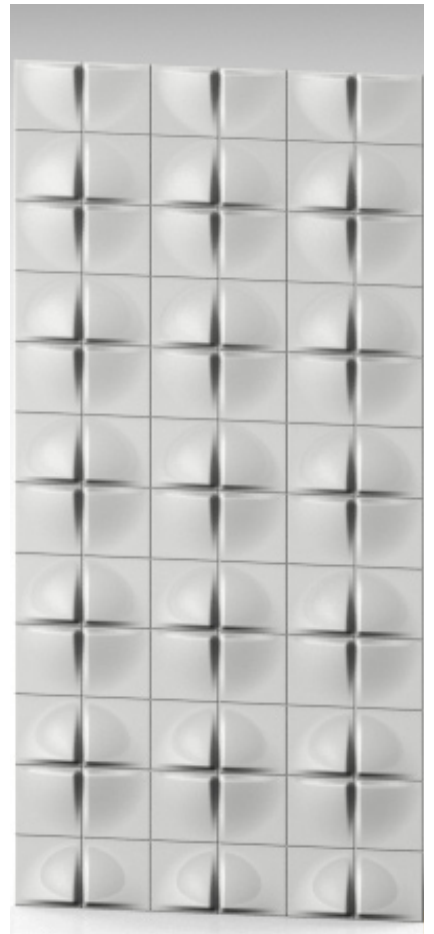

Fig. 34- Tiled ceramic wall by $O M C$

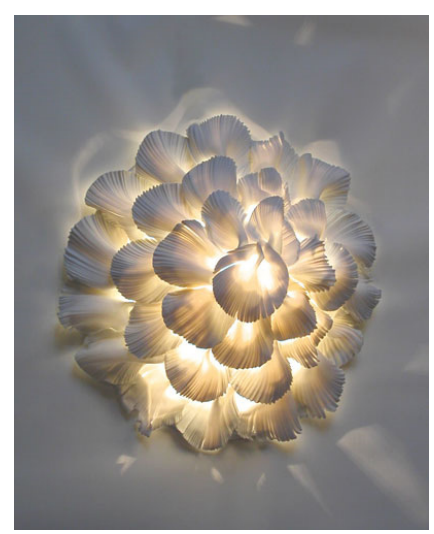

Fig. 35- Semi-translucent ceramic sculpture by Margaret O’Rorke
The material used to construct the mashrabiya has a significant impact upon both its construction and its effectiveness. Wood, the traditional material, had both advantages and disadvantages. Its appearance was visually dramatic, providing a point of distinction between the heavy earth walls used to construct the rest of the building. The textured surface softened the shadows on the inside of each baluster, reducing the glare and creating a soft appearance. Its humidity buffering effect and ability to endure high temperatures were also important. However it did tend to warp in the heat, which had to be dealt with by making loose joints when constructing the screen. And, as can be seen by the current state of many of the older mashrabiyas in the Middle East, the wooden screens eventually weather and decay.

Ultimately though, the fact that wood was used meant that the construction process was a long and arduous one, a process that was incapable of meeting a high level of demand or of adapting to new economies of scale. By contrast, the production of large numbers of components usually requires an additive rather than subtractive construction process, such as by forming them out of a mould. This dramatically reduces the amount of labour and time involved while ensuring a high degree of accuracy and consistency between the elements. Any new material used needs to be mass producible, strong, able to cope with extremes in temperature and humidity and must be capable of expressing a certain visual softness.

Architectural ceramics have been utilised within the building industry for thousands of years and are re-emerging in a number of contemporary designs. ${ }^{64}$ The ability to precisely control the attributes of each ceramic piece, in terms of both its shape and material qualities, has lead to its use in a number of cutting edge designs. As an additive, mould driven production process it is ideal for the production of large numbers of delicate components as required by the mashrabiya. New methods such as ceramic injection moulding (CIM) automate the process, reducing costs and labour dramatically. ${ }^{65}$ Additionally many types of ceramics are appropriate in terms of their material properties for use within desert architecture. High strength porcelain is thermally inert, meaning it won't be affected by the dramatic shifts in temperature of the desert. It is waterproof, extremely strong and able to be produced with a semi-translucent appearance, much like that of china plates when seen in front of a bright light. ${ }^{66}$ This is an interesting attribute which, when applied within the context of the mashrabiya, could further reduce glare and also create a 'glowing' effect to the screen, highlighting the intricate way in which it filters the light.

64 Lefteri, Chris. Ceramics: Materials for inspirational design, p.125

65 Lefteri, p. 96

66 Lefteri, p. 61 


\section{Final Mashrabiya design}

Fig. 36- The final mashrabiya design for the northern face of Giles Weather Station is a cast porcelain screen utilising a double layered interwoven pattern of balusters.

$D / L=0.5$

$P F=0.56$

Vertical baluster angle $=60$ degrees

Horizontal baluster angle $=0$ degrees

Max. vertical sun angle = 60 degrees

Max. horizontal sun angle $=60$ degrees

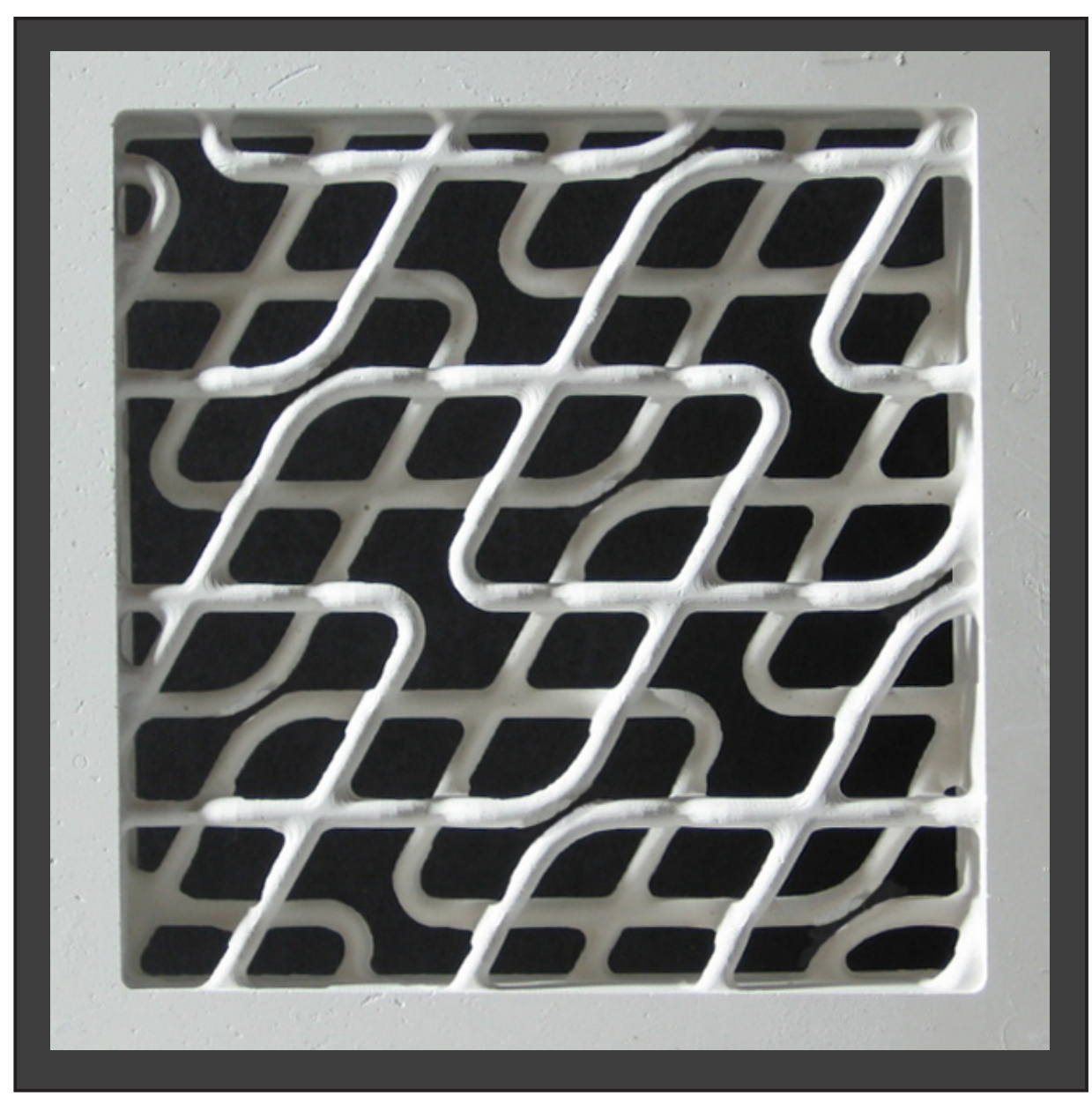

Fig. 37- Shadow diagram for June 21 ${ }^{\text {st }}$, showing the amount of light entering the space during midwinter. The amount of early morning sun entering the building is greatly increased while the late afternoon sun is reduced to a managable level. This creates a situation where the daily intake of solar gain is precisely controlled, ensuring the temperature throughout the entire year is stablised.

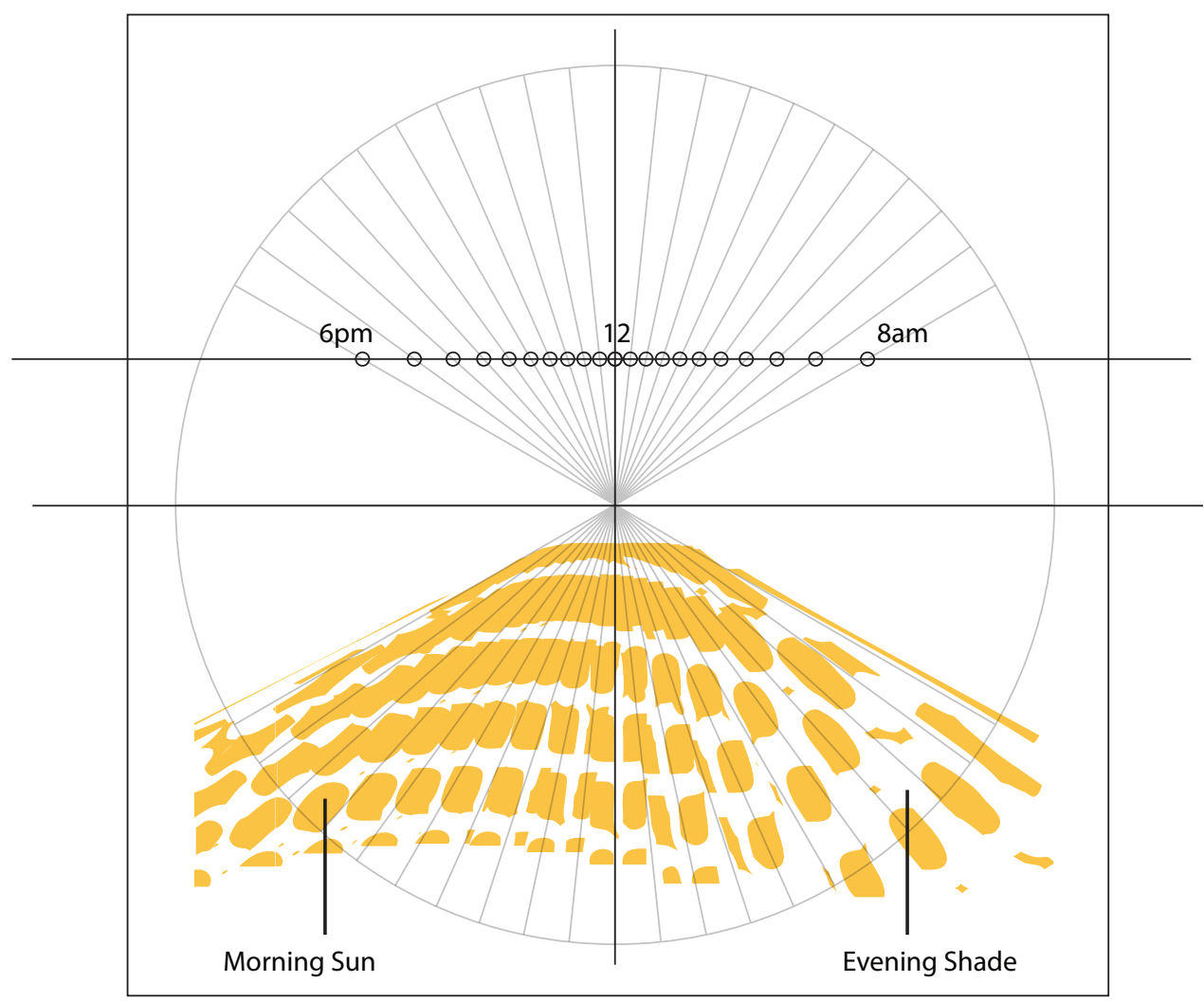




\subsection{Conclusion}

This analysis has led to the development of a number of previously unidentified variables in the design and construction of the mashrabiya. The control that these variables give to the internal climate of the building far exceeds what was previously possible using traditional construction methods, resulting in more stable and comfortable conditions within the building. Each aspect of the climatic conditions can be defined on its own terms with a few minor changes to the parameters of the screen, and most of the interdependencies between variables have been removed. The result of this analysis is a number of rules and mathematical formulas for the optimal characteristics of the screen. These rules can be universally applied and ensure that the design of the screen results in precisely the right internal conditions throughout the course of the year, regardless of the geographic location or programmatic requirements.

By applying this analysis to the case study of the Giles Weather Station a climatically optimized screen has been developed that precisely suits the conditions found within the Gibson Desert. This new screen looks nothing like the traditional mashrabiya screens of old (see Fig. 36), a by-product of having so many more variables to work with due to the new production process. When applied to the northern facade of the building this screen will ensure the building has the correct heating, airflow and lighting conditions, along with the required level of privacy. By adopting a similar analytical approach to each facade of the building and the roof additional screens can be developed in the same manner, each suited to the particular requirements of that face of the building. The next step in this study involved applying this screen to the building in the form of a component. 


\section{Chapter 4: Application of the Mashrabiya}

With the precise physical parameters of the Giles mashrabiya defined, it remained to be seen how this research could be applied to an architectural form. On their own, the variables analysed are useless without a practical method of incorporating them into a building. Therefore this chapter develops a cheap, functional and easily assembled component based system to be applied to the Giles Weather Station.

The system developed is based around a small diamond shaped component which is constructed through a ceramic injection moulding process. This produces a large quantity of components at low cost and consequently increases their versatility within the building, as may be seen in the creation of features such as roof screens. This along with elements such as an integrated structural system and a series of misting sprays to facilitate evaporative cooling combine to form a cheap and effective method of applying mashrabiya to a built context. In preparing this research for application it was discovered that there are a number of key links between the design of the mashrabiya and the physical properties of the building itself. These links are used to tie the research to the architectural form, creating a direct connection between the variables analysed and the design of the Giles Weather Station. The nature of the work undertaken is such that the mashrabiya becomes an element of much greater architectural significance to the building than was traditionally possible. 


\subsection{Development of a Mashrabiya Component}

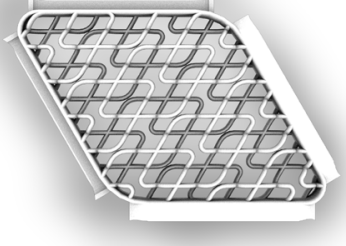

Fig. 38- Basic mashrabiya component

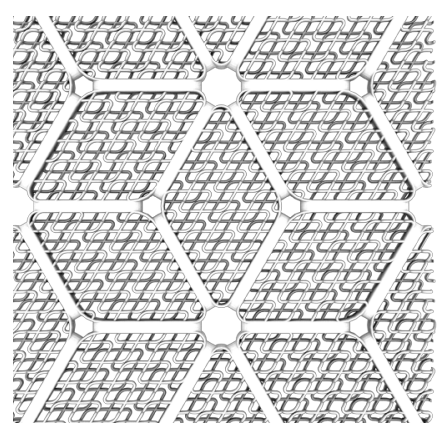

Fig. 39- Component tiling arrangement
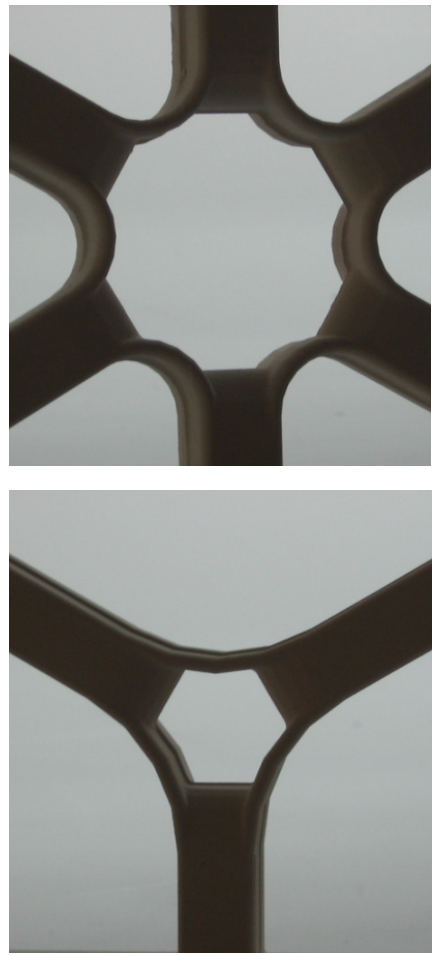

Fig. 40- Joint connection detail
For the mashrabiya to be a viable architectural element in the remote weather station context it must not only be capable of being produced quickly and cheaply offsite but also of being assembled easily once onsite. By using a single component that can be tiled across the surface in the same manner as a brick, the cost and time required in both production and assembly was able to be minimised.

The component created is a $420 \mathrm{~mm}$ by $300 \mathrm{~mm}$ diamond consisting of ten rows of balusters (see Fig. 38). The diamond shape was developed for two reasons. Firstly, the mashrabiya created for the Giles Weather Station is based upon a 60-degree baluster angle, meaning that a component with a matching base angle will be more functionally efficient. Secondly, the tessellation patterns associated with this tiling are visually appealing, creating a series of diamonds that flow across the surface of the building. The dark lines that are created by the edges of the component do not detract from the screen, but rather enhance it with their pattern. The rounded corners echo the rounded edges of the balusters themselves, drawing the detail through a hierarchy of scale. Each component has two different connection details along its edges, a positive and a negative detail. These interlock with their reciprocating neighbour once tiled together in a screen and are fastened through the use of a bonding agent, meaning that no secondary connection element is required.

It is worth noting at this stage that the decisions made in creating and applying this component were arrived at purely on the basis of a logical thought process. However these function based decisions were still able to be aesthetically interpreted by the designer. Another designer, applying the same basic thought process to a different site, would be certain to produce a dramatically different final screen. This is important, for although the design process is based upon a functionalist rationale, it still has the capacity to be creatively interpreted, much like the mashrabiyas of old. 

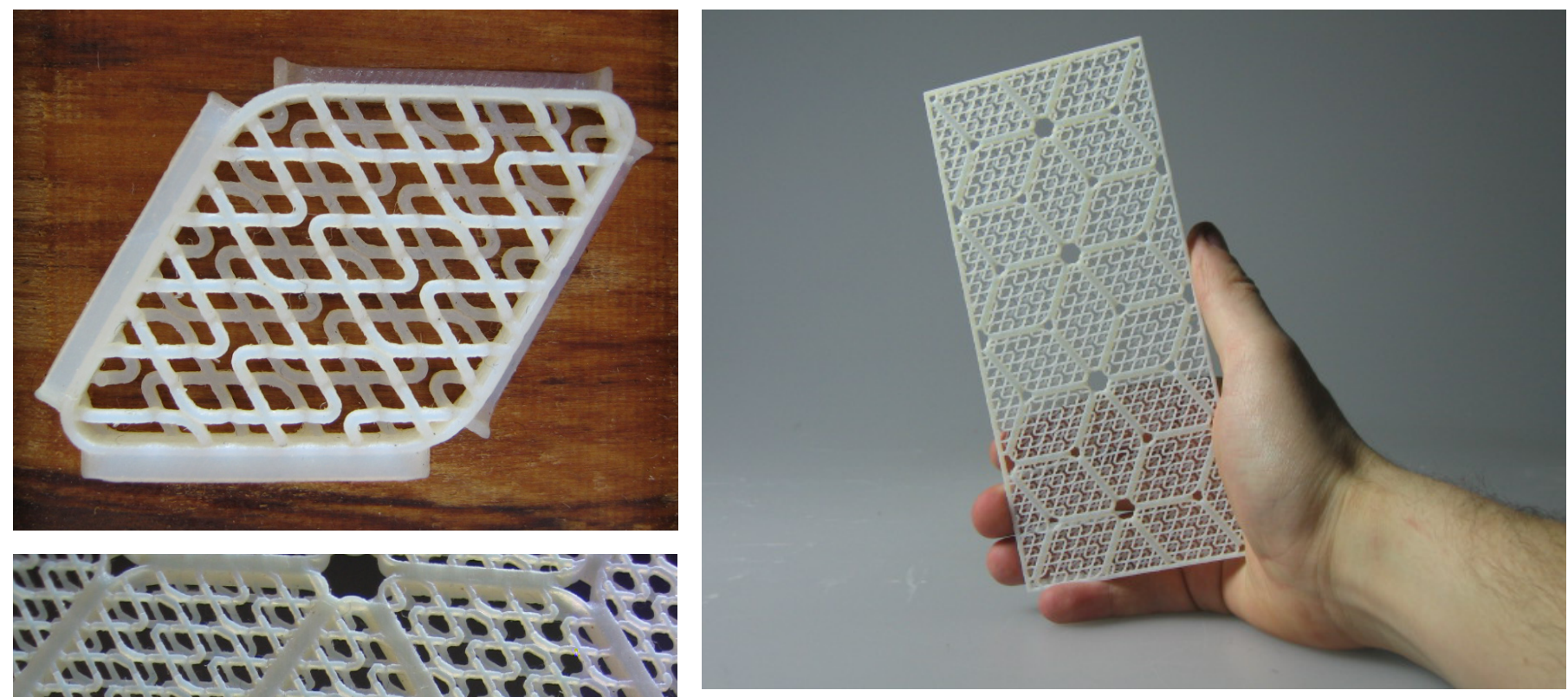

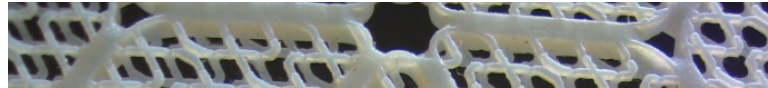

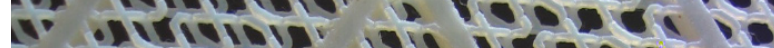

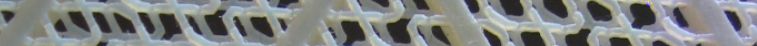

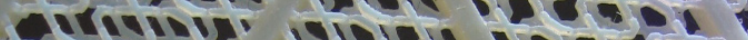

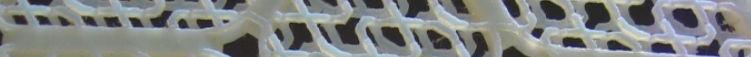

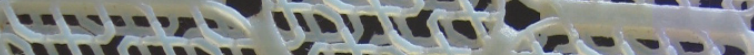

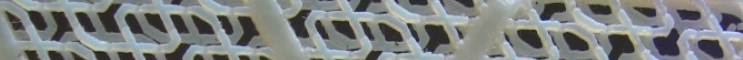

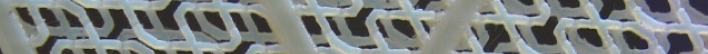

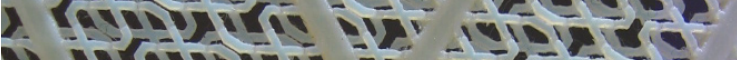
f- Mela

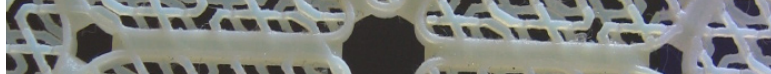

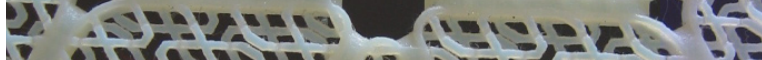

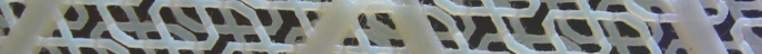

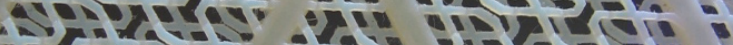

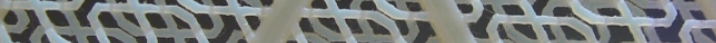

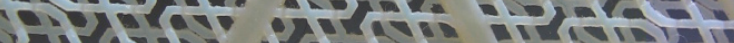
$-2=1-2=$

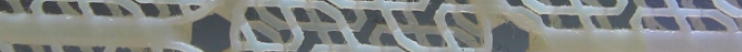

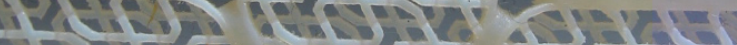

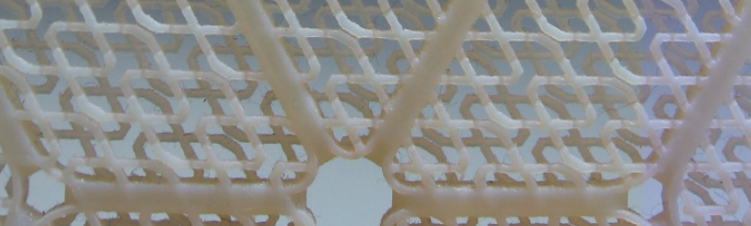
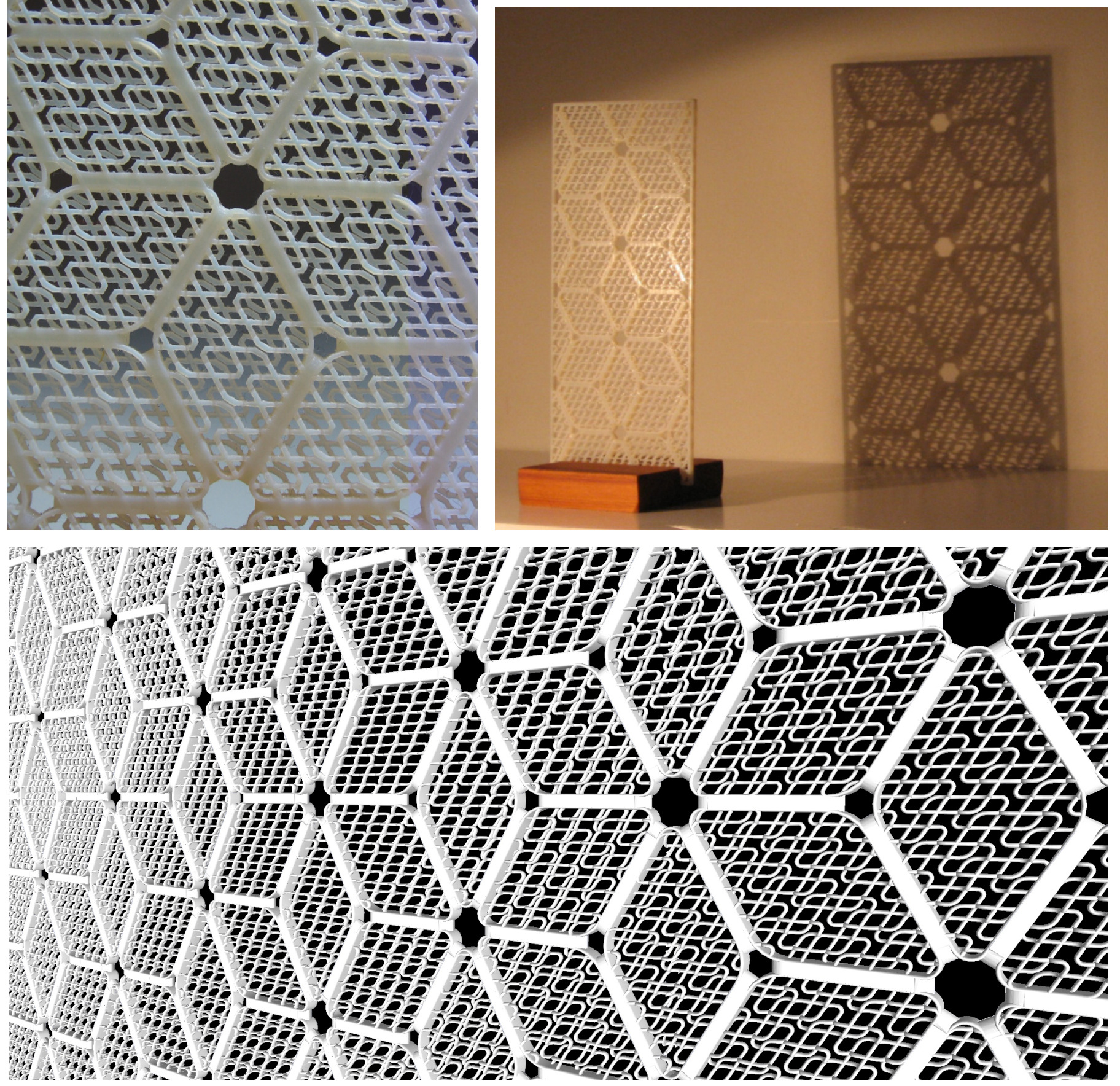

Fig. 41-Component Tessellations 


\subsection{Construction}

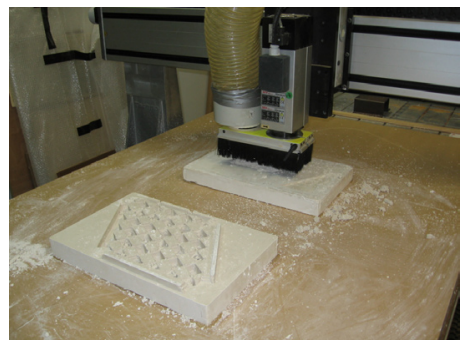

Fig. 42- CNC Milling of the inverted component mould.
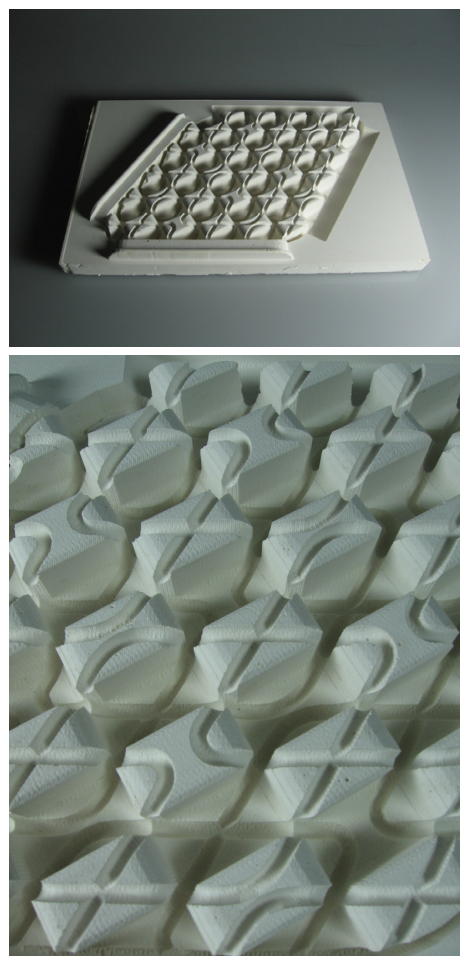

Fig. 43- Inverted mould ready for ceramic injection.

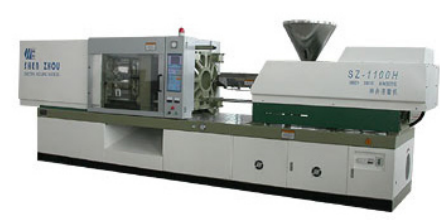

Fig. 44- CIM production machine
This research was based upon the premise that if new fabrication methods were used in the construction of the mashrabiya then it could be once again be a commercially viable architectural feature. The processes used to construct the components involve computer numerically controlled (CNC) milling and ceramic injection moulding (CIM). The combination of these two processes allows for the creation of a large number of identical, complex and precise forms at low cost.

Using a CNC milling device a two-part negative cast can be produced which is an inversion of the final component. This negative mould is used within a CIM machine, a mass-production based form of fabrication in which raw ceramic powder is injected and then heated within the mould. This is a very quick process, allowing individual components to be formed within a matter of seconds. ${ }^{67}$ The resulting 'greenware' is then fired in a kiln, the temperature of which determines its final physical properties, meaning the strength, transparency and finish can all be altered as required.

This form of construction, unlike that which was traditionally used, is able to rapidly produce cheap and highly accurate components. The degree of precision that can be afforded through contemporary fabrication techniques such as CNC milling and CIM casting mean that every point of the screen can be precisely optimised to within a fraction of a millimetre without errors emerging through the construction stage. 


\subsection{Structural additions}

Each component is designed to be self-supporting and to be capable of transferring both dead and live loads through to its edges. Beyond this however it needs to be transferred to the ground, so a structural grid is placed over the components. This primary structural layer is made up of a diamond shaped bracing frame constructed from light steel and interlocks with the individual components through the gaps in their connection details (see Fig. 45). This ensures no lateral movement occurs between the components and allows loads to be transferred directly between the screen and the ground.

The shape of the structural layer is designed to echo that of the original component with its rounded diamond form. This form allows the structural layer to spread evenly across the surface of the screen but also creates a visual hierarchy between elements. Through each of the layers of scale the patterning and attributes of the individual balusters remain clear, from the design of the components to the structural elements. This becomes particularly apparent when approaching the screen from a great distance, at which point it looks to be a solid white wall. As one nears it the diamond structural bracing appears, followed by the tessellated pattern of the components before finally the individual shape of each baluster can be seen (refer to Fig. 46 overleaf). At each level the same basic physical attributes are apparent, creating a hierarchy of scale that draws the eye deep into the intricacies of detail.

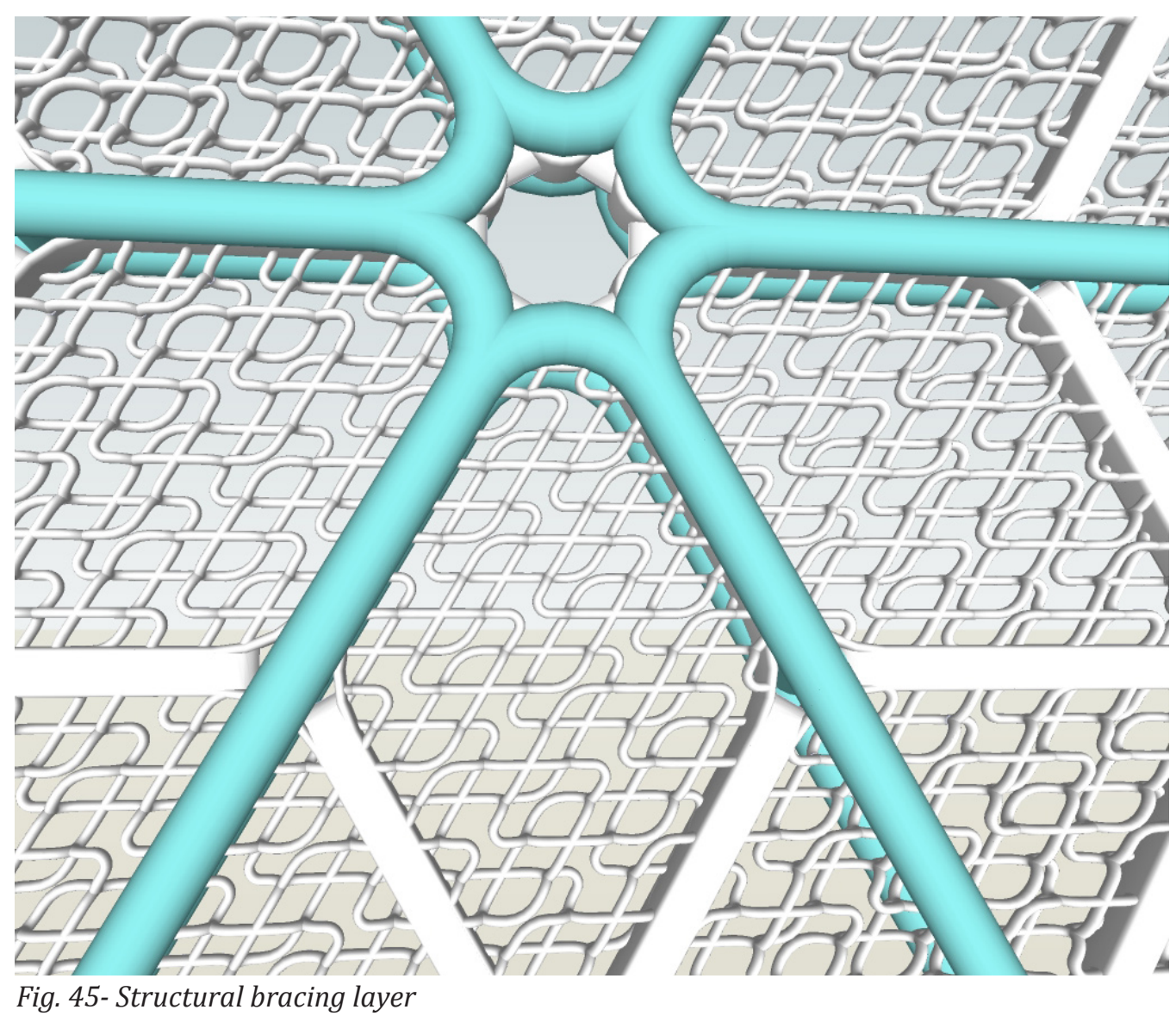


Fig. 46- This diagram shows the various scales of detail within the final screen de sign, from the individual balusters through to the structural elements.

The blue areas display the transparency of the screen when viewed in perpsective. As can be seen the overall transparency is not uniform, which has been developed to maximise solar gain during the cooler times of the year.

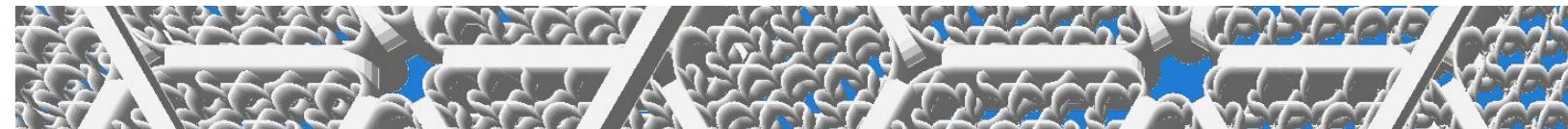

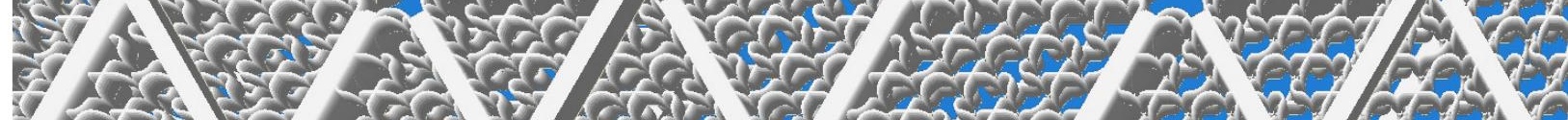

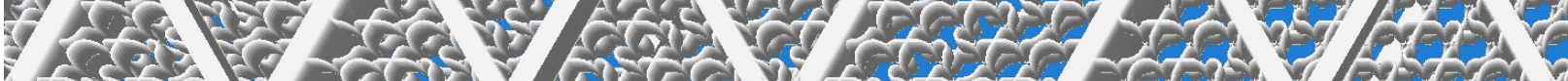

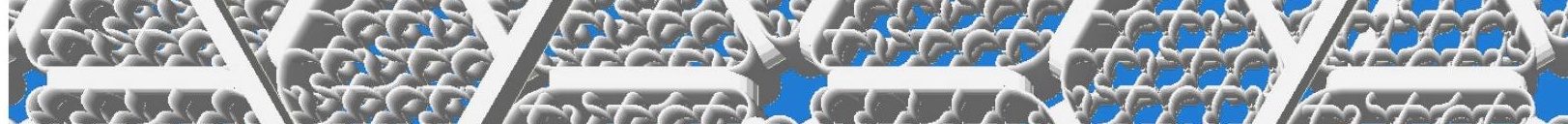

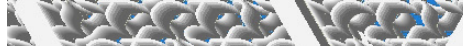

F.

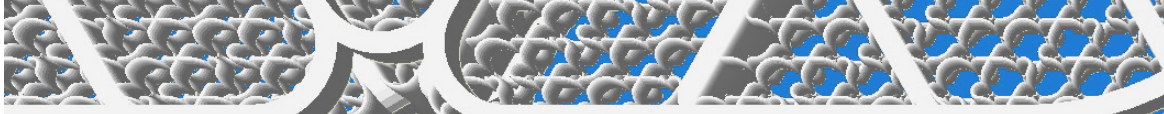

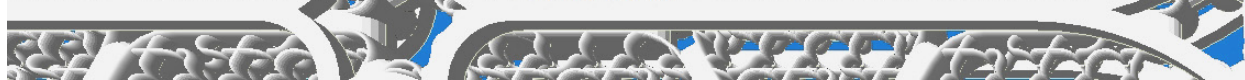

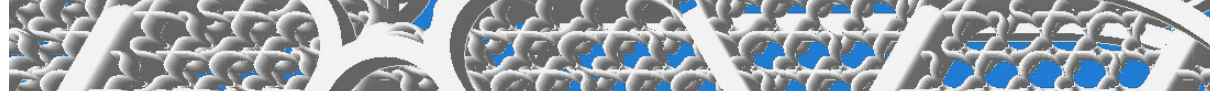
हf atact

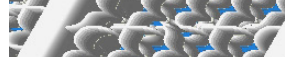

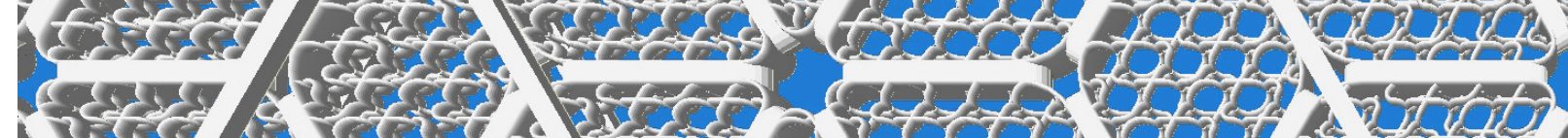
Prot

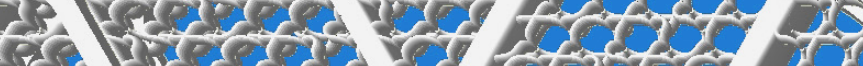
1.

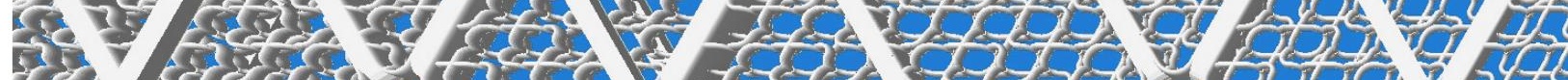

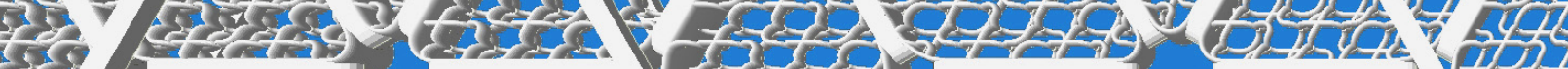
5.

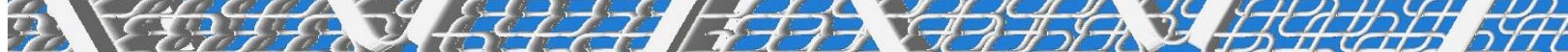

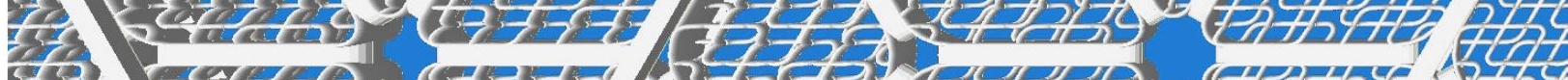

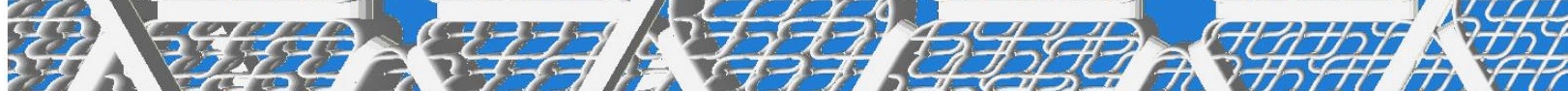

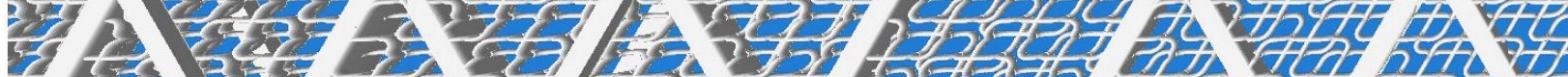

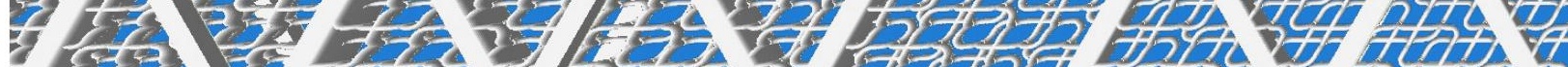

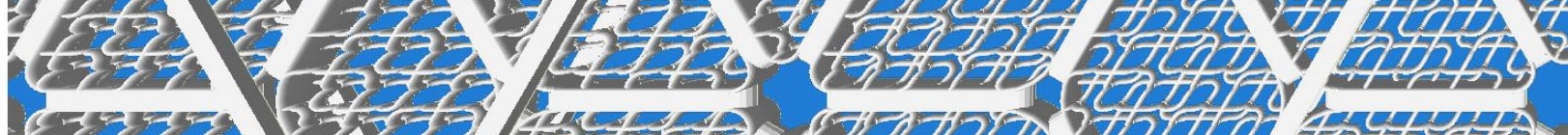

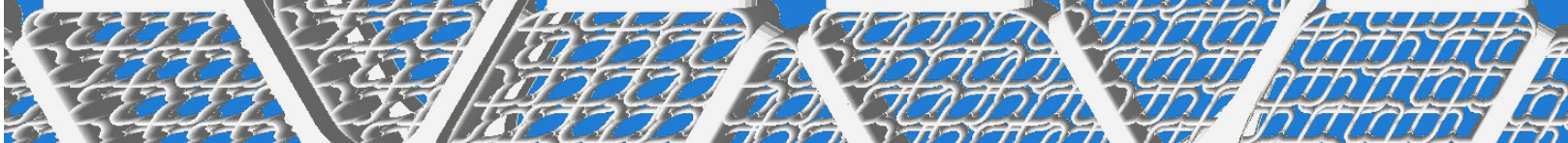

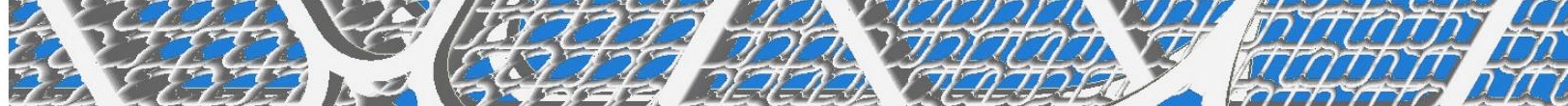

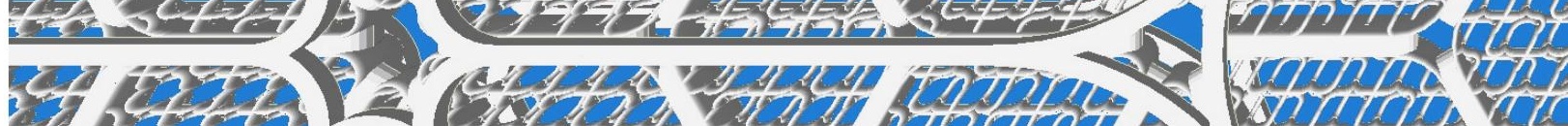

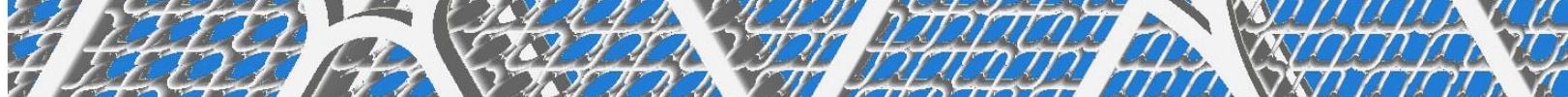

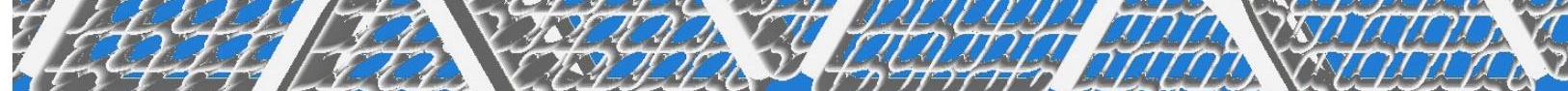

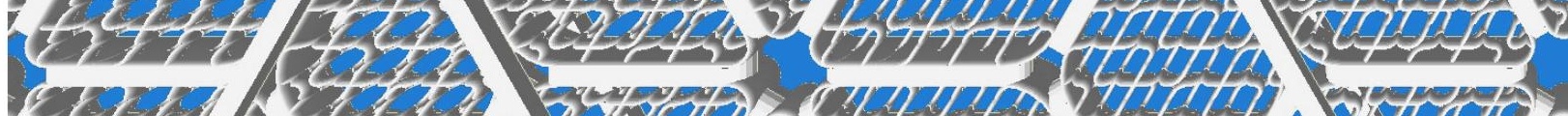

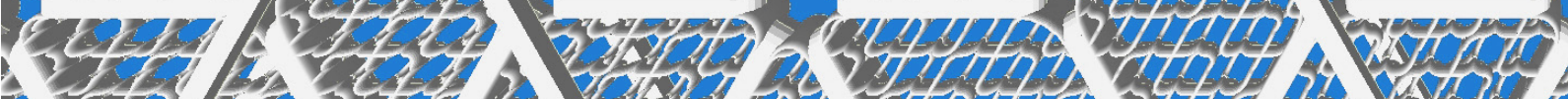

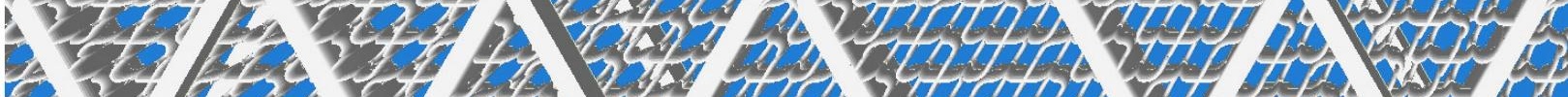

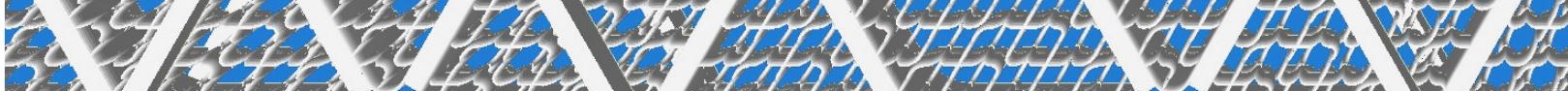

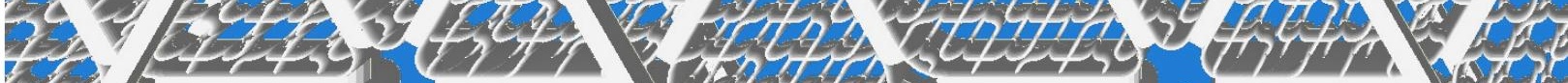

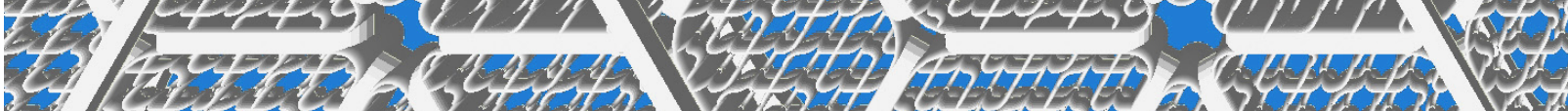

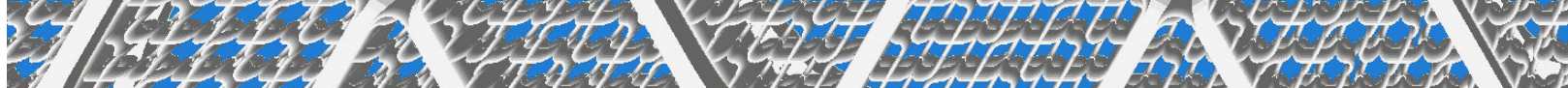

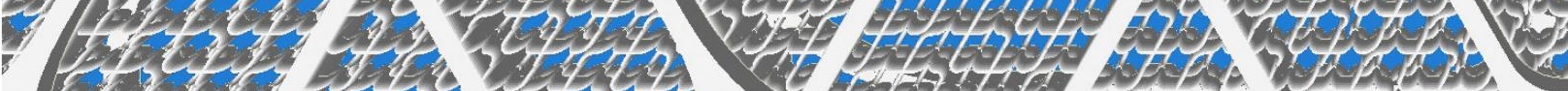
- Ely 
78 特

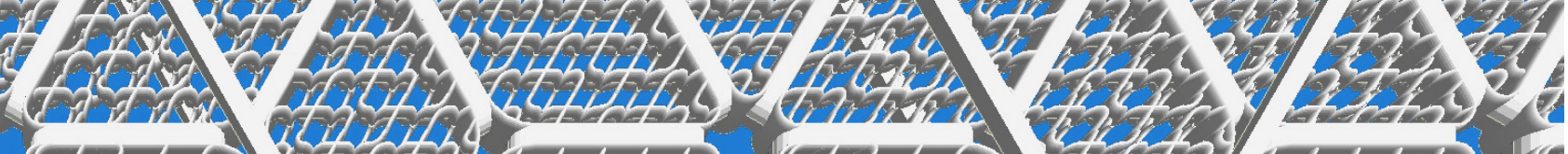

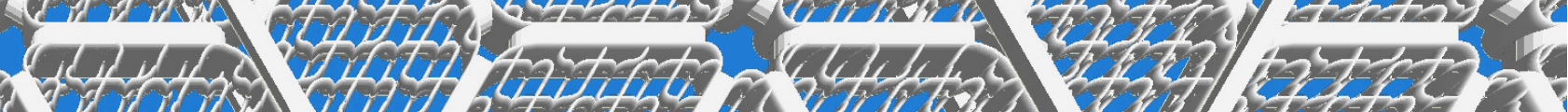

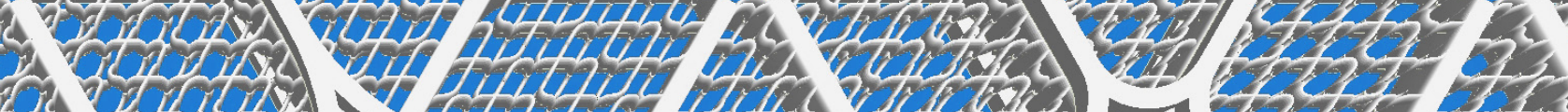

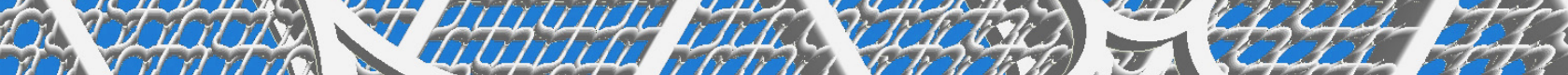

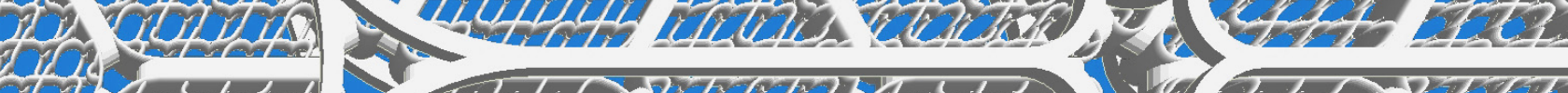

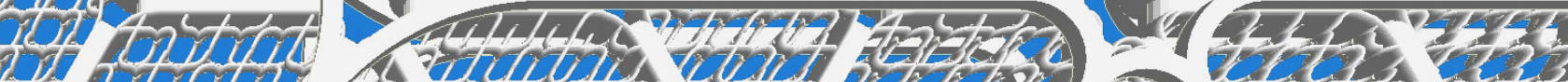

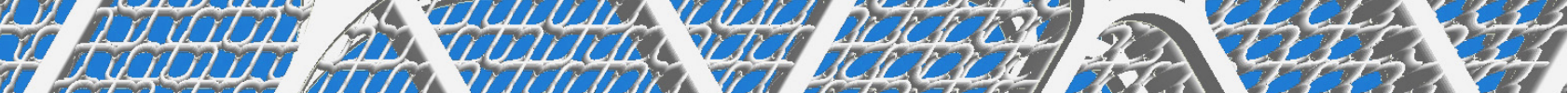
562 (6)

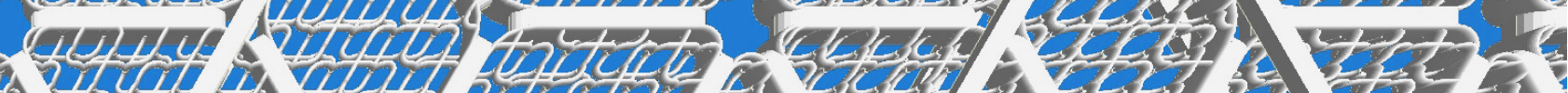
tot 34 5.

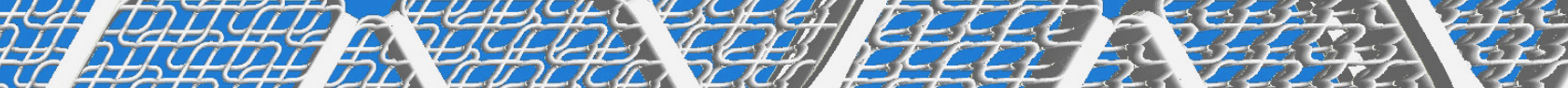

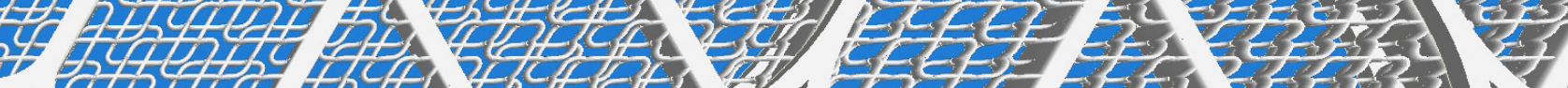

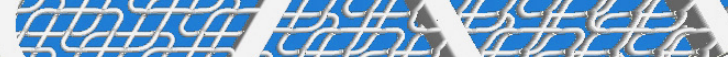

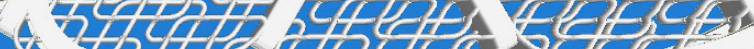

:

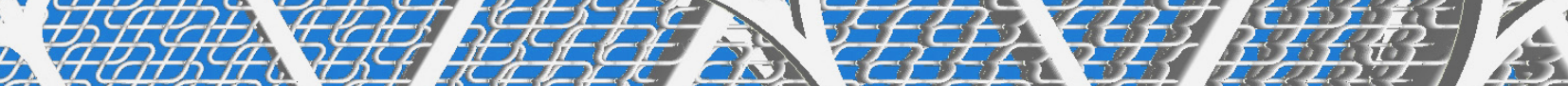

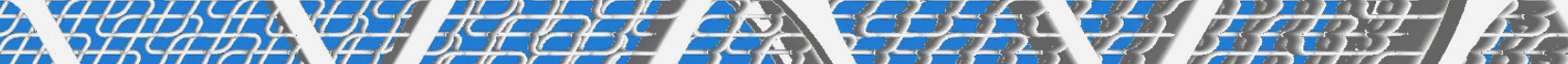

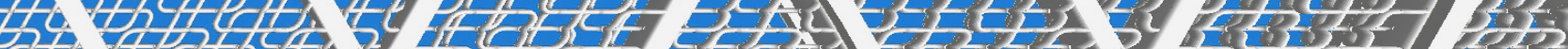

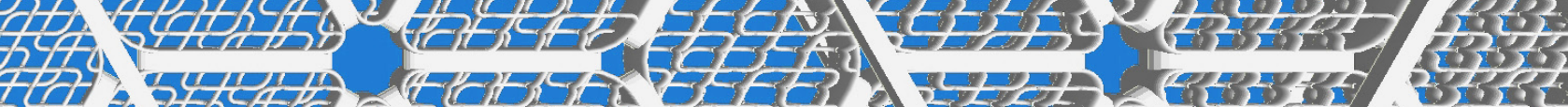
I 2 -

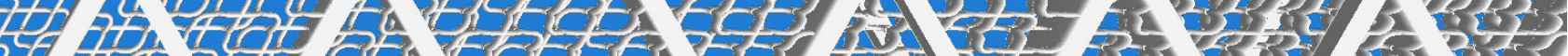

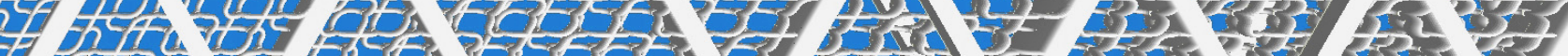

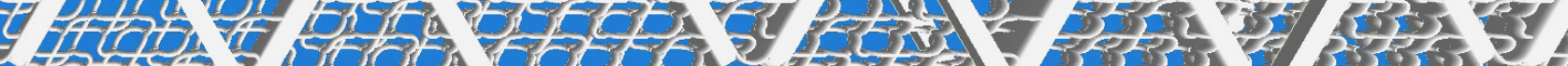
tatha ?

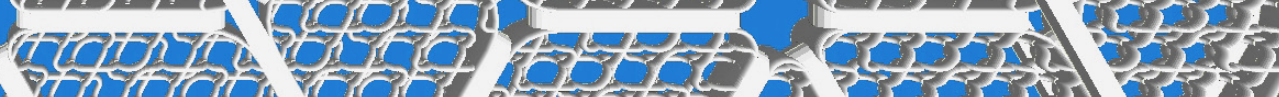

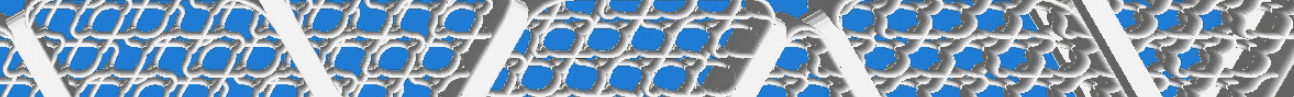

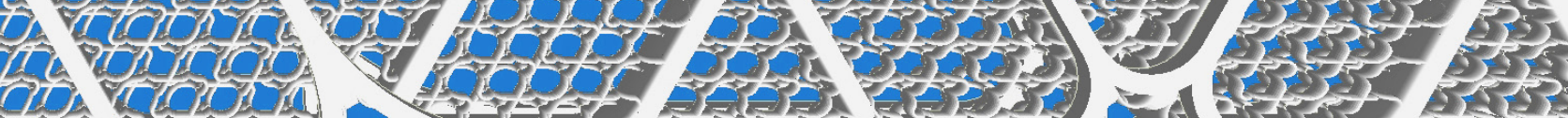

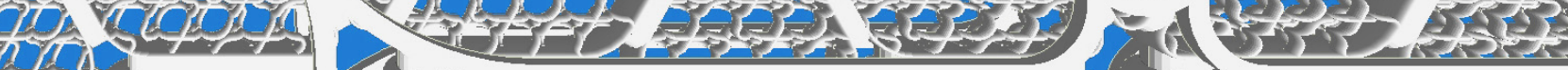

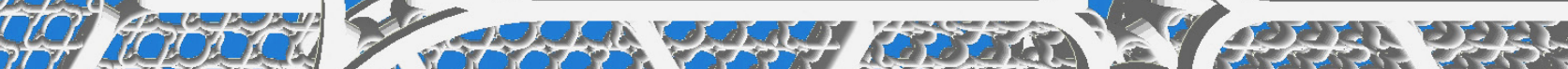

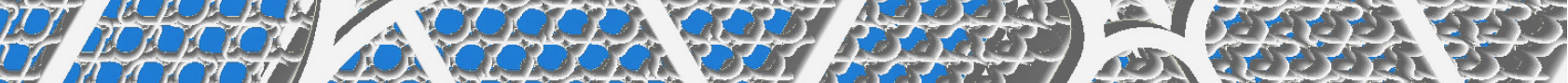

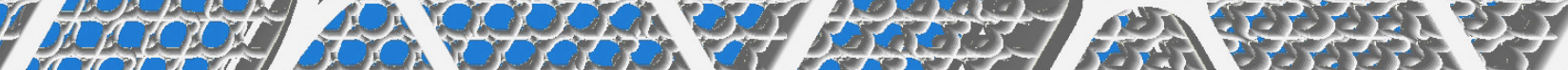

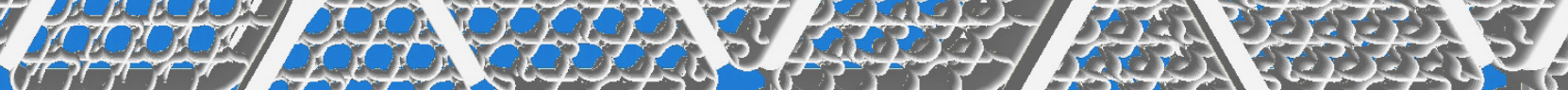

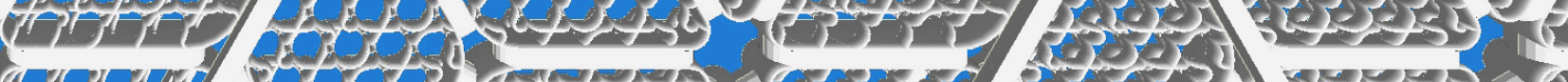

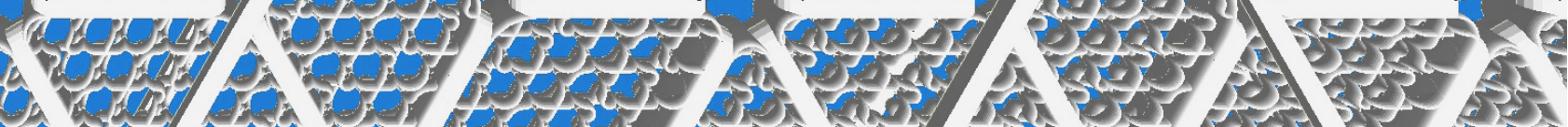

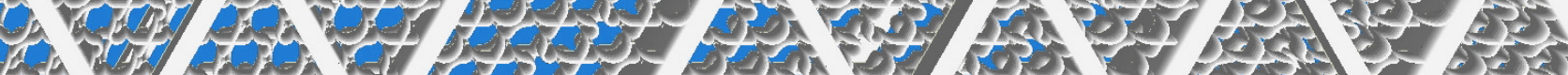

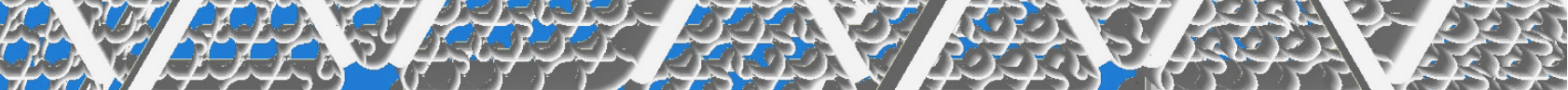

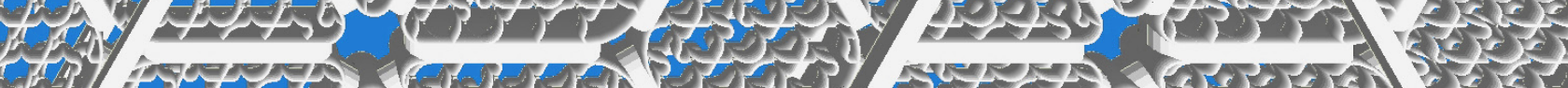

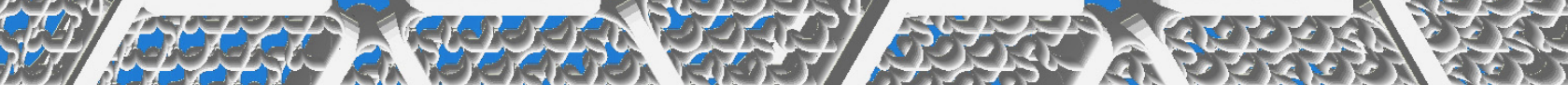

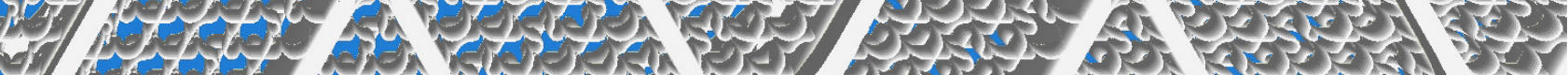

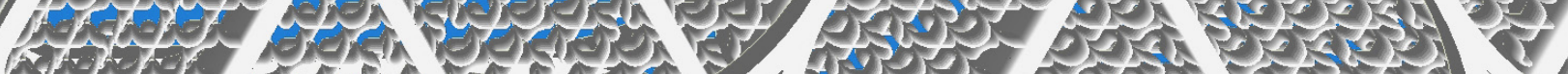

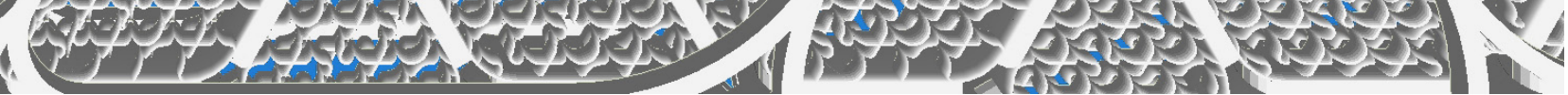




\subsection{Roof Screen}

The ease of production of the mashrabiya component allows it to be used in a far more versatile manner than was previously possible. One example of this is in the creation of a roof screen that can stretch over the entire building.

Using a climatic screen as a roof allows a more integrated relationship between the indoors and outdoors through elements such as thermally regulated courtyard spaces, covered 'outdoor' areas that have a controlled amount of sunlight and solar gain. This becomes an important architectural consideration as it allows the occupants of the building to move outside without being exposed to the crippling heat of the desert. Additionally, if a screen is placed over the roof of one of the rooms it can thereby control the roof's exposure to solar gain. In summer the thick roof slab can be shaded and remain cool whereas in winter it can receive heat from the sun, regulating the temperature of the room below.

The roof screen requires an additional layer of structure. The primary structural pieces ensure that the roof will act as a single unit, but this load then needs to be transferred down to the earth. For this reason a secondary structural system is introduced which has much larger structural members, again in the same diamond pattern, which lead the gravity loads downwards through a series of columns to the ground. The spacing of these columns proved to be at six metre intervals and created a grid which drove the layout of the building below.

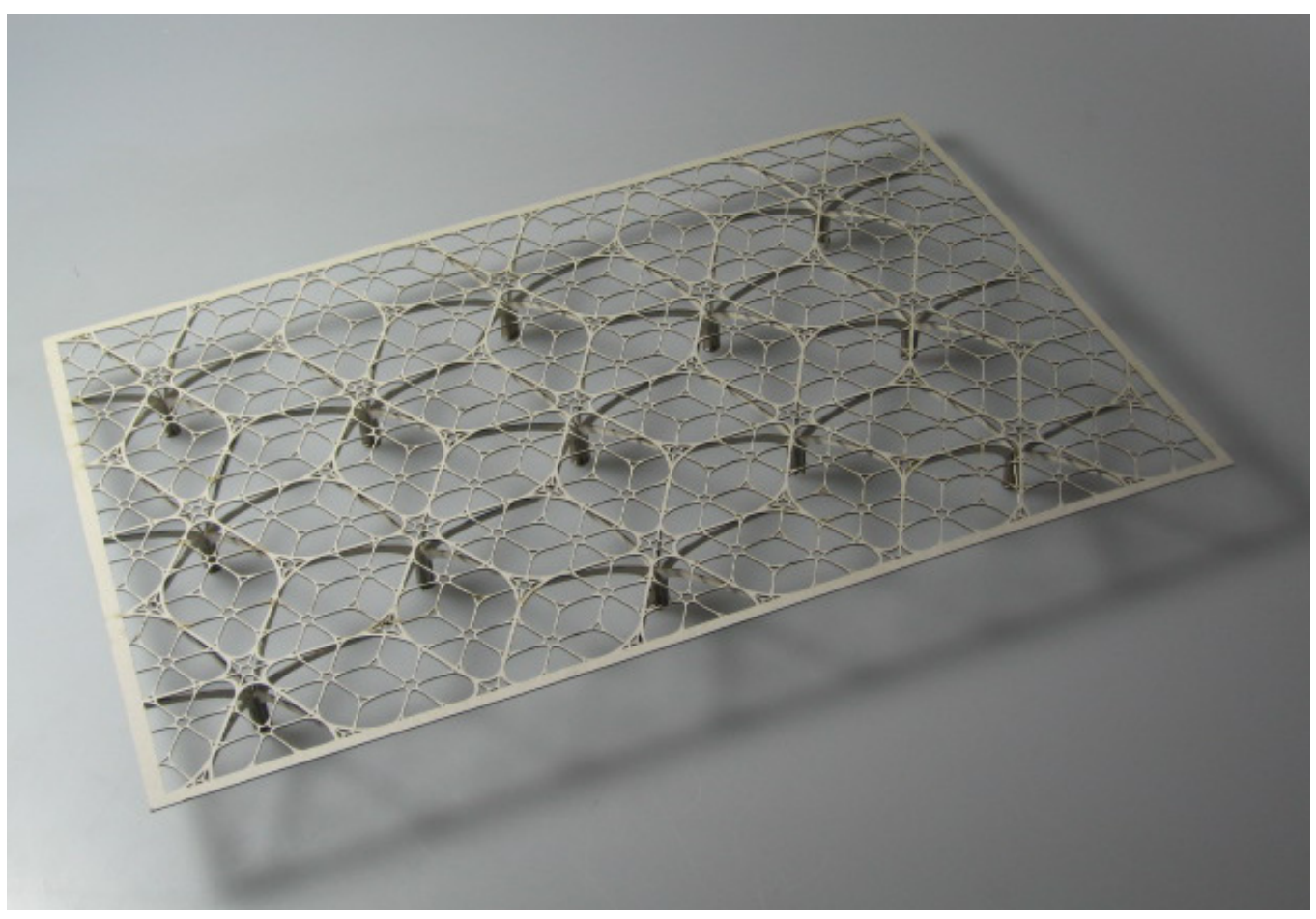

Fig. 47- Roof Screen Model 
Fig. 48- The roof screen is developed to reflect the same basic geometries that can be found in the smaller details such as the individual component and the shape of the balusters. The roof has number of different structural elements which all bring the load down to a series of columns which transfers it directly to the ground.

Fig. 49- The roof screen as viewed from above
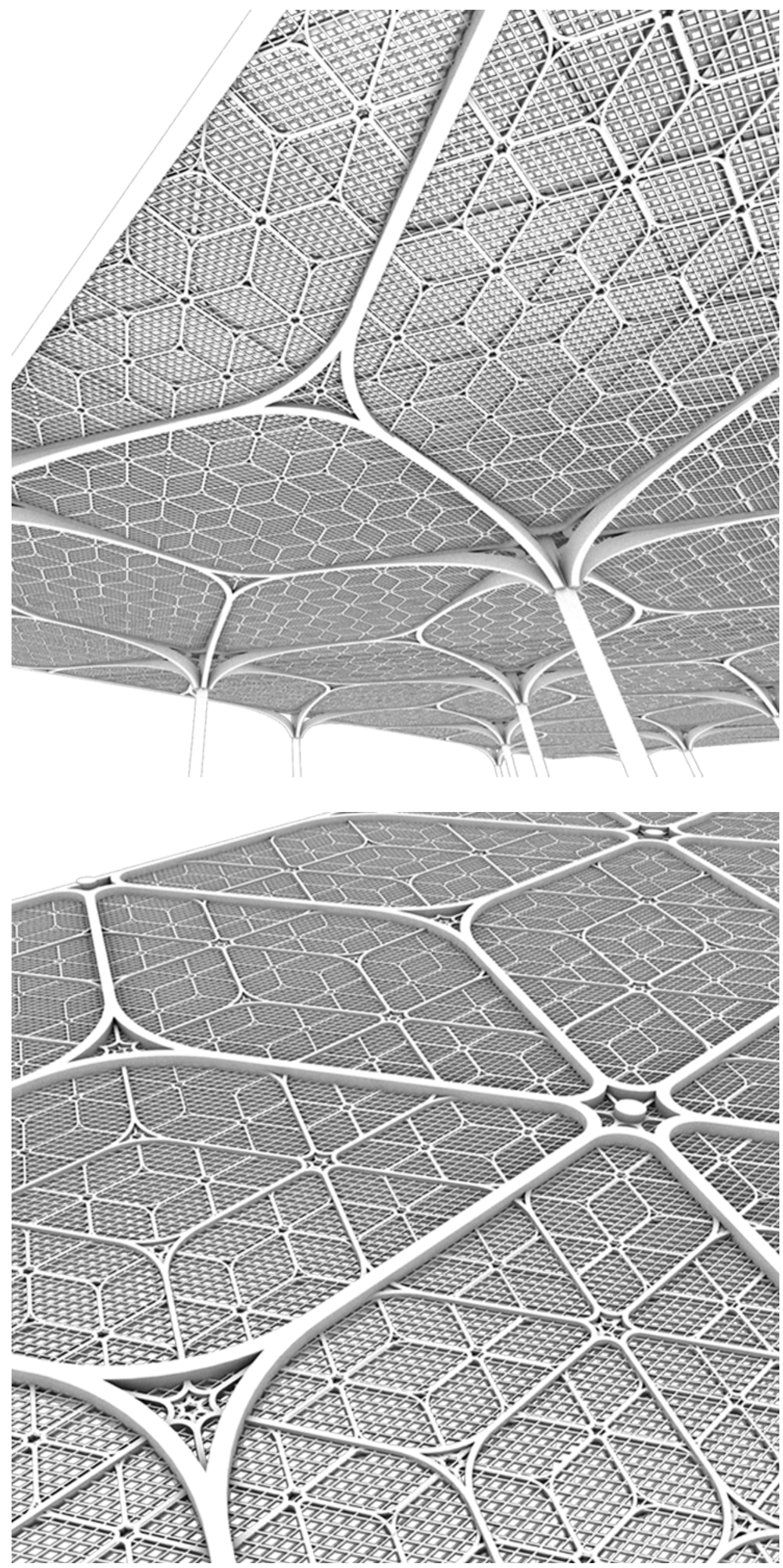


\subsection{Evaporative cooling sprays}

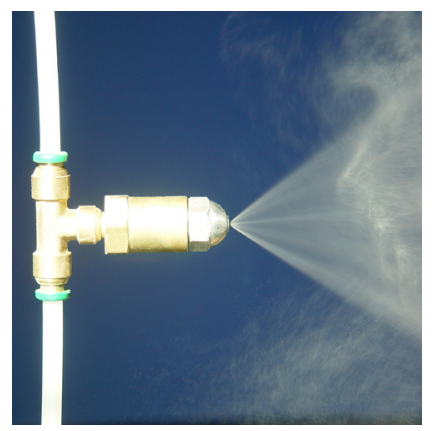

Fig. 50-Misting sprays have been proven to be the most efficient and effective method of performing evaporative cooling within extreme desert climates.

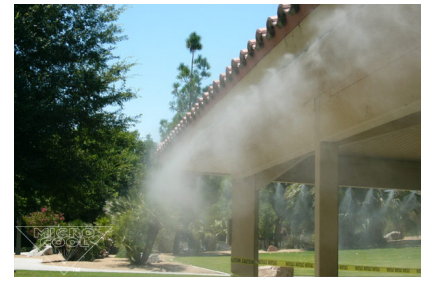

Fig. 51- A desert house in America is cooled through the use of fine misting sprays.
A viable solution was also required for the evaporative cooling process in the Giles Weather Station. Although the mashrabiya is very good at tempering the internal environment it does require an additional cooling mechanism to ensure that the air that passes through it is of the correct temperature and humidity. Porous clay jars filled with water were traditionally placed behind the mashrabiya to cool the air as it flowed past. Although effective this was not entirely efficient and was not deemed an appropriate solution for a contemporary adaptation of the mashrabiya.

As this study has been focussed upon optimizing functional performance it was determined that the best solution was to use strategically located misting sprays in the design of the screen. Evaporative cooling is a process that has been established to work most efficiently when the water is sprayed through a nozzle of $0.2 \mathrm{~mm}$ diameter. ${ }^{68}$ This creates water droplets which have a surface area to volume ratio that is optimized for evaporative cooling. By creating a network of sprays based upon this dimension it can be ensured that the amount of water and energy used for cooling is kept at a minimum.

Misting nozzles are placed at the junction points between the primary structural elements which allow for the nozzles to be spread evenly over the entirety of the screen (see Fig. 52). Hoses pass through the hollow structural elements and lead back to a water storage point that is supplied directly from the reservoir beneath the Gibson Desert. The misting sprays are sensor controlled to provide evaporative cooling only when required. This combination of the mashrabiya and sprays creates a suitable and efficient method of cooling for the building.

68 http://www.microcool.com/outdoor-cooling/index.htm 


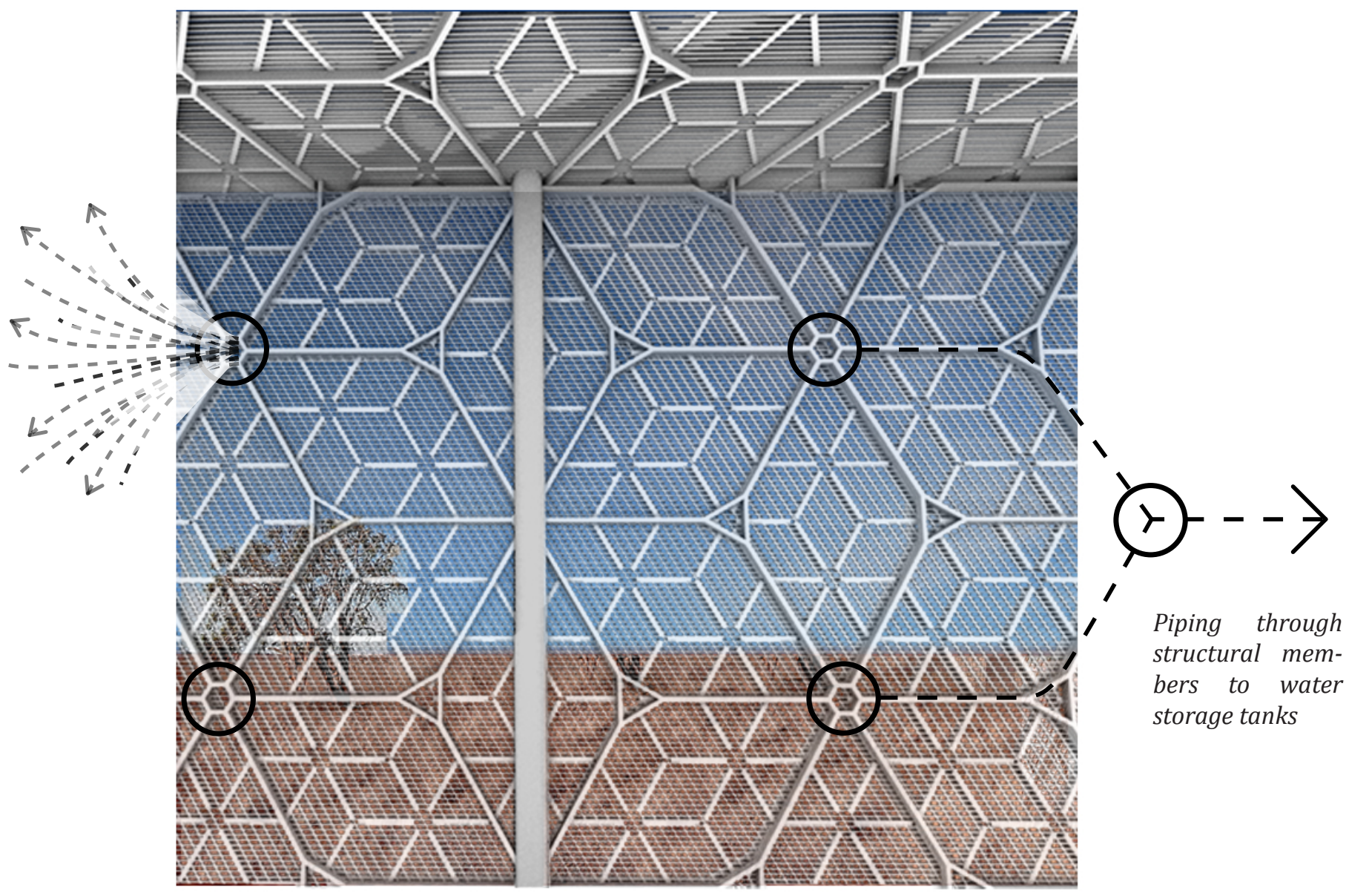

Fig. 52- Misting Spray Points 


\subsection{Thermal Chimneys}

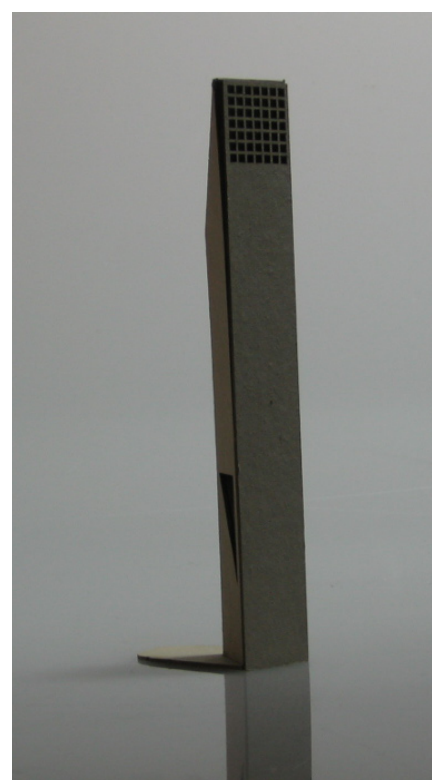

Fig. 53- Thermal chimney design

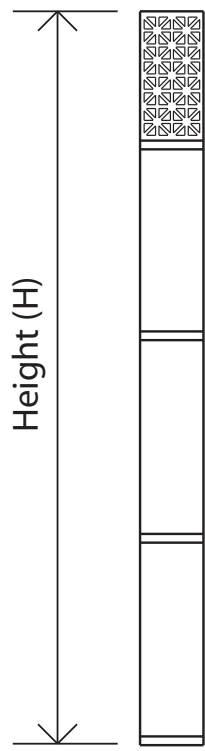

Fig. 54- Relationship between mashrabiya porosity and thermal chimney height
The amount of air that flows though a room needs to be tightly controlled and depends upon two main factors: the size of the air intake and the air driver. In this instance the air intake is the mashrabiya and the air driver is a thermal chimney. As the size and porosity of the screen is determined primarily by lighting conditions (see 3.3) the dimensions of the thermal chimney must be adjusted to allow sufficient airflow.

By applying an equation to find the required dimensions for the thermal chimney ${ }^{69}$ it can be seen that there is a logarithmic relationship between the height of the thermal chimney and the porosity of the screen (see Fig. 54). So if for lighting reasons the porosity of the screen is reduced then the height of the adjacent thermal chimney must increase dramatically to create the required airflow. It should be noted that this calculation is based upon peak air flow during calm conditions. By contrast, of course, when a lower airflow rate is required the thermal chimney can be shut off by means of a flue.

The size of the thermal chimneys at Giles varies according to the porosity of the screen covering the adjacent room, which is defined by lighting and privacy requirements. This meant that the thermal chimneys over the residential areas of the building were much larger than those over the office spaces, which draws an interesting link between the program, the detail and the architectural form of the building.

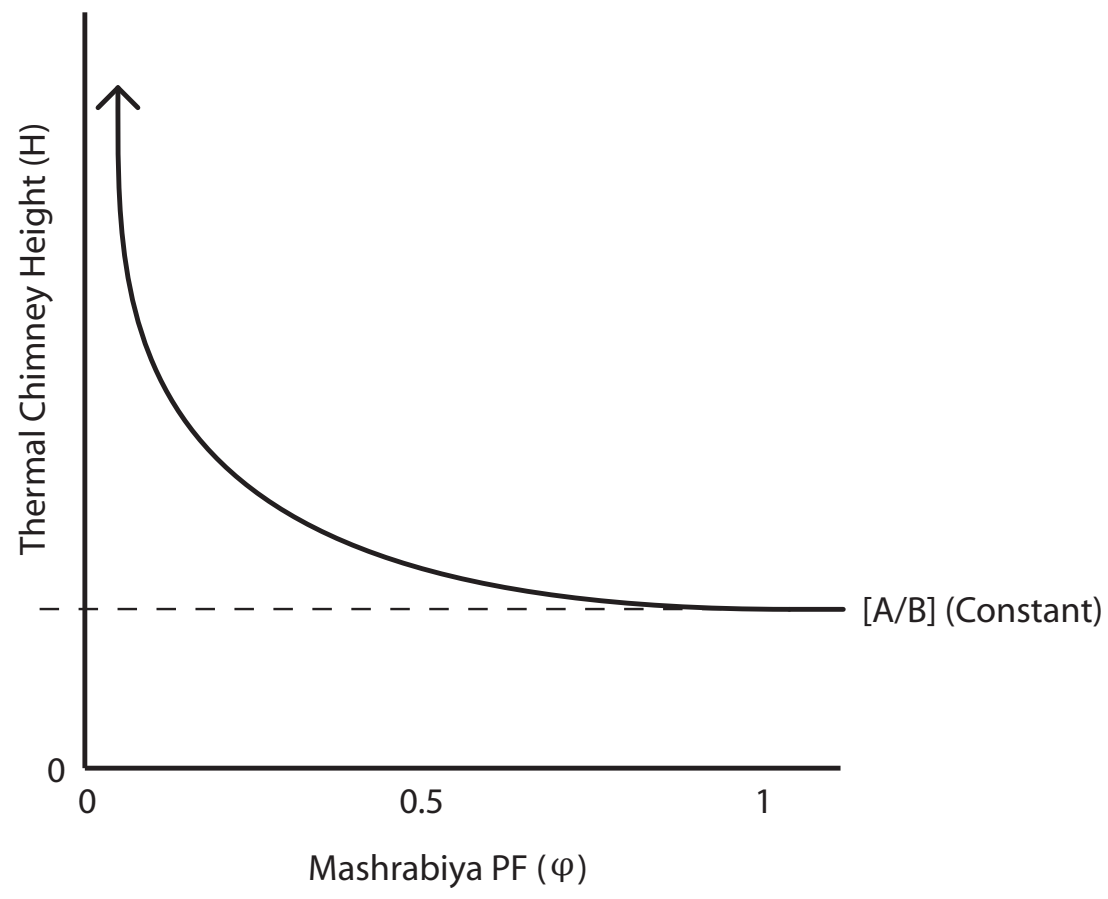

$69\left[\Delta \mathrm{T}_{\mathrm{e}}=\mathrm{A} / \mathrm{B}+\left(\mathrm{T}_{\mathrm{i}}-\mathrm{A} / \mathrm{B}\right) \exp -\mathrm{BwH} /\left(\mathrm{p}_{\mathrm{e}} \mathrm{c}_{\mathrm{p}} \mathrm{Q}\right)\right]$. For a breakdown of this equation refer to: Ghiaus, Cristian and Francis Allard, eds. Natural ventilation in the urban environment: assessment and design, p.154. 


\subsection{Architectural interpretation}

Refer to Fig. 56 on following pages for a detailed diagram of these points
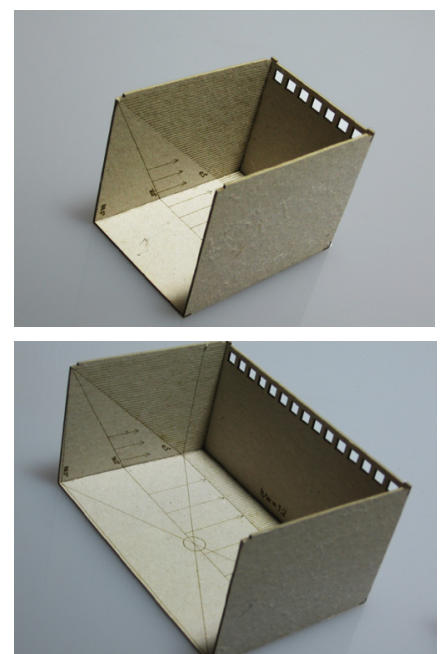

Fig. 55- Height/Width ratio analysis
As well as the design of the mashrabiya affecting the height of the thermal chimneys there are a number of other links between the variables of the screen and the wider architectural form. Although these may be relatively small changes the impact that they can have on the optimum sizing of the building is dramatic, and results in a number of architectural parameters which need to be taken into account when designing the building (refer to Fig. 56 overleaf). This is unusual in that the greater architectural form is in many ways subservient to the smaller details of the building.

For instance, the optimum ratio between the height of the walls and the width of the room is dependant to some degree upon the maximum vertical and horizontal sun angles allowed by the mashrabiya. The sun angles define whether the greatest amount of solar gain will be on the walls or floor of the building. The ratio between room width and height determines which surface the majority of the sunlight will be on and how much heat will be transferred therein. By ensuring that the vertical and horizontal solar gain for Giles was evenly distributed within the internal space the optimum height/width ratio of the room was determined to be 2:1 (see Fig 55). By applying this to the $6 \mathrm{~m}$ grid spacing established by the roof screen (see 4.4 ), the result is an optimal opening size of $3 \mathrm{~m}$ high by $6 \mathrm{~m}$ wide.

Additionally, the length of each room is determined to some extent by the amount of ambient light that is permitted to enter the space. If only a small amount is allowed in then the space has to be quite small, otherwise it becomes too dark. If a high level of light is allowed to enter then the room can extend much further away from the window screen. The amount of ambient light within the space is determined by the porosity of the screen, meaning the length of the room is dependent upon the PF value. The optimum room length can be tested using computer simulation software to establish the lighting levels at different points of the room, which for the standard screen used at Giles $(\mathrm{PF}=0.56)$ the maximum room length was determined to be $10 \mathrm{~m}$. This creates a standard room template of $3 \mathrm{~m}$ high, $6 \mathrm{~m}$ wide and $10 \mathrm{~m}$ long.

One method of regulating the temperature of the building is to partially sink it underground, using the heat storage capacity of the earth to stabilise the internal temperature through summer and winter. By creating a split level between the ground and the subterranean floors an added amount of light can be brought into the space, heating the earth floor in winter and warming the room from within. The setback of the split level is defined by the maximum vertical winter sun angle allowed through the mashrabiya, and defined by the equation $\left[\mathrm{L}=\mathrm{h}^{1} /\left(\tan \theta^{1}\right)\right]$ (refer to Fig. 55 overleaf). For Giles the optimum split level setback was found to be $3 \mathrm{~m}$. 


\section{Fig. 56-Architectural Analysis}
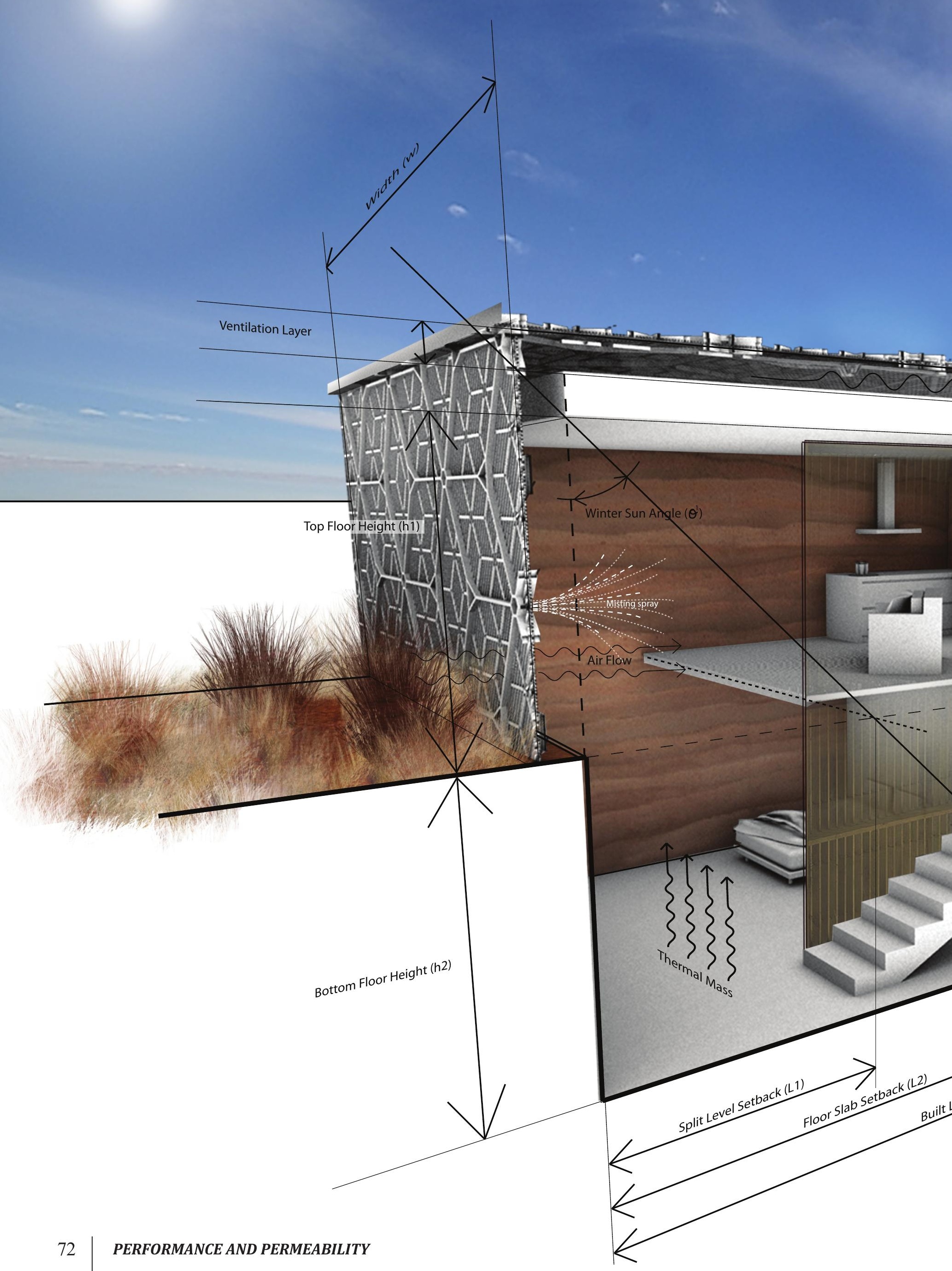


\subsection{Conclusion}

This chapter established a component based system which is able to be used to apply the research to the Giles Weather Station. With the functional, structural and constructional issues identified and dealt with the screen has changed from being a number of optimised variables to a viable architectural element, capable of being used within a built form. The development of a cheap and easily constructed mashrabiya component greatly increases the versatility of the screen, evident in its use as a roofing element. This, along with the development of misting sprays and a logical structural system, has transformed the mashrabiya from a simple window screen into a much more significant architectural intervention, the use of which is limited only by the mind of the designer.

Along with the actual physical issues of applying the screen to a building there is also the relationship that it has with the architectural form itself. An interesting result of this study has been the discovery of a number of links between the optimal physical parameters of the building and the individual variables of the mashrabiya. This has led to a basic architectural typology that is to some degree subservient to the design of the screen, which changes the design process from being programmatically driven to detail driven.

With these findings in place the mashrabiya has become ready to be applied to the Giles Weather Station. 


\section{Chapter 5: Architectural Application}

Based upon what has been established up to this point a conceptual design stance for Giles Weather Station has been developed. With the research conducted so far the mashrabiya is both cheaper and more versatile, meaning it has the potential to be used in a much more ambitious fashion than was previously thought possible.

Therefore this design utilises a climatically perfect 'mashrabiya shell' to enclose the entire building. By having a separate layer of mashrabiyas acting independently of the built form it can create a microcosm within which the building can exist. Instead of the building battling with the desert heat it is placed within an environment where the air, light and temperature are precisely controlled. It is similar conceptually to that of a greenhouse which, through an enclosed shell with a mediating boundary layer, creates a thermally defined zone that is optimised for the plants within.

The original weather station was comprised of a number of independent dwellings separated by pathways. By using the mashrabiya as a shell over the building some level of independence between dwellings has been provided whilst still holding them together within a much larger form. Additional mashrabiyas could be used between dwellings as privacy screens, further differentiating the spatial boundaries. This, together with established principles of desert architecture such as the use of thermally massive walls, sunken courtyards and passive ventilation, has created a viable typology with which to solve the architectural problems facing the Giles Weather Station. 


\subsection{Building Plan}

The plan of the building has been created in accordance with established principles of traditional desert architecture. ${ }^{70}$ The use of small confined spaces enclosed within large amounts of thermal mass creates passive thermal zones which are able to be independently regulated for comfort. The traditional use of sunken courtyards led to the idea of sinking half of the building beneath the surface of the desert. This creates two layers to the building, an upper layer at ground level which is open, breezy and looks out across the desert expanses and a lower level which is darker, cooler and more internally focussed. The building is orientated along an East-West axis to maximise the effectiveness of the mashrabiya on the northern face of the building, creating a long building consisting of three adjacent zones.

The first, a residential zone, has four independent living quarters for the workers, as well as a rear courtyard and a services area. Each living unit is thermally independent of the others and consists of a north facing room containing a split level, allowing the sun into the lower level to heat the earth floor in winter and creating a natural ventilation passage between layers. The mashrabiya allows the rooms to be far more accessible and open than they otherwise could be, blurring the line between the interior and exterior.

The second zone is a mixture of recreational and tourist space. As the weather station is near the Desert Highway a number of visitors arrive each day. The tourist area contains artefacts and information about the work performed at the station, engaging them directly with the building. This area also contains features such as a bar and a swimming pool for the workers to relax in, whose privacy is protected through the use of strategically located mashrabiyas.

The third zone is the working area, which contains the laboratories and office space required to conduct research. As these spaces need more light and less privacy than the accommodation units the mashrabiya are more porous.

Each of these three zones is designed to maximize the collection and storage of cool night air, allow for natural ventilation and create the right levels of privacy/transparency between rooms. The basis of the architectural design is firmly rooted in Middle Eastern desert architecture traditions, yet the interpretation of these traditions is directly based on the specific programmatic requirements of the Giles Weather Station.

70 Konya, Allan. Design primer for hot climates 


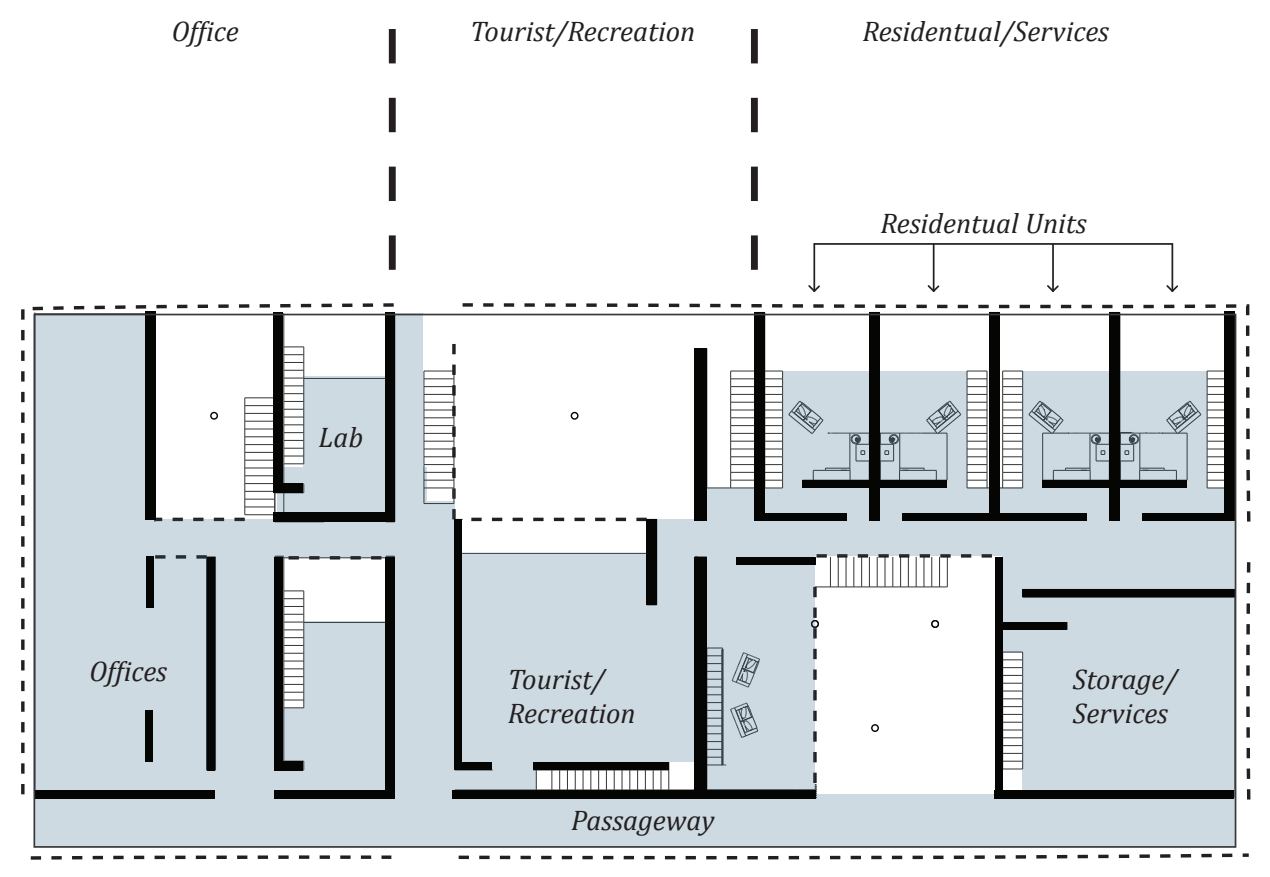

Ground Level

Subterranean Level
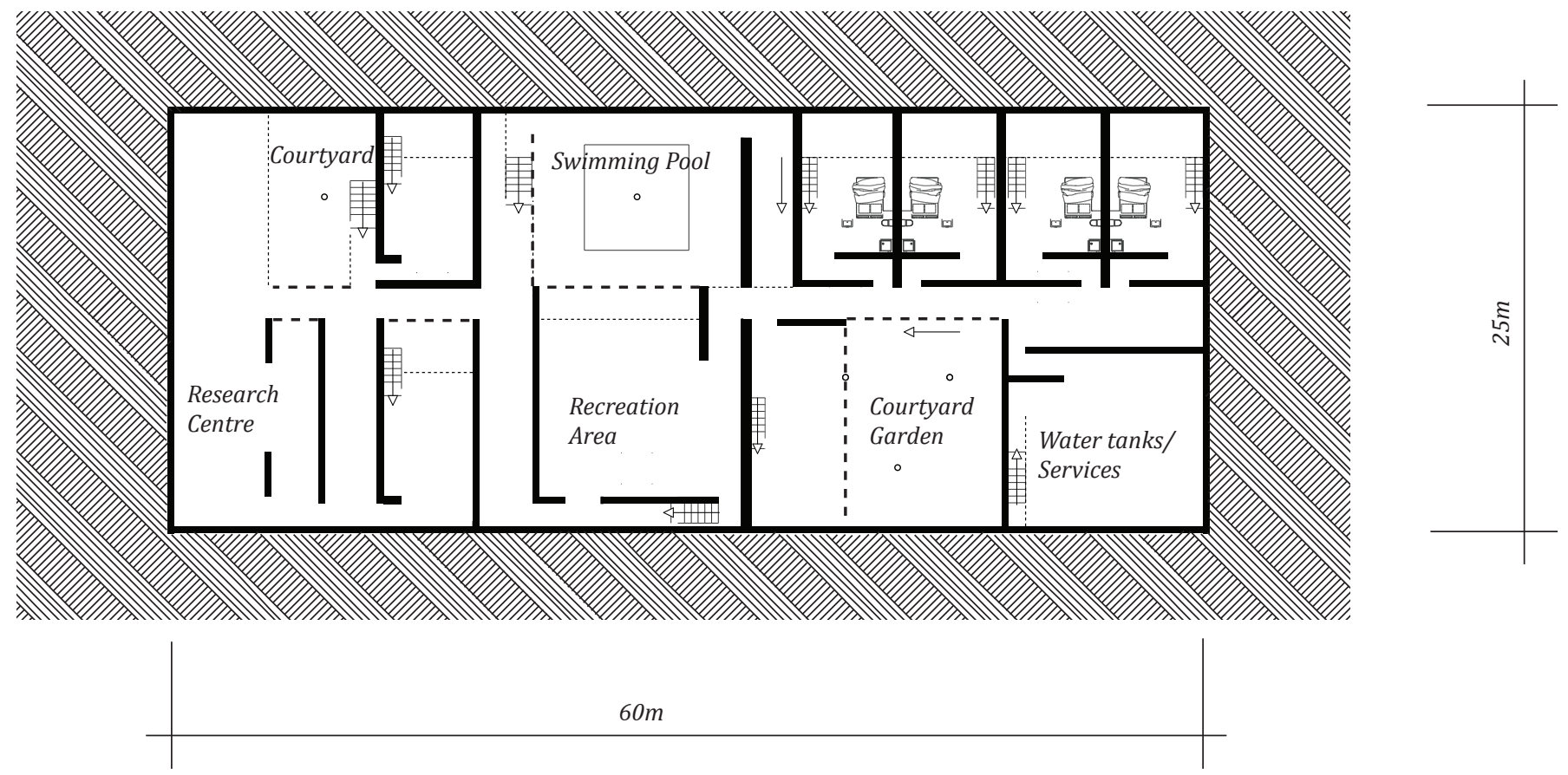

Fig. 57- Plan

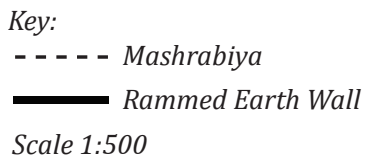



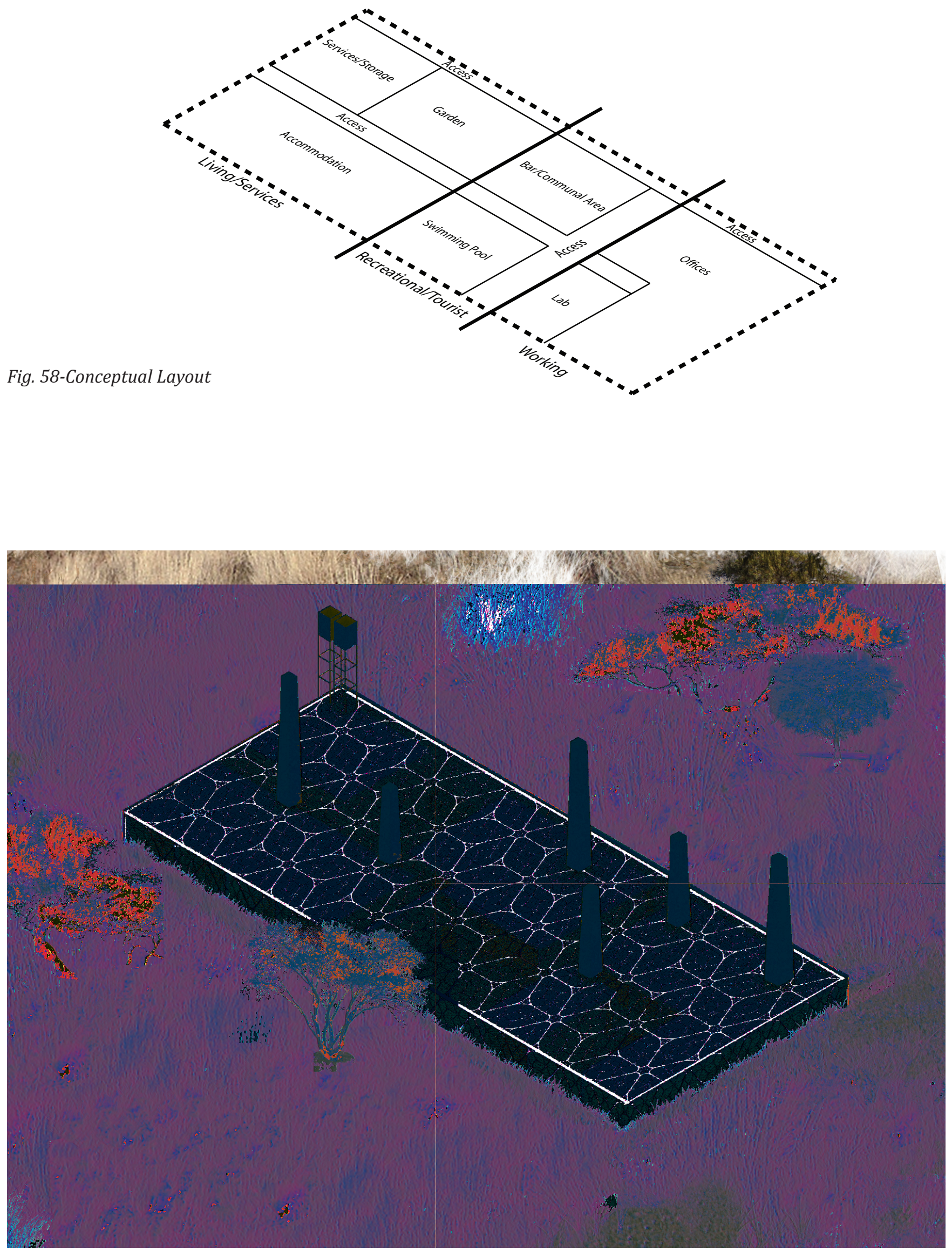

Fig. 59-Combined Scheme 


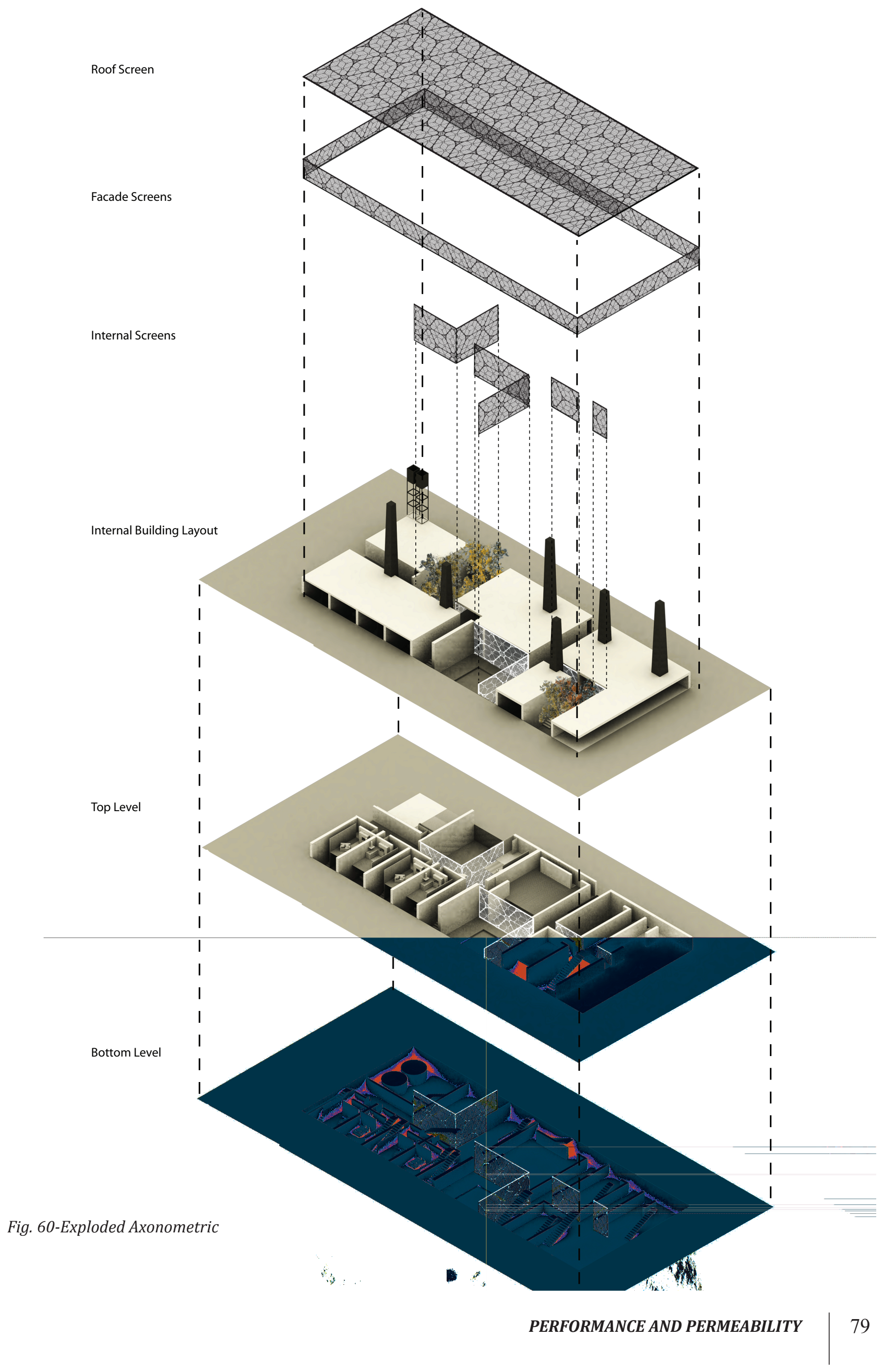




\section{a) Giles Weather Station with mashrabiya shell}

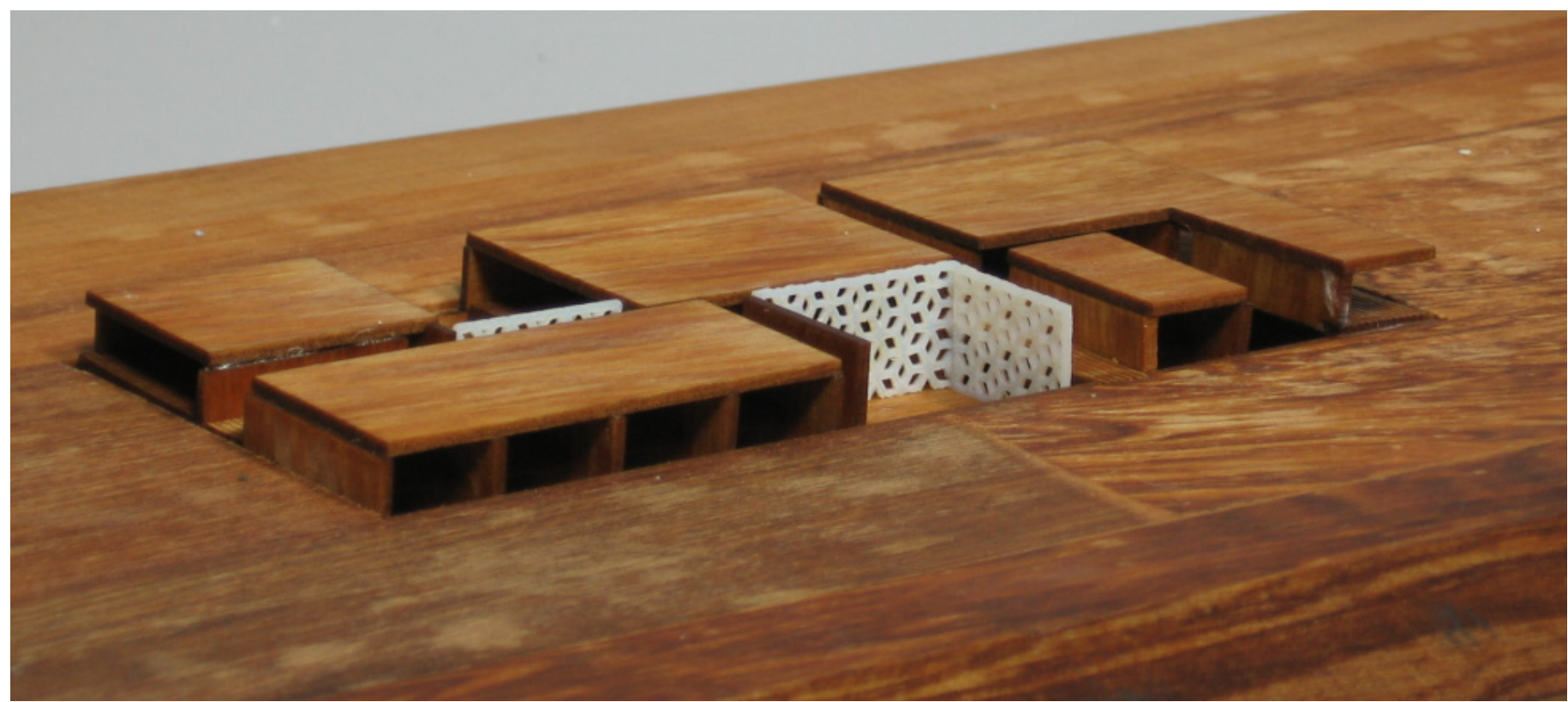

b) Northern face of the building, viewed without mashrabiya shell

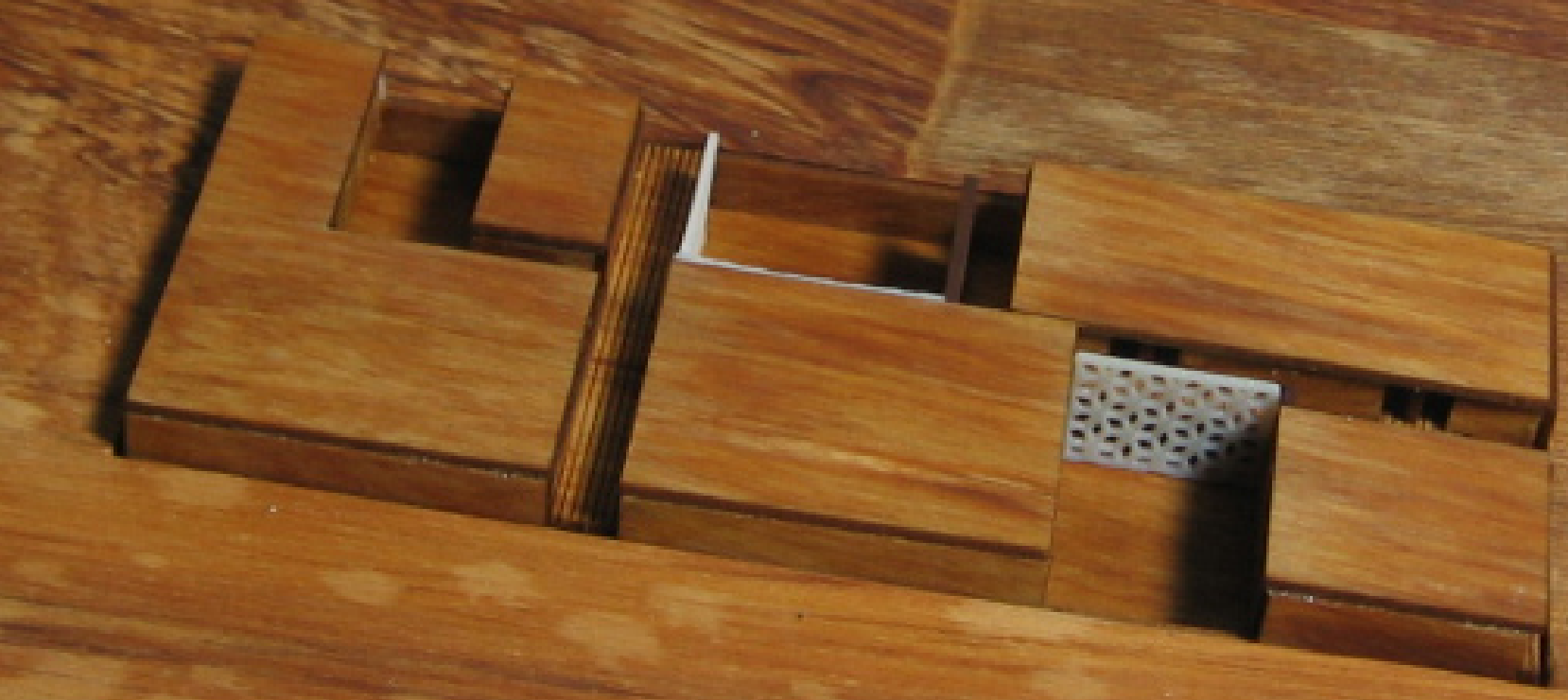

c) Southern face of the building, viewed without mashrabiya shell 

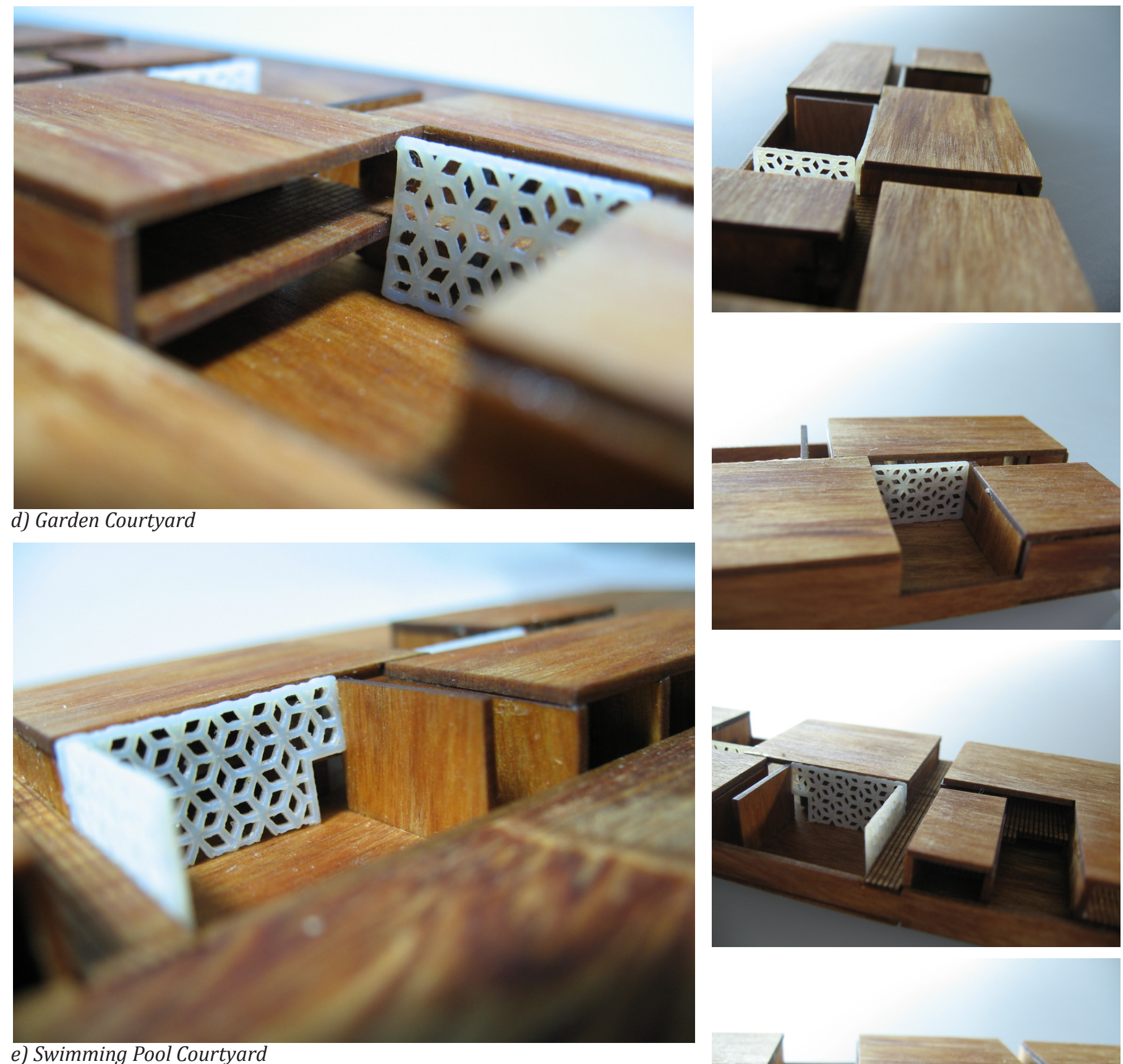

e) Swimming Pool Courtyard
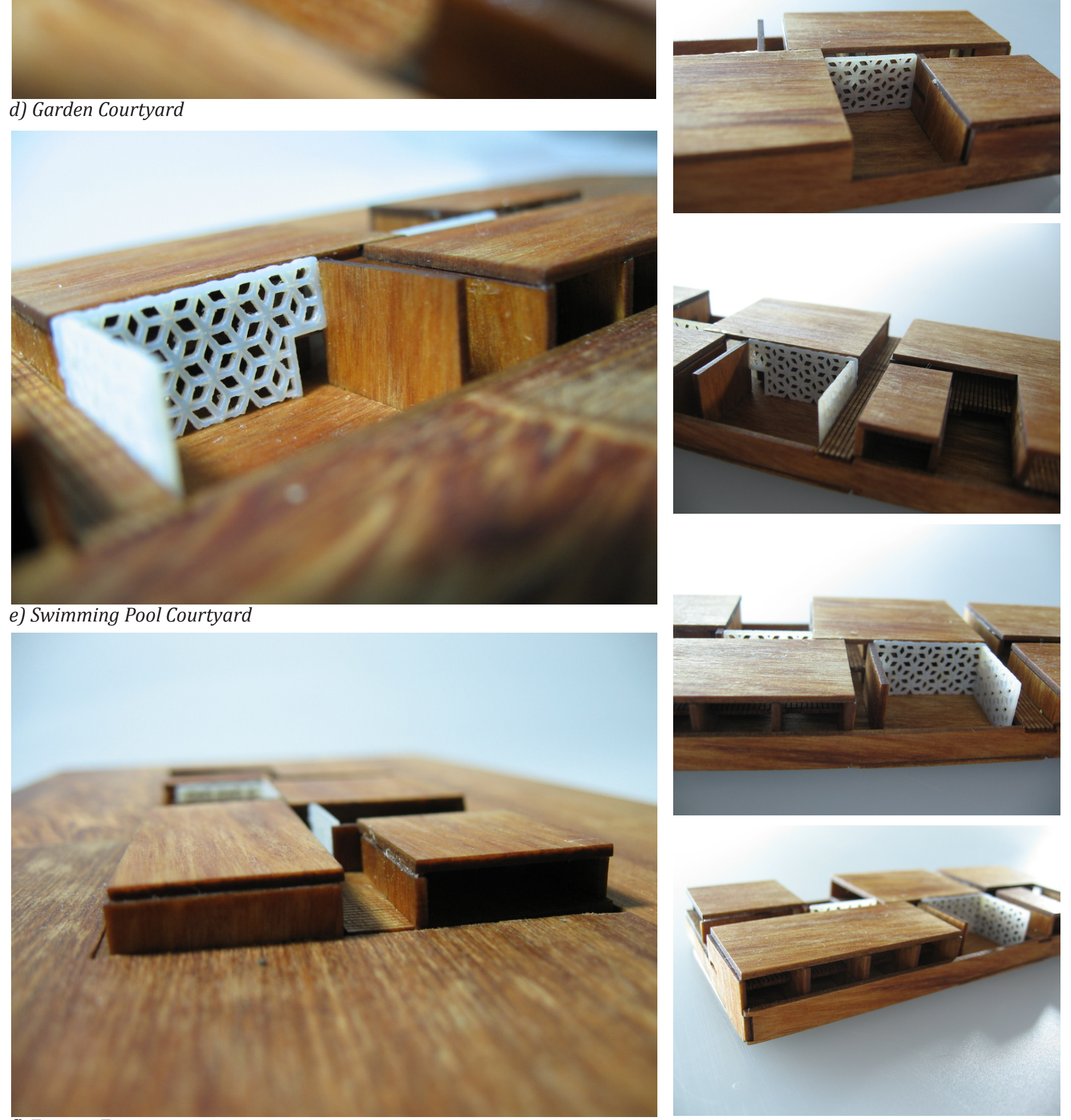


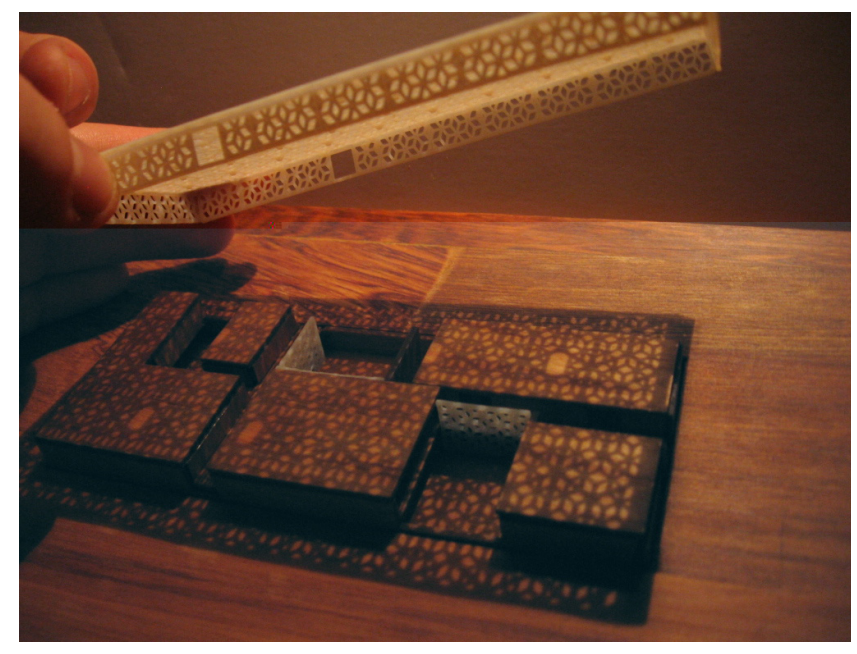

Fig. 62- Lighting Model

Here the true power of the 'mashrabiya shell' is shown. The shell creates a tightly controlled internal environment, with every shadow and dappled patch of sunlight being tailored precisely to the building's unique thermal requirements. This results in both sheltered buildings and courtyards that allow for constant, comfortable occupation.
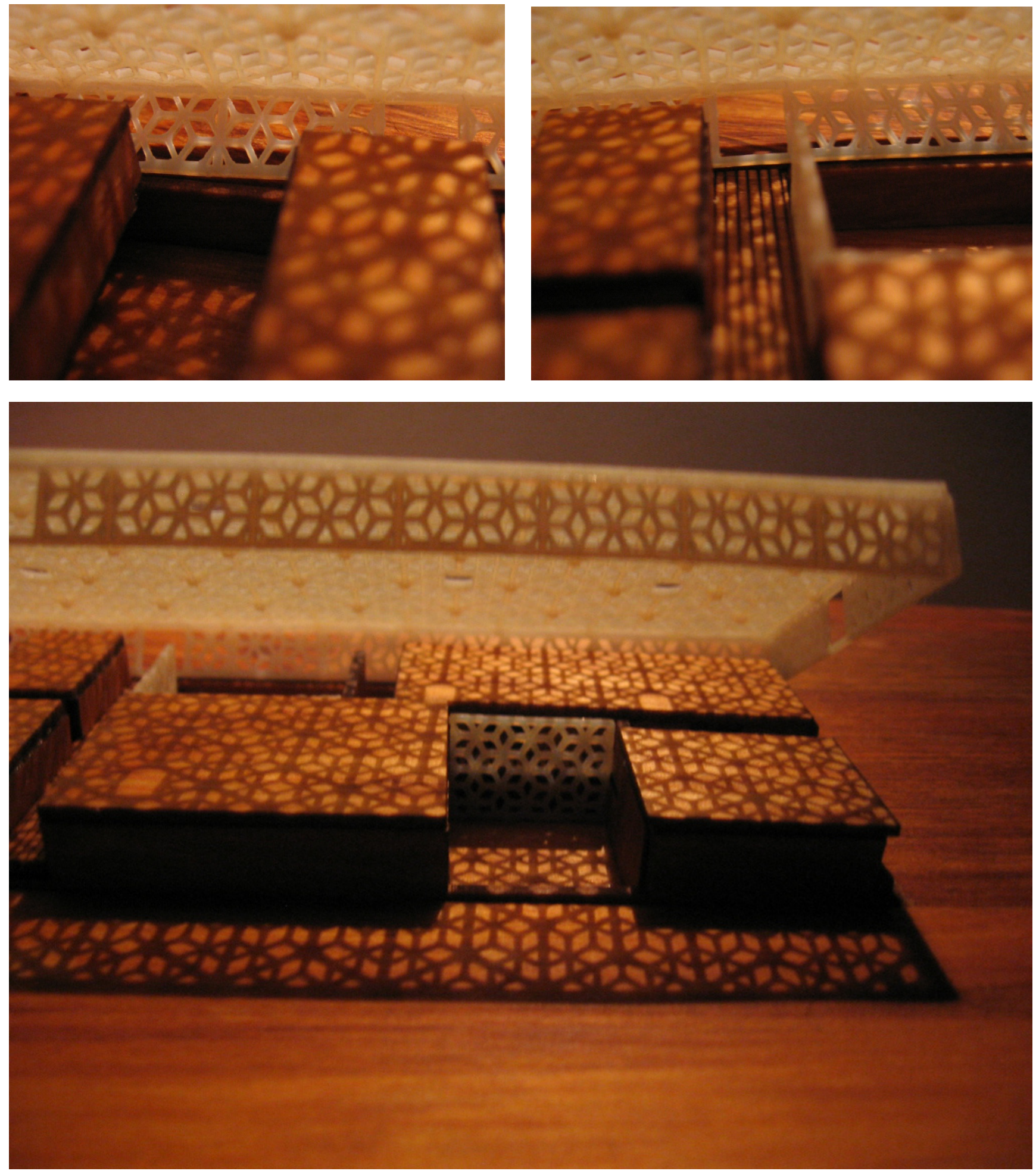

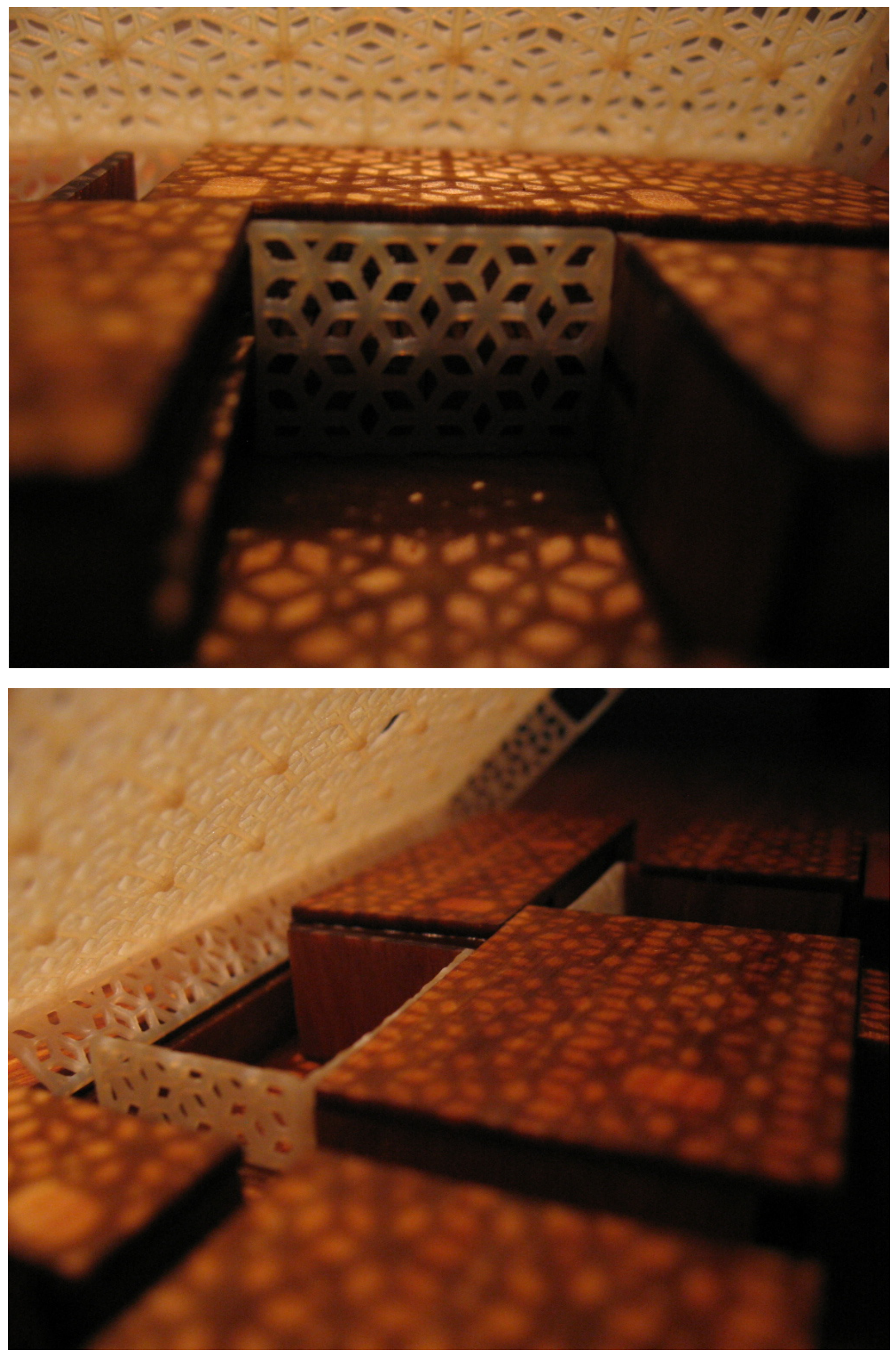
Fig. 63- Bas-Relief Studies

These studies were conducted to experience the tectonics of the large rammed earth walls combined with the delicate intricacies of the mashrabiya screen. The screen has to be applied carefully to ensure that it is not overpowered by the visual weight of the walls. If designed correctly the two can compliment each other, creating a building that is both solid in form and delicate in detail.

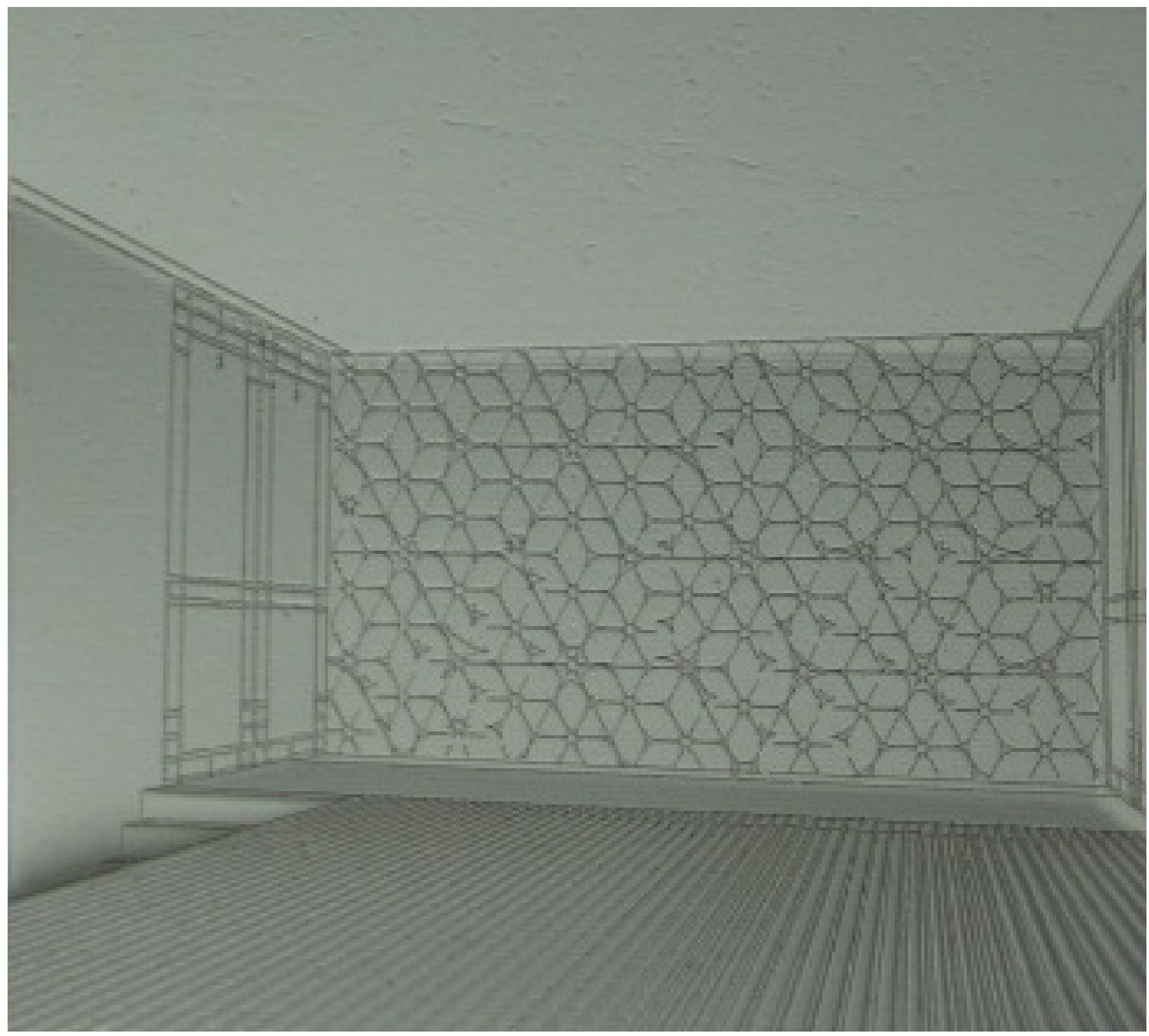



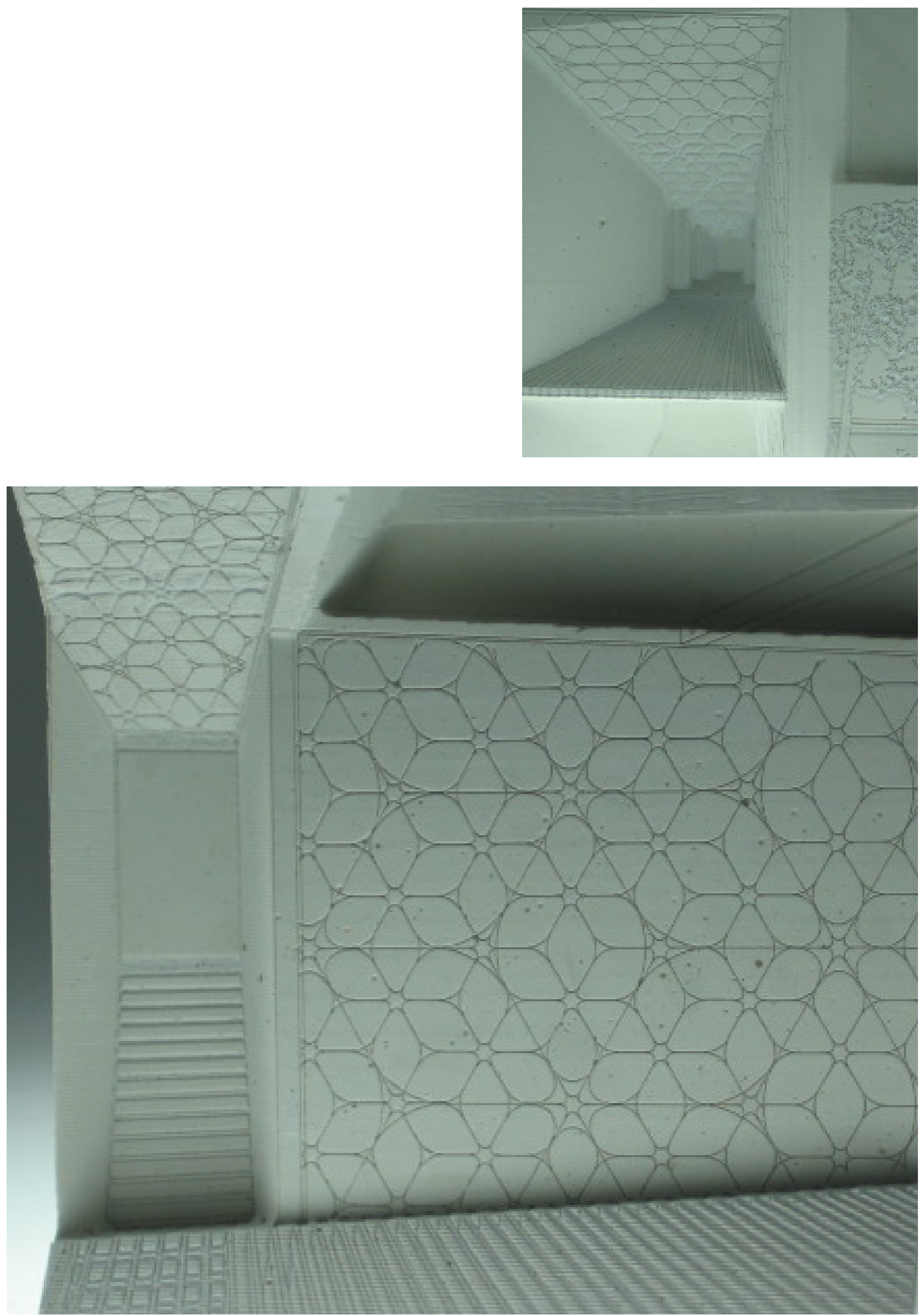


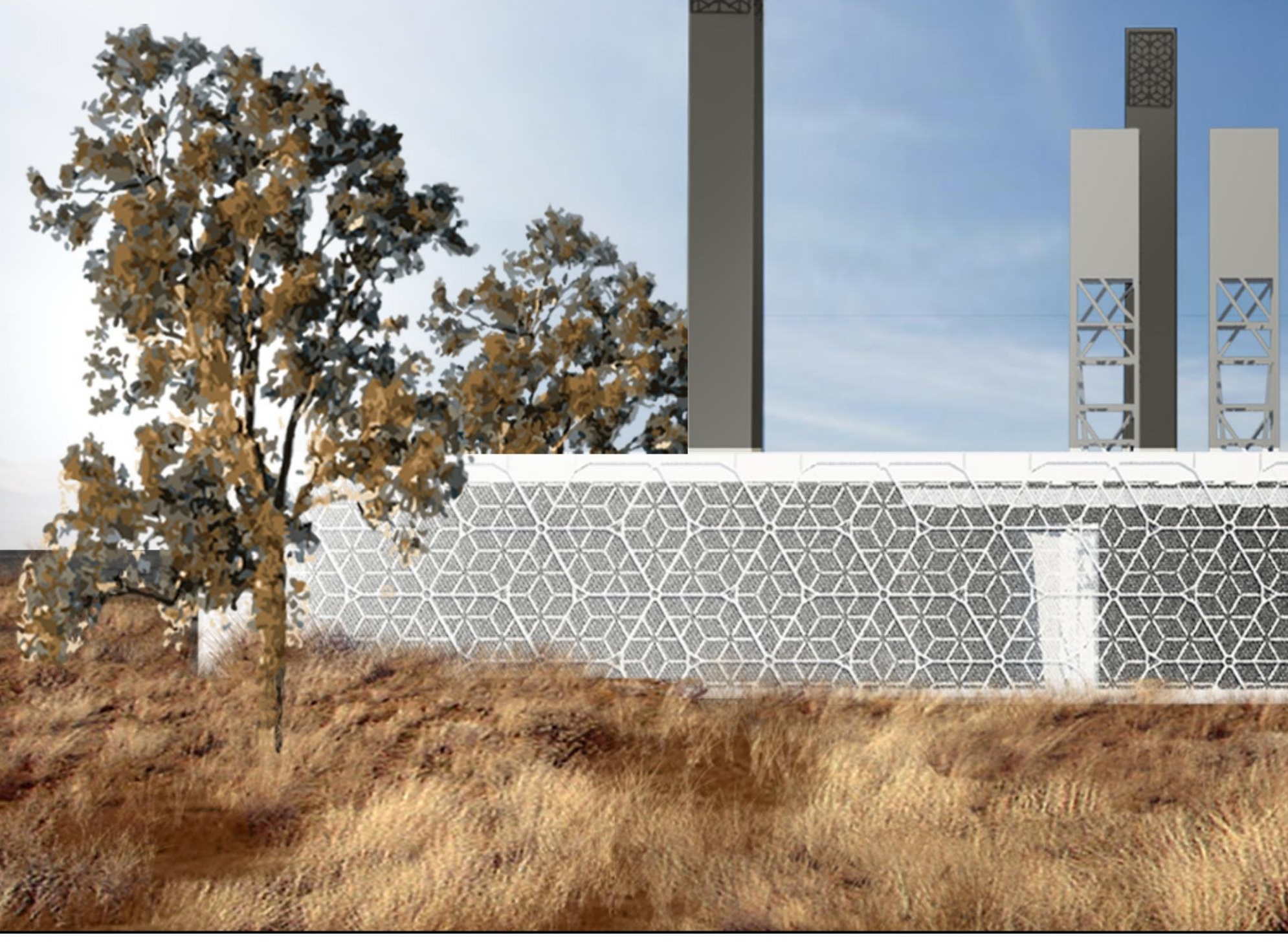

Fig. 64- Western Elevation

The screens create a visually dynamic surface that slowly reveals different layers of detail as the viewer approaches. From the outside they shroud the building in mystery, hiding the occupants from view. In the barren emptiness of the Gibson Desert this building becomes a landmark, a simple form that rises from the red earth to become a prominant feature in the otherwise bare landscape. 


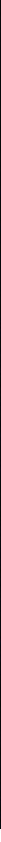




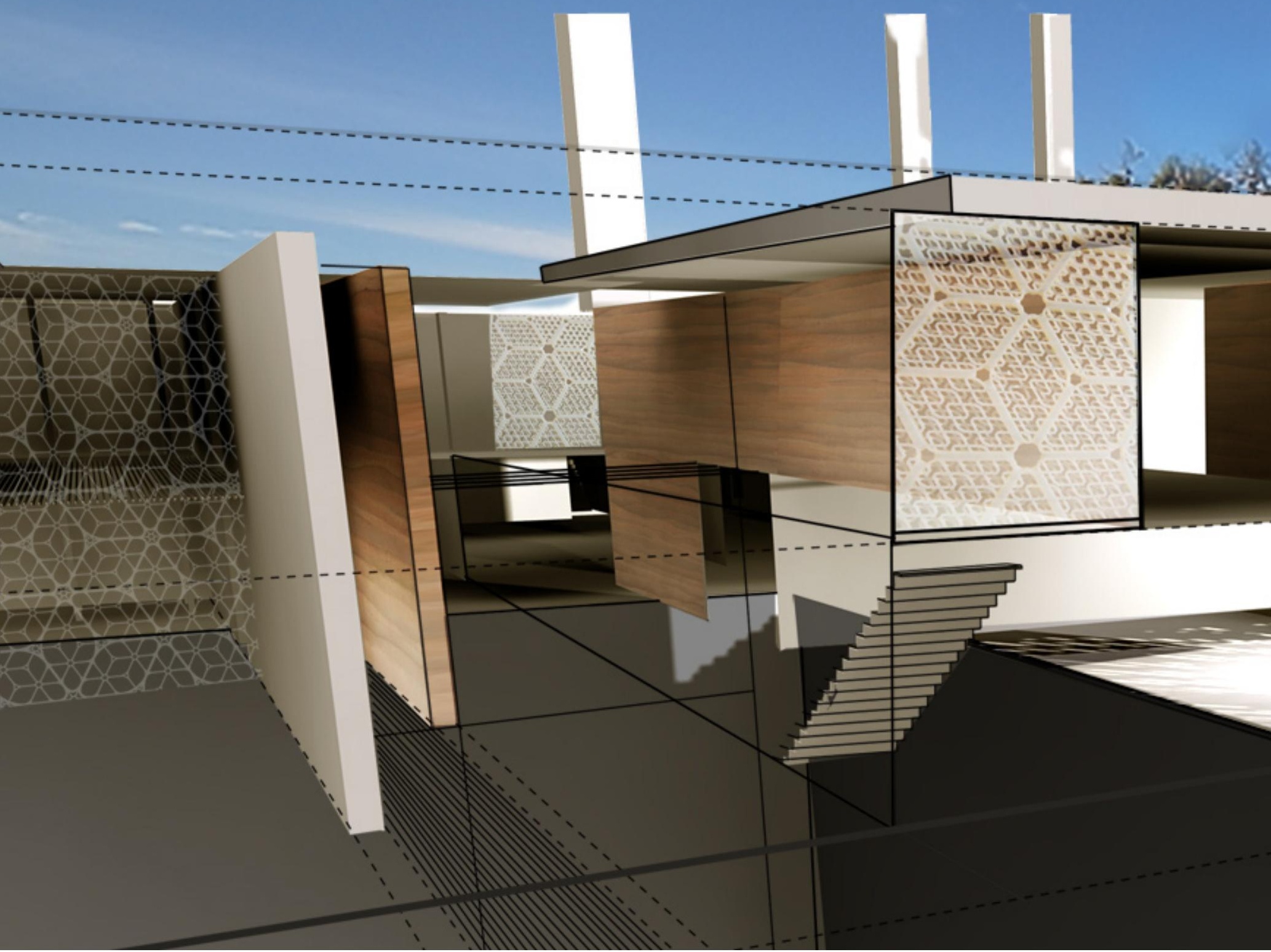

Fig. 65- Exploded Sectional Perspective

The interior of the building is full of interwoven spaces, with layered rooms providing for tight air currents and controlled ventilation. Internal courtyards draw the cool night air into the subterranean level, which then filters its way between spaces, cooling the building as it goes. 
1

I

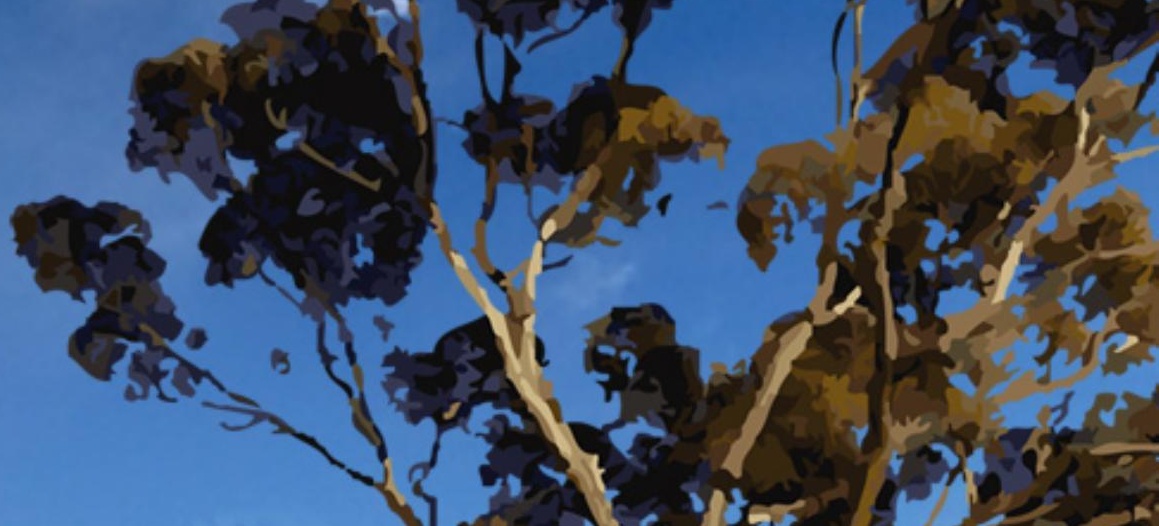

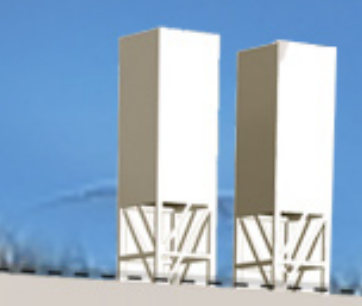
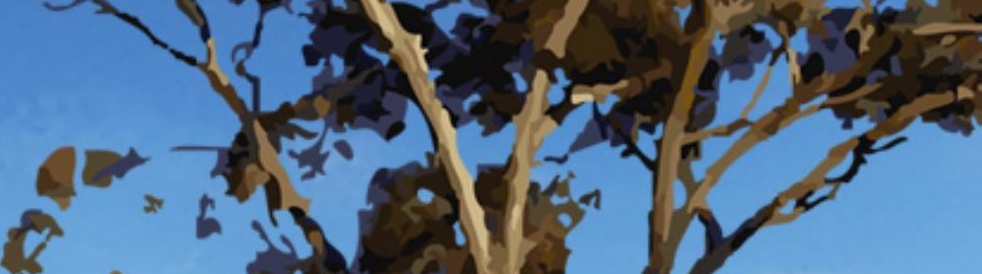

2
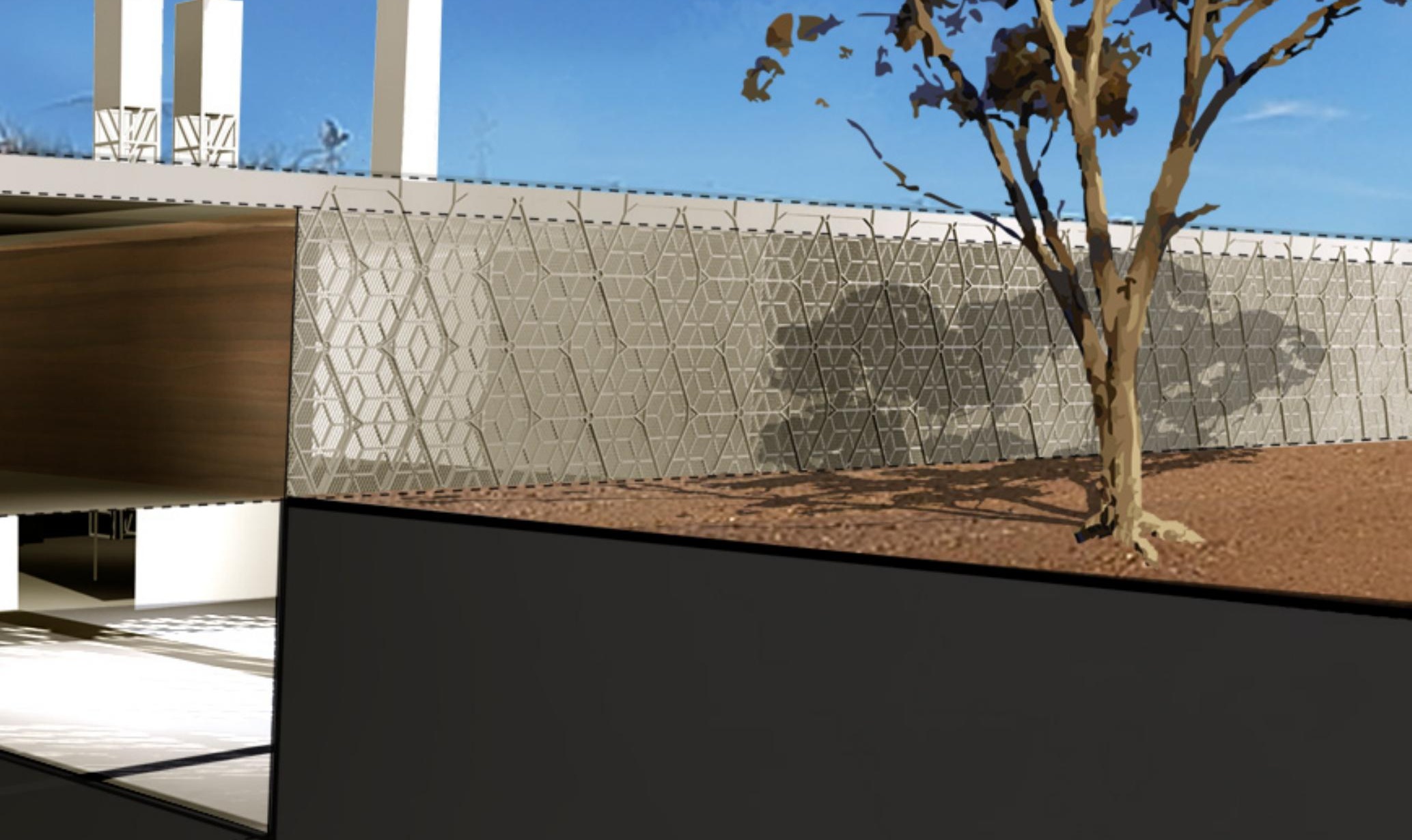
The design of each living unit is created to provide the optimal living conditions for the occupant. The unit comprises of two spaces. The first is on the upper split level, which looks out through the mashrabiya onto the open desert beyond. This space contains both the kitchen and the living area. The floor of the split level is constructed of closely spaced wooden slats which allow air to pass between the two levels. The lower level contains the bedroom and bathroom, and is the more private of the two spaces.

The walls are constructed from rammed earth sourced from the site, which retains the vivid reds and oranges that can be found within the local soil. This allows the building to respond closely to the local conditions, and regardless of the fact that it is based upon architectural principles sourced from the Middle East it still reflects its Australian context, both in terms of materiality and design. 


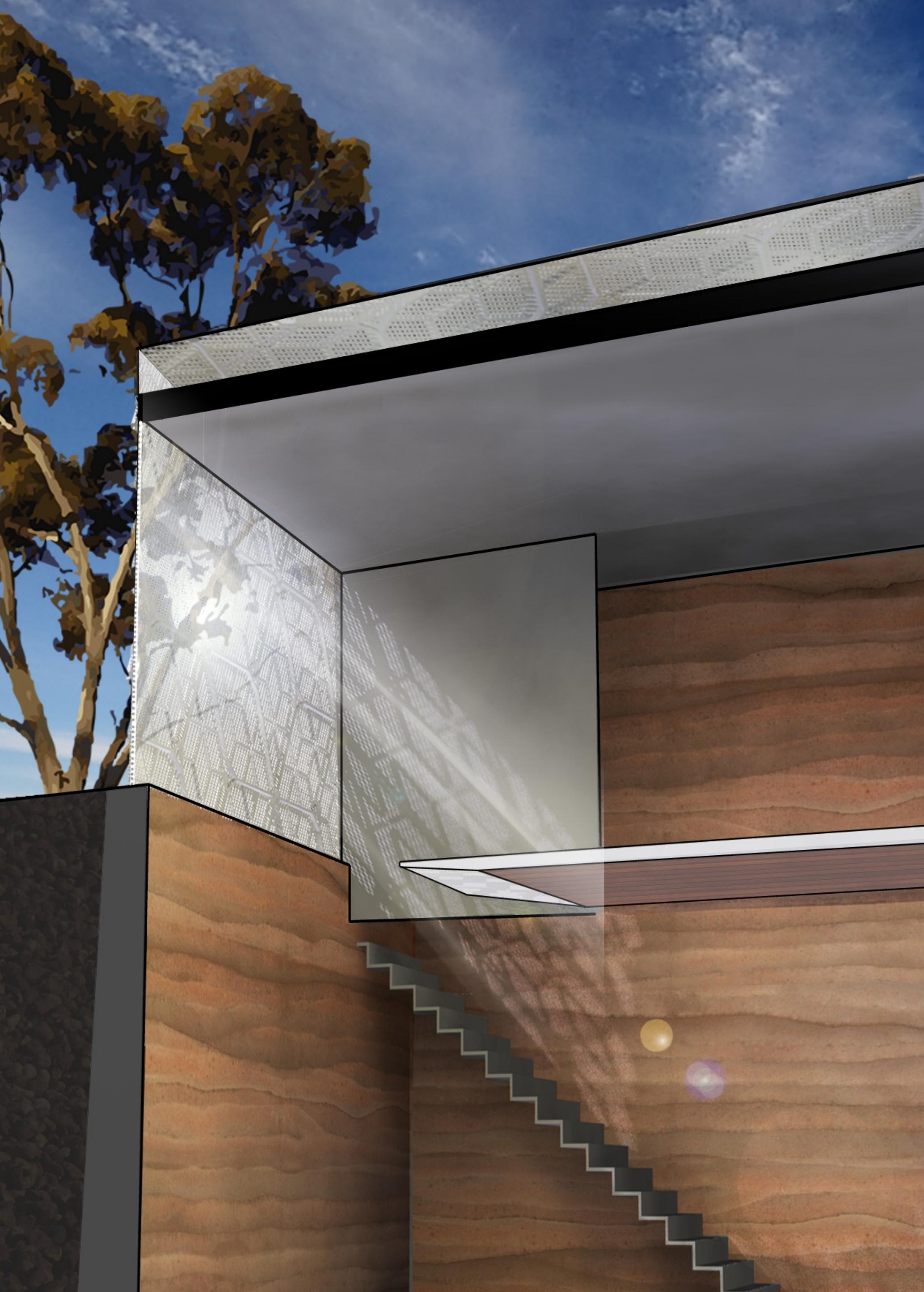


One of the most dazzling effects of the mashrabiya was the way in which it filtered winter sunlight. By using a screen on the roof the effect can be enhanced even further with the interior courtyards becoming dappled by a myriad of tiny patterns, not unlike being beneath a tree. The soft shadows dance their way across the internal surfaces, slowly heating them as they do so. The courtyards become small havens of respite against the fierce external conditions, protected from both sun and heat yet for all purposes still 'outside.' They tie the building together and demonstrate that the building can not only be functional but also enjoyable. 
I.

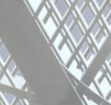

- $12-1$

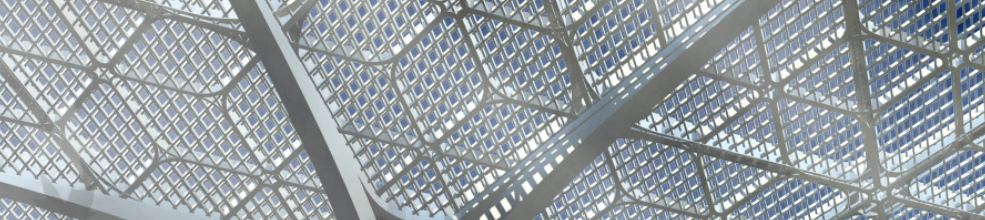

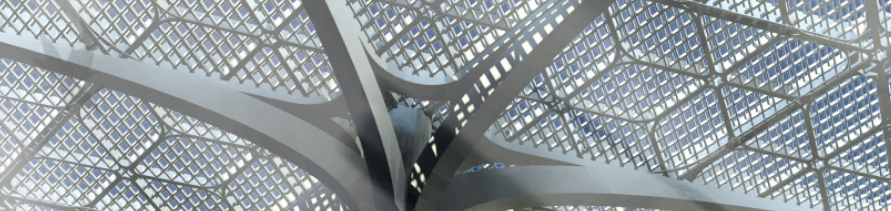

12 , $\frac{6}{6}$ . . . ats

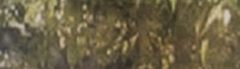
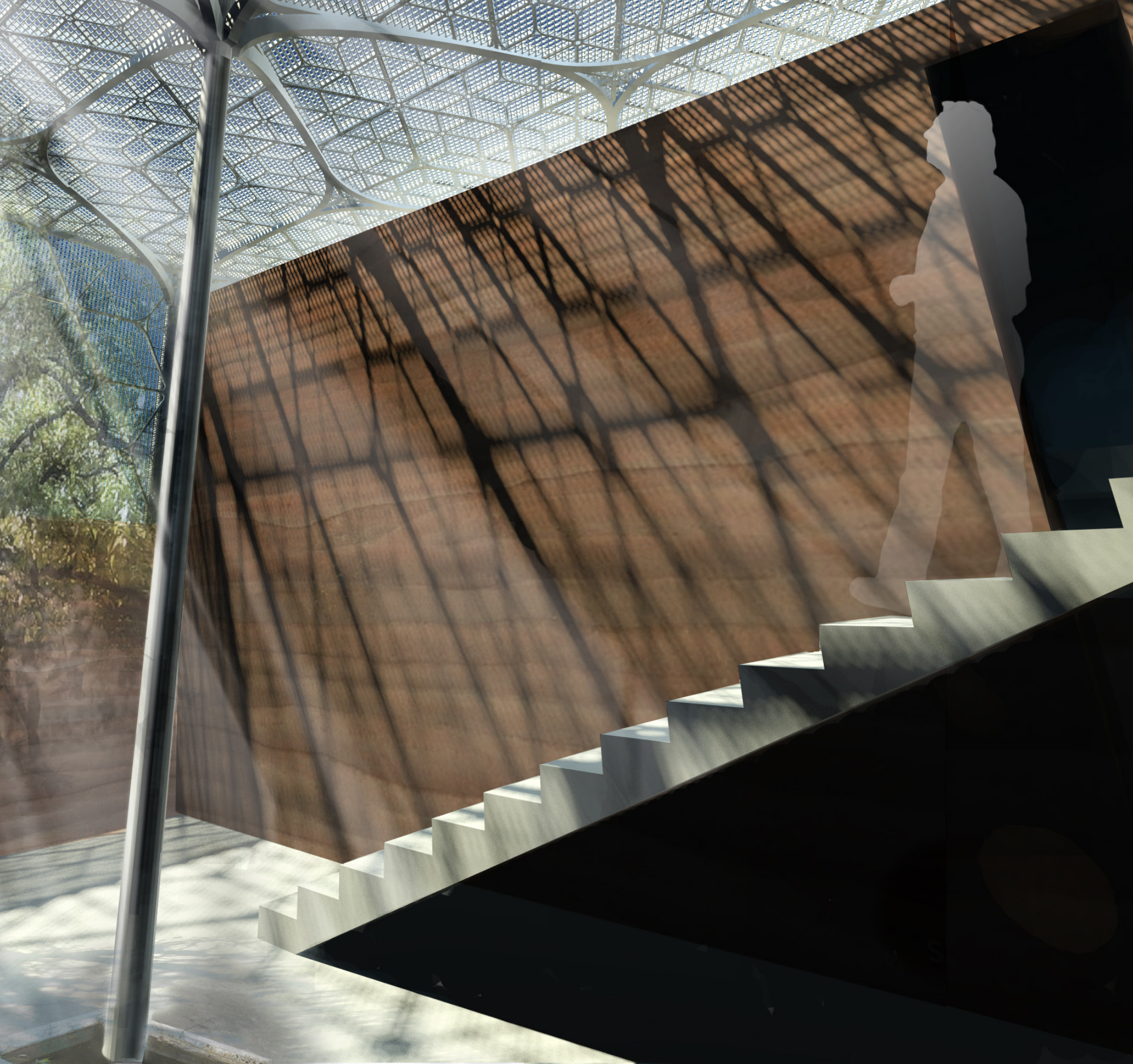

30

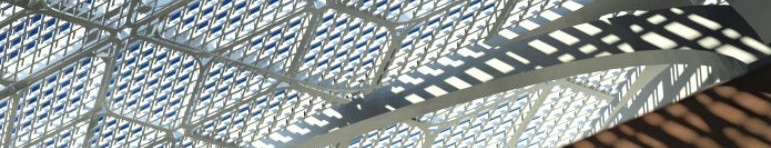

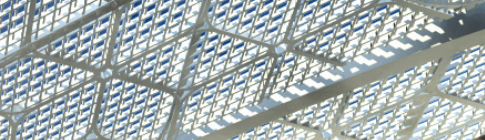

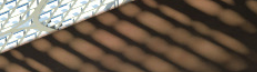


Visually the building is a stunning counterpoint to the barren emptiness of the desert, the patterns providing a uniquely delicate approach to the harshness of the conditions. The overall form is kept to a simple rectangular geometry to draw focus into the materiality and detail of the walls and to create a more decisive intervention into the desert landscape. From far away the building looks like a basic white square, resting alone beneath the sun. It is only on approach that the true nature of the building reveals itself, one layer of detail at a time. 


\section{Chapter 6: Discussions}

"What is to be answered is if those examples which compose historical prototypes can be applied nowadays, if they have already been applied, if they were efficient and if the contemporary applications constitute an evolution of historical prototypes or innovative approaches."

Saranti, K. Air moving in and through building: historical prototypes and contemporary applications, p.1 


\section{Discussion}

A number of interesting themes have been raised in this research. For the most part they can be grouped into three distinct categories; the contemporary interpretation of traditional architectural elements, the individual parameters of the mashrabiya and the application of the revised mashrabiya in the Gibson Desert.

\subsection{Traditional craft and contemporary fabrication}

By combining traditional architectural ideas with contemporary technology significant changes to the mashrabiya and its application have been made. Firstly, the new construction process allows the mashrabiya to be manufactured cheaply and quickly, making it competitive with other climatic modifiers. Secondly, the new mashrabiya is able to perform more efficiently. Thirdly, it allows the screen to be far more versatile in its application, the use of it extending from simple window openings to an all-encompassing climatic shell over the building.

The use of new methods of fabrication takes a now defunct architectural form and makes it commercially viable. This is fundamentally important as the incorporation of traditional knowledge into a contemporary sphere is based upon the ability to compete with modern ideas both in terms of cost and effectiveness. The combination of CNC milling and CIM casting allows for large scale production of extremely precise components at relatively minimal cost, enabling the traditional architectural solution to become both architecturally and commercially valid.

By using a CNC router to create component moulds it is possible to greatly increase the accuracy and construction of the mashrabiya. It increased the number of variables that can be manipulated during production and dramatically improves the degree of control that can be had over the functional performance of the screen. With the equations and rules that have been established over the course of this research the effectiveness of the mashrabiya screen can be precisely calculated prior to its production and tailored specifically to each individual site and program.

Finally, new construction processes have not only expanded upon the functionality of the mashrabiya but also increased its versatility. The ease of production allows it to be used to a far greater extent throughout the building such as on the roof and each façade, which has been used in this study to create a climatically perfect 'shell' to encase the entire building. The effect that this has on the interior climate is extreme, creating a microcosm within the desert wherein every aspect of the thermal environment is controlled. This scope of use was never considered possible with the traditional mashrabiya as the constraints implied within 
the construction were too rigid to allow for such ambitious use.

The mashrabiya is but one example of a craft based architectural form which has almost disappeared due to rapid global changes. The work conducted in this study could easily be applied to a variety of other 'lost' architectural forms, simply by using the same analytical process and applying contemporary technology. That which might appear to be redundant on face value could potentially contain valuable knowledge. "Architects must thoroughly analyze traditional building methods and forms using scientific principles and an understanding of social and cultural requirements before discarding any of them." ${ }^{\prime 1}$ If thorough analysis of these elements were to be performed within a modern context the results could be dramatic.

\subsection{Individual Parameters of the Mashrabiya}

There is little doubt that the results of this research have developed the mashrabiya both in terms of its efficiency and versatility. The increased precision and control that is afforded by computer aided production processes has given rise to a whole new set of variables which alter the performance of the mashrabiya in ways which were never previously possible. With so many new variables it becomes possible to tailor a shading mask that is perfectly optimized for the given climatic requirements of a building, determining precisely the heating/cooling attributes of the screen.

It should be noted however that the control of direct light took precedence in this study. This was based upon sound reasoning yet it does lead to the possibility that the other performance attributes were subservient to this factor, such that despite the much greater level of control over each of the functional aspects a degree of interdependency between the variables could have interfered with the final outcome. For example, if the porosity is determined based upon the direct lighting requirements it means that the privacy and airflow aspects are affected as a result. Subsequently, these had to be regulated by strategically placed artificial lighting, offsetting the balusters and through the use of a thermal chimney to ensure some degree of control.

A question can be raised at this stage as to whether the screen that has been developed, in being so different, is still a 'mashrabiya.' The aim of this research was never to replicate the form of the mashrabiya, but rather to tap into the knowledge and functional aspects that it once provided to desert architecture. As a result the new screen is born from a series of rules and principles based upon individual variables rather than an explicit reproduction and the end form is dramatically different to that of the traditional mashrabiya. Since it is being used in a completely new cultural context it may well be a good thing and perhaps even calls for 71 Shearer, p.xvii 
the finding of a new name.

An unexpected result of this study was the extent to which the variables of the mashrabiya could alter the design of the building behind it. The optimum dimensions of the rooms, the offset of split levels, the size of the thermal chimneys and the height/length ratio of the openings all change as the mashrabiya is altered. This result was unexpected yet pleasing. It meant that in designing the Giles Weather station the architectural form could be subservient to the design of the screen, which is unusual yet reveals the enormous impact each of these variables can have on the ultimate performance of the building.

The depth of this research lies in the fact that it can be almost universally applied beyond the Giles Weather Station. The efficiency and control of the mashrabiya has been dramatically increased in this study due to the creation of a series of rules and equations which can determine precisely the practical performance of the screen during its design phase, regardless of the location or function of the building. In fact, there is a possibility that this form of screen could work even more successfully within more moderate climates. As the mashrabiya has already been optimized over hundreds of years as a passive cooling mechanism within the traditional Middle Eastern dwelling the number of improvements that could be made to the cooling aspect was limited. However, a lot has been done in this study to improve its heating efficiency within the winter months of the year. If this screen were to be applied to a milder climate where a significant amount of the year was too cold it could potentially be even more successful at stabilising the overall temperature than just in its application to excess heat.

\subsection{Giles Weather Station}

The Giles Weather Station can be treated as a case study for the wider application of the screen. The design and layout was produced to test the conditions within which the mashrabiya is known to operate most effectively. As such it is designed in accord with certain strategies that have been developed over countless years within traditional Middle Eastern desert architecture: the use of sunken courtyards, tightly packed dwellings and large earth walls are all proven ways of reducing the excessive summer heat.

However, the use of a mashrabiya 'shell' to cover the entire building is an ambitious shift from its use in traditional window openings to the creation of a climatically perfect microcosm within which the building exists. The research conducted into the parameters and function of the mashrabiya has resulted not only in a new approach to the mashrabiya, but also to desert architecture itself. The all-encompassing 'shell' changes the response of the building to the desert conditions in a manner that was unexpected, yet pleasing. This was only made 
possible due to the analysis performed at the beginning of this study.

One of the main issues faced early on in the design of the Giles Weather Station concerned the adoption of a building element unique to one particular location and culture and transferring it to a completely new country and cultural context. However, it is clear that the extreme heat and light problems faced within the Gibson Desert have already been dealt with successfully by the mashrabiya in the Middle East. As Walter Shearer points out, "it would be of great benefit [if] societies with similar conditions could share their traditional solutions to specific problems. Following appraisal, some solutions may be rejected as inappropriate, but a scientific understanding of the principles upon which they are based could serve as a useful foundation upon which to develop new solutions more in keeping with the local economics, environment, and society than those that have replaced the traditional ones."72 This is really what is being transferred between these two locations- not the mashrabiya itself, but rather the principles upon which it is based- which can be seen in the substantial difference between the screens in the two locations, both visually and in application. Additionally, the Giles building and screens have been designed to reflect both the location and climate. The use of the red soil gathered from the site to make the huge rammed earth walls, the low lying forms, the patterning and many more aspects have been developed to echo the specific identity of the site. Although many of these solutions were based upon Middle Eastern building traditions the final outcome is a unique and independent building designed to reflect its Australian context.

72 Shearer, p.xvii 
Chapter 7: Conclusion 


\section{Conclusion}

The aim of this research was to fully investigate a traditional architectural element, the mashrabiya, and determine whether it could be applied to the contemporary context of the Giles Weather Station in the Gibson Desert of Australia. This required an understanding of its functional and social significance within traditional desert architecture along with a direct analysis of its performance variables. To become a viable feature the construction process had to be completely rethought, and was done so with the use of computer aided manufacturing. This combination of traditional architectural knowledge with contemporary production processes produced surprisingly dramatic results, changing the form, performance and overall versatility of the mashrabiya. It allowed an expensive and rare window screen to become a much more significant architectural feature that defined the form and spatial qualities of the entire Giles Weather Station.

As a result of this study the Giles Weather Station became unique in its form and climatic functionality and hence far more effective and architecturally appropriate for the context of the Gibson Desert. The building is unlike anything else in the Gibson Desert and is capable of controlling the internal environment in a manner that is far more ambitious than was able to be attempted in the traditional use of the mashrabiya. The weather station has becomes iconic as a result of this research, an example of the expressive and aesthetic qualities that can be born from a logical investigation of function and performance. And indeed, the visual qualities of the screen seem almost to outweigh its functional merits, in that they provide a stunningly unique form of architectural expression to the building in the shape of delicate lace-like patterns shrouding the form. The fact that the aesthetics are driven primarily by a desire for functional performance only adds to their appeal. This intricacy of detail was one of the endearing attributes of the traditional mashrabiya that is so sorely lacking in the contemporary alternatives of mechanically driven cooling systems such as air conditioners. If for no other reason, this study can be counted as a success in that it created a functional and practical solution to a critically important climatic problem that still engaged with the much wider idea of architectural beauty.

The use of the mashrabiya as a climatic 'shell' over the entirety of the building is testament to how much more versatile it has become due to the research conducted. The use of the screen transcends its traditional application and becomes much more engaged with the totality of the architectural solution in Giles, becoming intrinsically linked with the wellbeing and the daily experience of the occupants. It creates a microcosm within which the building can exist, a perfect environment that has been precisely controlled through the manipulation of a few small variables. This method of creating an entirely new climatic zone within which 
the building itself can exist is a far cry from both the traditional architecture of the Middle East and more contemporary examples of desert architecture. Although it was never the intended outcome, the research has not only reinterpreted the mashrabiya but taken a new look at the architectural response to extreme climate. The fact that this was possible was due to conducting in-depth analysis of traditional knowledge and combining that analysis with the design potential afforded through contemporary technology. This drove the design of the mashrabiya in a completely new and unexpected direction, and the Giles Weather Station was greatly enhanced as a result. 
Angus, T. C. Control of indoor climate

Oxford, Pergamon Press, 1968

Aronson, Shlomo ed. Aridscapes : proyectar en tierras ásperas y frágiles = de signing in harsh and fragile lands

Barcelona, GG, 2008

Boutet, Terry S. Controlling air movement- A manual for architects and builders New York, McGraw-Hill, c1987

Bowen, Arthur, Eugene Clark and Kenneth Labs, eds. Passive cooling Newark, American Section of the International Solar Energy Society, c1981

Briggs, Martin S. Muhammadan architecture in Egypt and Palestine New York, Da Capo Press, 1974

Brown. G.Z. Sun, wind, and light : architectural design strategies New York, Wiley, c1985

Cook, Jeffrey (ed.) Passive cooling systems

Cambridge: MIT Press, c1989

Coonley, Douglas R. Design with wind Harrisville, Total Environment Action, 1974

Fathy, Hassan. Natural energy and vernacular architecture : principles and examples with reference to hot arid climates Chicago, University of Chicago Press, 1986

Gandemer, Jacques, and Alain Guyot. La Protection Contre Le Vent Paris, CSTB, 1981

Ghiaus, Cristian and Francis Allard, eds. Natural ventilation in the urban environment : assessment and design Sterling, Earthscan, 2005

Giles, Ernest. Australia twice traversed : the romance of exploration, being a narrative compiled from the journals of five exploring expeditions into and through cen tral South Australia and Western Australia, from 1872 to 1876 Adelaide, Libraries Board of South Australia, 1964

Golany, Gideon, ed. Desert planning : international lessons London, Architectural Press, 1982

Gombrich, E.H. Sense of order : a study in the psychology of decorative art Oxford, Phaidon, c1979

Hefuna, Susan. Xcultural codes Heidelberg, Kehrer, c2004

Joy, Rick. Desert Works New York, Princeton Architectural Press, 2002

Kolarevic, Branko and Kevin R. Klinger, eds. Manufacturing material effects : rethinking design and making in architecture New York, Routledge, 2008

Koch-Nielsen, Holger. Stay cool: a design guide for the built environment in hot climates London, James \& James, 2002 
Konya, Allan. Design primer for hot climates

London, Architectural Press, 1980

Lane, Edward William. An account of the manners and customs of the modern Egyptians: written in Egypt during the years 1833-1835

London, A. Gardner, 1895

Lefteri, Chris. Ceramics: Materials for inspirational design

Hove, RotoVision, 2003

McCullough, Malcolm. Abstracting craft: the practiced digital hand Cambridge, MIT Press, c1996.

Moss, Keith. Heat and mass transfer in buildings

London, Taylor \& Francis, 2007

Olgyay, Victor. Design with climate: bioclimatic approach to architectural regionalism Princeton, Princeton University Press, 1963

Pye, David. The nature and art of workmanship London, Cambridge U.P., 1968

Richards, J.M., Ismail Serageldin and Darl Rastorfer. Hassan Fathy Singapore, Concept Media, c1985

Sakr, Tarek Mohamed Refaat. Early twentieth-century Islamic architecture in Cairo Cairo, American University in Cairo Press, c1993

Santamouris, M., and D. Asimakopoulos, eds. Passive cooling of buildings London, James \& James, c1996

Steele, James. Architecture for people: The complete work of Hassan Fathy London, Thames and Hudson, 1997

Yannas, Simos, ed. Passive and low energy architecture: proceedings of the Second Inter national PLEA Conference, Crete, Greece, 28 June-1 July 1983 Oxford, Pergamon Press, 1983

\section{Journal Articles}

AI-Azzawi, Subhi. Indigenous courtyard houses: A comprehensive checklist for identify ing, analysing and appraising their passive solar design characteristics Published in: Renewable Energy, Vol.5, 1994, pp. 1099-1123

Al-Shareefa, F.M., D.J. Oldhamb and D.J. Carter. A computer model for predicting the day light performance of complex parallel shading systems

Published in: Building and Environment 36, 2001, pp. 605-618

Alp, Ahmet Vefik. Vernacular climate control in desert architecture Published in: Energy and Buildings Volume 16, Issues 3-4, 1991, pp. 809-815

Batty, W.J., H. Al-Hinai and S.D. Probert. Natural-cooling techniques for residential build ings in hot climates

Published in: Applied Energy Volume 39, Issue 4, 1991, pp. 301-337

Baroum, A.H. Energy responses to vernacular shelter and settlement in continental Mo rocco, North Africa

Published in: Passive and Low Energy Architecture-Proceedings of the second inter national PLEA Conference Crete, 28 June-1 July 1983, 1983, pp.265-272 
Bofah, K.K. and K.G. Al-Hinai. Field tests of porous fences in the regime of sand-laden wind Journal of Wind Engineering and Industrial Aerodynamics, Volume 23, 1986, pp. 309-319

Badawy, Alexander. Architectural Provision against Heat in the Orient Published in: Journal of Near Eastern Studies, Vol. 17 No. 2, Apr. 1958, pp. 122-128

Belakehal, K., Tabet Aoul and A. Bennadji. Sunlighting and daylighting strategies in the traditional urban spaces and buildings of the hot arid regions Published in: Renewable Energy 29, 2004, pp. 687-702

Ben-Hamouche, Mustapha. Climate, cities and sustainability in the Arabian region: com pactness as a new paradigm in urban design and planning IJAR, Vol. 2 Issue 2, July 2008, pp. 196-208

Fardeheb, Fewzi. Examination and review of passive solar cooling strategies in Middle Eastern and North African vernacular architecture Published in: Proceedings of ISES World Congress 2007 (Vol. I - Vol. V), 2009, pp. 2511-2515

Gallo, Cettina. Passive cooling as design methodology: some examples from the past to the present.

Published in: Renewable Energy, Vol. 8, Issues 1-4, 1996, pp. 309-314

Gelil, Nermine Abdel. A new mashrabiyya for contemporary Cairo: Integrating tradition al latticework from Islamic and Japanese cultures

Published in: Journal of Asian Architecture and Building Engineering, Vol.5 no.1, 2006, pp. 37-44

Gupta, Vinod. Natural Cooling Systems of Jaisalmer

Published in: Architectural Science Review, Vol.28 No.3, 1985, pp.58-64

Jekot, Barbara P. Selected study of architectural envelopes controlling sun radiation - the integration of nature into design

Published in: South African Journal of Art History, Vol. 23 no.3, 2008, pp 56-65.

Kenzari, Bechir and Yasser Elsheshtawy. The Ambiguous Veil: On Transparency, the Mashrabiy'ya, and Architecture

Published in: Journal of Architectural Education, Vol. 56 Issue 4, 2003, pp.17-25

Khattab, Omar. Reconstruction of Traditional Architecture: A Design Education Tool Published in: GBER, Vol. 2 No 2, 2002, pp 29-39

Miguel, Anthio F. Airflow through porous screens: from theory to practical considerations Published in: Energy and Buildings 28, 1998, pp. 63-69

Salloum, A. "El Rawashin" of Jeddah, Saudi Arabia

Published in: Passive and Low Energy Architecture-Proceedings of the second inter national PLEA Conference Crete, 28 June-1 July 1983, 1983, pp. 245-252

Talib, K. Review of climatic design concepts and details in traditional architecture in various climatic zones - Saudi Arabia

Published in: Passive and Low Energy Architecture-Proceedings of the second inter national PLEA Conference Crete, 28 June-1 July 1983, 1983, pp.233-244

Oliveira, Fernando and Leonardo Bittencourt. Air flow through louvered windows in small rooms

Published in: Environmentally Friendly Cities, Proceedings of the Fifteenth PLEA 98 International Conference (Lisbon, Portugal, June 1-3), James \& James, London, pp393-396 
Saranti, K. Air moving in and through building: historical prototypes and contemporary applications

International Workshop on Energy Performance and Environmental Quality of

Buildings, July 2006, Milos island, Greece

Akbar, Sameer. The Diminishing Role of Windows from Traditional to Modern: The Case of Jeddah, Saudi Arabia

Role of windows in Saudi Arabia, 1994, p. 16-21.

\section{Academic Papers}

Al-Shareef, F.M. Natural light control in Hadjazi architecture : an investigation of the Rowshan performance by computer simulation.

Liverpool Univ. (United Kingdom) 1996

Weenink, Jenny. Hassan Fathy : the re-interpretation of traditional architecture Wellington, Victoria University, 1989.

Aljofi, E. The potentiality of reflected sunlight through Rawshan screens International Conference."Passive and Low Energy Cooling 817 for the Built Environment.", May 2005, Santorini, Greece

other

Storm Boys. Report on Giles Weather Station shown on Landline, ABC network, 2006. Reporter: Tim Lee

http://www.abc.net.au/landline/content/2006/s2274308.htm

'Shading and sun control.' Publication by the American Institute of Architects Washington, D.C. The Institute, 1981 
Fig. 1- The Gibson Desert of central Australia http://www.flickr.com/photos/garry61/484989211/

Fig. 2-Residentual units at the Giles Weather Station http://www.bom.gov.au/sa/giles/photos.shtml

Fig. 3- Mashrabiya used within a building in Cairo, Egypt http://www.flickr.com/photos/jamalaly/99638435/

Fig. 4-Ancient mud building within the Egyptian Desert http://upload.wikimedia.org/wikipedia/commons/7/7c/Desert_building-dakhlaegypt.jpg

Fig. 5- The Bayt Al-Suhaymi house in Cairo http://egyptfan.blogspot.com/2010/04/beit-el-sehemy-house-of-sehemy.html

Fig. 6- Inside the Bayt Al-Suhaymi http://www.flickr.com/photos/ahmedalbadawyshots/4674462452/

Fig. 7- Examples of different styles and patterns of mashrabiya found within Cairo. Briggs, Martin S. Muhammadan Architecture in Egypt and Palestine. p.213

Fig. 8-Craftsmen in Cairo turning the lengthy primary balusters on a lathe www.sainttropezboutique.us/products/architectural/wood-lattice-screens.aspx

Fig. 9- A small section of a mashrabiya, held in place with elastic bands www.touregypt.net/featurestories/mashrabiya.htm

Fig. 10- Decaying mashrabiya in Eritrea www.flickr.com/photos/mytripsmypics/412412797/

Fig. 11- Mashrabiya inspired screens on Jean Nouvel's Institut du Monde Arabe in Paris www.flickr.com/photos/jmvnoos/3511977075/

Fig. 12- Interior view of Institut du Monde Arabe in Paris www.paris-lavillette.archi.fr/site-forum/2003-2004/IMA.htm

Fig. 13- Detail view of Institut du Monde Arabe in Paris images.france-for-visitors.com/images/large/institut-du-monde-arabe.jpg

Fig. 14- Heating, cooling and solar degree hours for Giles

Fig. 15- Mashrabiya casting shadows within a building www.flickr.com/photos/helenromberg/361457014/

Fig. 16- Mashrabiya allowing ambient light within a building www.flickr.com/photos/32038542@N07/4009984164/

Fig. 17-Plan and elevation of a mashrabiya baluster Fathy, Hassan. Natural Energy and Vernacular Architecture p.91

Fig. 18- A town in Pakistan utilising wind catchers or 'malqafs' Fathy, Hassan. Natural Energy and Vernacular Architecture p.114

Fig. 19-Porous clay water jar used to cool the air Konya, Allan. Design primer for hot climates p.57

Fig. 20-Psychrometric chart for Giles Autodesk weather tool

Fig. 21- External view of a mashrabiya Fathy, Hassan. Natural Energy and Vernacular Architecture p.100

Fig. 22- Internal view of the same mashrabiya Fathy, Hassan. Natural Energy and Vernacular Architecture p.101

Fig. 23-View of an ancient street lined with mashrabiyas www.davidrobertslithographs.com

Fig. 24- Screen carved from plaster by a computer numerically controlled (CNC) router

Fig. 25- Traditional Mashrabiya Typology

Fig. 26- Stereographic diagrams

Fig. 27-Baluster Diameter/Length Ratio Analysis

Fig. 27a-D/L Ratio

Fig. 27b-Giles Weather Station

Fig. 27c- Test Screen

Fig. 27d-Results

Fig. 28-Baluster Angle Analysis

Fig. 28a-Baluster Angle

Fig. 28b- Test Screen

Fig. 28c- Results

Fig. 29- Baluster Section Analysis

Fig. 29a-Baluster Section

Fig. 29b- Test Screen

Fig. 29c- Results

Fig. 30-Single and Double layered mashrabiyas 
Fig. 31- Sectional Layer Analysis

Fig. 31a-Sectional Layer

Fig. 31b- Test Screen

Fig. 31c- Results

Fig. 32-Baluster Offset Analysis

Fig. 32a-Baluster Offset

Fig. 32b-Test Screen

Fig. 33- Test Patterns

Fig. 34- Tiled ceramic wall by OMC

http://www.omcdesign.com/index.php? $m=16 \& s=1$

Fig. 35-Semi-translucent ceramic sculpture by Margaret O'Rorke

http://www.caa.org.uk/exhibitions/archive/2006/take-me-home/margaretororke.html

Fig. 36- The final mashrabiya design

Fig. 37- Shadow diagram for June 21

Fig. 38-Basic mashrabiya component

Fig. 39- Component tiling arrangement

Fig. 40- Joint connection detail

Fig. 41-Component Tessellations

Fig. 42- CNC Milling of the inverted component mould

Fig. 43-Inverted mould ready for ceramic injection.

Fig. 44- CIM production machine

Fig. 45-Structural Bracing Layer

Fig. 46- Various scales of detail within the final screen design

Fig. 47- Roof Screen Model

Fig. 48- Roof Screen (bottom)

Fig. 49- Roof Screen (top)

Fig. 50- Misting spray

www.microcool.com/outdoor-cooling/

Fig. 51- A house within an American desert cooled through the use of fine misting sprays www.microcool.com/outdoor-cooling/

Fig. 52- Misting Spray Points

Fig. 53- Thermal chimney design

Fig. 54- Relationship between mashrabiya porosity and thermal chimney height

Fig. 55- Height/Width ratio analysis

Fig. 56- Architectural Analysis

Fig. 57- Conceptual Layout

Fig. 58- Combined Scheme

Fig. 59- Exploded Axonometric

Fig. 60-Plan

Fig. 61-Model Photographs

Fig. 62- Lighting Model

Fig. 63- Bas-Relief Studies

Fig. 64- Western Elevation

Fig. 65- Exploded Sectional Perspective

Fig. 66-Sectional Perspective

Fig. 67-Perspective

Fig. 68-Internal Perspective

Fig. 69- External Perspective

Fig. 70-Psychrometric Chart

Fig. 71- Climate Data

Fig. 72- Direct Solar Radiation (January - June)

Fig. 73-Average Temperature (January - June)

Fig. 74- Direct Solar Radiation (July - December)

Fig. 75-Average Temperature (July - December)

Fig. 76- Average Wind Speed

Fig. 77- 'D/L ratio' test screen results for direct solar radiation

Fig. 78- 'D/L ratio' test screen results for solar shading

Fig. 79- 'Baluster angle' test screen results for direct solar radiation

Fig. 80- 'Baluster angle' test screen results for solar shading

Fig. 81- 'Baluster section' test screen results for direct solar radiation

Fig. 82- 'Baluster section' test screen results for solar shading

Fig. 83- 'Sectional layers' test screen results for direct solar radiation

Fig. 84- 'Sectional layers' test screen results for solar shading

Fig. 85- Annual solar radiation for final screen 


\section{Appendix 1}

Giles Weather Data 
Monthly Climate Statistics for 'GILES METEOROLOGICAL OFFICE' [013017]

Created on [ 15 Feb 2011 00:56:03 GMT+00:00]

Commenced: 1956. Last Record: 2011. Latitude: 25.03 Degrees South. Longitude: 128.30 Degrees East. Elevation: $598 \mathrm{~m}$

Data accessed from: Australia Bureau of Meteorology, www.bom.gov.au/climate/averages/tables/cw_013017.shtml

\begin{tabular}{|c|c|c|c|c|}
\hline Statistic Element & January & February & March & April \\
\hline Mean maximum temperature (Degrees C) for years 1956 to 2010 & 37.3 & 36 & 33.8 & 29.4 \\
\hline Highest temperature (Degrees C) for years 1956 to 2010 & 44.5 & 44.4 & 42.2 & 38.3 \\
\hline Date of Highest temperature for years 1956 to 2010 & 2-Jan-73 & 7-Feb-94 & 6-Mar-59 & 1-Apr-09 \\
\hline Lowest maximum temperature (Degrees C) for years 1956 to 2010 & $\begin{array}{r}19.1 \\
\end{array}$ & 18.1 & 15.1 & 14.2 \\
\hline Date of Lowest maximum temperature for years 1956 to 2010 & 11-Jan-83 & $28-F e b-87$ & 26-Mar-82 & 20-Apr-00 \\
\hline Decile 1 maximum temperature (Degrees C) for years 1956 to 2010 & 32.4 & 30.6 & 28.1 & 24 \\
\hline Decile 9 maximum temperature (Degrees C) for years 1956 to 2010 & 41.3 & 40.3 & 38.4 & 34.3 \\
\hline Mean number of days >= 30 Degrees C for years 1956 to 2010 & 29.7 & 25.9 & 26 & 14.6 \\
\hline Mean number of days >= 35 Degrees C for years 1956 to 2010 & 24.1 & 19 & 13.7 & 2.1 \\
\hline Mean number of days >= 40 Degrees C for years 1956 to 2010 & 6.8 & 4 & 0.8 & 0 \\
\hline Mean minimum temperature (Degrees C) for years 1956 to 2010 & 23.5 & 22.9 & 20.6 & 16.5 \\
\hline Lowest temperature (Degrees C) for years 1956 to 2010 & 11.7 & 9.8 & 8.9 & 5.4 \\
\hline Date of Lowest temperature for years 1956 to 2010 & 13-Jan-83 & 23-Feb-67 & 25-Mar-01 & 23-Apr-70 \\
\hline Highest minimum temperature (Degrees C) for years 1956 to 2010 & 32.1 & 31.2 & 30.4 & 27.4 \\
\hline Date of Highest minimum temperature for years 1956 to 2010 & 3-Jan-90 & $18-F e b-65$ & 6-Mar-86 & 2-Apr-86 \\
\hline Decile 1 minimum temperature (Degrees C) for years 1956 to 2010 & 19.3 & 18.5 & 15.9 & 11.3 \\
\hline Decile 9 minimum temperature (Degrees C) for years 1956 to 2010 & 27.5 & 27.1 & 25.2 & 21.4 \\
\hline Mean number of days <= 2 Degrees C for years 1956 to 2010 & 0 & 0 & 0 & 0 \\
\hline Mean number of days <= 0 Degrees C for years 1956 to 2010 & 0 & 0 & 0 & 0 \\
\hline Mean daily ground minimum temperature Degrees C for years 1956 to 2010 & 22 & 21.6 & 19 & 14.6 \\
\hline Lowest ground temperature Degrees C for years 1956 to 2010 & 9.5 & 9.1 & 6.2 & 3.4 \\
\hline Date of Lowest ground temperature for years 1956 to 2010 & 13-Jan-83 & 23-Feb-67 & 17-Mar-81 & 23-Apr-70 \\
\hline Mean number of days ground min. temp. <= -1 Degrees C for years 1956 to 2010 & 0 & 0 & 0 & 0 \\
\hline Mean rainfall (mm) for years 1956 to 2011 & 29.1 & 44.4 & 35.3 & 16.3 \\
\hline Highest rainfall (mm) for years 1956 to 2011 & 122 & 312.2 & 330.6 & 123.8 \\
\hline Date of Highest rainfall for years 1956 to 2011 & 1973 & 1974 & 1989 & 2000 \\
\hline Lowest rainfall $(\mathrm{mm})$ for years 1956 to 2011 & 0 & 0 & 0 & 0 \\
\hline Date of Lowest rainfall for years 1956 to 2011 & 1965 & 2005 & 1997 & 2005 \\
\hline Decile 1 monthly rainfall (mm) for years 1956 to 2011 & 2.5 & 0.9 & 0.1 & 0 \\
\hline Decile 5 (median) monthly rainfall (mm) for years 1956 to 2011 & 20.2 & 20.8 & 13.6 & 6.1 \\
\hline Decile 9 monthly rainfall $(\mathrm{mm})$ for years 1956 to 2011 & 61.3 & 127.3 & 84.6 & 36.8 \\
\hline Highest daily rainfall (mm) for years 1956 to 2011 & 104.2 & 217.2 & 121.6 & 54.2 \\
\hline Date of Highest daily rainfall for years 1956 to 2011 & 11-Jan-83 & 22-Feb-74 & 13-Mar-89 & 6-Apr-74 \\
\hline Mean number of days of rain for years 1800 to 3000 & 5.4 & 5.3 & 4.3 & 2.9 \\
\hline Mean number of days of rain >= $1 \mathrm{~mm}$ for years 1956 to 2011 & 3.9 & 4 & 3 & 1.9 \\
\hline Mean number of days of rain >= $10 \mathrm{~mm}$ for years 1956 to 2011 & 0.9 & 1.1 & 1 & 0.5 \\
\hline Mean number of days of rain >= $25 \mathrm{~mm}$ for years 1956 to 2011 & 0.2 & 0.3 & 0.4 & 0.1 \\
\hline Mean daily wind run $(\mathrm{km})$ for years 1956 to 2010 & 361 & 360 & 344 & 311 \\
\hline Maximum wind gust speed (km/h) for years 1956 to 2010 & 113 & 122 & 95 & 85 \\
\hline Date of Maximum wind gust speed for years 1956 to 2010 & 6-Jan-75 & 14-Feb-86 & 13-Mar-69 & 6-Apr-90 \\
\hline Mean daily sunshine (hours) for years 1956 to 2010 & 10.2 & 9.5 & 9.4 & 9.1 \\
\hline Mean daily solar exposure $\left(\mathrm{MJ} /\left(\mathrm{m}^{*} \mathrm{~m}\right)\right)$ for years 1990 to 2011 & 27.9 & 25.1 & 23 & 19.1 \\
\hline Mean number of clear days for years 1978 to 2010 & 13.5 & 10.8 & 14.2 & 14.1 \\
\hline Mean number of cloudy days for years 1978 to 2010 & 6.8 & 7.9 & 7.3 & 6.4 \\
\hline Mean daily evaporation (mm) for years 1967 to 2010 & 14.5 & 13 & 11.3 & 8.4 \\
\hline Mean 9am temperature (Degrees C) for years 1978 to 2010 & 26.9 & 25.7 & 23.8 & 21.1 \\
\hline Mean 9am wet bulb temperature (Degrees C) for years 1978 to 2010 & 17.3 & 17.3 & 15.5 & 13.4 \\
\hline Mean 9am dew point temperature (Degrees C) for years 1978 to 2010 & 9 & 10.2 & 7.6 & 5.6 \\
\hline Mean 9am relative humidity (\%) for years 1978 to 2010 & 38 & 44 & 41 & 41 \\
\hline Mean 9am cloud cover (okas) for years 1978 to 2010 & 3 & 3.4 & 2.9 & 3 \\
\hline Mean 9am wind speed (km/h) for years 1956 to 2010 & 17.5 & 15.1 & 14.9 & 13.8 \\
\hline Mean 3pm temperature (Degrees C) for years 1978 to 2010 & 35.3 & 34.2 & 32 & 28.4 \\
\hline Mean 3pm wet bulb temperature (Degrees C) for years 1978 to 2010 & 19.7 & 19.8 & 18.2 & 15.9 \\
\hline Mean 3pm dew point temperature (Degrees C) for years 1978 to 2010 & 7 & 8.3 & 6.1 & 3.8 \\
\hline Mean 3pm relative humidity (\%) for years 1978 to 2010 & 21 & 25 & 24 & 24 \\
\hline Mean 3pm cloud cover (oktas) for years 1978 to 2010 & 3.4 & 3.9 & 3.4 & 3.2 \\
\hline Mean 3pm wind speed $(\mathrm{km} / \mathrm{h})$ for years 1956 to 2010 & 15.4 & 14.9 & 14.5 & 13.5 \\
\hline
\end{tabular}




\begin{tabular}{|c|c|c|c|c|c|c|c|c|c|c|c|}
\hline May & June & July & August & September & October & November & December & Annual & $\begin{array}{l}\text { Number of } \\
\text { Years }\end{array}$ & Start Year & End Year \\
\hline 23.7 & 20.3 & 20 & 22.5 & 27.3 & 31.6 & 34.3 & 35.7 & 29.3 & 54 & 1956 & 2010 \\
\hline 33.9 & 29.9 & 30.8 & 33.2 & 38.2 & 41.6 & 43.9 & 44.8 & 44.8 & 54 & 1956 & 2010 \\
\hline 1-May-90 & 1-Jun-91 & 30-Jul-08 & 24-Aug-95 & 30-Sep-98 & $29-$-oct-77 & 17-Nov-09 & 27-Dec-86 & 27-Dec-86 & $\mathrm{N} / \mathrm{A}$ & 1956 & 2010 \\
\hline 10.6 & 12.1 & 9.2 & 9 & 11.4 & 15.4 & 17.8 & 16.7 & 9 & 54 & 1956 & 2010 \\
\hline 26-Мay-64 & 22-Jun-81 & 11-Jul-97 & 1-Aug-75 & 5-Sep-77 & 3-Oct-75 & 14-Nov-94 & 1-Dec-66 & 1-Aug-75 & $\mathrm{N} / \mathrm{A}$ & 1956 & 2010 \\
\hline 18.8 & 16.4 & 15.7 & 17.6 & 21.2 & 25.6 & 28.4 & 30.6 & & 55 & 1956 & 2010 \\
\hline 28.6 & 24.6 & 24.6 & 27.8 & 32.8 & 36.9 & 39.4 & 40.3 & & 55 & 1956 & 2010 \\
\hline 1.8 & 0 & 0.1 & 0.8 & 9.5 & 20.8 & 25.3 & 28.5 & 183 & 54 & 1956 & 2010 \\
\hline 0 & 0 & 0 & 0 & 0.7 & 8.2 & 14.5 & 19.6 & 101.9 & 54 & 1956 & 2010 \\
\hline 0 & 0 & 0 & 0 & 0 & 0.2 & 2 & 3.9 & 17.7 & 54 & 1956 & 2010 \\
\hline 11.4 & 8.1 & 6.9 & 8.7 & 12.9 & 17.1 & 19.9 & 21.9 & 15.9 & 54 & 1956 & 2010 \\
\hline 1.8 & -1.6 & -1.1 & -0.6 & 2 & 5.5 & 7 & 9.5 & -1.6 & 54 & 1956 & 2010 \\
\hline 31-Мау-00 & \begin{tabular}{|l|} 
23-Jun-81 \\
\end{tabular} & 17-Jul-61 & 21-Aug-68 & 5-Sep-79 & 24-Oct-75 & 21-Nov-92 & 2-Dec-66 & 23-Jun-81 & N/A & 1956 & 2010 \\
\hline 23.2 & 20.2 & 20.5 & 20.8 & 25.5 & 29.3 & 30 & 31.4 & 32.1 & 54 & 1956 & 2010 \\
\hline 13-Мау-58 & 5-Jun-98 & 29-Jul-75 & 20-Aug-95 & $20-$ Sep-81 & 19-Oct-88 & 23-Nov-87 & 31-Dec-10 & 3-Jan-90 & $\mathrm{N} / \mathrm{A}$ & 1956 & 2010 \\
\hline $\begin{array}{r}6.7 \\
\end{array}$ & 3.3 & 2.6 & 4 & 7.1 & 11.5 & 14.8 & 17.2 & & 55 & 1956 & 2010 \\
\hline 16.2 & 13.1 & 11.7 & 14 & 18.5 & 22.7 & 25 & 26.4 & & 55 & 1956 & 2010 \\
\hline 0 & 0.8 & 1.9 & 0.7 & 0 & 0 & 0 & 0 & 3.4 & 54 & 1956 & 2010 \\
\hline 0 & 0.1 & 0.2 & 0.1 & 0 & 0 & 0 & 0 & 0.4 & 54 & 1956 & 2010 \\
\hline 9.4 & 6.1 & 4.6 & 6.3 & 10.6 & 14.9 & 18.1 & 20.3 & 14 & 54 & 1956 & 2010 \\
\hline-2.4 & -7.2 & -5.8 & -4.2 & -1.1 & 2.9 & 4.1 & 7.8 & -7.2 & 54 & 1956 & 2010 \\
\hline 27-Мay-81 & 23-Jun-81 & 1-Jul-90 & 21-Aug-68 & 13-Sep-78 & $8-0 c t-68$ & 14-Nov-94 & 4-Dec-68 & 23-Jun-81 & $\mathrm{N} / \mathrm{A}$ & 1956 & 2010 \\
\hline 0 & 0.6 & 1.6 & 0.5 & 0 & 0 & 0 & 0 & 2.7 & 54 & 1956 & 2010 \\
\hline 19.8 & 17.5 & 11.7 & 10.6 & 11.5 & 14.6 & 27.6 & 43.8 & 282 & 55 & 1956 & 2011 \\
\hline $\begin{array}{l}93.4 \\
\end{array}$ & 113.9 & 55.2 & 77.6 & 63.2 & 98.4 & 136.4 & 327.4 & 843.4 & 55 & 1956 & 2011 \\
\hline 1988 & 1968 & 1986 & 2005 & 2010 & 1975 & 1991 & 2001 & 2001 & $\mathrm{~N} / \mathrm{A}$ & 1956 & 2011 \\
\hline 0 & 0 & 0 & 0 & 0 & 0 & 0 & 0.8 & 38 & 55 & 1956 & 2011 \\
\hline 2008 & 2010 & 2003 & 2007 & 2007 & 1982 & 1969 & 1961 & 1961 & $\mathrm{~N} / \mathrm{A}$ & 1956 & 2011 \\
\hline 0 & 0 & 0 & 0 & 0 & 0.1 & 1.2 & 5.4 & 142 & 55 & 1956 & 2011 \\
\hline 6.2 & 7.6 & 2.7 & 1.6 & 2.3 & 5.2 & 12.7 & 29 & 250 & 55 & 1956 & 2011 \\
\hline 64.6 & 43.1 & 40.5 & 36.9 & 31.4 & 46.3 & 73.4 & 91.7 & 450 & 55 & 1956 & 2011 \\
\hline 54.6 & 53 & 40.4 & 64.4 & 58.8 & 39.4 & 68.2 & 121.2 & 217.2 & 55 & 1956 & 2011 \\
\hline 24-Мау-92 & 13-Jun-95 & 22-Jul-86 & 27-Aug-05 & 17-Sep-03 & 7-Oct-75 & 22-Nov-91 & 9-Dec-01 & $22-F e b-74$ & $\mathrm{~N} / \mathrm{A}$ & 1956 & 2011 \\
\hline 3.6 & $\begin{array}{r}3.2 \\
\end{array}$ & 2.4 & 2.3 & 2.6 & 3.3 & 5.2 & 6.6 & 47.1 & 55 & 1956 & 2011 \\
\hline 2.4 & 2 & 1.6 & 1.3 & 1.6 & 2.2 & 3.2 & 4.7 & 31.8 & 55 & 1956 & 2011 \\
\hline 0.6 & 0.6 & 0.3 & 0.3 & 0.4 & 0.4 & 0.8 & 1.3 & 8.2 & 55 & 1956 & 2011 \\
\hline 0.1 & 0.1 & 0.1 & 0.1 & 0.1 & 0.1 & 0.2 & 0.4 & 2.2 & 55 & 1956 & 2011 \\
\hline 279 & 270 & 277 & 296 & 332 & 359 & 361 & 368 & 327 & 29 & 1956 & 2010 \\
\hline 82 & 84 & 82 & 84 & 97 & 118 & 139 & 121 & 139 & 53 & 1956 & 2010 \\
\hline 10-May-63 & 19-Jun-86 & 9-Jul-83 & 11-Aug-59 & 28-Sep-68 & 11-Oct-66 & 16-Nov-79 & 6-Dec-71 & 16-Nov-79 & $\mathrm{N} / \mathrm{A}$ & 1956 & 2010 \\
\hline 8.5 & 8.4 & 9 & 9.8 & 10.1 & 10.5 & 10.3 & 9.8 & 9.5 & 54 & 1956 & 2010 \\
\hline 16 & 14.3 & 15.3 & 18.6 & 22.4 & 25.8 & 27.4 & 27.3 & 21.8 & 21 & 1990 & 2011 \\
\hline 16 & 16.7 & 20.8 & 22.8 & 20.6 & 18.4 & 13.7 & 12.7 & 194.3 & 32 & 1978 & 2010 \\
\hline 7.3 & 6.2 & 4.3 & \begin{tabular}{ll|}
3.4 \\
\end{tabular} & 2.6 & 3.7 & 5.7 & 9.1 & 70.7 & 32 & 1978 & 2010 \\
\hline 5.6 & 4.3 & 4.7 & 6.2 & 8.9 & 11.7 & 13.1 & 13.7 & 9.6 & 43 & 1967 & 2010 \\
\hline 15.6 & 11.6 & 10.9 & 13.8 & 19 & 23 & 24.3 & 25.7 & 20.1 & 32 & 1978 & 2010 \\
\hline 10.4 & 7.7 & 6.7 & 7.9 & 10.7 & 13 & 14.7 & 16.6 & 12.6 & 32 & 1978 & 2010 \\
\hline $\begin{array}{ll}4.4 \\
\end{array}$ & 2.7 & 0.7 & \begin{tabular}{|c|}
-0.4 \\
\end{tabular} & 0 & 1.2 & 4.7 & 8.3 & 4.5 & 32 & 1978 & 2010 \\
\hline 51 & 57 & 53 & 42 & 32 & 29 & 34 & 40 & 42 & 32 & 1978 & 2010 \\
\hline 2.8 & 2.6 & 2 & 1.7 & 1.7 & 2 & 2.8 & 3.4 & 2.6 & 32 & 1978 & 2010 \\
\hline 11 & 10.1 & 10.6 & 12.9 & 16.6 & 19.7 & 19 & 18.3 & 15 & 52 & 1956 & 2010 \\
\hline 23 & 19.4 & 19.1 & 21.9 & 26.8 & 30.8 & 32.6 & 33.7 & 28.1 & 32 & 1978 & 2010 \\
\hline 13.2 & 11.1 & 10.3 & 11.3 & 13.5 & 15.6 & 17.2 & 18.8 & 15.4 & 32 & 1978 & 2010 \\
\hline 2.4 & 0.8 & -1.4 & -2.8 & -2.7 & -1.2 & 2.3 & 5.9 & 2.4 & 32 & 1978 & 2010 \\
\hline 30 & 31 & 29 & 22 & 17 & 16 & 18 & 23 & 23 & 32 & 1978 & 2010 \\
\hline 3.1 & 2.7 & 1.9 & 1.6 & 1.9 & 2.6 & 3.4 & $\begin{array}{l}3.7 \\
\end{array}$ & 2.9 & 32 & 1978 & 2010 \\
\hline 13.7 & 14.1 & 15 & 16.1 & 17.5 & 17.7 & 16.7 & 15.4 & 15.4 & 52 & 1956 & 2010 \\
\hline
\end{tabular}




\section{Psychrometric Chart}

Location: Giles, AUS

Frequency: 1st January to 31st December

Weekday Times: 00:00-24:00 Hrs

Weekend Times: 00:00-24:00 Hrs

Barometric Pressure: $101.36 \mathrm{kPa}$

(c) Weather Tool

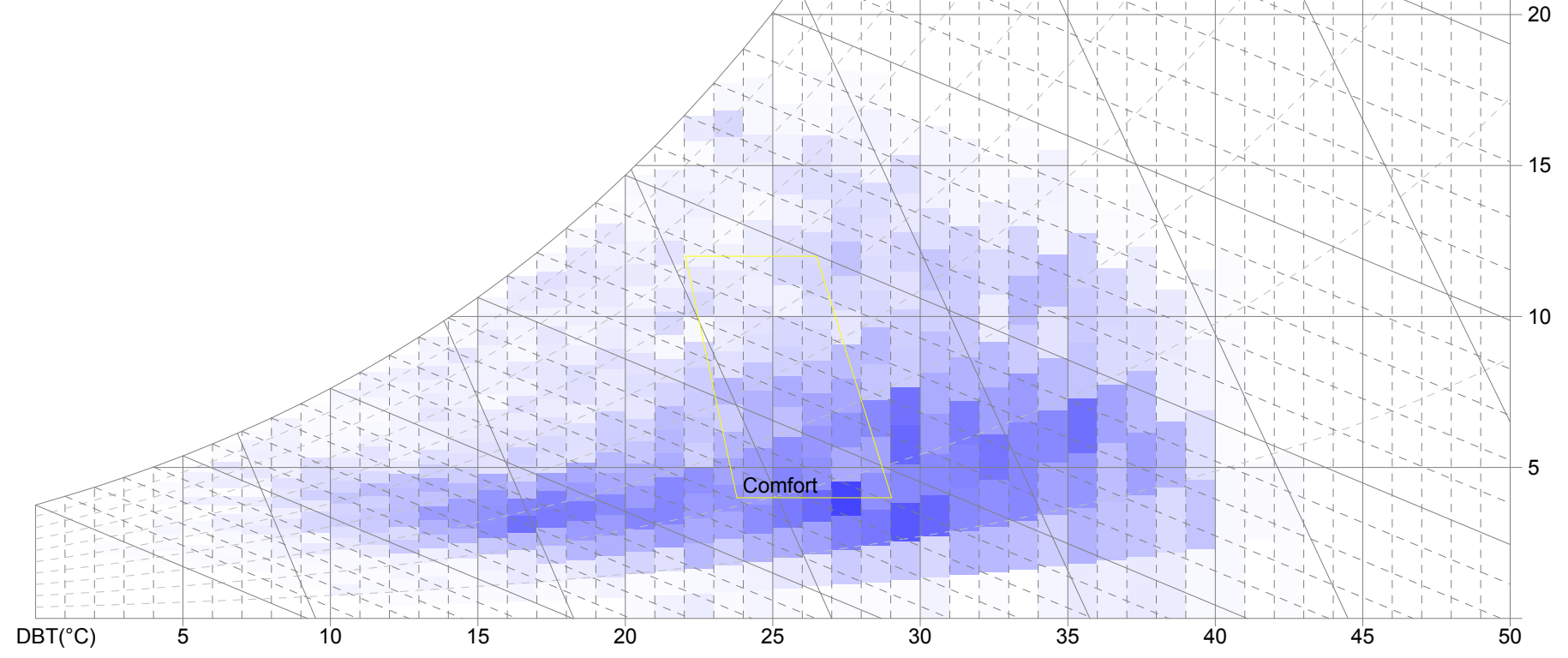

Fig. 70- Psychrometric Chart 


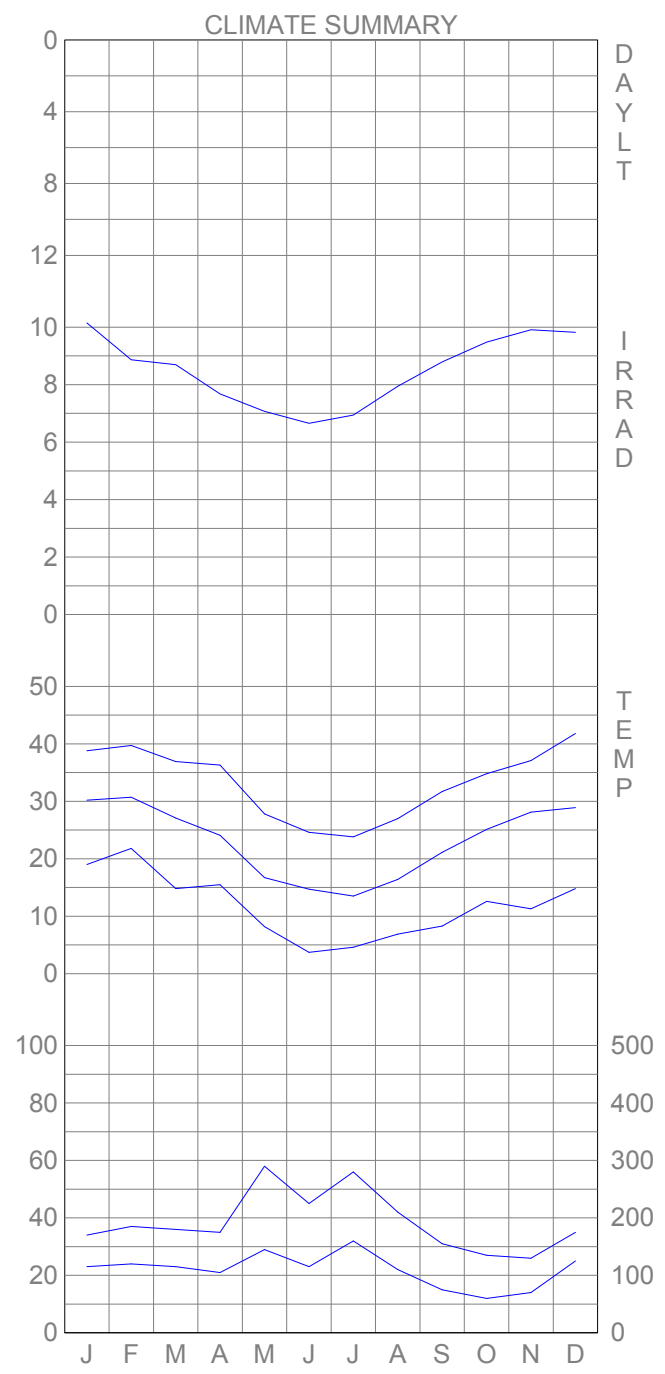

NAME: Giles

LOCATION: AUS

DESIGN SKY: Not Available

LATITUDE: $\mathbf{- 2 5 . 0 ^ { \circ }}$

LONGITUDE: $\mathbf{1 2 8 . 3 ^ { \circ }}$

ALTITUDE: $\mathbf{5 9 8 . 0} \mathbf{~ m}$

TIMEZONE: $\mathbf{+ 8 . 0}$ hrs

(C) Weather Tool
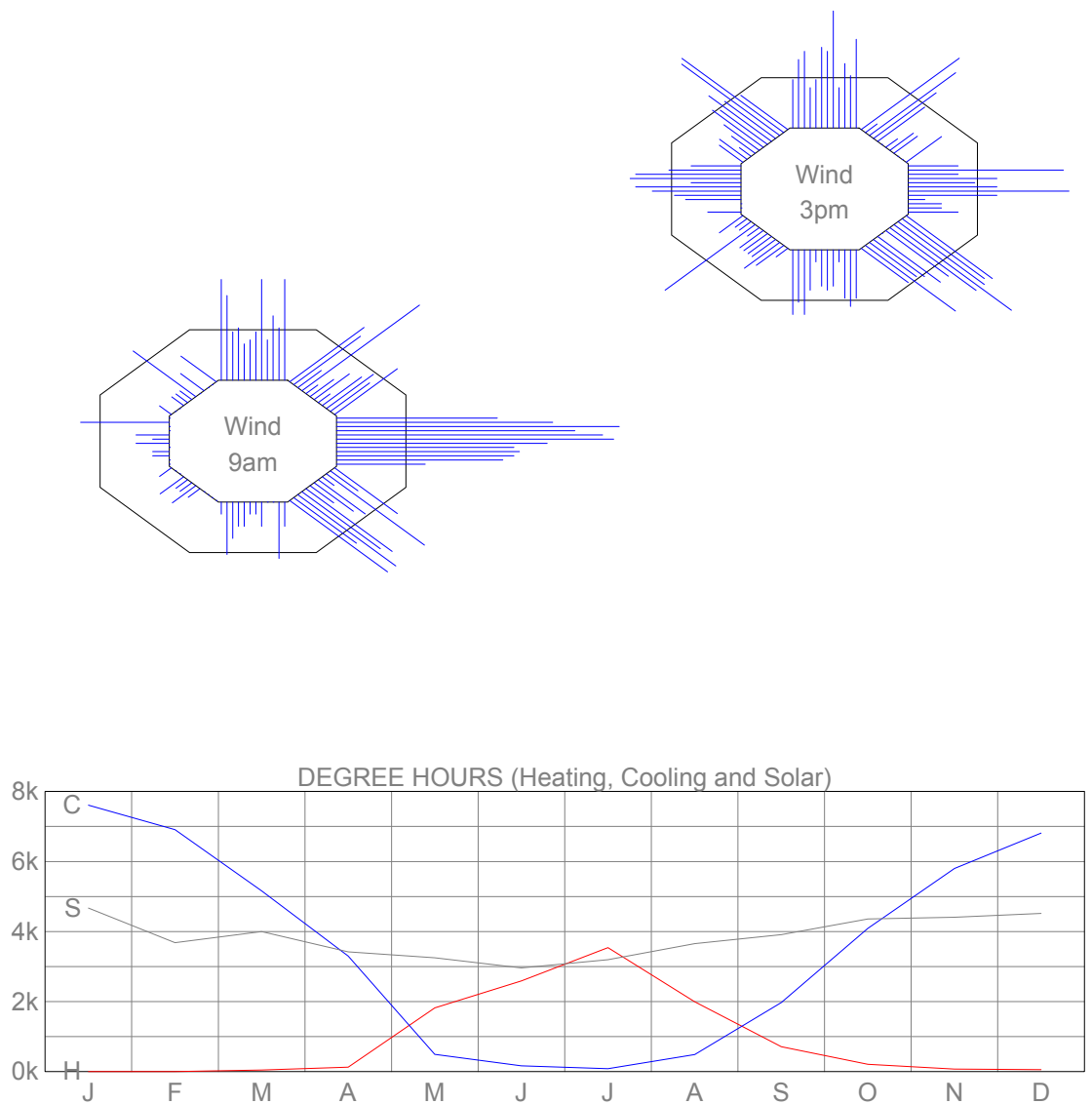

Fig. 71-Climate Data 


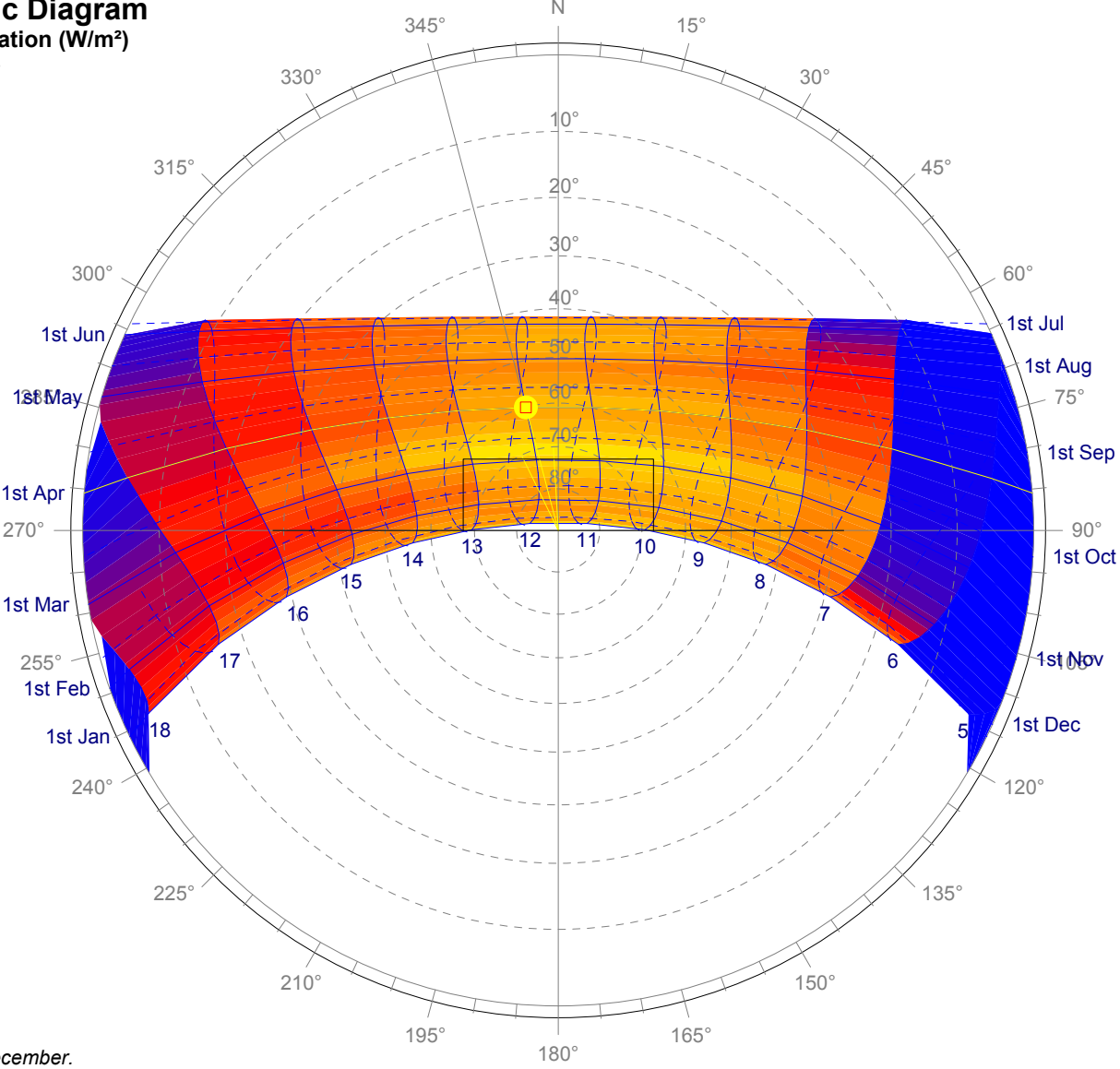

Fig. 72- Direct Solar Radiation (January - June)

Stereographic Diagram

Average Temperature $\left({ }^{\circ} \mathrm{C}\right)$

Location: Giles, AUS

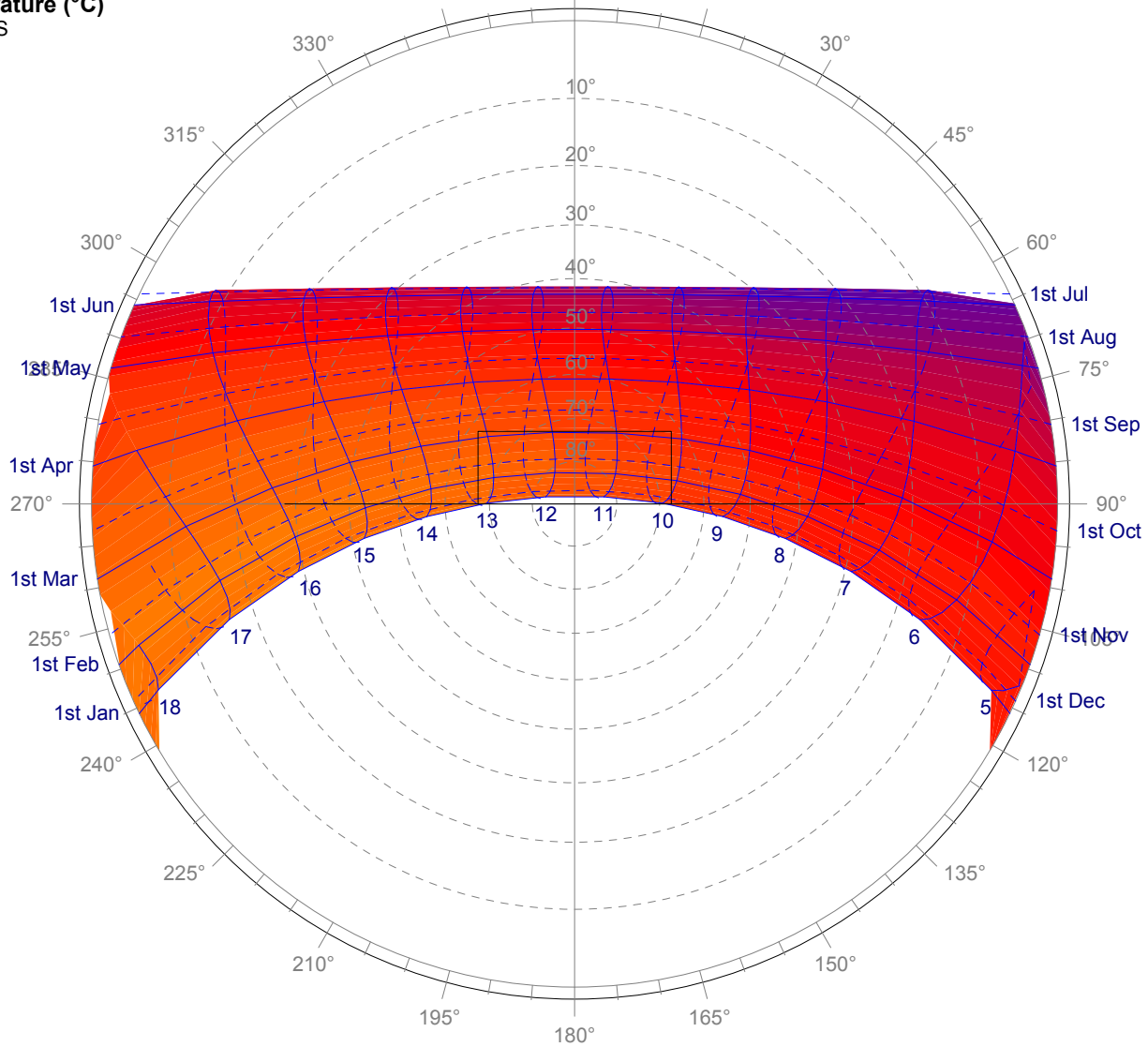

Fig. 73- Average Temperature (January - June) 
Stereographic Diagram Direct Solar Radiation $\left(\mathrm{W} / \mathrm{m}^{2}\right)$ Location: Giles, AUS

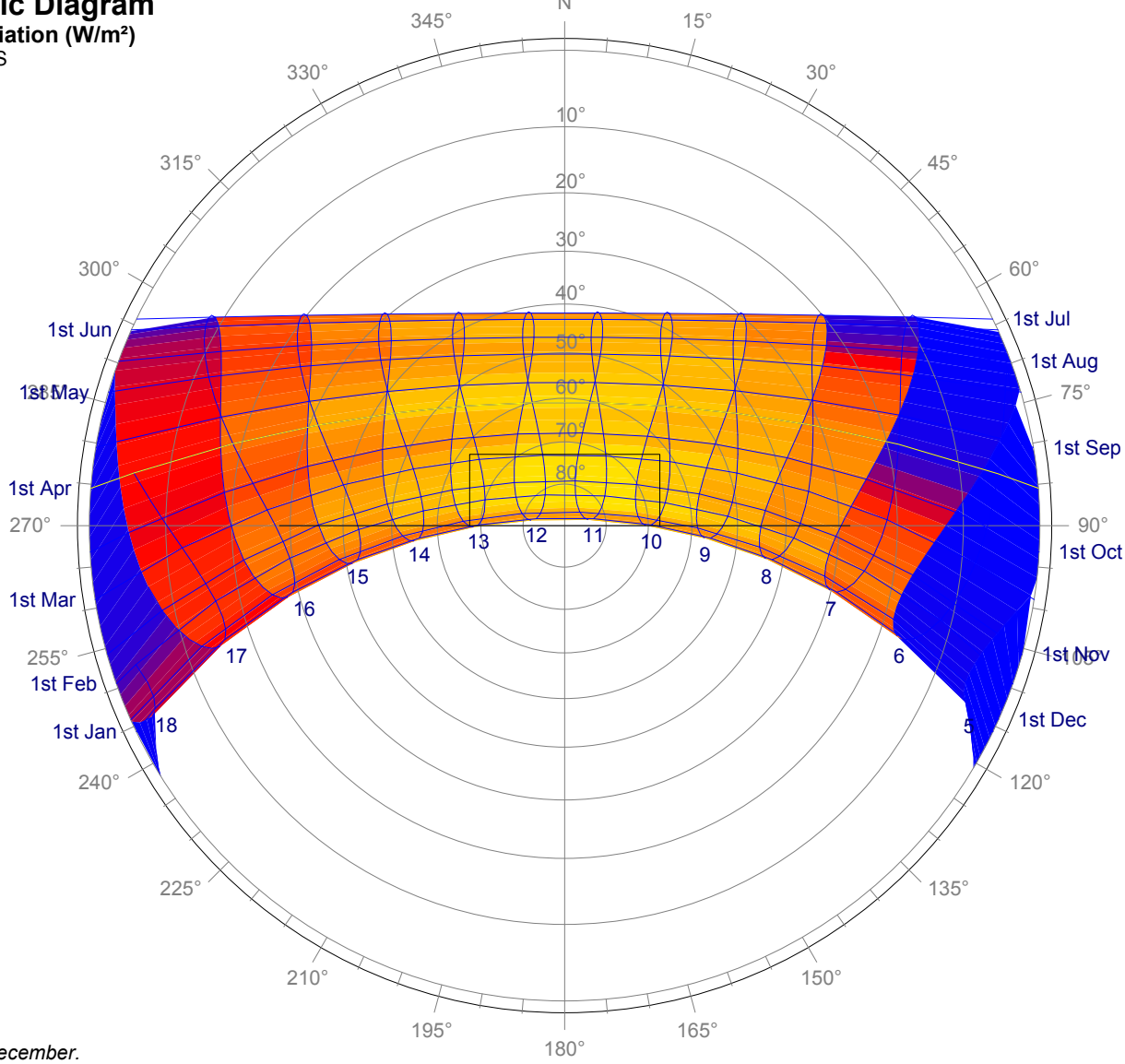

Time: $12: 00$

Dotted lines: July-December.

Fig. 74- Direct Solar Radiation (July - December)

\section{Stereographic Diagram} Average Temperature $\left({ }^{\circ} \mathrm{C}\right)$ Location: Giles, AUS

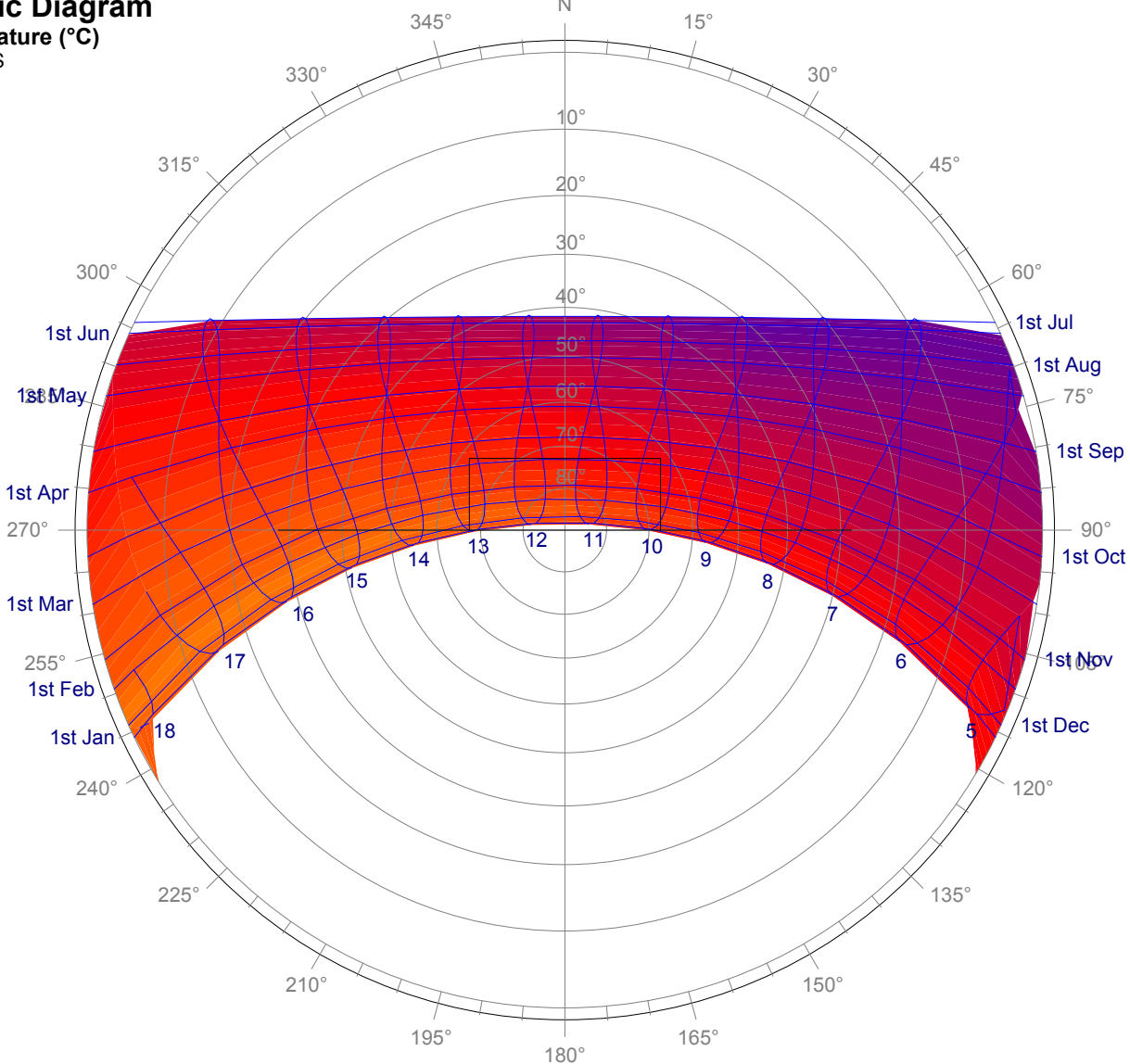

Fig. 75- Average Temperature (July - December) 


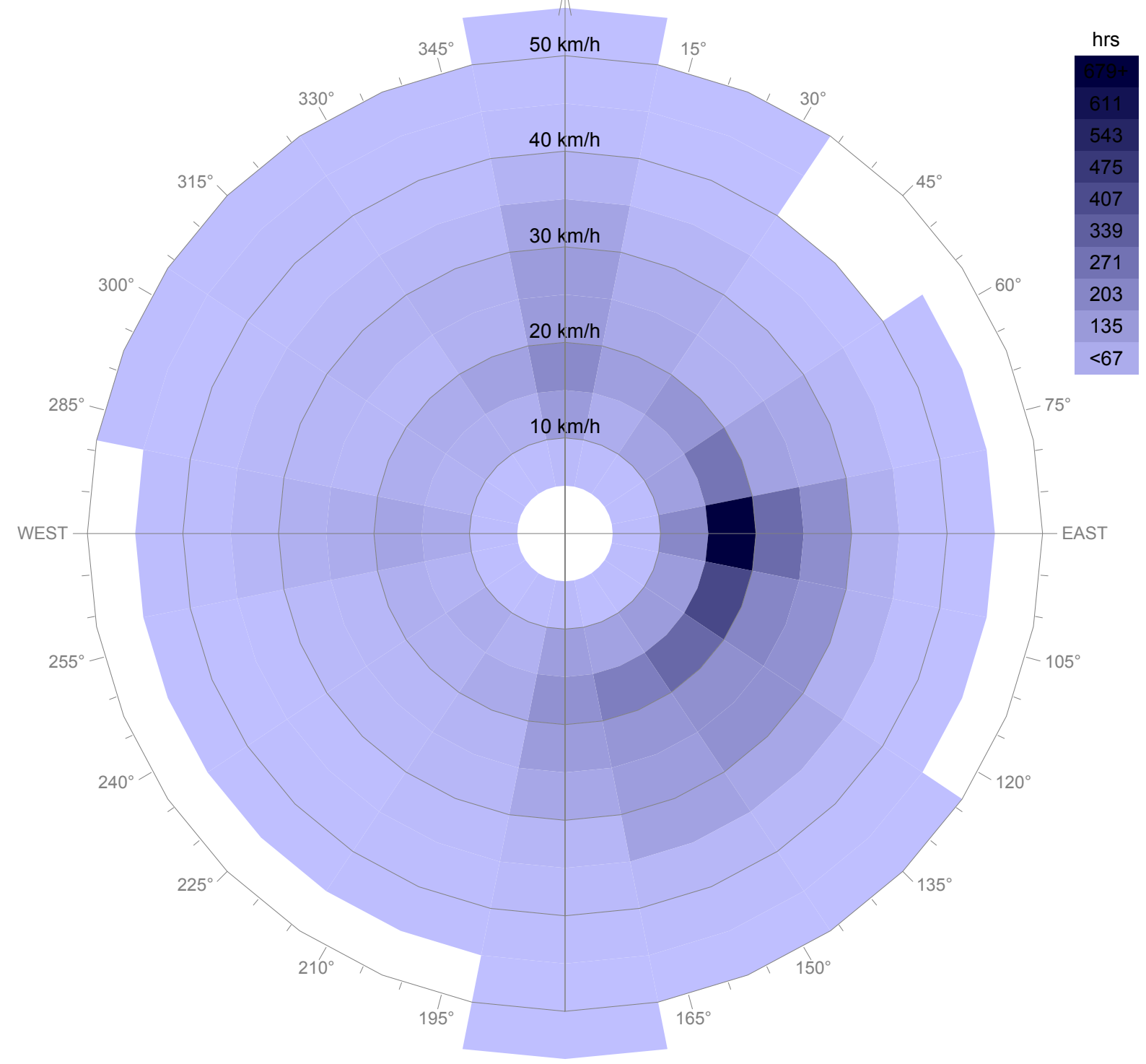

Fig. 76- Average Wind Speed 


\section{Appendix 2}

Computer Analysis Results. Data analyzed within Ecotect Analysis 2010 


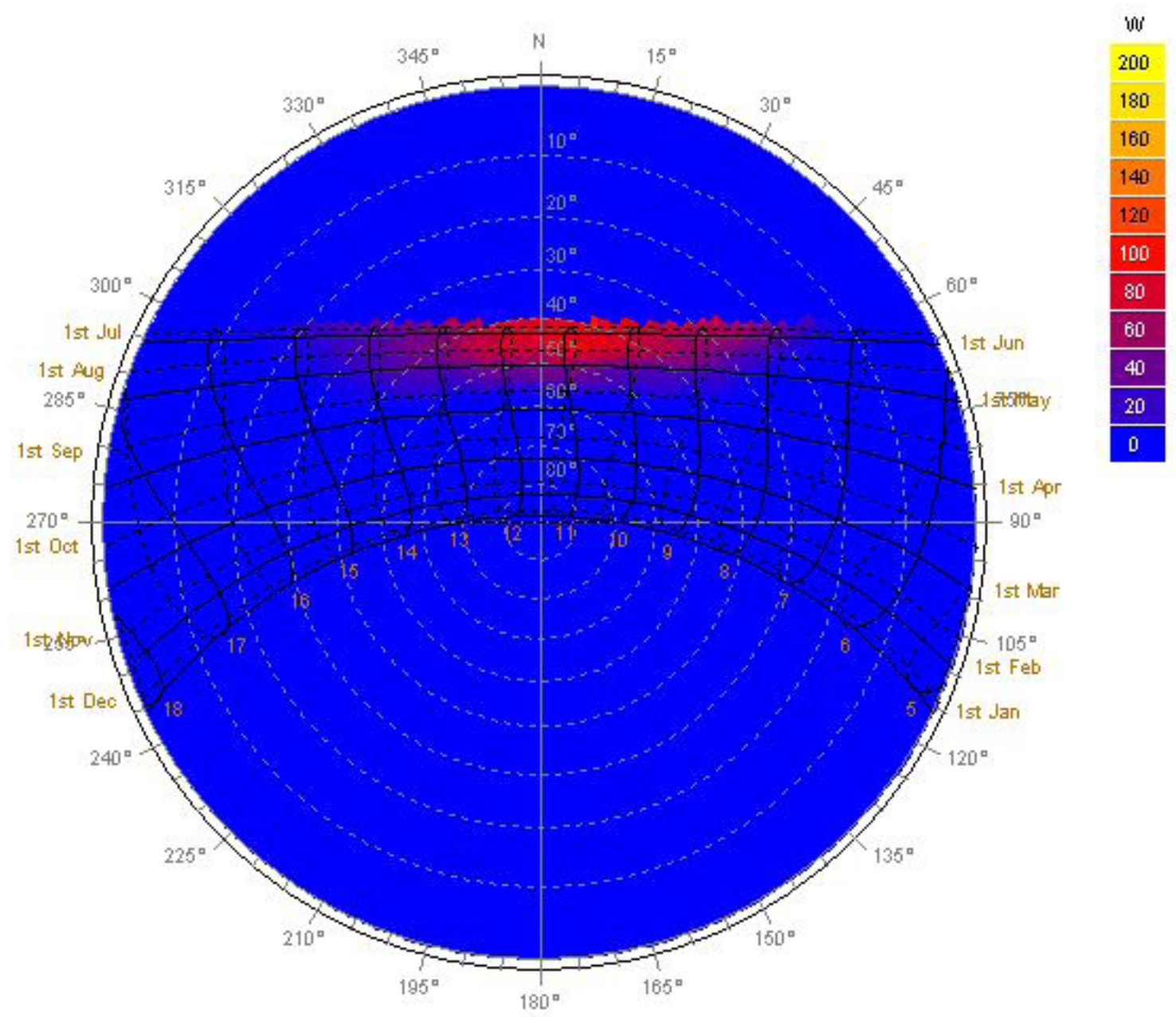

Fig. 77- 'D/L ratio' test screen results for direct solar radiation

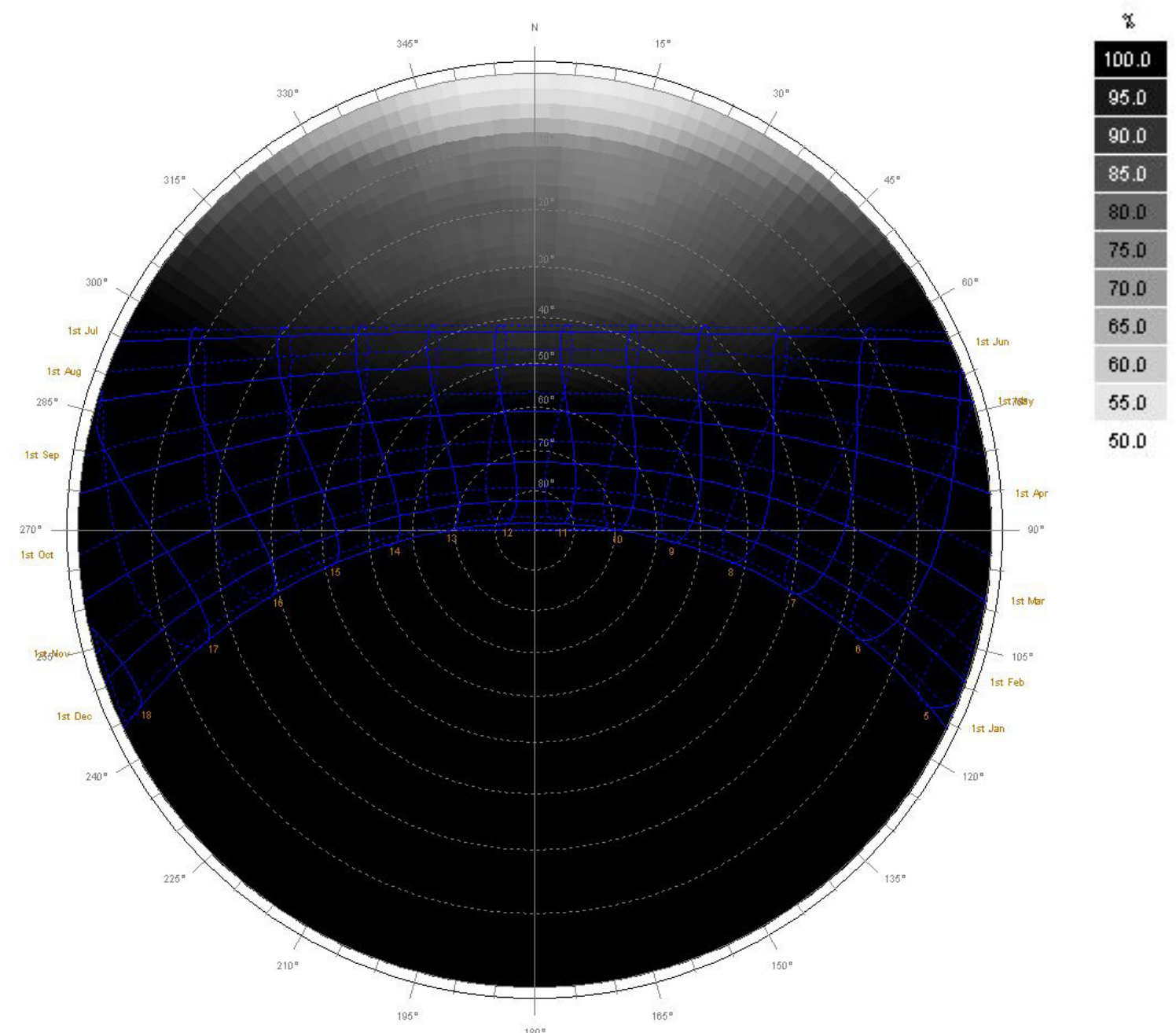

Fig. 78- 'D/L ratio' test screen results for solar shading 


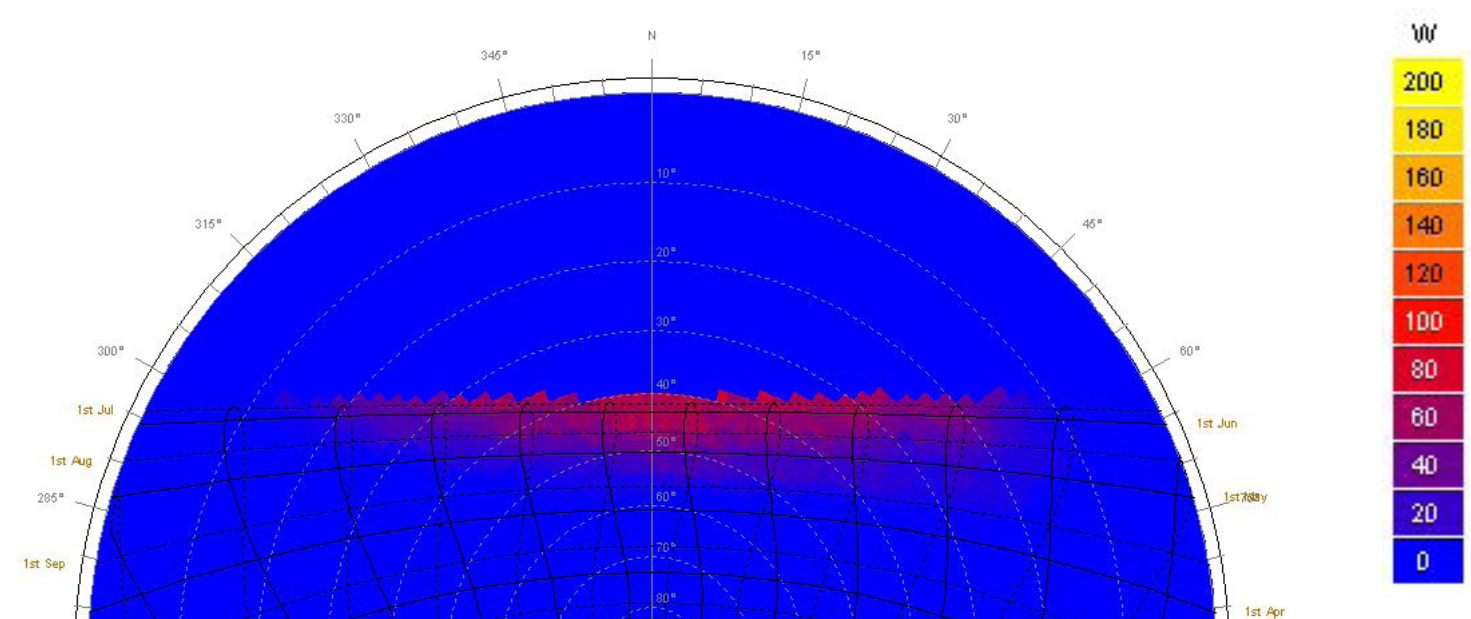

Fig. 79- 'Baluster angle' test screen results for direct solar radiation

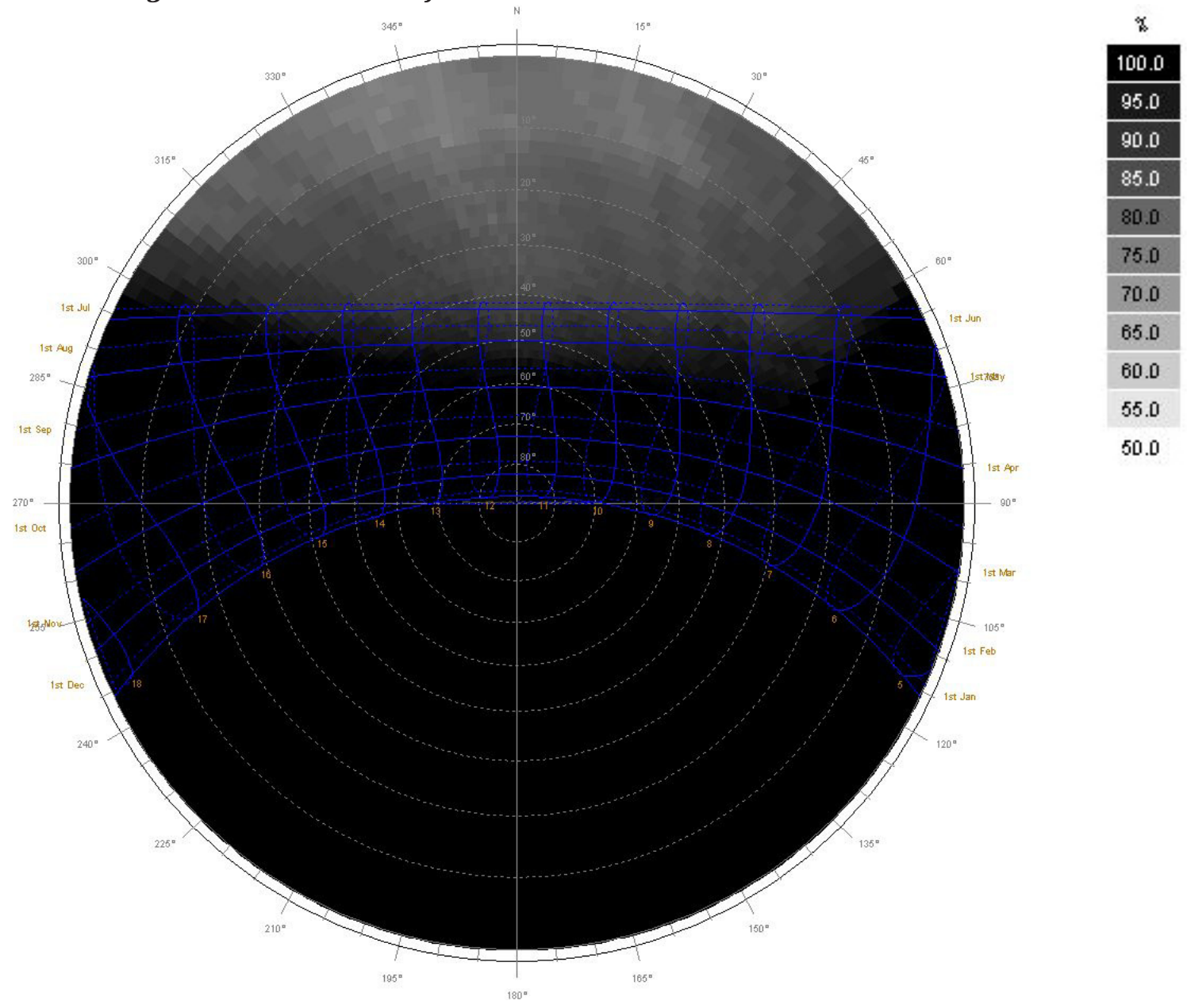

Fig. 80- 'Baluster angle' test screen results for solar shading 


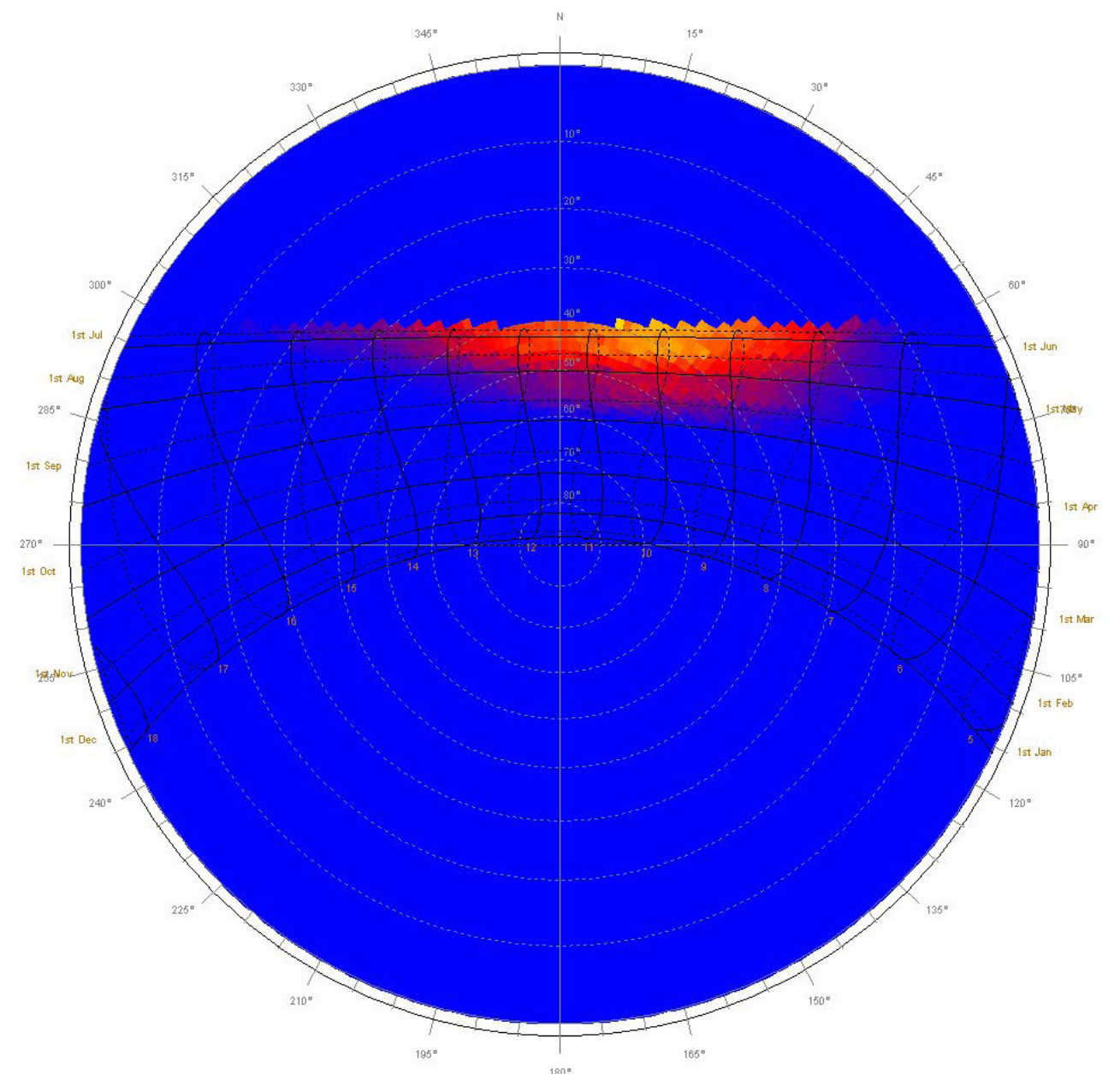

\begin{tabular}{|c|}
\hline wo \\
\hline 200 \\
\hline 180 \\
\hline 160 \\
\hline 140 \\
\hline 120 \\
\hline 100 \\
\hline 80 \\
\hline 60 \\
\hline 40 \\
\hline 20 \\
\hline 0 \\
\hline
\end{tabular}

Fig. 81- 'Baluster section' test screen results for direct solar radiation

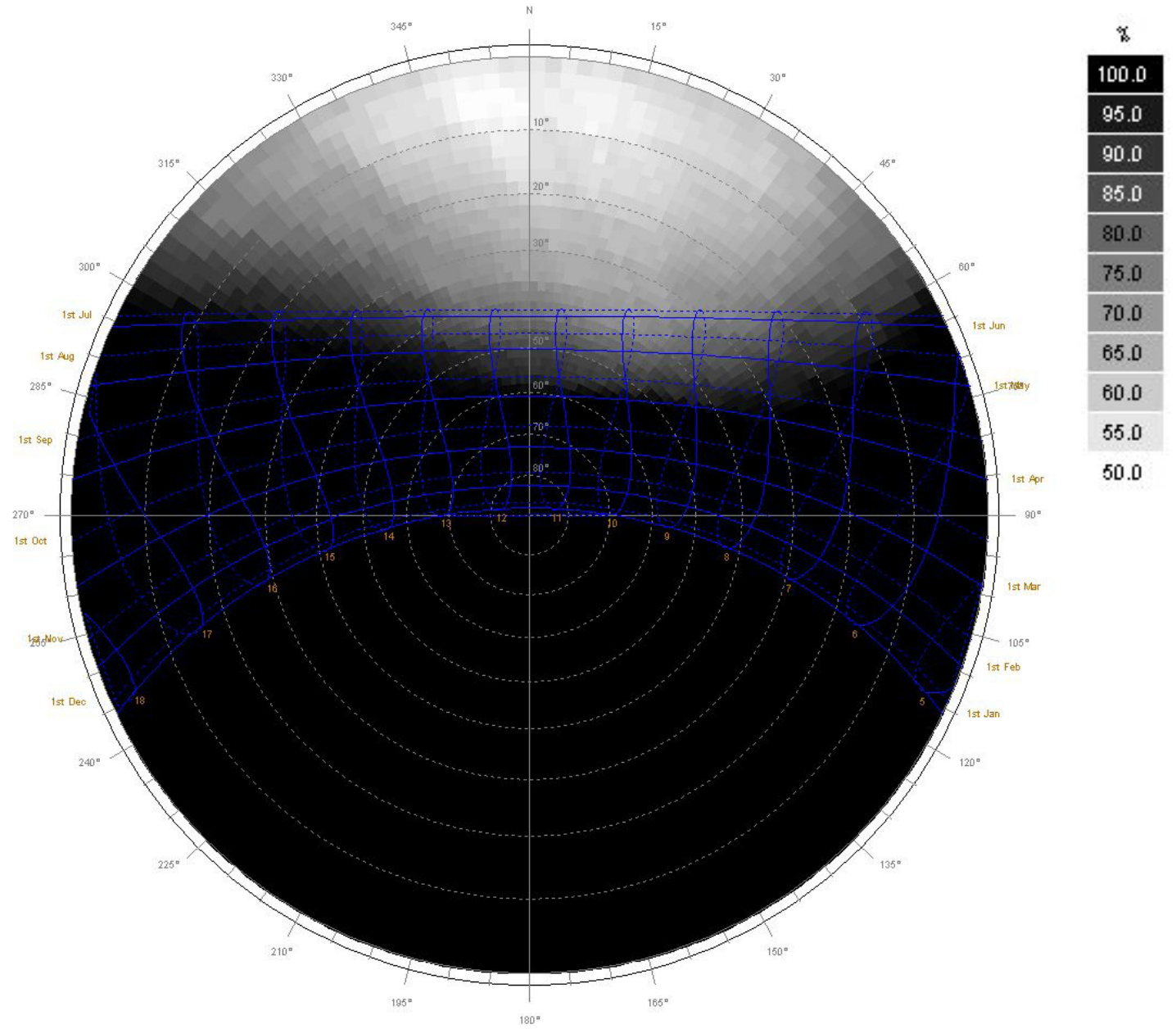

Fig. 82- 'Baluster section' test screen results for solar shading 


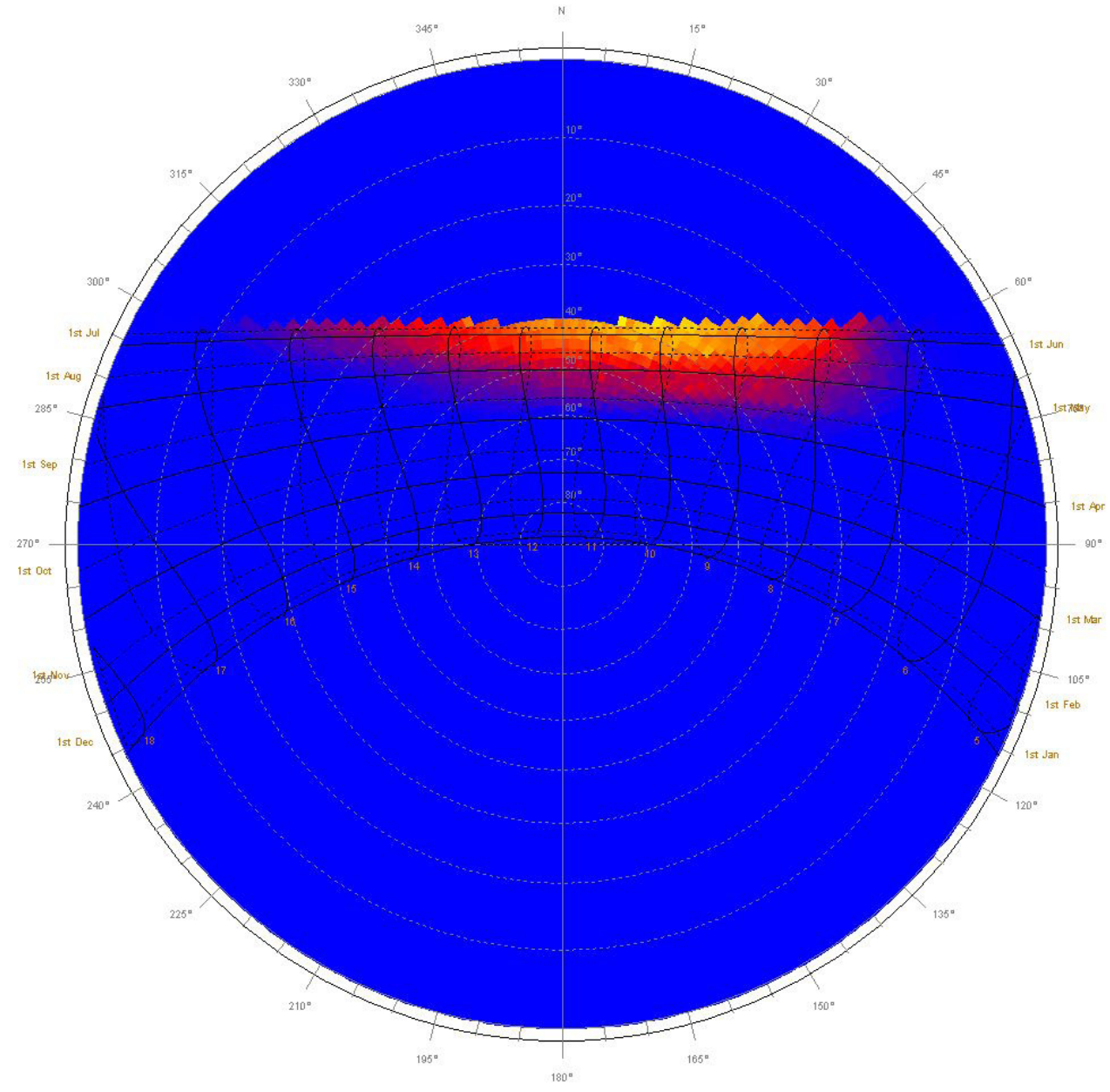

Fig. 83- 'Sectional layers' test screen results for direct solar radiation

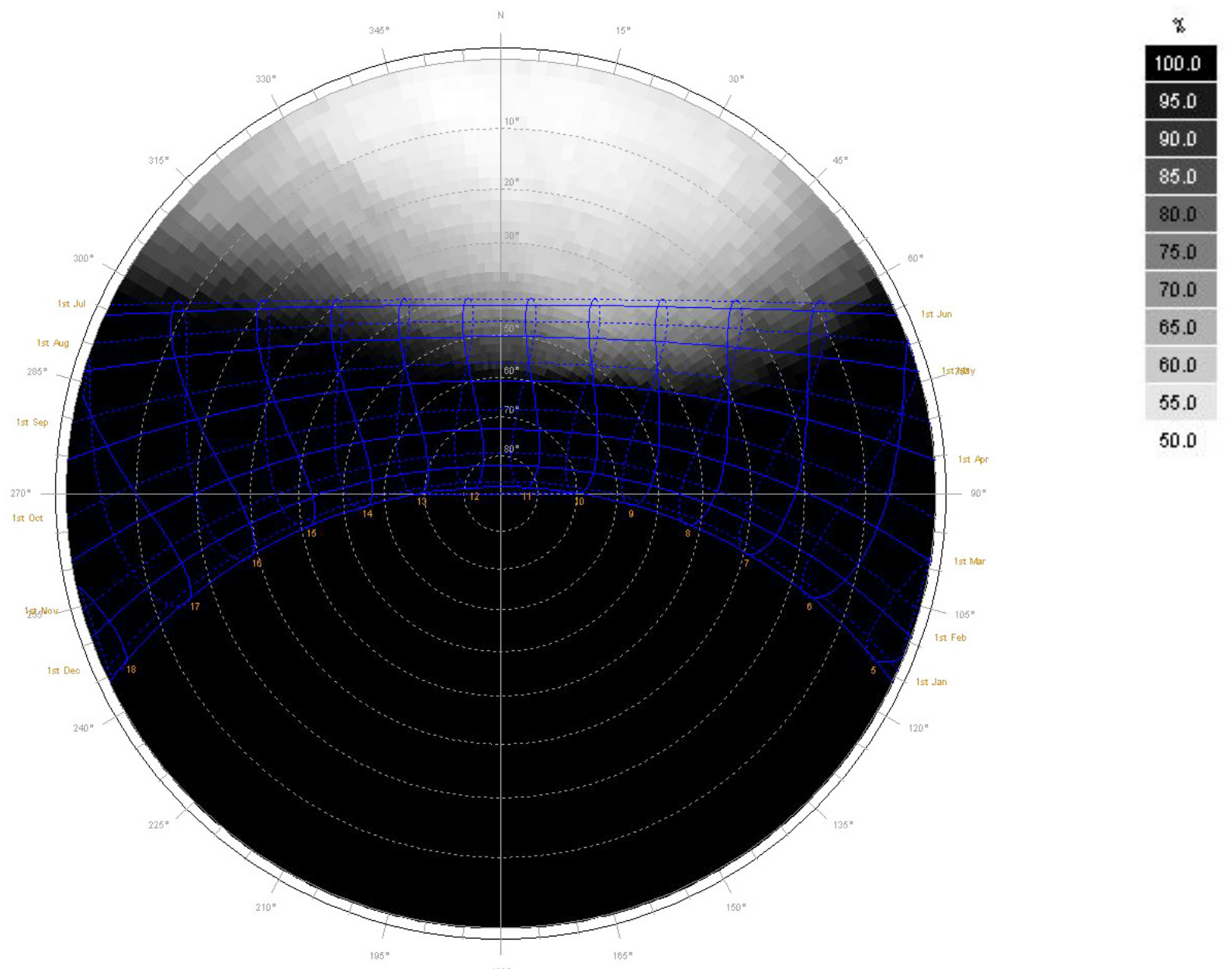

Fig. 84- 'Sectional layers' test screen results for solar shading 


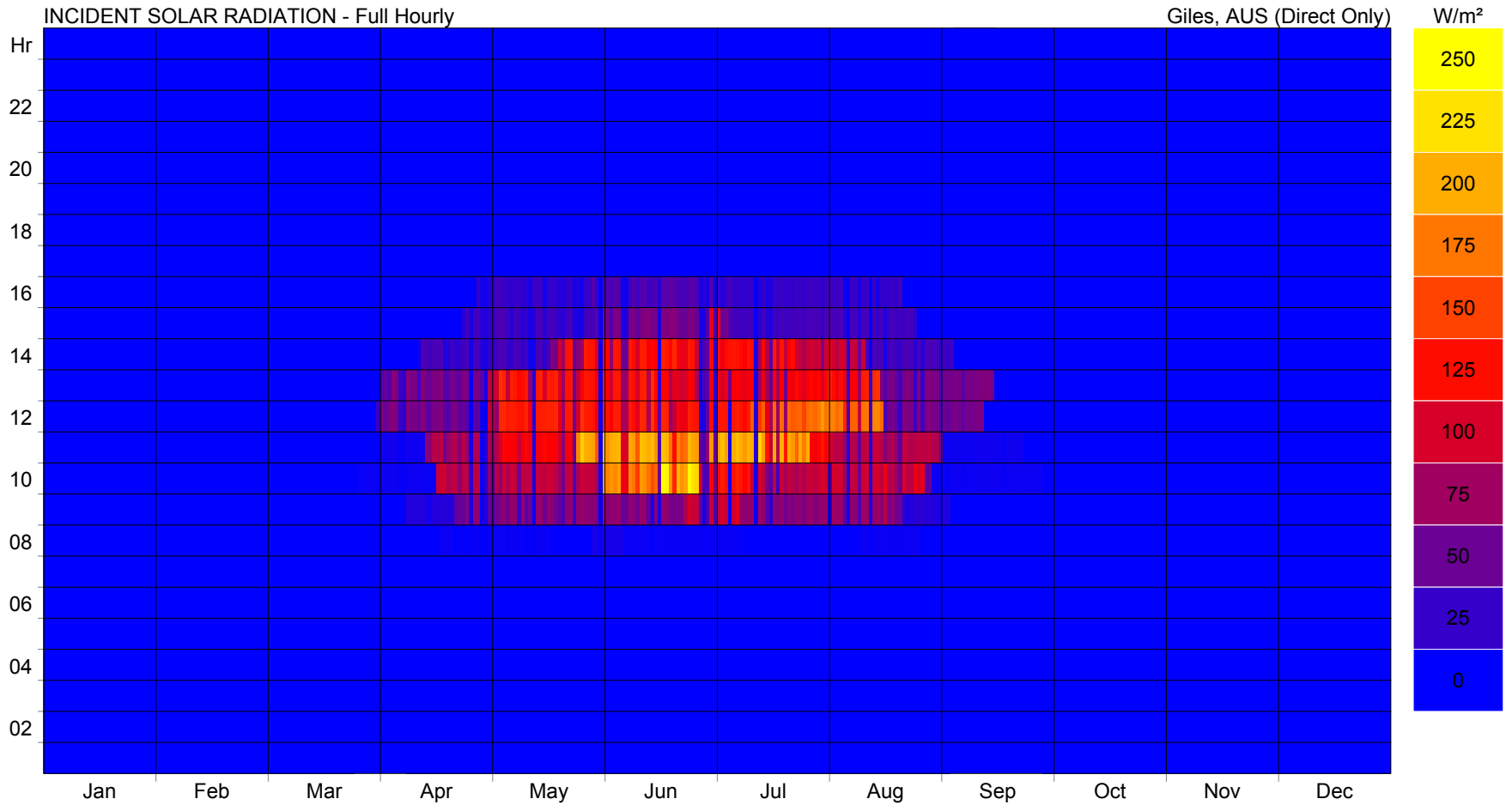

Fig. 85- Annual solar radiation for final screen 
